\title{
Transmembrane Signalling: Structural and Functional Studies on Histidine Kinase CitA
}

\author{
Dissertation \\ for the award of the degree \\ Doctor rerum naturalium \\ of the Georg-August University Göttingen
}

within the doctoral program Biomolecules: Structure - Function -

Dynamics

of the Georg-August University Graduate School of Science (GAUSS)

submitted by

Benjamin Schomburg

from Löhne

Göttingen 2014 


\section{Thesis Committee}

Prof. Dr. Christian Griesinger

Dept. of NMR-based Structural Biology

Max-Planck-Institute for Biophysical Chemistry, Göttingen

Prof. Dr. Claudia Steinem

Institute for Organic and Biomolecular Chemistry, University of Göttingen

Prof. Dr. Blanche Schwappach

Dept. of Biochemistry I, University of Göttingen Medical School

\section{Examination Board}

Referee: Prof. Dr. Christian Griesinger

Dept. of NMR-based Structural Biology, Max-Planck-Institute for Biophysical Chemistry, Göttingen

2nd Referee:

Prof. Dr. Claudia Steinem

Institute for Organic and Biomolecular Chemistry, University of Göttingen

\section{Further members of the Examination Board}

Prof. Dr. Blanche Schwappach

Dept. of Biochemistry I, University of Göttingen Medical School

Prof. Dr. Patrick Cramer

Dept. of Molecular Biology, Max-Planck-Institute for Biophysical Chemistry, Göttingen

Prof. Dr. Michael Meinecke

Dept. of Cellular Biochemistry, University of Göttingen Medical School

Dr. Martin Kollmar

Dept. of NMR-based Structural Biology, Max-Planck-Institute for Biophysical Chemistry, Göttingen

Date of oral examination: 28.01 .2015 
Affidavit

I hereby declare that I wrote this thesis Transmembrane Signalling: Structural and functional Studies on Histidine Kinase CitA on my own and without the use of any other than the cited sources and tools.

Place, Date

Signature 



\section{Contents}

Contents v v

\begin{tabular}{lll}
\hline & Introduction & 1
\end{tabular}

1.1 Stimulus perception in cells $\ldots \ldots \ldots \ldots \ldots$. . . . . . . . . 1

1.2 Structural features of histidine kinases $\ldots \ldots \ldots \ldots$. . . . . . . . 4

1.3 Two-component systems $\ldots \ldots \ldots \ldots \ldots$

1.4 PAS domains $\ldots \ldots \ldots \ldots \ldots \ldots \ldots \ldots$

1.5 CitA family $\ldots \ldots \ldots \ldots \ldots \ldots \ldots$

$1.6 \quad$ Geobacillus thermodenitrificans $\ldots \ldots \ldots \ldots$. . . . . . . . . 11

1.7 NMR assignment strategy $\ldots \ldots \ldots \ldots \ldots \ldots$

2 Materials and Methods $\quad 15$

2.1 Chemicals and equipment . . . . . . . . . . . . . . . 15

2.2 Construct selection . . . . . . . . . . . . . . . . . . 15

2.3 Strains, plasmids and primers . . . . . . . . . . . . . . 15

2.4 Cloning techniques $\ldots \ldots \ldots \ldots \ldots \ldots$

2.4 .1 Polymerase chain reaction $(\mathrm{PCR})$. . . . . . . . . . . 18

$2.4 .2 \quad$ Agarose gel electrophoresis . . . . . . . . . . . . . . . 18

2.4 .3 Restriction digestion of $\mathrm{DNA} \ldots \ldots \ldots \ldots$

2.4 .4 Ligation of DNA fragments . . . . . . . . . . . . . . . 19

2.4 .5 Plasmid purification $\ldots \ldots \ldots \ldots$

2.4 .6 DNA sequencing . . . . . . . . . . . . . . . . . . 19

2.4 .7 Site-directed mutagenesis . . . . . . . . . . . . . . . 19 
2.5 Transformation and cultivation of Escherichia coli $\ldots \ldots \ldots \ldots$. . . . 20

$2.5 .1 \quad$ Unlabelled protein $\ldots \ldots \ldots \ldots \ldots$

2.5 .2 Selenomethionine-labelled protein . . . . . . . . . . . . . . 21

$2.5 .3{ }^{13} \mathrm{C}^{15} \mathrm{~N}$ labelled protein $\ldots \ldots \ldots \ldots \ldots \ldots \ldots . \ldots \ldots 22$

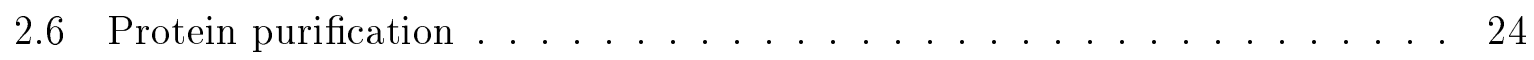

2.6 .1 PAS domains $\ldots \ldots \ldots \ldots \ldots \ldots \ldots \ldots$

2.6 .2 Gt CitApc solid-state NMR samples . . . . . . . . . . 26

2.7 Crystallisation of PAS domains $\ldots \ldots \ldots \ldots \ldots \ldots$

2.8 Liquid-state NMR experiments $\ldots \ldots \ldots \ldots \ldots \ldots \ldots$

$2.8 .1 \quad$ General procedures $\ldots \ldots \ldots \ldots \ldots$

2.8 .2 Secondary structure determination $\ldots \ldots \ldots \ldots \ldots$

2.8 .3 Ligand affinity determination $\ldots \ldots \ldots \ldots \ldots \ldots$

2.9 Solid-state NMR experiments $\ldots \ldots \ldots \ldots \ldots \ldots$

$2.9 .1 \quad$ PDSD spectra $\ldots \ldots \ldots \ldots \ldots \ldots \ldots \ldots \ldots \ldots$

2.9 .2 Triple-resonance spectra $\ldots \ldots \ldots \ldots \ldots \ldots \ldots$

$2.9 .3 \quad$ INEPT spectra $\ldots \ldots \ldots \ldots \ldots \ldots \ldots \ldots$

\begin{tabular}{lll}
\hline 3 & Results & 37
\end{tabular}

3.1 The periplasmic PAS domain (PASp) $\ldots \ldots \ldots \ldots \ldots \ldots$

3.2 The cytosolic PAS domain (PASc) $\ldots \ldots \ldots \ldots \ldots \ldots$

3.3 Liposome-embedded CitApc . . . . . . . . . . . . . . . . . . . . . . 49

4 Discussion $\quad 57$

4.1 The periplasmic PAS domain (PASp) $\ldots \ldots \ldots \ldots \ldots \ldots$

$4.1 .1 \quad$ Citrate binding and activation of PASp $\ldots \ldots \ldots \ldots$

4.2 The cytosolic PAS domain $(\mathrm{PASc}) \ldots \ldots \ldots \ldots \ldots \ldots \ldots \ldots \ldots$

4.3 Liposome-embedded CitApc . . . . . . . . . . . . . . . . . . . 64

$4.3 .1 \quad$ CitApc in Asolectin . . . . . . . . . . . . . . . . . . 64

4.3 .2 CitApc R93A in DMPC $\ldots \ldots \ldots \ldots \ldots \ldots$

4.3 .3 Citrate affinity of PASp $\ldots \ldots \ldots \ldots \ldots \ldots \ldots$

4.3 .4 Signalling effects in the cytosolic PAS domain . . . . . . . . 73 
$4.3 .5 \quad$ PASc in context of full-length CitA . . . . . . . . . . 75

4.3 .6 Signal transduction model . . . . . . . . . . . . . 77

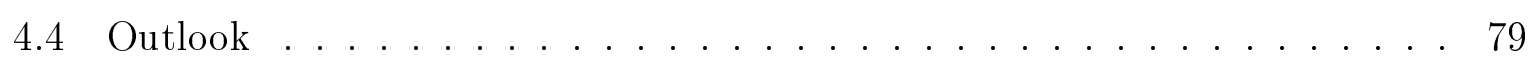

\begin{tabular}{lll}
\hline & Abstract & 83
\end{tabular}

\begin{tabular}{ll}
\hline Bibliography & 85
\end{tabular}

\begin{tabular}{lll}
\hline & Acknowledgements & 99
\end{tabular}

\begin{tabular}{lll}
\hline List of abbreviations & 101
\end{tabular}

\begin{tabular}{lll}
\hline & Appendix & 105
\end{tabular}

$8.1 \quad$ Expression vectors $\ldots \ldots \ldots \ldots \ldots$

8.2 PASc crystal data collection, phasing and refinement statistics . . . . . 107

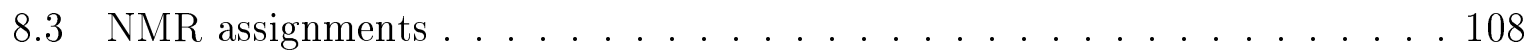

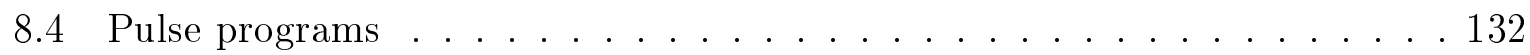

8.4 .1 Liquid-state NMR . . . . . . . . . . . . . . . . 132

8.4 .2 Solid-state NMR . . . . . . . . . . . . . . . 138 



\section{Introduction}

\subsection{Stimulus perception in cells}

In an ever-changing environment, the ability to adapt is key to the survival of all organisms. To be able to monitor and react to environmental stimuli, signal uptake and processing needs to be executed by cells. Hence chemical signals, like changes in osmolarity, availability of nutrients or toxic conditions have to be communicated across the cellular plasma membrane. To this end, a variety of different classes of receptors are utilised, including G-protein coupled receptors, ion channels and enzyme-linked receptors. In the class of enzyme-linked receptors, receptor kinases constitute a large family of proteins that allow for interwoven signalling networks in which different pathways can interact with each other.

Receptor kinases are employed by virtually all organisms and are characterised by a kinase domain that phosphorylates specific amino acid residues (primarily serine/threonine, tyrosine or histidine) either of an effector protein or within the receptor itself (Hanson and Schulman, 1992). Signal processing through phosphorylation has the advantage of being reversible, adaptable and efficient, using a small modification to a protein for a recognisable effect on structural and thus functional properties (Westheimer, 1987). The reversibility is provided by protein phosphatases that selectively dephosphorylate the phosphoprotein. Since the kinases and phosphatases can be triggered by different inputs, crosstalk between different pathways is easily achieved. The net state of phosphorylation is determined by the activity of all relevant kinases and phosphatases and can thus be more complex than a simple on/off switch (Bray, 1995). The adaptability is generated by a large pool of receptor domains that selectively recognise input molecules and 
kinases/phosphatases that then selectively modify target proteins. Lastly, a phosphorylation mechanism is efficient through its use of ATP as a high energy phosphate donor to ensure a thermodynamically favourable reaction, while the dephosphorylation is readily achievable through bulk water allowing for energetically favourable hydrolysis.

Histidine phosphorylation, the main phosphorylation mechanism in prokaryotes, was unknown until 30 years after initial findings of protein phosphorylation (Boyer et al. 1962). Signalling through protein phosphorylation was therefore believed to be absent in prokaryotes, mostly because of the susceptibility of phosphoramidates of phosphorylated histidines in activated prokaryotic kinases to hydrolysis in the acidic assays used at the time. The first evidence for prokaryotic histidine phosphorylation can be credited to in vitro-studies of the histidine kinases (HKs) NtrB (Ninfa et al., 1988) and CheA (Hess et al. 1988). HKs and their signalling targets, the response regulators (RRs), have since emerged as the most abundant signalling system in prokaryotes. HKs are found in virtually all bacterial species, with only few exceptions (Koretke et al., 2000). In addition, around five percent of all known histidine kinases are found in fungi, amoebae and plants (Thomason and Kay, 2000).

In prokaryotes, the roles of histidine kinase signalling systems include sensing of nutrients, chemoattractants, osmotic conditions, cell density and more. In eukaryotes, histidine kinases have been found governing hormone-dependent developmental processes. Since HKs are not found in animal genomes, one major research interest is the potential for developing new classes of antimicrobial drugs. Instead of toxic effects to bacteria, binding to HKs could be used in these new antibiotics to trigger an immune response to HKs. Alternatively, HKs important for microbial toxicity could be inhibited. These indirect drugs would cause less side effects and, more importantly, would be less likely to evoke resistance compared to classical antibiotics (Wolanin et al., 2002). 


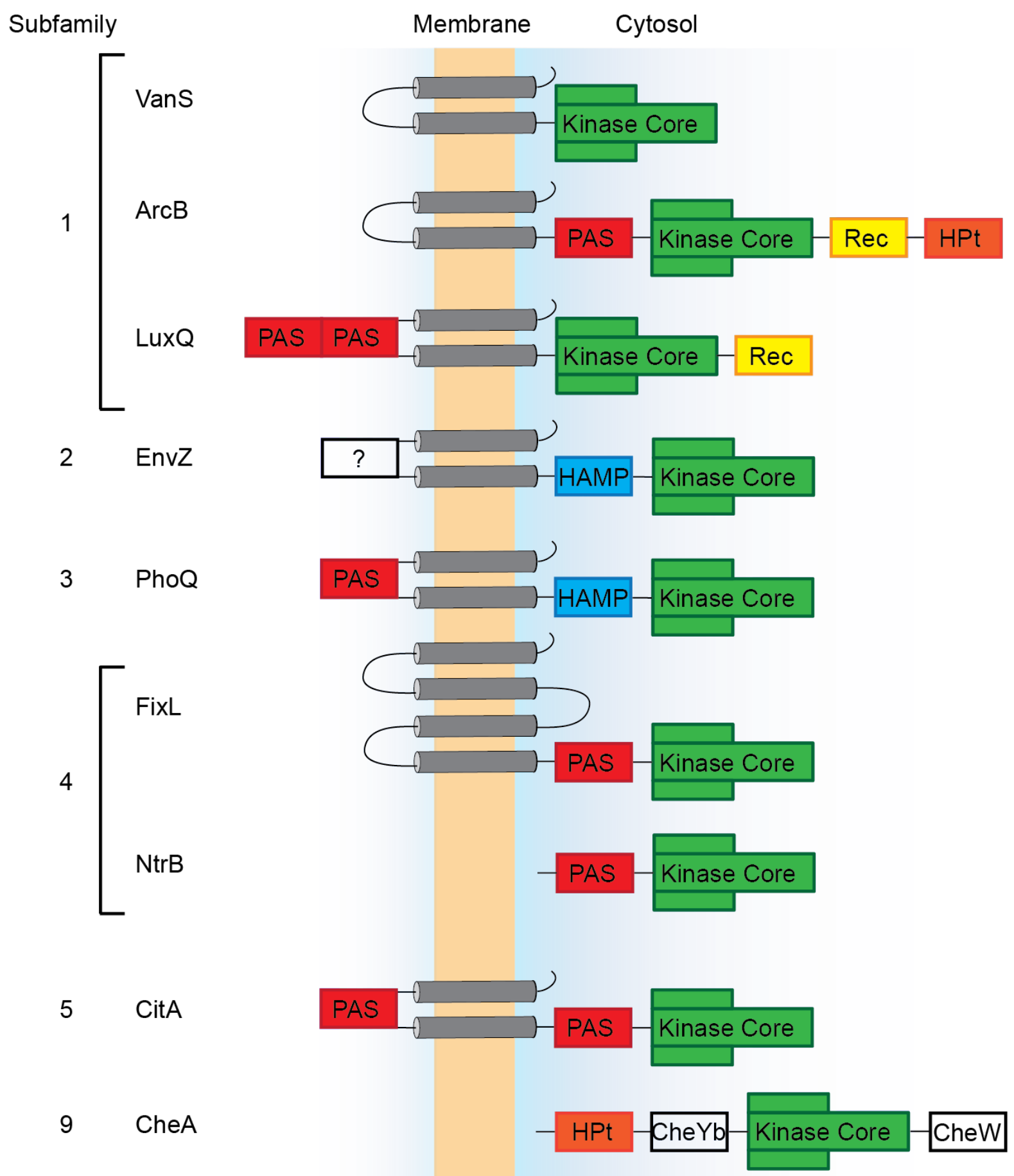

Figure 1.1: Domain organisation of selected histidine kinases. Different HK subfamilies can be classified based on conserved homology motifs in the kinase core. Even within one family, the domain organisation varies greatly, as exemplified for subfamily 1. $83 \%$ of HKs contain transmembrane segments and relay signals across the cellular membrane. 
HKs are an extremely diverse class of proteins with modular design. They are classified by a conserved kinase core consisting of a dimerisation and histidine phosphorylation domain (DHp) and the catalytic, ATP-binding kinase (CA). Based on conserved homology motifs in both DHp and CA domains, HKs can be divided into 11 distinct subfamilies (see figure 1.1) (Grebe and Stock, 1999). Subfamily 1 is the most common type of HK, comprising around $20 \%$ of all known sequences and including all eukaryotic HKs. It also contains almost all hybrid HKs. One distinct class of HK is subfamily 9 in which one of the homology motifs, the H-box (containing the phosphorylatable histidine), is missing. Therefore, signal transduction through DHp phosphorylation is not possible. The subfamily 9 HKs are exclusively found in chemotaxis systems, in which they interact with auxiliary sensory components (Borkovich and Simon, 1991). Other HK subfamilies are characterised solely based on homology motifs and cannot be assigned to specific functional groups.

In general, HK subfamilies do not share domain architectures, but are characterised by the aforementioned homology motifs around the phosphorylatable histidine and the active site of the CA domain. As a result, different classes of HKs bind to different, specific classes of RRs based on structural motifs in the protein-protein interface Grebe and Stock, 1999).

\subsection{Structural features of histidine kinases}

Over the last years, a number of structures have been solved of the complete kinase core $(\mathrm{DHp}+\mathrm{CA})$, isolated DHp and CA domains as well as of RRs and HK-RR domain complexes for various HKs, revealing details on the activation and phosphate transfer mechanism (for a selection of available structures, see (Zapf et al., 2000, Marina et al. 2005; Albanesi et al., 2009, Casino et al., 2009; Yamada et al., 2009; Podgornaia et al., 2013; Wang et al., 2013)). The DHp domain consists of two anti-parallel helices forming a four-helix bundle through dimerisation. The CA domains are loosely attached to DHp by a flexible linker, allowing for different orientations of CA towards the conserved histidine in DHp domains. Unlike catalytic domains of Ser/Thr or Tyr kinases, the CA domain 
of HKs is structurally related to the GHL ATPase superfamily, named after its members GyrB, Hsp90 and MutL (Dutta and Inouye, 2001) and thus not evolutionarily related. The kinase core structures reveal two distinct histidine phosphorylation routes, either cis or trans, with one kinase phosphorylating the histidine residue either of the same or of the other monomer. Recently, the helix bundle loops connecting the two $\alpha$-helices in DHp have been identified as the determinant for cis or trans autophosphorylation Ashenberg et al. , 2013). The length of this loop determines the helix bundle handedness, which in turn dictates the accessible phosphorylation site. In all structures solved to date that catch the $\mathrm{CA}$ domain in a kinase competent state, the phosphorylation reaction is asymmetric. While one of the CA domains approaches the activated histidine, the other is far away. Based on these structures, alternating reaction cycles for the individual CA domains in the dimer are proposed. In the crystal structures solved to date, the asymmetry of the CA domains is reflected in an asymmetric DHp assembly. Nonetheless, the asymmetry in DHp might be a result of crystal packing artefacts, which is suggested by symmetrical solution NMR structures of chimeric constructs including the EnvZ DHp domain (Ferris et al., 2012).

Both the asymmetry and the flexibility involved complicate structural studies on the kinase core. However, a mechanistic model for autophosphorylation was recently proposed based on structure-guided functional analysis (Casino et al., 2014). In this model, a nucleophilic attack of histidine on the $\gamma$-phosphate in ATP is made possible by a conserved aspartate in DHp acting as a general base. The $\gamma$-phosphate of ATP is positioned for the nucleophilic attack by conserved CA residues and shielded by a coordinated magnesium ion. The active site is thus formed by both the DHp and the CA domains. The phosphorylation mechanism seems to be comparable in cis or trans. In addition to kinase and phosphotransferase functionality, most HKs act as phosphatases on RRs. Depending on switching between states in the receptor domain, the net state of the protein is either kinase/transferase or phosphatase (Perego and Hoch, 1996, Hsing et al., 1998). 


\subsection{Two-component systems}

In a prototypical system, a HK forms a two-component system (TCS) with its cognate RR which is activated by the kinase and triggers cellular responses to extracellular stimuli. Since approximately $83 \%$ of HKs are transmembrane proteins (Cock and Whitworth. 2007), a soluble RR is essential for transducing signals to cytosolic cell components. In the most simple case, the HK autophosphorylates on a conserved histidine upon signal recognition, creating a high-energy phosphoramidate. The phosphate is consecutively transferred to a conserved aspartate in the receiver domain (REC) of the cognate RR (see figure 1.2). Both HKs and RRs are highly modular proteins, allowing for integration of a wide variety of input signals and output responses. The prototypical RR consists of an $N$-terminal REC domain and a variable $C$-terminal effector domain. The REC domain is conserved in all known RRs with an average sequence identity of $26 \%$. In contrast, effector domains are structurally and functionally diverse. The most prominent class of RRs $(63 \%)$ contains DNA-binding effector domains of various structural families to alter gene expression levels. Other roles of effector domains include RNA binding, protein binding, and enzymatic functions (Gao and Stock, 2009).

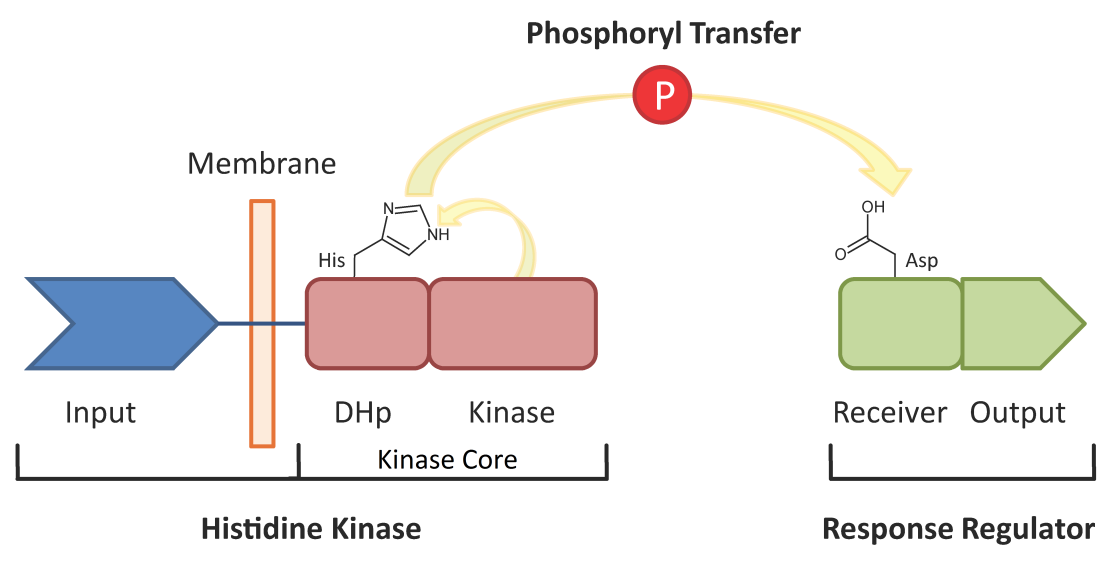

Figure 1.2: Schematic diagram of a minimal two-component system. The histidine kinase consists of a stimulus receiving receptor domain (input), the dimerisation and histidine phosphorylation domain (DHp) and the kinase domain. DHp and kinase form the conserved kinase core. Upon activation a conserved histidine in DHp is phosphorylated and the phosphoryl group consecutively transferred to an aspartate residue in the receiver domain (REC) of a response regulator. The activated response regulator then triggers cellular response through the output domain. 
Additionally, RRs consisting of stand-alone REC domains lacking effector domains have been identified. These either function in chemotaxis systems by binding directly to motor proteins, or as part of a phosphorelay system. Phosphorelay systems are more complex than prototypical TCSs and involve several His-Asp phosphate transfer steps. HKs of phosphorelay systems contain REC domains and are termed hybrid HKs. Upon activation, phosphate is transferred from the conserved histidine in DHp to an aspartate residue of the internal REC domain. The phosphate of the REC domain is then transferred to a histidine phosphotransfer (HPt) domain, which is structurally related to DHp and can either be part of a soluble protein or of the kinase itself to create a phosphorylation cascade. From the HPt domain, the phosphorylation signal can be transferred to another REC domain, for example on a RR (Ogino et al., 1998, Perego, 1998). Hybrid HKs are found in around $25 \%$ of TCSs and open up possibilities for integration of different signalling pathways and multiple checkpoints along the phosphate transfer pathway.

\subsection{PAS domains}

For perceiving stimuli, HKs utilise a wide variety of different receptor domains. A presentation of all types of receptors is beyond the scope of this introduction; signal perception mechanisms are reviewed in detail elsewhere (Szurmant et al., 2007, Krell et al., 2010). The most abundant class of sensor domains is the PAS domain which can be found in at least $33 \%$ of HKs (Gao and Stock, 2009). PAS domains are named after the first proteins in which the structural motif was first recognised, PER (period clock protein in Drosophila melanogaster), ARNT (aryl hydrocarbon receptor nuclear translocator of vertebrates) and SIM (single-minded protein in D. melanogaster). In prokaryotes, PAS domains are mainly found in HKs and serve as receptors associated with a wide range of stimuli, including light, redox potential, oxygen, small ligands and the overall cellular energy level (Taylor and Zhulin, 1999). In addition to HKs, PAS domains play a role in Ser/Thr kinases, circadian clock proteins, voltage-gated ion channels and cyclic nucleotide phosphodiesterases in both prokaryotes and eukaryotes. 
Given that the PAS fold is found in all kingdoms of life, it is not surprising that the sequence homology is fairly low and prediction of PAS domains was almost impossible before the advent of algorithms like PSI BLAST Altschul et al. 1990). In fact, several PAS domains, for example receptor domains of HKs CitA, DcuS and PhoQ, have only been identified based on $3 \mathrm{D}$ structures and not on the primary sequence (Reinelt et al., 2003, Pappalardo et al., 2003; Cho et al., 2006). The PAS fold consists of an N-terminal helix cap, a central $\beta$-scaffold of five anti-parallel strands and a varying number of short helices on one face of the $\beta$-sheet (see

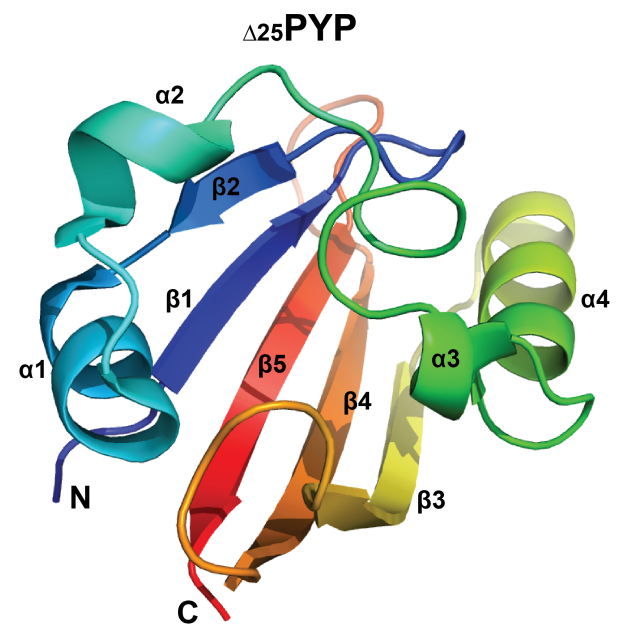

Figure 1.3: The PAS domain core. The photoactive yellow protein is viewed as a prototypic PAS domain. Deleting the $N$-terminal helix leaves an idependently folding PAS core. Structural elements are labelled. PDB accession code: 1ODV (Vreede et al., 2003) figure 1.3). The $N$-terminal cap is least conserved, both structurally (Vreede et al. 2003) and based on amino acid sequence (Taylor and Zhulin, 1999).

Signal perception through PAS domains is possible through several different mechanisms. Most frequently, small molecule ligands bind to a cavity in the centre of the PAS core (the PAS fold excluding the $N$-terminal cap), as evident from structural and functional analysis on CitA (Kaspar et al., 1999; Reinelt et al., 2003; Sevvana et al., 2008) or TodS (Mosqueda et al., 1999; Lacal et al., 2006). Another widely used mechanism of signal recognition through PAS domains involves bound cofactors. Cofactor-mediated stimulus perception is mainly found in systems associated with redox potential, oxygen concentration and light perception (Taylor and Zhulin, 1999). Bound cofactors include flavine adenine dinucleotide (Key et al., 2007) and heme (Gong et al., 2000). A third mode of stimulus perception is oxidation of cysteine-containing PAS domains to alter domain dynamics. In the HK ArcB, oxidative stress leads to inactivation of the kinase by the formation of two intermolecular cysteine bonds in PAS domains of a HK dimer, thus rigidifying the domain (Malpica et al., 2004). In PhoQ, yet another stimulus perception 
mechanism is described, in which divalent cations bind at the PAS - membrane interface to trigger different conformations (Cho et al., 2006; Cheung et al., 2008).

In addition to stimulus perception, PAS domains also seem to be involved in signal propagation. Several HKs, including LuxQ (Neiditch et al., 2006) and CitA (Etzkorn et al. 2008) contain PAS domains that are not involved in ligand binding. The role of these PAS domains is difficult to study, as structural rearrangements cannot be triggered by ligand binding. Functional studies of these non-ligand binding PAS domains therefore have to be carried out in context of the multi-domain kinases, which is one of the aims of the study presented here.

\subsection{CitA family}

As shown above, the most prevalent domain organisation in HKs is characterised by a periplasmic sensory domain flanked by two transmembrane helices, with a cytosolic, $C$ terminal kinase core (see figure 1.1). In addition, PAS domains are the most widely used receptor domain. The CitA HK family with a periplasmic, citrate binding receptor domain and a second, cytosolic PAS domain preceding the kinase core is therefore an ideal candidate for structural studies on HKs. Over the last two decades, two proteins of the CitA family, DcuS and CitA itself, have been extensively studied.

DcuS is a $\mathrm{C}_{4}$-dicarboxylate receptor first identified in 1998 as part of the DcuS-DcuR TCS (Zientz et al., 1998). The DcuS-DcuR system is responsible for activating genes for dicarboxylate transport and fermentation in response to the availability of aspartate, fumarate, malate, maleate and succinate (Zientz et al., 1998; Golby et al., 1999). Fumarate-dependent activation, phosphoryl transfer to DcuR and binding of DcuR to DNA was shown in vitro (Janausch et al., 2002; Abo-Amer et al. 2003). With the availability of liquid-state NMR - (Pappalardo et al., 2003; Kneuper et al., 2005) and X-ray crystal structures (Cheung and Hendrickson, 2008) of the periplasmic, ligand binding domain, a first view of structural reorganisations in the periplasmic PAS domain is possible. However, as a model protein for a two-state signalling system DcuS is less than ideal as it requires the presence of dicarboxylate transporters DctA or DcuB to reach a ligand re- 
sponsive state. Without either of the transmembrane transporters, DcuS is constitutively switched ON (Steinmetz et al., 2014).

Like DcuS, the citrate receptor CitA contains one periplasmic (PASp) and one cytosolic PAS domain (PASc). The expression of citrate transporters and fermentation proteins is controlled by the CitA/CitB TCS (Bott et al. 1995). Unlike DcuS, CitA ligand binding is highly selective; closely related isocitrate and tricarballylate are not recognised by PASp (Kaspar et al., 1999; Kaspar and Bott, 2002). Crystal structures available for Klebsiella pneumoniae CitA PASp in both citrate-free and citrate-bound forms (Reinelt et al., 2003 . Sevvana et al. , 2008) reveal major structural rearrangements. Upon citrate binding, the PASp $\beta$-sheet tightens around the citrate binding pocket, executing a pull on the $C$ terminal strand and the adjacent second transmembrane helix. This finding is in line with a potential piston-movement model for signalling (Ottemann et al., 1999 , Sevvana et al. 2008). In contrast to DcuS, CitA can be described in both signalling states without the presence of an accessory binding protein. Additional proteins may well be involved in the signalling process, but the active as well as the inactive receptor state can be prepared both in vitro and in vivo.

Structural studies on membrane-embedded constructs of CitA-family HKs were so far inconclusive as to the signalling mechanism. Solid-state NMR studies on membrane-bound Escherichia coli DcuS (Etzkorn et al., 2008) were complicated by the unavailability of the inactive receptor state and structural information on the cytosolic PAS domain. As an alternative system, CitA is available in both signalling states, but like in DcuS, isolated PASc of K. pneumoniae CitA is not stable in solution for NMR or crystallisation studies. With E. coli CitA PASc, a CitA-family cytosolic PAS domain was isolated in solution for the first time and assigned via liquid-state NMR in the course of this study. However, only the periplasmic receptor domain was visible in solid-state NMR experiments of membrane-embedded E. coli CitA constructs, necessitating the characterisation of a different HK candidate for structural studies. 


\subsection{Geobacillus thermodenitrificans}

Proteins from thermophilic organisms are popular targets in structural biology owing to the increased rigidity over mesophilic proteins (Razvi and Scholtz, 2006). As structural studies on E. coli DcuS, K. pneumoniae CitA and E. coli CitA were inconclusive, CitA homologues were sought in thermophiles. While PASc was not stable in solution for DcuS and K. pneumoniae CitA, E. coli CitA PASc was assigned in solution, but could not be detected in solid-state spectra of membane-embedded CitA constructs. By switching to thermophilic systems, PASc dynamics could be expected to decrease at ambient temperatures compared with mesophilic systems allowing the detection in solidstate spectra.

A CitA homologue was found in Geobacillus thermodenitrificans , a thermophile first described as Denitrobacterium thermophilus (Ambroz, 1913) and later characterised based on metabolic and genomic properties (White et al., 1993). G. thermodenitrificans is found in soil samples all over the world and in various habitats, including hot springs, shallow marine vents and deep subterranean oil reservoirs (Maugeri et al. 2002 ; Feng et al., 2007; Chamkha et al., 2008; Adiguzel et al., 2009; Yao et al., 2013). Interest in G. thermodenitrificans is mostly fuelled by the potential of gaining biotechnologically important enzymes, namely alkane degradation enzymes (Feng et al., 2007). As a possible source of a more rigid CitA homologue, $G$. thermodenitrificans was also identified as an ideal target for this study.

\subsection{NMR assignment strategy}

Histidine kinases are large, multi-domain membrane proteins with a dimeric functional assembly. These properties make them difficult targets for liquid-state NMR or crystallisation. While liquid-state NMR is limited by molecular tumbling times that increase with particle size, crystallography of membrane proteins is limited to proteins that form tight three-dimensional packings in artificial membrane systems. To overcome the limitations of those two techniques alone, a combination approach analogous to the one described by Etzkorn et al. was employed (Etzkorn et al. 2008). The CitA receptor family is selected 
as a target for various reasons: first, PAS domains are the most abundant receptor domain in HKs and the CitA domain organisation (a periplasmic sensor domain flanked by two transmembrane helices) is most common among HKs. Second, the function of cytosolic PAS domains not involved in signal recognition (like in chemotaxis sensors or oxidative stress receptors) is unclear and can be studied in the CitA model system. Third, unlike in most other HKs, the small molecule ligand for CitA is known and binding well characterised; both signalling states of the receptor are experimentally accessible. Last, CitA contains two PAS domains with a high content of $\beta$-sheets, resulting in well dispersed ${ }^{13} \mathrm{C}$ and ${ }^{15} \mathrm{~N}$ NMR resonances facilitating assignment.

A

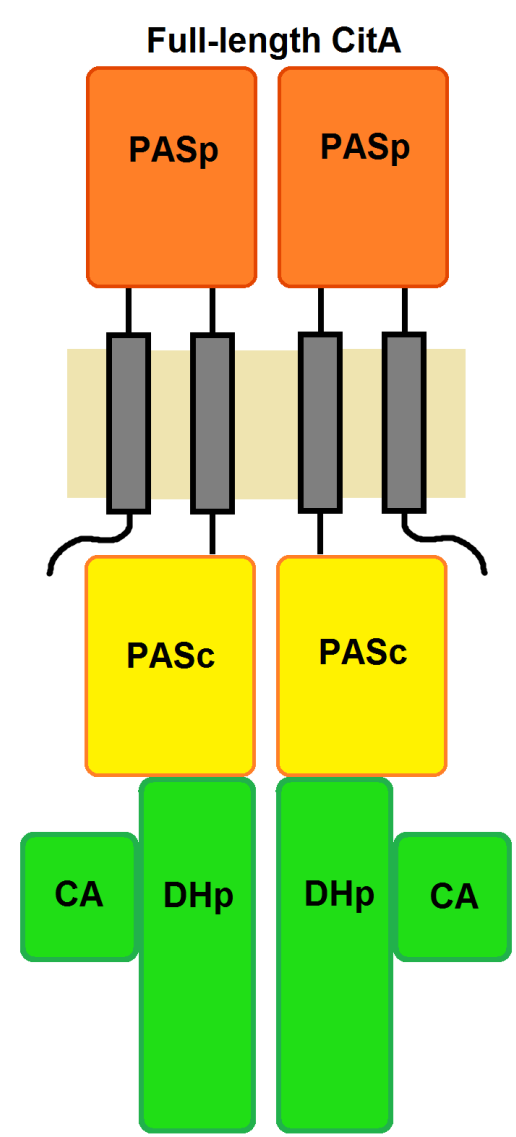

B

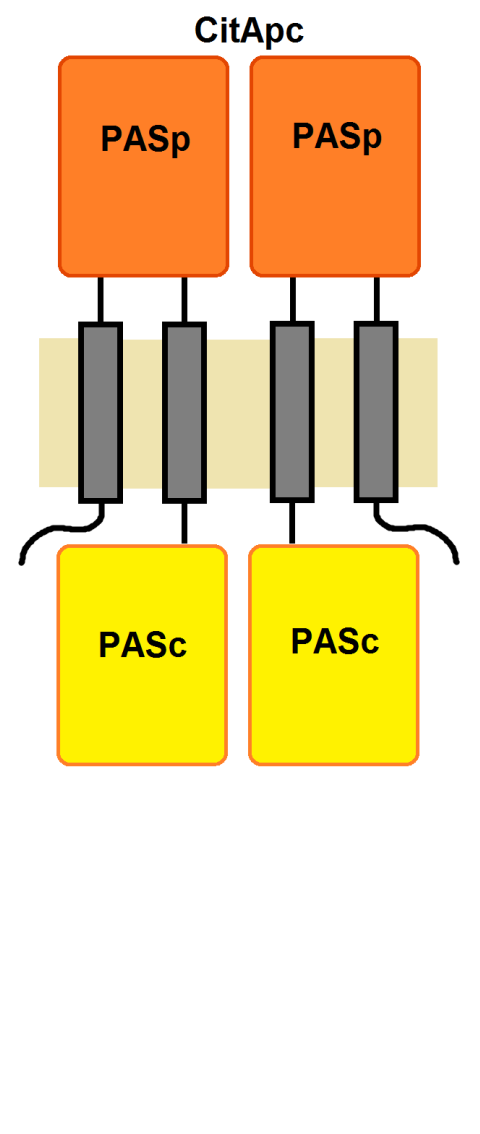

C

PAS domains
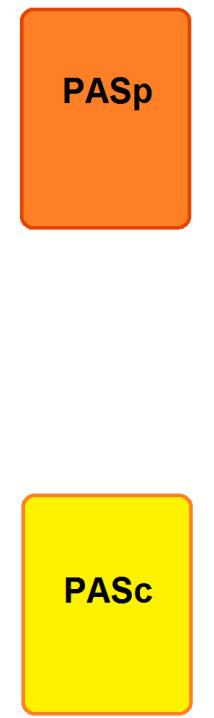

Figure 1.4: Construct design for structural studies. Full-length CitA with a molecular weight of $59 \mathrm{kDa}$ per monomer (A) was shortened by removing the kinase core (DHp and kinase domains), yielding the $34 \mathrm{kDa}$ CitApc construct used for solid-state NMR studies (B). The individual PAS domains were produced as soluble proteins with a molecular mass of 14 and $13 \mathrm{kDa}$ for PASp and PASc, respectively (C). 
As the key question of this study is concerning signal transduction across the membrane and not kinase activation, the DHp and CA domains were omitted from all studied protein constructs. Excluding the kinase core reduces the molecular weight from 59 to $34 \mathrm{kDa}$ per monomer. This shortened construct, termed CitApc (for periplasmic and cytosolic PAS domains), is used for solid-state NMR spectroscopy on liposome-embedded protein samples. As the remaining 321 amino acid CitApc construct is still challenging to assign de novo by solid-state NMR, the individual PAS domains were produced as isolated, soluble proteins (see figure 1.4). The isolated domains can be assigned via liquid-state NMR and used for crystallisation trials to aid in interpreting the solid-state NMR results. Based on liquid-state resonance assignments, peak positions can be predicted for solidstate spectra (see figure 1.5), provided that the structure does not undergo major changes in context of the transmembrane helices. Ideally, the PAS domains can then be assigned in CitApc based on liquid-state data and the remaining, unassigned resonances can be attributed to the transmembrane helices. As these resonances are only a small subset of the full spectrum, a de novo assignment of the transmembrane helices can then be carried out based on three-dimensional solid-state NMR experiments. In cases where the isolated domains experience different local structure in context of the transmembrane helices, these differences will also be revealed by incompatibility of liquid-state assignments and solid-state peak positions as well as by sequential assignment. 


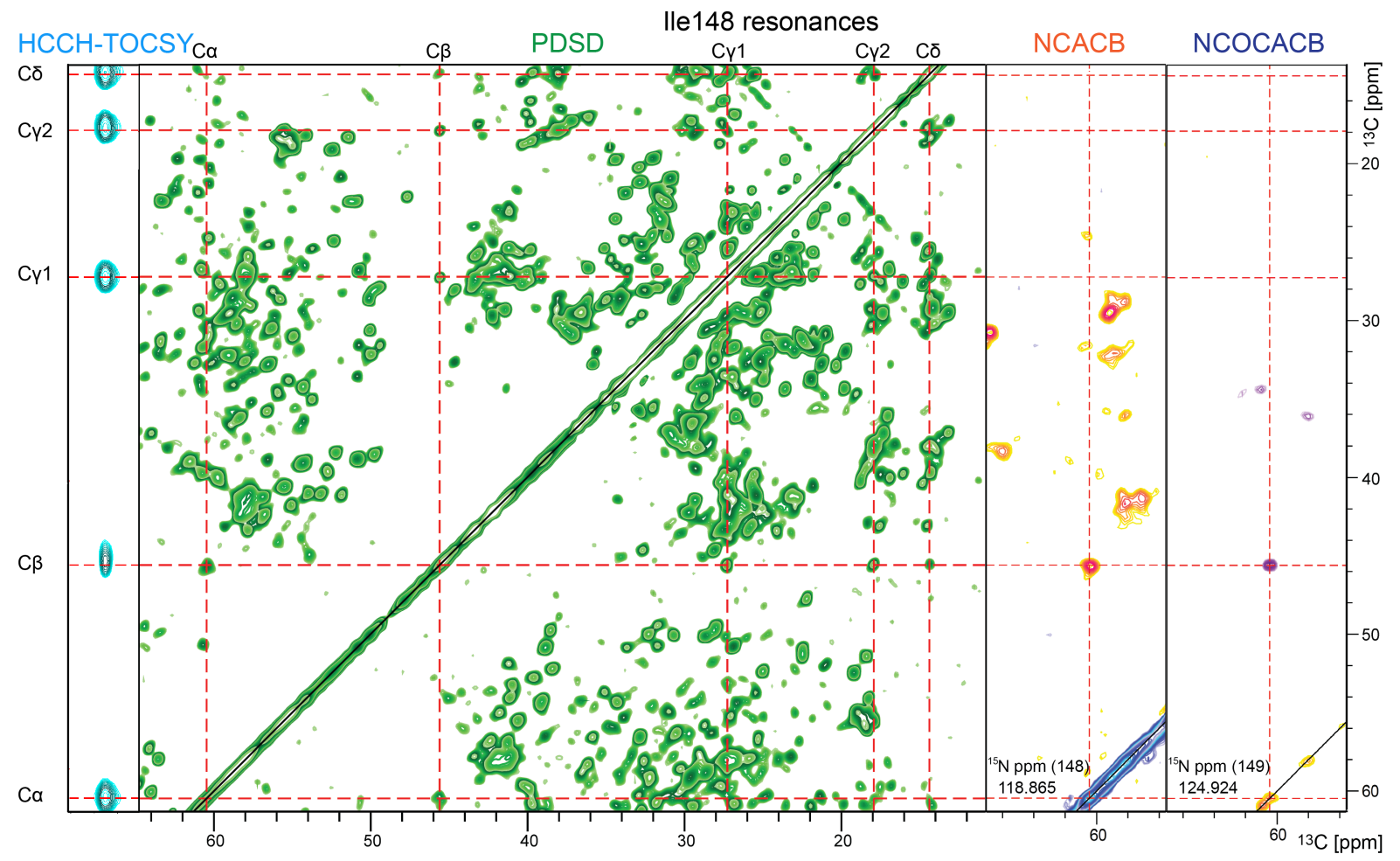

Figure 1.5: Assignment strategy for membrane-embedded CitApc. Liquid-state NMR assignments of isolated PAS domains were used to facilitate solid-state NMR assignments of CitApc. Expected peak positions in solid-state spectra can be predicted from liquid-state chemical shifts (red line intersections) in carbon and nitrogen dimensions. The strategy is exemplified for 2D PDSD, 3D NCACB and 3D NCOCACB assignments of Ile 148 based on liquid-state assignments in an HCCH-TOCSY. In 3D spectra, the corresponding nitrogen plane for Ile 148 (NCACB) and Val 149 (NCOCACB) are shown. 


\section{Materials and Methods}

\subsection{Chemicals and equipment}

Chemicals for the preparation of buffers, solutions and media were obtained from the companies Carl Roth GmbH \& Co. KG (Karlsruhe, GER), Sigma-Aldrich Chemie GmbH (Steinheim, GER), and Merck Millipore (Darmstadt, GER) unless otherwise stated. Restriction enzymes were acquired from THERMo Fisher ScIENTIFIC FERMENTAS (Vilnius, LIT) and New England BioLabs (Ipswich, USA). Preparation of plasmid DNA, DNA extraction from gels and PCR purification were carried out using kits from MACHEREY-NAGEL (Dueren, GER).

\subsection{Construct selection}

Constructs for Geobacillus thermodenitrificans CitA PASp (residues 33-161), PASc (residues 200-309) and CitApc (residues 1-309) were selected based on secondary structure and fold prediction using Phyre2 (Kelley and Sternberg, 2009) paired with domain prediction using InterProScan 5 (Zdobnov and Apweiler, 2001; Goujon et al., 2010).

\subsection{Strains, plasmids and primers}

G. thermodenitrificans CitA DNA was kindly provided by the group of Prof. Gottfried Unden, Johannes Gutenberg-Universität Mainz, GER. Escherichia coli XL 2blue (endA1 supE44 thi-1 recA1 gyrA96 relA1 lac) was used for cloning, E. coli BL21(DE3) (B dcm ompT hsdS $\mathrm{r}_{\mathrm{B}^{-}} \mathrm{m}_{\mathrm{B}^{-}}$gal $\Lambda \mathrm{DE} 3$ ) for PAS domain protein expression. 
For production of selenomethionine containing protein, methionine auxotroph E. coli 834 cells (hsdS metE gal ompT) were used. Membrane-embedded constructs for solidstate NMR spectroscopy were expressed in E. coli C43(DE3) cells ( $F^{-}$omp T gal dcm $\left.h s d S_{\mathrm{B}}\left(\mathrm{r}_{\mathrm{B}^{-}} \mathrm{m}_{\mathrm{B}^{-}}\right)(\mathrm{DE} 3)\right)$. Expression constructs for solid-state samples $\left(\mathrm{CitApc}_{1-309}\right)$ were cloned into pET16bTEV, individual domains $\left(\mathrm{PASp}_{33-161}\right.$ or $\mathrm{PASc}_{200-309}$ ) into pET28aZ2 vectors (MERCK MILLIPORE). Oligonucleotides for construct generation and mutagenesis were obtained from SEQLAB (Göttingen, GER) and are listed in table 2.1. 


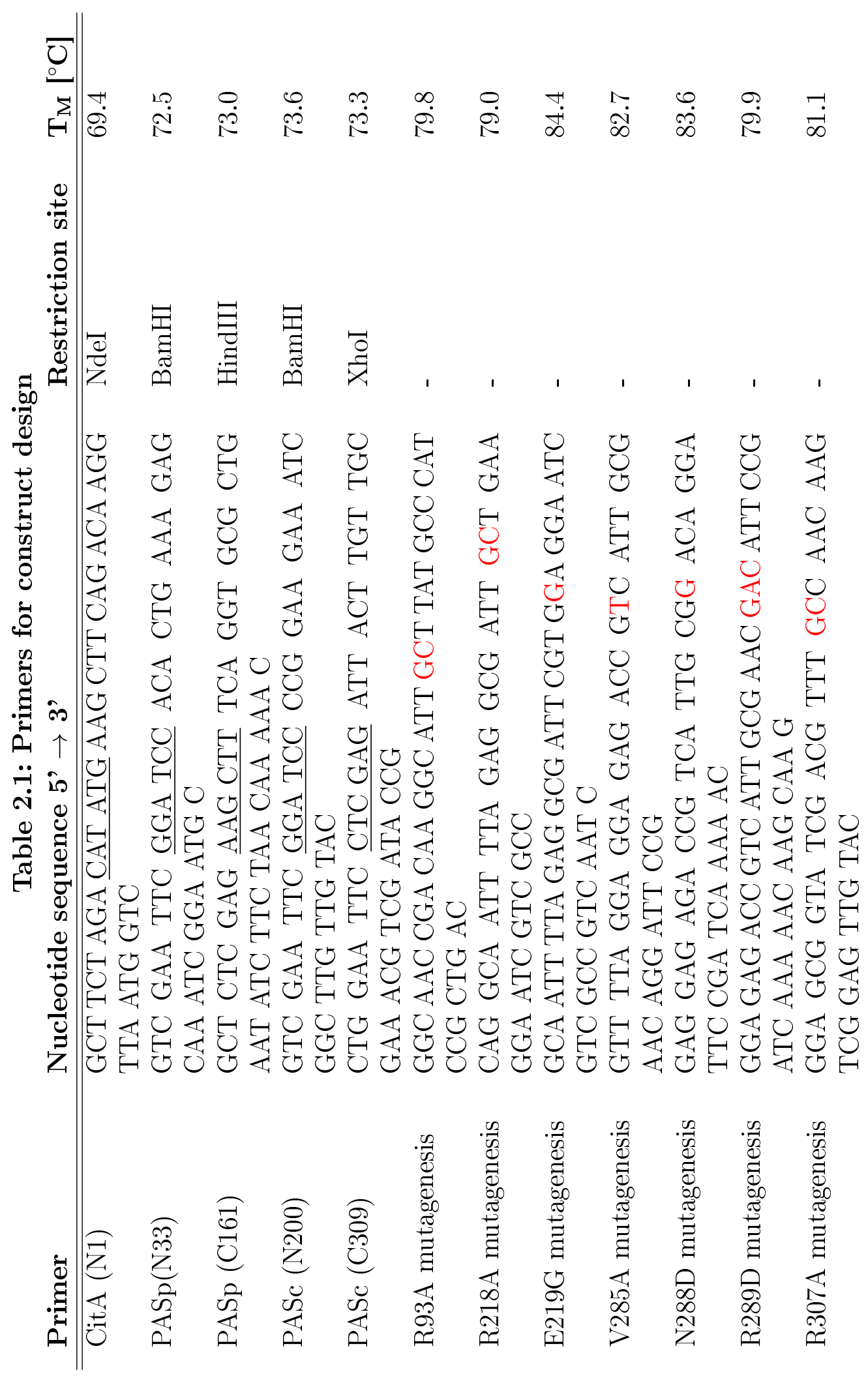




\subsection{Cloning techniques}

\subsubsection{Polymerase chain reaction (PCR)}

DNA for CitA constructs was amplified via polymerase chain reaction (Saiki et al., 1988) using the Phusion High Fidelity PCR Kit from NEw England BioLabs. Reactions were set up with $5 \times$ reaction buffer, $100 \mathrm{ng}$ template DNA, $0.25 \mathrm{mM}$ of each dNTP, $500 \mathrm{nM}$ forward and reverse primers and $2 \mathrm{U}$ polymerase in a total volume of $40 \mu \mathrm{L}$. PCR reactions were carried out in a PCR Sprint thermal cycler from Thermo ScIENTIFIC Hybaid (Ashford, UK). The reaction setup was heated to $98{ }^{\circ} \mathrm{C}$ for 30 seconds, followed by 25 cycles of denaturation $\left(98{ }^{\circ} \mathrm{C}, 10\right.$ seconds), annealing $\left(55^{\circ} \mathrm{C}, 30\right.$ seconds) and elongation $\left(72{ }^{\circ} \mathrm{C}, 30\right.$ seconds). In a final step, the setup was kept at $72{ }^{\circ} \mathrm{C}$ for 10 minutes. The PCR products were subsequently purified using a NucleoSpin Gel and PCR Clean-Up Kit from MACHEREY-NAGEL following the supplier's instructions.

\subsubsection{Agarose gel electrophoresis}

Purified PCR products were mixed with $6 \times$ DNA loading dye (40\% Ficoll 400, $0.5 \%$ bromphenol blue, $0.5 \%$ xylene cyanol) and separated on agarose gels Aaij and Borst, 1972 ) containing $2 \%$ agarose in TAE buffer (40 mM Tris-Cl, $20 \mathrm{mM}$ acetic acid, $1 \mathrm{mM}$ EDTA, pH 8.0) and $0.005 \%$ ethidium bromide, using DNA marker (GeneRuler 1 kB DNA Ladder (Thermo Fisher SCIENTIFIC FERMENTAS)) as a reference. The gel was run in TAE buffer at $100 \mathrm{~V}$ for 60 minutes. DNA bands of PCR products were excised from the gel and purified using a NucleoSpin Gel and PCR Clean-Up Kit following the supplier's instructions.

\subsubsection{Restriction digestion of DNA}

The blunt ends of the purified PCR products as well as the target vectors were digested using restriction endonucleases specified in table 2.1 (Nath and Azzolina, 1981). Restriction enzymes and buffers were obtained from Fermentas and New England BioLabs. For digestion, $3-5 \mu \mathrm{g}$ of vector/PCR product were added to $10 \times$ reaction buffer containing 
$5 \mathrm{U}$ endonuclease adjusted to a final volume of $50 \mu \mathrm{L}$ and incubated at $37^{\circ} \mathrm{C}$ for 2 hours. The reaction was then purified using a NucleoSpin Gel and PCR Clean-Up Kit following the supplier's instructions.

\subsubsection{Ligation of DNA fragments}

The cleaved DNA fragments from PCR were ligated with the prepared vectors using T4 ligase and buffer from NEw England BioLabs (Sugino et al., 1977). Ligation reactions were set up at a vector/insert ratio of 1:1 in a total volume of $20 \mu \mathrm{L}$ and incubated at $14{ }^{\circ} \mathrm{C}$ over night. The reaction was subsequently terminated by heating up to $65{ }^{\circ} \mathrm{C}$ for 10 minutes. $5 \mu \mathrm{L}$ of the ligation set-up were used to transform XL2-blue cells.

\subsubsection{Plasmid purification}

Plasmids were purified from overnight cultures of XL2-blue cells (see 2.5) by means of midi-prep. Cells were spun down by centrifugation and plasmids purified using a NucleoBond Xtra Midi purification kit by MACHEREY-NAGEL following the company's manual.

\subsubsection{DNA sequencing}

DNA sequencing (Sanger and Coulson, 1975) was carried out by SEQLAB (Göttingen, GER). Samples for sequencing contained 500 - $600 \mathrm{ng}$ plasmid DNA and 20 pmol of either $\mathrm{T} 7$ promoter or $\mathrm{T} 7$ terminator primer in a total volume of $7 \mu \mathrm{L}$, adjusted with water.

\subsubsection{Site-directed mutagenesis}

Mutants of G. thermodenitrificans PASp and PASc constructs were generated via site-directed mutagenesis utilising the primers shown in table 2.1. Mutagenesis PCR reactions were set up using a QuikChange II Site-Directed Mutagenesis Kit (AgILENT Technologies, Santa Clara, USA). $25 \mathrm{ng}$ of template PAS-domain plasmid and $150 \mathrm{ng}$ of both forward and reverse primers were added to $2.5 \mathrm{U}$ PfuUltra DNA polymerase and $1 \mu \mathrm{L}$ dNTP mix in $10 \times$ reaction buffer with a total volume of $50 \mu \mathrm{L}$. 
PCR reactions were carried out in a PCR Sprint thermal cycler. The reaction mix was heated to $95^{\circ} \mathrm{C}$ for 30 seconds, followed by 12 cycles of denaturation ( $95^{\circ} \mathrm{C}, 30$ seconds), annealing $\left(55^{\circ} \mathrm{C}, 1\right.$ minute) and elongation $\left(68^{\circ} \mathrm{C}, 6\right.$ minutes). In a final step, the setup was kept at $68{ }^{\circ} \mathrm{C}$ for 10 minutes. The PCR products were subsequently purified using a NucleoSpin Gel and PCR Clean-Up Kit following the supplier's instructions.

\subsection{Transformation and cultivation of Escherichia coli}

\subsubsection{Unlabelled protein}

All E. coli cells were transformed using $50 \mu \mathrm{L}$ aliquots of cells that were thawed on ice. $0.5 \mathrm{LL}$ plasmid DNA was added, followed by another 30 minutes incubation on ice. Cells were transformed by heat shock ( 45 seconds at $42{ }^{\circ} \mathrm{C}$ ) and kept on ice for another two minutes. $50 \mu \mathrm{L}$ of $2 \times$ YT medium (1.6\% tryptone, $1 \%$ yeast extract, $0.5 \% \mathrm{NaCl}$ adjusted to $\mathrm{pH} 7.0$ with $\mathrm{NaOH}$ ) was added and the cells were icubated at $37^{\circ} \mathrm{C}$ for one hour. Cells were harvested by centrifugation (7,500 g for 5 minutes at room temperature) and resuspended in $30 \mu \mathrm{L} 2 \times$ YT medium. The cell suspension was plated out on Luria-Bertani (LB) agar plates (1\% tryptone, $0.5 \%$ yeast extract, $1 \% \mathrm{NaCl}, 1.5 \%$ agar) containing the appropriate antibiotic $(0.01 \%$ ampicillin for pET16bTEV, $0.007 \%$ kanamycin for pET28aZ2) and incubated over night at $37^{\circ} \mathrm{C}$.

Over-night suspension cultures of E. coli , both for midi-prep and for production of unlabelled protein, were set up by picking a colony from an agar plate and resuspending it in $1 \mathrm{~mL} \mathrm{LB}$ medium (1\% tryptone, $0.5 \%$ yeast extract, $1 \% \mathrm{NaCl}$ adjusted to $\mathrm{pH} 7.2$ with $\mathrm{NaOH}$ ) with the appropriate antibiotic. Cells were cultivated for 5 - 6 hours at $37{ }^{\circ} \mathrm{C}$ in an incubator shaker. $20 \mu \mathrm{L}$ cell culture were subsequently transferred to $100 \mathrm{~mL} \mathrm{LB}$ medium with the appropriate antibiotic and incubated over night at $37^{\circ} \mathrm{C}$ in an incubator shaker.

$350 \mu \mathrm{L}$ of the $1 \mathrm{~mL}$ day culture were added to $150 \mu \mathrm{L} 50 \%$ glycerol for setting up glycerol stocks. Cells were harvested by centrifugation ( 15 minutes at $4,300 \mathrm{~g}, 4^{\circ} \mathrm{C}$ ) either to be used in midi-preps (see 2.4.5) or for production of protein samples for crystallisation.

Protein sample production was carried out by adding $25 \mathrm{~mL}$ of the overnight culture 
to $1 \mathrm{~L}$ of fresh LB medium with $0.007 \%$ kanamycin and incubating at $37^{\circ} \mathrm{C}$ in an incubator shaker until an optical density at $600 \mathrm{~nm}\left(\mathrm{OD}_{600}\right)$ of 0.5 was reached. Afterwards, the temperature was decreased to $30^{\circ} \mathrm{C}$ and the culture was grown until an $\mathrm{OD}_{600}$ of 0.7 was reached. Protein expression was then induced by adding $0.5 \mathrm{mM}$ isopropyl $\beta$ D-1-thiogalactopyranoside (IPTG) and cells were harvested 5 hours after induction by centrifugation $\left(20\right.$ minutes at $\left.7,400 \mathrm{~g}, 4^{\circ} \mathrm{C}\right)$. Pellets were stored at $-80{ }^{\circ} \mathrm{C}$ until purification.

\subsubsection{Selenomethionine-labelled protein}

For production of selenomethionine (SeMet)-labelled protein for crystallisation (Hendrickson et al. 1990), plasmids were transformed into methionine auxotroph E. coli B834(DE3) (Novagen, Darmstadt, GER). Day cultures were set up from agar plates using $1 \mathrm{~mL}$ of minimal medium (see table 2.2) containing $50 \mathrm{\mu g}$ L-methionine. After 6 hours, over-night cultures were set up by adding $50 \mu \mathrm{L}$ of day culture to $100 \mathrm{~mL}$ of minimal medium supplemented with $5 \mathrm{mg}$ of L-methionine. The whole over-night culture was subsequently added to $1 \mathrm{~L}$ of minimal medium with $50 \mathrm{mg}$ L-methionine and grown at $37{ }^{\circ} \mathrm{C}$ until $\mathrm{OD}_{600}$ of 0.6 was reached. The temperature was then reduced to $30{ }^{\circ} \mathrm{C}$, and the cells were harvested at an $\mathrm{OD}_{600}$ of 1.0 by centrifugation (20 minutes at 7,400 g, $4{ }^{\circ} \mathrm{C}$ ). Cells were then re-suspended in $1 \mathrm{~L}$ of minimal medium without methionine and incubated for 6 hours at $30{ }^{\circ} \mathrm{C}$. After addition of $50 \mathrm{mg}$ seleno-L-methionine, protein expression was induced after another 30 minutes by addition of $0.5 \mathrm{mM}$ IPTG. Cells were harvested five hours after induction by centrifugation (20 minutes at 7,400 g, $4{ }^{\circ} \mathrm{C}$ ) and stored at $-80{ }^{\circ} \mathrm{C}$. 
Table 2.2: Minimal medium for SeMet protein expression

\begin{tabular}{|c|c|}
\hline \multicolumn{2}{|l|}{ SeMet minimal medium } \\
\hline $100 \times$ Trace elements & $1 \%$ \\
\hline $20 \%$ Glucose & $2 \%$ \\
\hline $\mathrm{MgSO}_{4}$ & $1 \mathrm{mM}$ \\
\hline $\mathrm{CaCl}_{2}$ & $0.3 \mathrm{mM}$ \\
\hline Thiamine $\cdot \mathrm{HCl}$ & $1 \mathrm{mg} / \mathrm{L}$ \\
\hline $\mathrm{NH}_{4} \mathrm{Cl}$ & $1 \mathrm{~g} / \mathrm{L}$ \\
\hline L-Methionine & $50 \mathrm{mg} / \mathrm{L}$ \\
\hline $10 \times$ M9 Salts & $10 \%$ \\
\hline \multicolumn{2}{|l|}{$100 \times$ Trace elements } \\
\hline Na-ethylenediaminetetraacetate (EDTA) & $5 \mathrm{~g} / \mathrm{L}, \mathrm{pH} 7.5$ \\
\hline $\mathrm{FeCl}_{3} \cdot 6 \mathrm{H}_{2} \mathrm{O}$ & $0.83 \mathrm{~g} / \mathrm{L}$ \\
\hline $\mathrm{ZnCl}_{2}$ & $84 \mathrm{mg} / \mathrm{L}$ \\
\hline $\mathrm{CuCl}_{2} \cdot 2 \mathrm{H}_{2} \mathrm{O}$ & $13 \mathrm{mg} / \mathrm{L}$ \\
\hline $\mathrm{CoCl}_{2} \cdot 6 \mathrm{H}_{2} \mathrm{O}$ & $10 \mathrm{mg} / \mathrm{L}$ \\
\hline $\mathrm{H}_{3} \mathrm{BO}_{3}$ & $10 \mathrm{mg} / \mathrm{L}$ \\
\hline $\mathrm{MnCl}_{2} \cdot 6 \mathrm{H}_{2} \mathrm{O}$ & $1.6 \mathrm{mg} / \mathrm{L}$ \\
\hline \multicolumn{2}{|l|}{$10 \times$ M9 Salts, pH 7.4} \\
\hline $\mathrm{Na}_{2} \mathrm{HPO}_{4}$ & $80 \mathrm{~g} / \mathrm{L}$ \\
\hline $\mathrm{KH}_{2} \mathrm{PO}_{4}$ & $40 \mathrm{~g} / \mathrm{L}$ \\
\hline $\mathrm{NaCl}$ & $5 \mathrm{~g} / \mathrm{L}$ \\
\hline
\end{tabular}

\subsection{3 ${ }^{13} \mathrm{C}-{ }^{15} \mathrm{~N}$ labelled protein}

Uniform doubly labelled samples for liquid-state NMR were produced in E. coli BL21(DE3) cells in M9 minimal medium (McIntosh and Dahlquist, 1990). Day cultures were set up analogous to 2.5.1, over-night cultures were grown in $50 \mathrm{~mL}$ minimal medium (see table 2.3 containing ${ }^{13} \mathrm{C}$-glucose and ${ }^{15} \mathrm{~N}$-ammonium chloride. For protein expression, $25 \mathrm{~mL}$ over-night culture was added to $1 \mathrm{~L}$ minimal medium and grown at $37^{\circ} \mathrm{C}$ until an $\mathrm{OD}_{600}$ of 0.5 was reached, the temperature was then reduced to $30{ }^{\circ} \mathrm{C}$. Expression was induced with $0.5 \mathrm{mM}$ IPTG at an $\mathrm{OD}_{600}$ of 0.7 . Cells were harvested 5 hours after induction.

For solid-state samples, expression constructs were transformed into E. coli C43(DE3) as described in 2.5.1. Day cultures in $1 \mathrm{~mL} 2 \times$ YT medium were transferred to $100 \mathrm{~mL}$ minimal medium and grown over night as detailed above. For expression culture, the overnight culture was diluted 1:30 in $3 \mathrm{~L}$ of fresh minimal medium containing ${ }^{13} \mathrm{C}$-glucose and 
${ }^{15} \mathrm{~N}$-ammonium chloride. Cells were grown to an $\mathrm{OD}_{600}$ of 0.4 at $37^{\circ} \mathrm{C}$, the temperature was then reduced to $20{ }^{\circ} \mathrm{C}$ and expression induced at an $\mathrm{OD}_{600}$ of $0.9-1.0$ with $0.5 \mathrm{mM}$ IPTG. Cells were harvested after growing over-night at $20{ }^{\circ} \mathrm{C}$.

Table 2.3: Minimal medium for ${ }^{13} \mathrm{C}-{ }^{15} \mathrm{~N}$ labelled protein expression

\begin{tabular}{|c|c|}
\hline \multicolumn{2}{|l|}{ NMR minimal medium } \\
\hline $100 \times$ Trace elements & $1 \%$ \\
\hline $20 \%{ }^{13} \mathrm{C}$-glucose & $2 \%$ \\
\hline $\mathrm{MgSO}_{4}$ & $2 \mathrm{mM}$ \\
\hline $\mathrm{CaCl}_{2}$ & $0.1 \mathrm{mM}$ \\
\hline Thiamine $\cdot \mathrm{HCl}$ & $30 \mathrm{mg} / \mathrm{L}$ \\
\hline${ }^{15} \mathrm{~N}-\mathrm{NH}_{4} \mathrm{Cl}$ & $1 \mathrm{~g} / \mathrm{L}$ \\
\hline $5 \times$ M9 Salts & $20 \%$ \\
\hline \multicolumn{2}{|l|}{$100 \times$ Trace elements } \\
\hline Na-ethylenediaminetetraacetate (EDTA) & $5 \mathrm{~g} / \mathrm{L}$ \\
\hline $\mathrm{FeSO}_{4} \cdot 7 \mathrm{H}_{2} \mathrm{O}$ & $6 \mathrm{~g} / \mathrm{L}$ \\
\hline $\mathrm{MnCl}_{2} \cdot 4 \mathrm{H}_{2} \mathrm{O}$ & $1.15 \mathrm{~g} / \mathrm{L}$ \\
\hline $\mathrm{ZnSO}_{4} \cdot 7 \mathrm{H}_{2} \mathrm{O}$ & $700 \mathrm{mg} / \mathrm{L}$ \\
\hline $\mathrm{CuCl}_{2} \cdot 2 \mathrm{H}_{2} \mathrm{O}$ & $300 \mathrm{mg} / \mathrm{L}$ \\
\hline $\mathrm{CoCl}_{2} \cdot 6 \mathrm{H}_{2} \mathrm{O}$ & $10 \mathrm{mg} / \mathrm{L}$ \\
\hline $\mathrm{H}_{3} \mathrm{BO}_{3}$ & $20 \mathrm{mg} / \mathrm{L}$ \\
\hline$\left(\mathrm{NH}_{4}\right)_{6} \mathrm{Mo}_{7} \mathrm{O}_{2} 4 \cdot 4 \mathrm{H}_{2} \mathrm{O}$ & $250 \mathrm{mg} / \mathrm{L}$ \\
\hline \multicolumn{2}{|l|}{$\begin{array}{r}5 \times \text { M9 Salts, pH } 7.4 \\
\end{array}$} \\
\hline $\mathrm{Na}_{2} \mathrm{HPO}_{4}$ & $33.9 \mathrm{~g} / \mathrm{L}$ \\
\hline $\mathrm{KH}_{2} \mathrm{PO}_{4}$ & $15 \mathrm{~g} / \mathrm{L}$ \\
\hline $\mathrm{NaCl}$ & $2.5 \mathrm{~g} / \mathrm{L}$ \\
\hline
\end{tabular}




\subsection{Protein purification}

\subsubsection{PAS domains}

\section{Cell lysis}

All PASp and PASc constructs were purified following the same protocol. Cell pellets from $1 \mathrm{~L}$ expression cultures were re-suspended in $60 \mathrm{~mL}$ lysis buffer $(20 \mathrm{mM}$ Tris $\cdot \mathrm{HCl}$ pH 7.9, $300 \mathrm{mM} \mathrm{NaCl}, 10 \mathrm{mM}$ imidazole, $0.5 \mathrm{mM}$ phenylmethylsulfonylfluoride (PMSF)) on ice. Per $100 \mathrm{~mL}$ of lysis buffer, one cOmplete (EDTA free) protease inhibitor cocktail tablet (Roche Diagnostics, Basel, CH) was added. Cells were ruptured by sonication, cellular debris was removed by centrifugation ( 45 minutes at $48,000 \mathrm{~g}, 4^{\circ} \mathrm{C}$ ).

\section{Ni-NTA purification}

In a first purification step, Ni-NTA (nitrilotriacetic acid) resin (QIAGEN, Hilden, GER) was used to enrich histidine-tagged PAS domains. $2.5 \mathrm{~mL}$ resin were equilibrated with $50 \mathrm{~mL}$ lysis buffer before adding the supernatant from cell lysis. The suspension was mixed on a tilting shaker for one hour at $4{ }^{\circ} \mathrm{C}$ and transferred to a disposable plastic column (Thermo Fisher Scientific). The flow-through was collected and the resin washed with $100 \mathrm{~mL}$ lysis buffer. Target proteins were eluted with $8 \times 2 \mathrm{~mL}$ elution buffer A (20 mM Tris $\cdot \mathrm{HCl} \mathrm{pH} 7.9,300 \mathrm{mM} \mathrm{NaCl}, 100 \mathrm{mM}$ imidazole) and $8 \times 2 \mathrm{~mL}$ elution buffer B (20 mM Tris. $\mathrm{HCl}$ pH 7.9, $300 \mathrm{mM} \mathrm{NaCl,} 500 \mathrm{mM}$ imidazole). Purification was monitored with SDS-PAGE (Sodium dodecyl sulfate polyacrylamide gel electrophoresis). Gels were run for 60 minutes at $120 \mathrm{~V}$ (see table 2.4). Protein fractions containing the target protein were pooled and dialysed over night in $2 \mathrm{~L}$ TEV-buffer $(50 \mathrm{mM}$ Tris $\cdot \mathrm{HCl}$ pH 7.9, $0.5 \mathrm{mM}$ EDTA, $150 \mathrm{mM} \mathrm{NaCl}, 1 \mathrm{mM}$ dithiothreitol (DTT), $0.5 \mathrm{mM} \mathrm{PMSF}$ ) at $4{ }^{\circ} \mathrm{C}$. 
Table 2.4: $17.5 \%$ SDS-PAGE gels

\begin{tabular}{|l|l|}
\hline \multicolumn{2}{|c|}{ Stacking gel } \\
\hline $30 \%$ acrylamide & $10 \%$ \\
Tris·HCl pH $6.8(1 \mathrm{M})$ & $12.5 \%$ \\
$10 \%$ sodium dodecylsulfate (SDS) & $1 \%$ \\
$10 \%$ ammonium persulfate (APS) & $1 \%$ \\
tetramethylethylenediamine (TEMED) & $0.08 \%$ \\
$\mathrm{H}_{2} \mathrm{O}$ & $75.42 \%$ \\
\hline \hline \multicolumn{2}{|c|}{ Separating gel } \\
\hline $30 \%$ acrylamide & $60 \%$ \\
Tris·HCl pH $8.8(1 \mathrm{M})$ & $37.6 \%$ \\
$10 \%$ SDS & $1 \%$ \\
$10 \%$ APS & $1 \%$ \\
TEMED & $0.05 \%$ \\
$\mathrm{H}_{2} \mathrm{O}$ & $0.35 \%$ \\
\hline \hline \multicolumn{2}{|c|}{ running buffer } \\
\hline Tris base & $25 \mathrm{mM}$ \\
glycine & $192 \mathrm{mM}$ \\
SDS & $0.1 \%$ \\
\hline
\end{tabular}

\section{TEV-cleavage of His-tag}

Protein concentration of dialysed protein was approximated from UV-absorption spectra. The $N$-terminal His-tag was cleaved by adding $1 \mathrm{mg}$ TEV protease per $100 \mathrm{mg}$ protein and incubating for six hours at room temperature without stirring. Successful cleavage was verified by SDS-PAGE. The protein sample was then added to $2.5 \mathrm{~mL}$ of Ni-NTA agarose (equilibrated with $50 \mathrm{~mL}$ SEC buffer: $20 \mathrm{mM}$ sodium phosphate $\mathrm{pH}$ 6.5, $150 \mathrm{mM}$ $\mathrm{NaCl}$ ) and incubated for one hour. The resin was washed with $10 \mathrm{~mL}$ SEC buffer, flowthrough and wash fractions were pooled and dialysed over night at $4{ }^{\circ} \mathrm{C}$ against $2 \mathrm{~L}$ of SEC buffer.

\section{Size exclusion chromatography}

The dialysed protein samples were concentrated to $1.5 \mathrm{~mL}$ using Vivaspin 20 (10 kDa) spin concentrators (SARTORIUS, Göttingen, GER). The protein concentration was monitored via UV absorption spectra. Concentrated samples were purified via size exclusion chromatography (SEC) on a Superdex 75 16/60 column (GE LIFE SCIENCES, Little Chalfont, 
UK). The column was equilibrated with two column volumes SEC buffer, protein fractions were analysed by SDS-PAGE and fractions containing pure protein were pooled. The final PAS domain samples were dialysed over night at $4{ }^{\circ} \mathrm{C}$ against $2 \mathrm{~L}$ of NMR buffer $(20 \mathrm{mM}$ sodium phosphate $\mathrm{pH} 6.5,50 \mathrm{mM} \mathrm{NaCl}$ ). The buffer was used both for liquid-state NMR experiments and crystallisation set-ups. In a final step, samples were concentrated to 1.4 - $1.8 \mathrm{mM}$ using Vivaspin 20 (10 kDa molecular weight cut-off) concentrators and $0.01 \%$ sodium azide was added. All samples were stored at $4{ }^{\circ} \mathrm{C}$ when not used in experiments.

For determining the oligomeric state of proteins, analytical SEC was carried out on a Superdex 75 10/300 column (GE LIFE SCIENCES). $100 \mu \mathrm{L}$ protein samples at concentrations of $\tilde{1} \mathrm{mM}$ and the SEC buffer described above were used. To calculate the sample molecular weight based on elution volume, a standard protein mix (Gel filtration calibration kit LMW, GE LIFE SCIENCES) was separated on the same column. $1.5 \mathrm{mg}$ each of conalbumin, carbonic anhydrase, ribonuclease A and aprotinin were suspended in $500 \mu \mathrm{L}$ SEC buffer; $100 \mu \mathrm{L}$ of this sample was used for SEC.

\subsubsection{Gt CitApc solid-state NMR samples}

Solid-state NMR samples were kindly provided by Karin Giller (Department of NMRbased structural biology, Max-Planck-Institute for Biophysical Chemistry, Göttingen, GER) using the following protocol.

\section{Cell lysis}

Cell pellets were re-suspended on ice in $225 \mathrm{~mL}$ TKMD buffer $(50 \mathrm{mM}$ Tris $\cdot \mathrm{HCl} \mathrm{pH} 7.0$, $200 \mathrm{mM} \mathrm{KCl}, 5 \mathrm{mM} \mathrm{MgCl}_{2}, 5 \mathrm{mM} \beta$-mercaptoethanol, one spatula tip of DNAseI, two cOmplete (EDTA free) protease inhibitor cocktail tablets, $0.5 \mathrm{mM}$ PMSF) using a PotTer-Elvehjem homogeniser. The suspension was stirred at $4{ }^{\circ} \mathrm{C}$ for one hour before cell lysis utilising three cycles in a french pressure cell (20,000 psi). Cell debris was pelleted by centrifugation $\left(30\right.$ minutes at $4{ }^{\circ} \mathrm{C}$ and $27,500 \mathrm{~g}$ ), the supernatant was spun down in an ultracentrifuge (90 minutes at $4{ }^{\circ} \mathrm{C}$ and $102,089 \mathrm{~g}$ ). The ultracentrifugation pellet was re-suspended in $180 \mathrm{~mL} \mathrm{Ni-NTA-buffer} \mathrm{(20} \mathrm{mM} \mathrm{Tris·} \mathrm{HCl}$ pH 7.9, $500 \mathrm{mM} \mathrm{NaCl}, 10 \mathrm{mM}$ imidazole) with $5 \mathrm{mM} \beta$-mercaptoethanol, two cOmplete (EDTA free) protease inhibitor 
cocktail tablets, $0.5 \mathrm{mM}$ PMSF and $4 \%$ Triton X-100 (v/v) using a POTTER-ElvehJem homogeniser.

The suspension was stirred for three hours at $4{ }^{\circ} \mathrm{C}$ and subjected to ultracentrifugation a second time (one hour at $4^{\circ} \mathrm{C}$ and $109,251 \mathrm{~g}$ ). The supernatant was diluted to an end volume of $900 \mathrm{~mL}$ using Ni-NTA-buffer with three cOmplete (EDTA free) protease inhibitor cocktail tablets and $0.5 \mathrm{mM}$ PMSF to set the final concentration of Triton X-100 at $0.8 \%(\mathrm{v} / \mathrm{v})$.

\section{Ni-NTA purification}

The protein solution was loaded over-night onto a $5 \mathrm{~mL} \mathrm{Ni-NTA} \mathrm{column} \mathrm{(GE} \mathrm{LIFE}$ SCIENCES) at $0.7 \mathrm{~mL} / \mathrm{min}$ and $4{ }^{\circ} \mathrm{C}$. The column was washed with Ni-NTA-buffer (supplemented with half a tablet of cOmplete (EDTA free) protease inhibitor cocktail per $100 \mathrm{~mL}, 1 \mathrm{mM} \beta$-mercaptoethanol, $0.5 \mathrm{mM}$ PMSF and $0.2 \%(\mathrm{v} / \mathrm{v})$ Triton X-100) at $3 \mathrm{~mL} / \mathrm{min}$ until a baseline was reached. The detergent was changed on-column by washing with $80 \mathrm{~mL}$ of Ni-NTA-buffer supplemented with half a tablet of cOmplete (EDTA free) protease inhibitor cocktail per $100 \mathrm{~mL}, 1 \mathrm{mM} \beta$-mercaptoethanol, $0.5 \mathrm{mM}$ PMSF and $1 \%(\mathrm{v} / \mathrm{v})$ laurydimethylamine-oxide (LDAO) at $3 \mathrm{~mL} / \mathrm{min}$.

One-step elution was carried out by washing with elution buffer $(20 \mathrm{mM}$ Tris $\cdot \mathrm{HCl}$ $\mathrm{pH} 7.9,500 \mathrm{mM} \mathrm{NaCl}, 500 \mathrm{mM}$ imidazole) supplemented with one tablet of cOmplete (EDTA free) protease inhibitor cocktail per $100 \mathrm{~mL}, 1 \mathrm{mM} \beta$-mercaptoethanol, $0.5 \mathrm{mM}$ PMSF and $1 \%(\mathrm{v} / \mathrm{v}) \mathrm{LDAO}$ at $2 \mathrm{~mL} / \mathrm{min} .2 \mathrm{~mL}$ fractions were collected and analysed by SDS-PAGE.

\section{Size exclusion chromatography (SEC)}

Pure protein fractions were pooled and concentrated to $2.5 \mathrm{~mL}$ using Vivaspin 20 (30 kDa) spin concentrators. The protein concentration was monitored via UV absorption spectra. Concentrated samples were purified via size exclusion chromatography on Superdex 200 26/60 columns (GE LIFE SCIENCES). The column was equilibrated with two column volumes gel filtration buffer $(20 \mathrm{mM}$ Tris $\cdot \mathrm{HCl} \mathrm{pH}$ 7.4, $150 \mathrm{mM} \mathrm{NaCl}, 1 \mathrm{mM}$ DTT, $0.3 \%$ LDAO) and $2 \mathrm{~mL}$ fractions were collected. Protein fractions were analysed by SDS-PAGE 
gel electrophoresis and pure protein was pooled.

\section{Reconstitution in liposomes}

1,2-dimyristoyl-sn-glycero-3-phosphocholine (DMPC)- or asolectin lipid films were set up by dissolving the appropriate amount of lipids for a protein/lipid molar ratio of 1:100 in $2 \mathrm{~mL}$ of chloroform and methanol (1:1). The solvent was removed in a nitrogen gas stream followed by lyophilisation over-night. The lipid film was sonicated $(3 \times 15$ minutes $)$ in $1 \mathrm{~mL}$ gel filtration buffer before adding ultrafiltered protein samples. The mixture was incubated for two hours at room temperature on a tilting shaker. LDAO was subsequently removed by incubation with 2 g Bio-Beads SM-2 (BIO-RAD LABORATORIES, Hercules, USA) per $66 \mathrm{mg}$ LDAO on a tilting shaker at $4{ }^{\circ} \mathrm{C}$ over night. The sample was diluted to $40 \mathrm{~mL}$ with gel filtration buffer without LDAO and the Bio-Beads were removed on a disposable plastic column which was washed with $2 \times 10 \mathrm{~mL}$ gel filtration buffer without LDAO.

The liposomes were pelleted by ultracentrifugation (two hours at $4{ }^{\circ} \mathrm{C}$ and $109,251 \mathrm{~g}$ ) and the pellet washed and re-suspended with $60 \mathrm{~mL}$ of $20 \mathrm{mM}$ Tris $\cdot \mathrm{HCl} \mathrm{pH}$ 7.4. Ultracentrifugation was repeated (one hour at $4{ }^{\circ} \mathrm{C}$ and $109,251 \mathrm{~g}$ ) and the pellet re-suspended in $10 \mathrm{~mL}$ of $20 \mathrm{mM}$ Tris. $\mathrm{HCl} \mathrm{pH} \mathrm{7.4.} \mathrm{After} \mathrm{another} \mathrm{ultracentrifugation} \mathrm{step} \mathrm{(one} \mathrm{hour} \mathrm{at}$ $4{ }^{\circ} \mathrm{C}$ and $109,251 \mathrm{~g}$ ), the pellet was re-suspended in $1 \mathrm{~mL}$ of $20 \mathrm{mM}$ Tris $\cdot \mathrm{HCl} \mathrm{pH}$ 7.4. This step was repeated, following a final centrifugation run (one hour at $4{ }^{\circ} \mathrm{C}$ and $109,251 \mathrm{~g}$ ) after which the supernatant was removed, leaving $\tilde{2} 0 \mu \mathrm{L}$ of buffer. The sample was spun down another 30 minutes at $4^{\circ} \mathrm{C}$ and $109,251 \mathrm{~g}$ and stored at $4{ }^{\circ} \mathrm{C}$ before transferring to solid-state NMR rotors.

For producing citrate-bound G. thermodenitrificans CitApc R93A, the same protocol was used, adding $5 \mathrm{mM}$ sodium citrate to every buffer following cell lysis. 


\subsection{Crystallisation of PAS domains}

Crystallisation trials of PASp and PASc constructs were set up using the following samples:

\begin{tabular}{|l|l|}
\hline Construct & Concentration \\
\hline PASp (native) & $1.4 \mathrm{mM}$ \\
PASp R93A (native) & $1.4 \mathrm{mM}$ \\
PASp R93A (SeMet) & $1.4 \mathrm{mM}$ \\
PASp R93A + 6-fold citrate (native) & $1.4 \mathrm{mM}$ \\
PASc (native) & $1.0 \mathrm{mM}$ \\
PASc (SeMet) & $1.0 \mathrm{mM}$ \\
PASc R218A (SeMet) & $1.5 \mathrm{mM}$ \\
PASc E219G (native) & $1.4 \mathrm{mM}$ \\
PASc V285A (native) & $1.4 \mathrm{mM}$ \\
PASc V285A (SeMet) & $1.5 \mathrm{mM}$ \\
PASc N288D (native) & $1.5 \mathrm{mM}$ \\
PASc N288D (SeMet) & $1.5 \mathrm{mM}$ \\
PASc R289D (native) & $1.6 \mathrm{mM}$ \\
PASc R289D (SeMet) & $1.5 \mathrm{mM}$ \\
PASc R307A (native) & $1.5 \mathrm{mM}$ \\
PASc R307A (SeMet) & $1.5 \mathrm{mM}$ \\
\hline
\end{tabular}

All protein samples used for crystallisation were buffered with $20 \mathrm{mM}$ sodium phosphate, $\mathrm{pH} 6.5$ and $50 \mathrm{mM} \mathrm{NaCl}$. Initial crystallisation attempts were set up employing the sparse matrix screens Index HT, PEGion HT, Crystal Screen 1+2 (HAMPTON Research, Aliso Viejo, USA), PEGs Suite, JCSG+ Suite (QIAgen) and Wizard 1+2 (Rigaku Reagents, Bainbridge Island, USA). Drops were set up in 96-well plates (Greiner Bio One GmbH, Frickenhausen, GER) using the sitting drop vapour diffusion method. For each crystallisation condition, $200 \mathrm{~nL}$ of protein sample were mixed with $200 \mathrm{~nL}$ reservoir solution (Mosquito Crystal, TTP LABTECH LTD., Hertfordshire, $\mathrm{UK})$ and equilibrated against $100 \mu \mathrm{L}$ reservoir solution.

In a second step, set-ups yielding crystals were optimised by constructing grid screens around the initial crystallisation conditions by varying ingredient concentrations and buffer $\mathrm{pH}$. The grid screens were carried out in 96-well plates. The collection of Xray diffraction datasets and solution of crystal structures was carried out by Dr. Stefan Becker (Department of NMR-based Structural Biology, Max-Planck-Institute for Biophysical Chemistry, Göttingen, GER). 


\subsection{Liquid-state NMR experiments}

\subsubsection{General procedures}

Liquid-state NMR experiments were recorded on samples in $5 \mathrm{~mm}$ Shigemi tubes (SHIGEMI INC., Allison Park, USA) at concentrations between 1.4 and $1.7 \mathrm{mM}$. The experiments recorded for each sample are listed in table 2.5. All spectra were recorded at $25^{\circ} \mathrm{C}$ on Bruker spectrometers and processed using NMRpipe (Delaglio et al., 1995). Assignment was carried out using the CcpNMR Analysis software (Vranken et al., 2005; Stevens et al. 2011) and triple resonance backbone and side-chain assignment (Bax et al., 1990, Ikura et al., 1990; Frueh, 2014).

\subsubsection{Secondary structure determination}

Protein $\mathrm{C} \alpha$-chemical shifts are indicative of secondary structure and tend to shift upfield in $\beta$-strands and downfield in $\alpha$-helices when compared to random coil chemical shifts. For $\mathrm{C} \beta$-chemical shifts, the opposite trend can be observed (Metzler et al., 1993). By subtracting random coil chemical shifts $\left(\delta C_{\text {coil }}\right)$ from experimental values $\left(\delta C_{\text {exp }}\right)$, protein secondary structure can be predicted. $\mathrm{C} \alpha$ - and $\mathrm{C} \beta$ secondary shifts were merged by subtracting $\mathrm{C} \beta$ - from $\mathrm{C} \alpha$-secondary shifts. In this notation, negative values correspond to $\beta$-strand structure while positive values reflect $\alpha$-helical conformation. For calculating the $\mathrm{C} \alpha$-C $\beta$-secondary chemical shifts, random coil chemical shifts based on statistical analysis (Wang and Jardetzky, 2002) were used. 
Table 2.5: Liquid-state NMR experiments

\begin{tabular}{|c|c|c|}
\hline \multicolumn{3}{|c|}{ Gt CitA PASp } \\
\hline Spectrum & Field $[\mathrm{MHz}]$ & Recording time \\
\hline${ }^{15} \mathrm{~N}-\mathrm{HSQC}$ & 800 & $20 \mathrm{~m}$ \\
\hline${ }^{15} \mathrm{~N}-\mathrm{HSQC}-\mathrm{NOESY}$ & 800 & $3 \mathrm{~d}$ \\
\hline $\mathrm{HNCA}$ & 700 & $2 \mathrm{~d} 21 \mathrm{~h}$ \\
\hline CBCACONH & 600 & $2 \mathrm{~d} 18 \mathrm{~h}$ \\
\hline $\mathrm{HNCO}$ & 600 & $2 \mathrm{~d} 16 \mathrm{~h}$ \\
\hline HCCH-TOCSY & 700 & $2 \mathrm{~d} 16 \mathrm{~h}$ \\
\hline${ }^{13} \mathrm{C}-\mathrm{HSQC}-\mathrm{NOESY}$ & 700 & $4 \mathrm{~d} 21 \mathrm{~h}$ \\
\hline \multicolumn{3}{|c|}{ Gt CitA PASp R93A } \\
\hline Spectrum & Field [MHz] & Recording time \\
\hline${ }^{15} \mathrm{~N}-\mathrm{HSQC}$ & 800 & $20 \mathrm{~m}$ \\
\hline${ }^{15} \mathrm{~N}-\mathrm{HSQC}-\mathrm{NOESY}$ & 900 & $2 \mathrm{~d} 2 \mathrm{~h}$ \\
\hline $\mathrm{HNCA}$ & 700 & $1 \mathrm{~d} 19 \mathrm{~h}$ \\
\hline CBCACONH & 600 & $2 \mathrm{~d} 19 \mathrm{~h}$ \\
\hline $\mathrm{HNCO}$ & 600 & $23 \mathrm{~h}$ \\
\hline HCCH-TOCSY & 600 & $5 \mathrm{~d} 1 \mathrm{~h}$ \\
\hline${ }^{13} \mathrm{C}-\mathrm{HSQC}-\mathrm{NOESY}$ & 800 & $3 \mathrm{~d} 21 \mathrm{~h}$ \\
\hline \multicolumn{3}{|c|}{ Gt CitA PASp R93A + citrate } \\
\hline Spectrum & Field $[\mathrm{MHz}]$ & Recording time \\
\hline${ }^{15} \mathrm{~N}-\mathrm{HSQC}$ & 700 & $20 \mathrm{~m}$ \\
\hline${ }^{15} \mathrm{~N}-\mathrm{HSQC}-\mathrm{NOESY}$ & 900 & $2 \mathrm{~d} 2 \mathrm{~h}$ \\
\hline $\mathrm{HNCA}$ & 700 & $1 \mathrm{~d} 19 \mathrm{~h}$ \\
\hline CBCACONH & 900 & $2 \mathrm{~d} 17 \mathrm{~h}$ \\
\hline $\mathrm{HNCO}$ & 700 & $19 \mathrm{~h}$ \\
\hline HCCH-TOCSY & 700 & $2 \mathrm{~d} 16 \mathrm{~h}$ \\
\hline${ }^{13} \mathrm{C}-\mathrm{HSQC}-\mathrm{NOESY}$ & 700 & $3 \mathrm{~d} 17 \mathrm{~h}$ \\
\hline \multicolumn{3}{|c|}{ Gt CitA PASc } \\
\hline Spectrum & Field [MHz] & Recording time \\
\hline${ }^{15} \mathrm{~N}-\mathrm{HSQC}$ & 800 & $20 \mathrm{~m}$ \\
\hline${ }^{15} \mathrm{~N}-\mathrm{HSQC}-\mathrm{NOESY}$ & 800 & $3 \mathrm{~d} 6 \mathrm{~h}$ \\
\hline $\mathrm{HNCA}$ & 900 & $1 \mathrm{~d} 21 \mathrm{~h}$ \\
\hline CBCACONH & 900 & $2 \mathrm{~d} 15 \mathrm{~h}$ \\
\hline $\mathrm{HNCO}$ & 800 & $15 \mathrm{~h}$ \\
\hline HCCH-TOCSY & 600 & $2 \mathrm{~d} 20 \mathrm{~h}$ \\
\hline${ }^{13} \mathrm{C}-\mathrm{HSQC}-\mathrm{NOESY}$ & 800 & $6 \mathrm{~d} 15 \mathrm{~h}$ \\
\hline
\end{tabular}

\subsubsection{Ligand affinity determination}

The shift of ${ }^{15} \mathrm{~N}-\mathrm{HSQC}$ peaks in a ligand titration experiment can be utilised to determine dissociation constants (Ryan T et al., 1999; Auguin et al., 2004, Coudevylle et al., 2008). 
The dissociation constant $\mathrm{K}_{\mathrm{D}}$ is defined as

$$
K_{D}=\frac{[P][L]}{[P L]}
$$

where $[\mathrm{P}],[\mathrm{L}]$ and $[\mathrm{PL}]$ are the free protein, free ligand and protein-ligand complex concentrations.

The total protein and ligand concentrations $\left(\left[\mathrm{P}_{\text {tot }}\right]\right.$ and $\left[\mathrm{L}_{\text {tot }}\right]$, respectively) employed in the experiment can be expressed as the sum of the free and complex-bound concentrations. Substituting these expressions in equation 2.1 yields

$$
K_{D}=\frac{\left(\left[P_{t o t}\right]-[P L]\right)\left(\left[L_{t o t}\right]-[P L]\right)}{[P L]}
$$

After reorganisation, equation 2.2 can be solved for [PL].

$$
[P L]=\frac{\left[P_{t o t}\right]+\left[L_{t o t}\right]+K_{D} \pm \sqrt{\left(\left[P_{t o t}\right]+\left[L_{t o t}\right]+K_{D}\right)^{2}-4\left[P_{t o t}\right]\left[L_{t o t}\right]}}{2}
$$

For monomeric proteins with one binding site, a linear variation of the chemical shift $\Delta \delta p p m$ with the proportion of protein in the bound state as compared to the total protein concentration can be assumed.

$$
\Delta \delta p p m=\Delta \delta p p m_{M a x} \frac{[P L]}{\left[P_{t o t}\right]}
$$

$\Delta$ sppm $_{\text {Max }}$ represents the chemical shift difference between the ligand-free and ligandbound states at saturation. Substitution of equation 2.4 in equation 2.3 yields

$$
\Delta \delta p p m=\Delta \delta p m_{M a x} \frac{\left[P_{t o t}\right]+\left[L_{t o t}\right]+K_{D} \pm \sqrt{\left(\left[P_{t o t}\right]+\left[L_{t o t}\right]+K_{D}\right)^{2}-4\left[P_{t o t}\right]\left[L_{t o t}\right]}}{2\left[P_{t o t}\right]}
$$

Plotting the chemical shift difference $\Delta \delta p p m$ as a function of ligand concentration allows for determination of $\mathrm{K}_{\mathrm{D}}$ and $\Delta \delta p p m_{M a x}$ based on equation 2.5 .

Experiments were carried out at $20^{\circ} \mathrm{C}$ with a protein concentration of $1.4 \mathrm{mM}$. The solution was kept at pH 6.5 throughout the titration. Citrate was added in steps of $0.16 \mathrm{mM}$, $0.33 \mathrm{mM}, 0.66 \mathrm{mM}, 1.33 \mathrm{mM}, 2 \mathrm{mM}, 2.66 \mathrm{mM}$ and $3.33 \mathrm{mM}$ (final concentrations). 


\subsection{Solid-state NMR experiments}

\subsubsection{PDSD spectra}

Solid-state NMR spectroscopy at magic angle spinning (MAS) allows for acquisition of high-resolution spectra of samples where lack of fast isotropic motions makes liquid-state NMR impossible. CitApc samples embedded in liposomes were analysed by predicting solid-state peak positions in proton-driven spin diffusion (PDSD) spectra based on liquidstate assignments of the isolated PAS domains (see figure 1.5).

PDSD can be used to detect ${ }^{13} \mathrm{C}^{13} \mathrm{C}$ correlation spectra by exploiting the dense proton spin network. Magnetisation is transferred from proton to ${ }^{13} \mathrm{C}$ via cross-polarisation. Proton resonances are decoupled during t1 evolution and ${ }^{13} \mathrm{C}$ resonances consecutively stored on the $\mathrm{z}$-axis for spin diffusion during a mixing time $t_{\text {mix }}$. During $t_{\text {mix }}$, proton decoupling is switched off to allow for diffusion enhancement through the proton bath (Suter and Ernst, 1985; Dumez et al. 2011). After mixing, ${ }^{13} \mathrm{C}$ magnetisation is transferred back to the $x y$-plane for detection. Depending on $t_{\text {mix }}$, the information content of PDSD spectra can be varied. With short mixing times only short distance, intra-residual correlations can be detected, while longer mixing times allow for increased spin diffusion and the detection of inter-residual and long-range correlations. However, the signal/noise ratio at longer mixing time decreases and spectra get more crowded due to the additional inter-residual peaks. Because of the protein size, only short mixing-time (20 ms) PDSD spectra of CitApc constructs were acquired. The MAS speed was set to $11.4 \mathrm{kHz}$ at 850 $\mathrm{MHz}$ base frequency or $11 \mathrm{kHz}$ at $800 \mathrm{MHz}$ base frequency to remove spinning sidebands from the aliphatic region of the spectra (see figure 2.1. 


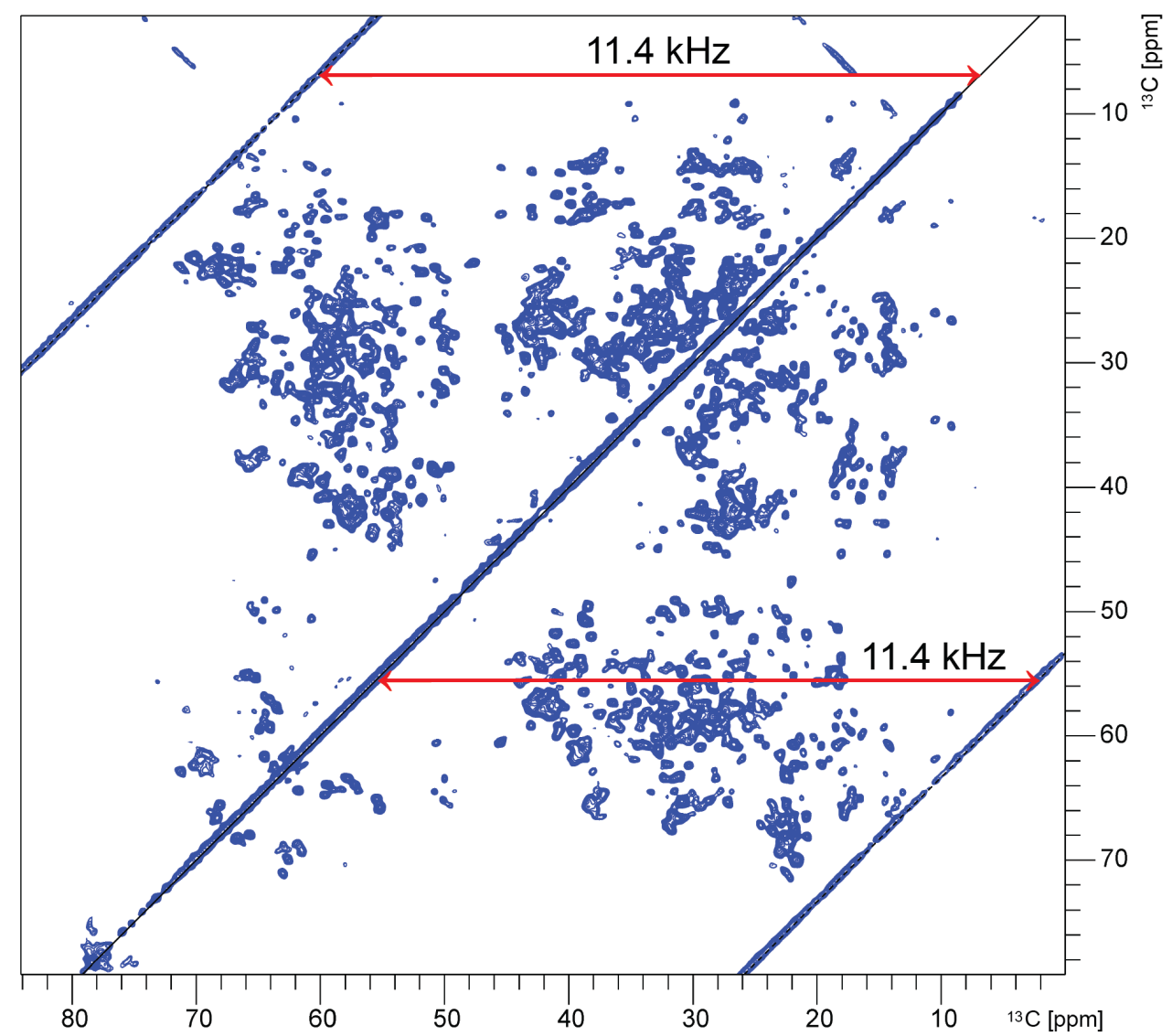

Figure 2.1: Aliphatic region in a $20 \mathrm{~ms}$ PDSD spectrum of wild-type CitApc. Most regions in a short mixing-time PDSD spectrum of CitApc experience peak overlap. Experiments with longer mixing times were therefore not recorded as overlap is expected to increase. At the MAS speed of $11.4 \mathrm{kHz}$ and a base frequency of $850 \mathrm{MHz}$ the spinning sidebands do not interfere with peaks in the aliphatic spectral region.

\subsubsection{Triple-resonance spectra}

For sequential assignment, spectra with intra-residual (residue i) and neighbouring-residue (i-1 or $\mathrm{i}+1)$ specific correlations are needed. In this work, CitApc sequential assignments were achieved by combining information from 3D NCACB, NCOCA and NCOCACBspectra. Ambiguities in the sequential assignment could be resolved with the additional information on $\mathrm{C} \alpha$-C $\alpha$-sequential contacts in a 2D CAncoCA spectrum (see figure 2.2).

The de novo sequential assignment in solid-state spectra depends on high-resolution 3D spectra with sufficient signal/noise. The signal/noise is generally relatively low for membrane proteins compared to crystalline material due to the diluting factor of the lipids. 


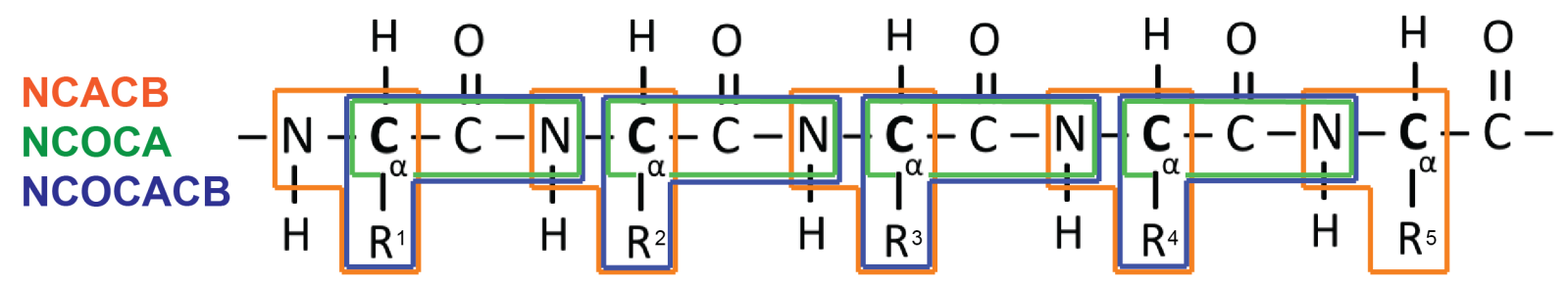

Figure 2.2: Sequential assignments based on solid-state spectra. Sequential assignments are made possible by combining intra-residual information from an NCACB experiment (orange) with inter-residue correlations to the preceding (i-1) residue from NCOCA (green) and NCOCACB (purple) spectra.

For CitApc, a protein/lipid molar ratio of $1 / 100$ is used, increasing the experimental time for high-quality spectra compared to crystalline protein samples. This is especially critical for experiments relying on homonuclear magnetisation transfer between $\mathrm{CO}$ and $\mathrm{C} \alpha$ (most used for correlating $\mathrm{N}$ of a given residue to $\mathrm{C} \alpha$ of the preceding residue) with a generally low transfer efficiency (Chevelkov et al., 2013b). Band-selective homonuclear cross-polarisation (BSH-CP) yields favourable $33 \%$ transfer efficiency at moderate MAS frequencies of $\sim 21 \mathrm{kHz}$ for protonated proteins (Chevelkov et al., 2013a; Shi et al., 2014), allowing for sequential assignment of CitApc constructs.

Most efficient recoupling using BSH-CP is obtained at effective radio-frequency (RF) fields $\omega_{r f}$ on CO and CA of twice the MAS frequency $\omega_{r}$,

$$
\sqrt{\Omega^{2}+\omega_{r f}^{2}}+\omega_{r f}=2 \omega_{r}
$$

where $\Omega$ is the CO chemical shift offset (with the carrier frequency on $\mathrm{C} \alpha$ ).

For CO-CA transfer in 3D NCOCA and NCOCACB and 2D CAncoCA experiments, CO-magnetisation is flipped to the effective field using a hard trim pulse before BSH-CP with the flip angle

$$
\theta=90^{\circ}-\arctan \left(\omega_{r f} / \Omega\right)
$$

All triple-resonance experiments were set up at $21 \mathrm{kHz}$ MAS. 


\subsubsection{INEPT spectra}

To detect mobile regions of CitApc, J-coupling based refocused ${ }^{1} \mathrm{H}^{13} \mathrm{C}-\mathrm{INEPT}$ spectra (Fyfe et al., 1995, Soubias et al., 2002) can be acquired. Since proton-proton dipolar couplings in solid samples are not averaged out, effective transverse dephasing times for rigid protein regions are very short. Therefore, only flexible protein regions where averaging of dipolar couplings is possible through rapid internal motions are detectable.

Solid-state NMR experiments were carried out on the spectrometers and at spinning speeds detailed below.

Table 2.6: Solid-state NMR experiments

\begin{tabular}{|c|c|c|c|c|c|}
\hline \multicolumn{6}{|c|}{ Gt CitApc wild-type (asolectin) } \\
\hline Spectrum & $\begin{array}{c}\text { Field } \\
{[\mathrm{MHz}]}\end{array}$ & $\begin{array}{l}\text { Rotor } \oslash \\
{[\mathrm{mm}]}\end{array}$ & $\begin{array}{c}\text { Spinning } \\
\text { speed }[\mathrm{kHz}]\end{array}$ & $\begin{array}{c}\text { Recording } \\
\text { time }\end{array}$ & $\begin{array}{c}\text { Temperature } \\
{\left[{ }^{\circ} \mathrm{C}\right]}\end{array}$ \\
\hline PDSD $20 \mathrm{~ms}$ & 850 & 4.0 & 11.4 & $3 \mathrm{~d} 8 \mathrm{~h}$ & 7 \\
\hline NCOCA 2D & 850 & 3.2 & 21 & $1 \mathrm{~d} 10 \mathrm{~h}$ & 6 \\
\hline NCOCA 3D & 850 & 3.2 & 21 & $2 \mathrm{~d} 23 \mathrm{~h}$ & 6 \\
\hline NCACB 3D & 850 & 3.2 & 21 & $6 \mathrm{~d} 23 \mathrm{~h}$ & 6 \\
\hline NCACO 2D & 850 & 3.2 & 21 & $1 \mathrm{~d} 10 \mathrm{~h}$ & 6 \\
\hline NCACO 3D & 850 & 3.2 & 21 & $5 \mathrm{~d} 13 \mathrm{~h}$ & 6 \\
\hline CANCO 3D & 850 & 3.2 & 21 & $5 \mathrm{~d} 7 \mathrm{~h}$ & 5 \\
\hline NCOCACB 2D & 850 & 3.2 & 21 & $4 \mathrm{~d} 19 \mathrm{~h}$ & 6 \\
\hline NCOCACB 3D & 850 & 3.2 & 21 & $8 \mathrm{~d} 7 \mathrm{~h}$ & 6 \\
\hline \multicolumn{6}{|c|}{ Gt CitApc R93A (DMPC, citrate-free) } \\
\hline Spectrum & $\begin{array}{c}\text { Field } \\
{[\mathrm{MHz}]}\end{array}$ & $\begin{array}{l}\text { Rotor } \oslash \\
{[\mathrm{mm}]}\end{array}$ & $\begin{array}{c}\text { Spinning } \\
\text { speed }[\mathrm{kHz}]\end{array}$ & $\begin{array}{c}\text { Recording } \\
\text { time }\end{array}$ & $\begin{array}{c}\text { Temperature } \\
{\left[{ }^{\circ} \mathrm{C}\right]}\end{array}$ \\
\hline PDSD $20 \mathrm{~ms}$ & 850 & 4.0 & 11.4 & $6 \mathrm{~d} 13 \mathrm{~h}$ & 7 \\
\hline HC-INEPT 2D & 850 & 4.0 & 8.333 & $20 \mathrm{~h}$ & 7 \\
\hline NCACB 2D & 850 & 3.2 & 21 & $20 \mathrm{~h}$ & 9 \\
\hline NCACB 3D & 850 & 3.2 & 21 & $5 \mathrm{~d} 21 \mathrm{~h}$ & 9 \\
\hline NCOCA 2D & 850 & 3.2 & 21 & $19 \mathrm{~h}$ & 9 \\
\hline NCOCA 3D & 850 & 3.2 & 21 & $7 \mathrm{~d} 22 \mathrm{~h}$ & 9 \\
\hline NCOCACB 3D & 850 & 3.2 & 21 & $10 \mathrm{~d}$ & 9 \\
\hline \multicolumn{6}{|c|}{ Gt CitApc R93A (DMPC, citrate-bound) } \\
\hline Spectrum & $\begin{array}{c}\text { Field } \\
{[\mathrm{MHz}]}\end{array}$ & $\begin{array}{l}\text { Rotor } \oslash \\
{[\mathrm{mm}]}\end{array}$ & $\begin{array}{c}\text { Spinning } \\
\text { speed }[\mathrm{kHz}]\end{array}$ & $\begin{array}{c}\text { Recording } \\
\text { time }\end{array}$ & $\begin{array}{c}\text { Temperature } \\
{\left[{ }^{\circ} \mathrm{C}\right]}\end{array}$ \\
\hline PDSD $20 \mathrm{~ms}$ & 800 & 4.0 & 11 & $7 \mathrm{~d} 6 \mathrm{~h}$ & 9 \\
\hline HC-INEPT 2D & 850 & 4.0 & 8.333 & $20 \mathrm{~h}$ & 6 \\
\hline NCACB 2D & 850 & 3.2 & 21 & $21 \mathrm{~h}$ & 7 \\
\hline NCACB 3D & 850 & 3.2 & 21 & $5 \mathrm{~d} 19 \mathrm{~h}$ & 7 \\
\hline NCOCACB 3D & 850 & 3.2 & 21 & $7 \mathrm{~d} 20 \mathrm{~h}$ & 7 \\
\hline CAncoCA 2D & 850 & 3.2 & 21 & $6 \mathrm{~d} 21 \mathrm{~h}$ & 7 \\
\hline
\end{tabular}




\section{Results}

\subsection{The periplasmic PAS domain (PASp)}

Samples of Geobacillus thermodenitrificans PASp $_{33-161}$ were purified as described in 2.6. From SEC elution profiles it is evident that PASp is monomeric in solution (see figure 3.1). Crystallisation attempts with G. thermodenitrificans PASp were unsuccessful, but based on crystal structures of homologous Klebsiella pneumoniae CitA PASp (PDB ID: 2V9A and 2J8O; identity: $40 \%$, homology: $59 \%$ ), both ligand-free and ligand-bound domain structures could be predicted using the I-TASSER protein fold prediction server (Zhang, 2008).

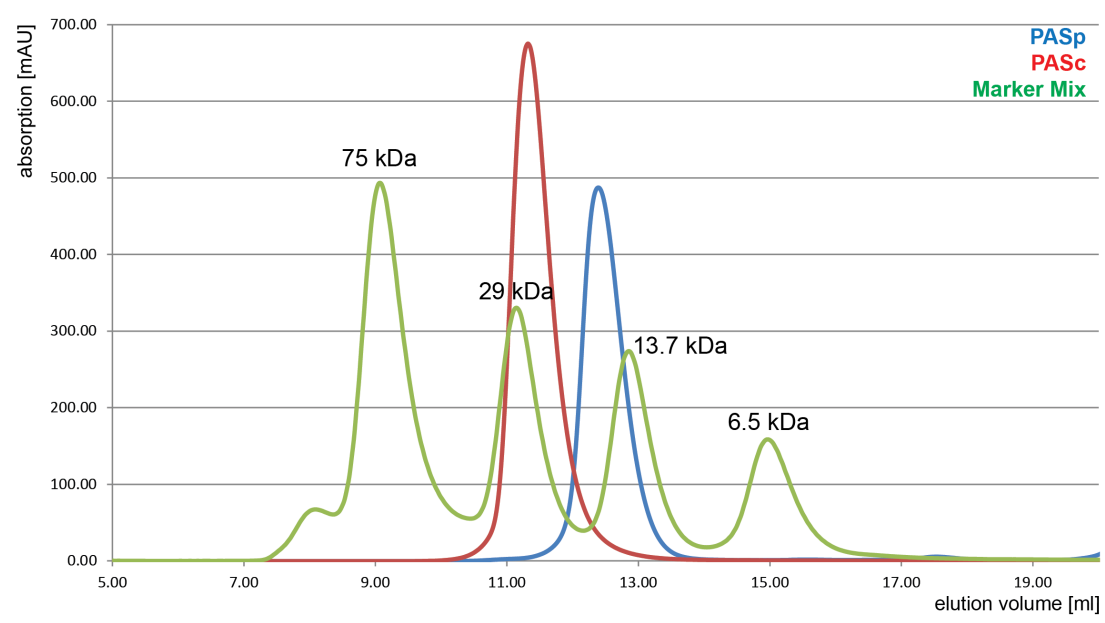

Figure 3.1: Size exclusion chromatography profiles of PAS constructs. The apparent molecular weight of PASp (blue) and PASc (red) can be calculated based on the elution profiles of proteins of known size (green). The apparent molecular weight of PASc corresponds to a dimeric state in solution. Peaks for isolated domains would be expected at 13.0 and $13.3 \mathrm{ml}$ for PASp and PASc, respectively. 


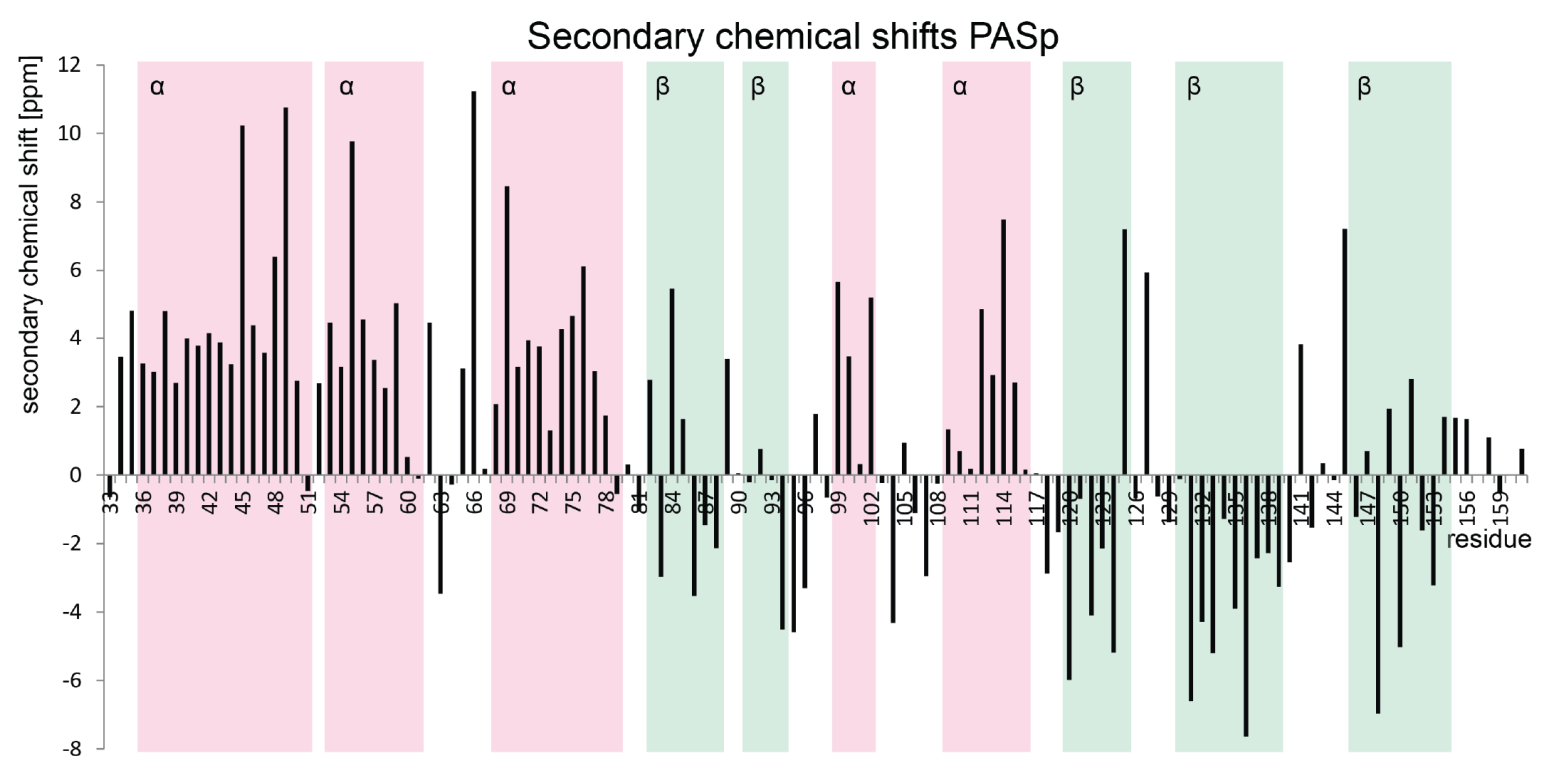

Figure 3.2: $\mathbf{C} \alpha-\mathrm{C} \beta$-secondary shift analysis of PASp in solution. The secondary chemical shifts reflect secondary structure propensity, with positive values indicating $\alpha$ helix, negative values corresponding to $\beta$-strands. The secondary structure elements of the PASp model are superimposed (red: $\alpha$-helix, green: $\beta$-strand). PASp was assigned in the citrate-bound state as citrate-free PASp is not experimentally accessible.

Uniformly ${ }^{13} \mathrm{C}-{ }^{15} \mathrm{~N}-$ labelled $\quad$ G. thermodenitrificans PASp was assigned based on liquidstate NMR experiments (see table 2.5). In total, $96 \%$ of proton, $90 \%$ of carbon and $74 \%$ of nitrogen resonances were assigned. The backbone assignment reached $98 \%$ completeness, the remainder being proline amides. The I-TASSER model of PASp could be validated by comparing secondary structure elements in the model to $\mathrm{C} \alpha$ - $\mathrm{C} \beta$-secondary chemical shifts in solution (see figure 3.2).

To quantify citrate binding capacity, an NMR titration experiment was carried out based on ${ }^{15} \mathrm{~N}-\mathrm{HSQC}$ experiments (Ryan T et al. 1999; Auguin et al., 2004; Coudevylle et al., 2008). Surprisingly, even a 10-fold excess of citrate did not show any effect on the HSQC spectra. Likewise, no binding was observed in an isothermal titration calorimetry experiment (Pierce et al. 1999). However, citrate binding of full-length G. thermodenitrificans CitA was shown in vivo (see figure 3.3 by the group of Prof. Gottfried Unden (Gutenberg-Universität Mainz, GER). 


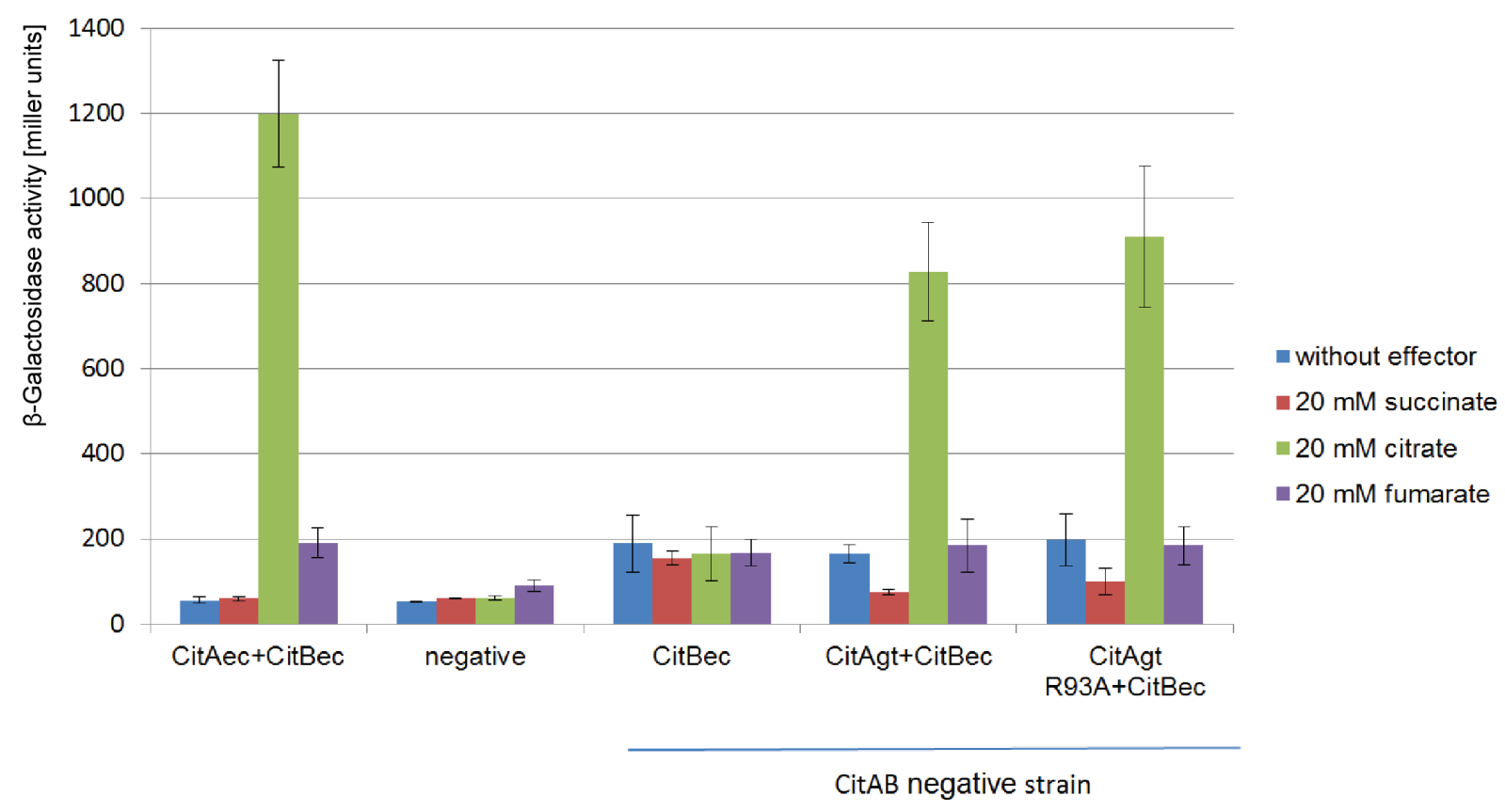

Figure 3.3: Activity and substrate specificity of Geobacillus thermodenitrificans CitA. G. thermodenitrificans CitA was verified as a citrate receptor in vivo. RR CitB-dependent reporter gene activity ( $\beta$-Galactosidase) was monitored as a function of different small molecule ligands in Escherichia coli cells. The native E. coli $\mathrm{CitA} / \mathrm{CitB}$ system displays selective activation upon citrate addition, while a CitA/CitB negative E. coli strain did not show any activity (left). The CitA/CitB negative E. coli strain complemented with RR CitB in absence of the cognate HK was inactive even in presence of ligands (centre). Complementation of the negative strain with either $G$. thermodenitrificans CitA (wild-type) or G. thermodenitrificans CitA R93A restored TCS activity and citrate specificity (right). The figure was kindly provided by Prof. Unden (GutenbergUniversität Mainz, GER).

This led to the assumption that isolated PASp might bind citrate with very high affinity, so that the citrate-free state is not observable. This hypothesis is underpinned by high ligand affinity of the homologous PASp-domain in K. pneumoniae CitA (Kaspar et al. 1999) and the presence of citrate in the crystal structure of Escherichia coli CitA PASp, although no citrate was added during purification and crystallisation. Based on the I-TASSER structural model, an R93A mutantion was introduced in the citrate binding pocket. The selected arginine 93 is part of the conserved residues constituting the binding pocket of citrate-binding PAS domains (Gerharz et al. 2003) (see figure 3.4. From crystal structures of K. pneumoniae and E. coli CitA PASp it is evident that the conserved arginine sidechain forms two hydrogen bridges to citrate. An alanine mutation 


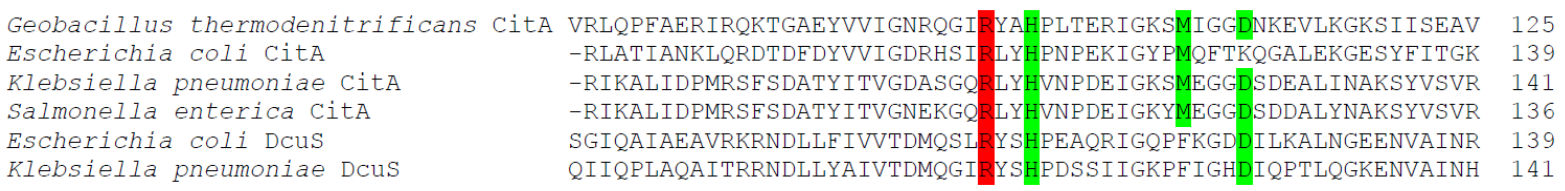

Figure 3.4: Alignment of CitA-family HK PASp domains. BLAST Alignment of selected CitA-family PASp domains reveals a conserved arginine (red) which can be identified as part of the ligand binding pocket in PASp crystal structures. Other conserved residues in the binding pocket are highlighted green. A conserved methionine (M106 in Geobacillus thermodenitrificans CitA) is only present in CitA HKs and lacking in DcuS systems.

is therefore assumed to weaken the PASp-citrate hydrogen bond network and reduce the binding affinity. In the course of this project, the effect of the conserved arginine mutation was evaluated for E. coli CitA, where the $\mathrm{K}_{\mathrm{D}}$ of wild-type PASp could be determined. Mutation of the conserved arginine, in this case R107, to alanine increased the dissociation constant from $240 \mathrm{nM}$ to $150 \mathrm{\mu M}$.

Like for wild-type PASp, ${ }^{13} \mathrm{C}^{15} \mathrm{~N}$-labelled samples were produced for liquid-state NMR studies. PASp R93A is monomeric in solution as seen in the SEC elution profile. The protein was again assigned based on 3D-experiments (see table 2.5). In total, $72 \%$ of proton, $80 \%$ of carbon and $70 \%$ of nitrogen resonances were assigned. $91 \%$ of backbone resonances could be identified.

As with wild-type PASp, PASp R93A was titrated with sodium citrate (see figure 3.5. In contrast to wild-type protein, PASp R93A spectra exhibit strong binding-induced chemical shift changes. The appearance of intermediate peaks between citrate-free and saturated citrate-bound peak positions during the NMR titration is indicative of fast exchange of citrate and PASp. Based on the NMR titration, the overall $\mathrm{K}_{\mathrm{D}}$ value was determined to be $624 \pm 21 \mu \mathrm{M}$. The dissociation constant of $G$. thermodenitrificans CitA PASp R93A is therefore in the same range as the $\mathrm{K}_{\mathrm{D}}$ of E. coli CitA PASp R107A, the corresponding mutant in this system. Like wild-type CitA, the receptor functionality of CitA R93A was verified in vivo by the group of Prof. Unden (see figure 3.3). The NMR assignment protocol was repeated for citrate-bound PASp R93A with a protein/citrate ratio of 1:6. In total, $75 \%$ of proton, $83 \%$ of carbon and $70 \%$ of nitrogen resonances were assigned, the backbone assignment was completed to $95 \%$. 


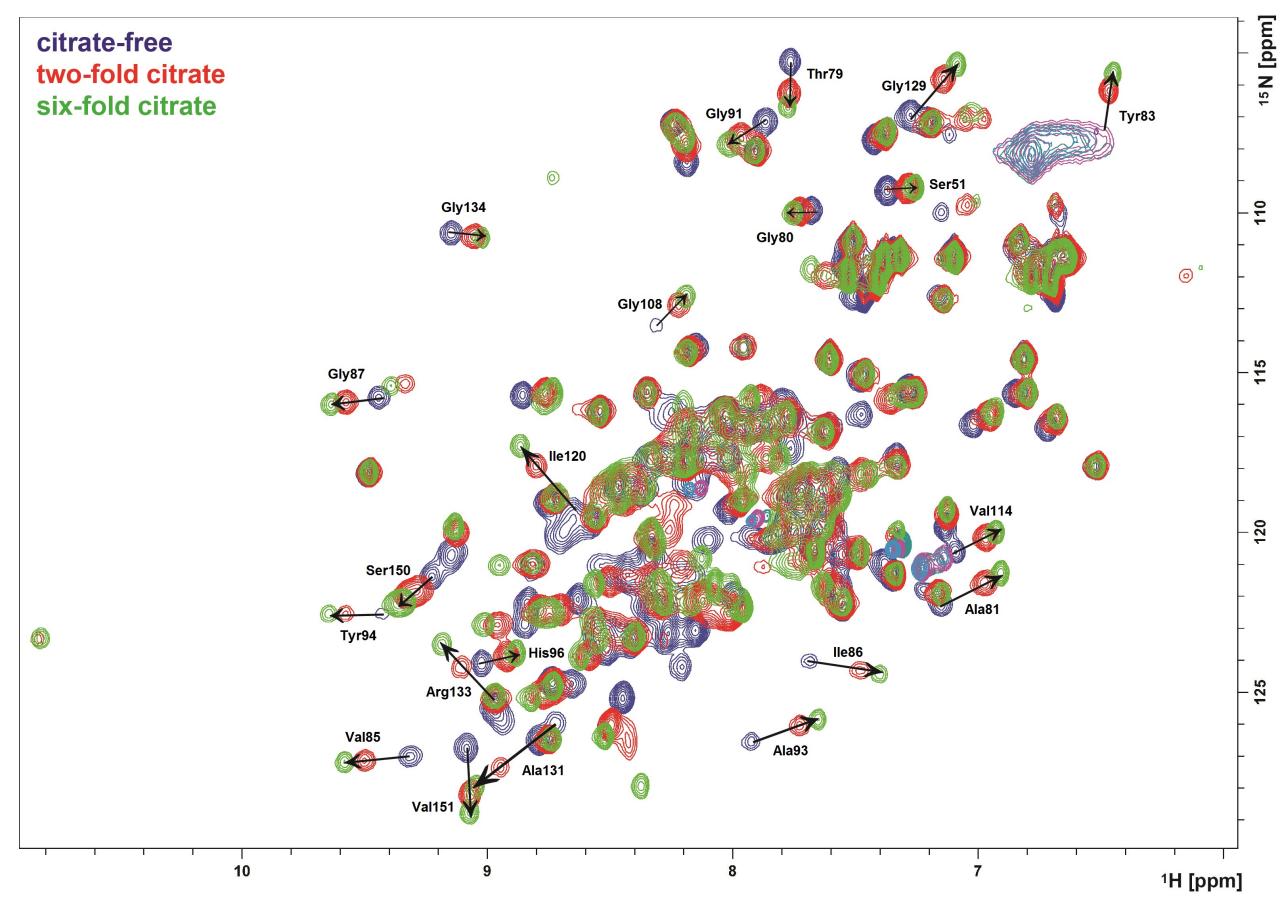

Figure 3.5: ${ }^{15} \mathrm{~N}-\mathrm{HSQC}$ titration of PASp R93A with citrate. Three representative ${ }^{15} \mathrm{~N}-\mathrm{HSQC}$ spectra of a titration of CitA PASp R93A with citrate. With increasing citrate concentration, several peaks shift significantly (some highlighted with arrows). Saturation is reached at six-fold excess of citrate, the calculated $\mathrm{K}_{\mathrm{D}}$ was $624 \mu \mathrm{M}$.

With the assignment of PASp R93A in both citrate-free and citrate-bound state, it is possible to compare the secondary structure features of the different constructs. In order to do so, secondary chemical shifts were calculated for PASp wild-type, citrate-free PASp R93A and citrate-bound PASp R93A. The difference in chemical shifts can then be determined for all pairings of PASp constructs (see figure 3.6. The chemical shift differences between citrate-free and citrate-bound PASp R93A are consistent with the shift changes between wild-type PASp and citrate-free PASp R93A, indicating that wild-type PASp is in a citrate-bound state. Comparison of citrate-bound PASp R93A and wild-type PASp displays less chemical shift alterations which suggests similar conformations of the two states. Although crystallisation attempts were carried out for PASp R93A (both citrate-free and citrate-bound), no diffracting crystals could be produced. 


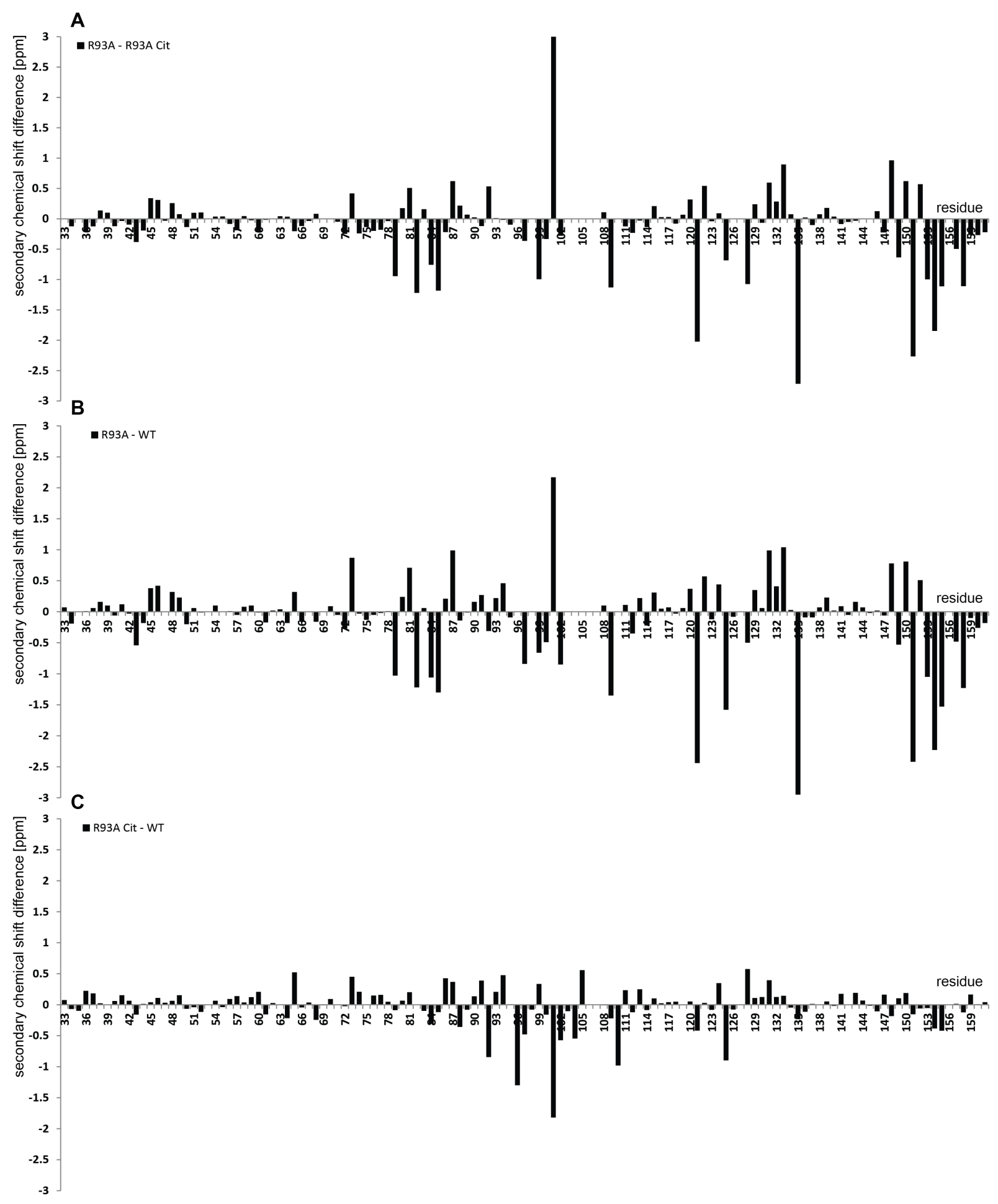

Figure 3.6: $\mathbf{C} \alpha-\mathrm{C} \beta$-secondary chemical shift differences between PASp constructs. A: Secondary chemical shift difference between citrate-free and citrate-bound CitA PASp R93A. B: Difference between citrate-free PASp R93A and wild-type PASp. C: Comparison of wild-type PASp and PASp R93A (citrate-bound). 


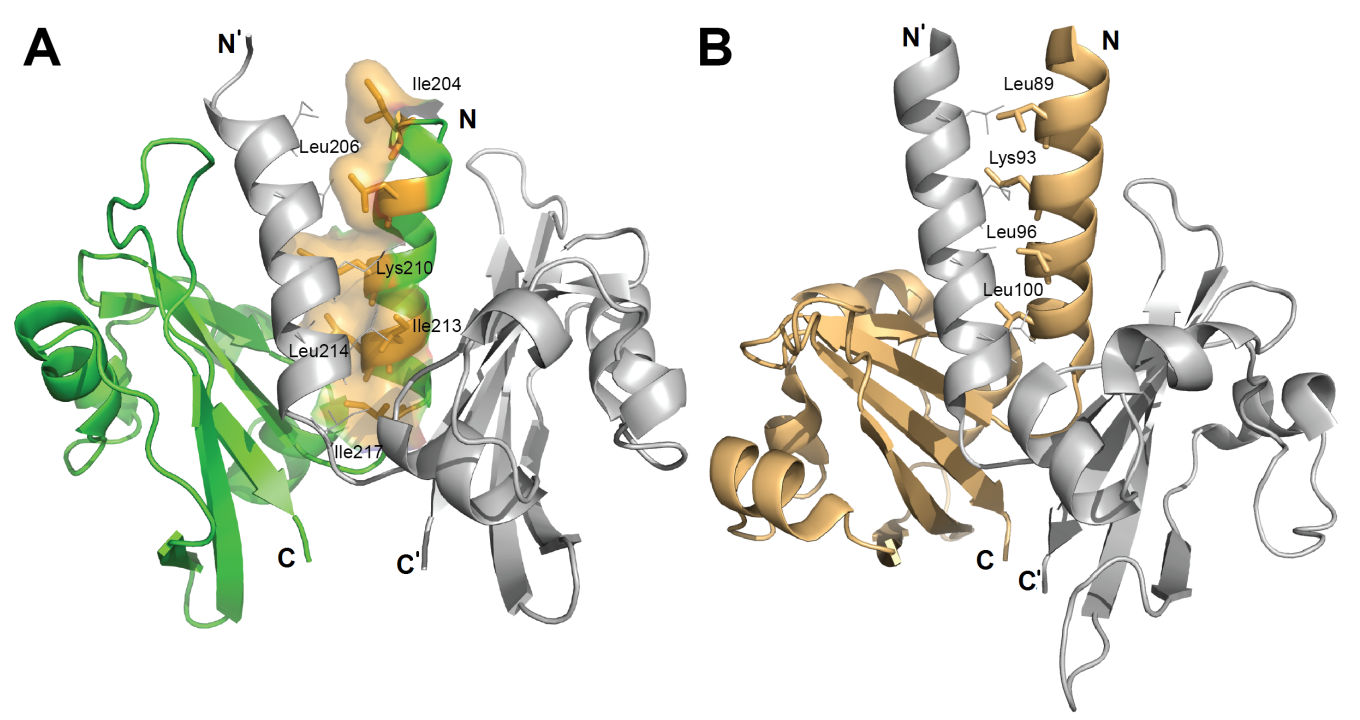

Figure 3.7: Crystal structure of CitA PASc. A: Crystal structure of PASc. Monomers are coloured green and grey. The hydrophobic zipper contacts in the Nterminal helix are shown as sticks for one monomer and as lines in the second monomer. The hydrophobic surface between the $N$-terminal helices is shown in light orange. B: The PAS-domain preceding the kinase core of the VicK crystal structure (PDB accession code:4I5S). Like for CitA PASc, hydrophobic contacts between the $N$-terminal helices are shown as sticks and lines.

\subsection{The cytosolic PAS domain (PASc)}

G. thermodenitrificans CitA PASc was purified in the same way as PASp. In contrast to PASp, PASc is a dimer in solution based on the gel filtration elution profile (see figure 3.1). Crystallisation of PASc yielded crystals which diffracted up to $1.78 \AA$. To solve the phase problem, PASc was also produced using selenomethionine labelling. The crystal structure was solved by Dr. Stefan Becker (Department of NMR-based Structural Biology, Max-Planck-Institute for Biophysical Chemistry, Göttingen, GER) using multiwavelength anomalous dispersion (see tables 8.1 and 8.2) and reveals a canonical PAS-fold with five $\beta$-strands sandwiched between an $N$-terminal $\alpha$-helix and four shorter helices (see figure 3.7A). The dimer found in the asymmetric unit reflects the dimeric state seen in solution and reveals an exchange of N-terminal helices between monomers. The interaction between $N$-terminal helices from different monomers is supported by a hydrophobic zipper motif similar to the PAS domain of VicK, the first HK with a PAS domain adjacent to the kinase core (Wang et al. 2013 . 


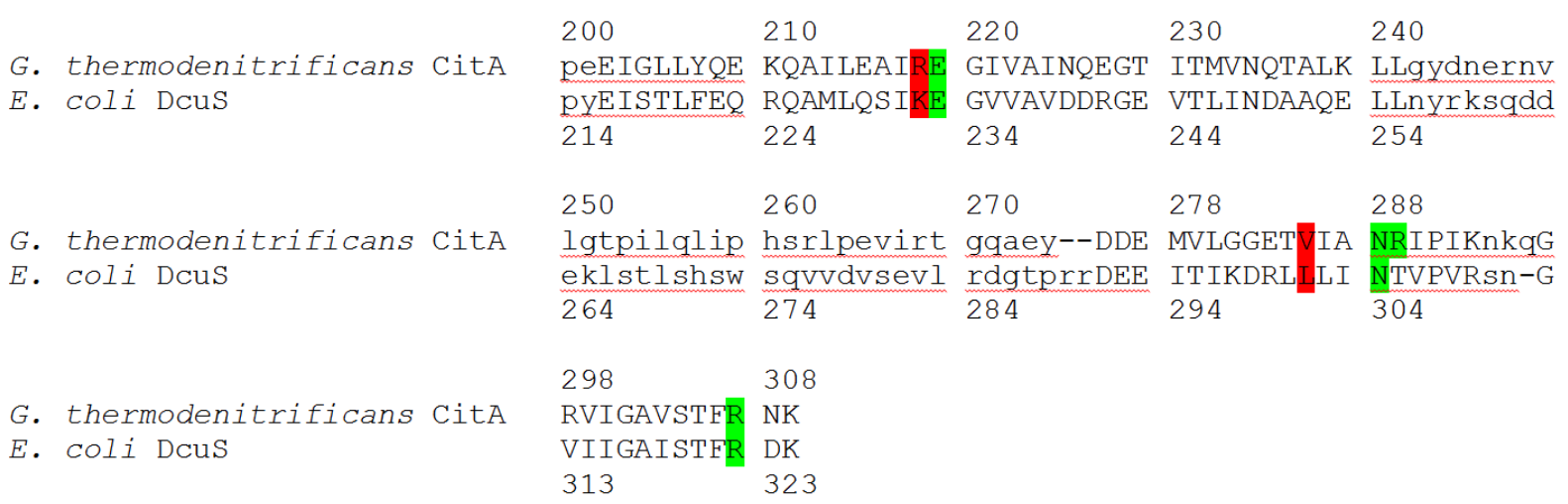

Figure 3.8: Alignment of Geobacillus thermodenitrificans CitA PASc and Escherichia coli DcuS PASc. Functional mutants in PASc of E. coli DcuS were transferred to $G$. thermodenitrificans CitA based on a sequence alignment. Transferred ONmutants in DcuS are highlighted green, OFF-mutants are shown in red. For DcuS N304D, R289 neighbouring the aligned N288 in CitA was selected as a second potential candidate for mutation. Capital letters indicate high sequence homology.

In DcuS, another HK of the CitA family, PASc mutants were tested for effects on the activity and dimerisation state of full-length DcuS (Monzel et al., 2013). The PASc mutants associated with alterations in DcuS signalling can be divided into ON-mutants leaving the HK in a constitutive kinase-competent state and OFF-mutants which trap the DcuS kinase in the inactive state. The ON-mutants trigger signalling even without dicarboxylate ligands while OFF-mutant DcuS variants cannot be activated by adding dicarboxylates. While OFF-mutants conserve the dimeric HK state and binding capability to DctA, a DcuS co-receptor, ON-mutants can be subdivided further. The ON I-subtype destroys the HK dimer, which most likely does not correspond to biologically relevant states. ON II-subtype mutants on the other hand retain the dimeric state; ON IIbmutants also still bind DctA while this interaction is lacking in ON IIa-mutants.

Based on the mutation analysis carried out in vivo on the PASc domain of homologous E. coli DcuS (Monzel et al. 2013), mutants of G. thermodenitrificans CitA PASc were generated. Conserved residues in G. thermodenitrificans CitA PASc that were mutated in DcuS PASc were identified based on a sequence alignment of E. coli DcuS PASc and G. thermodenitrificans CitA PASc (see figure 3.8) generated with Dialign (Morgenstern, 2004). While selection of OFF-mutants was not restrained, ON-mutants were chosen from the ON IIb-subtype. In contrast to ON I- and ON IIa-mutants, DcuS dimer formation 


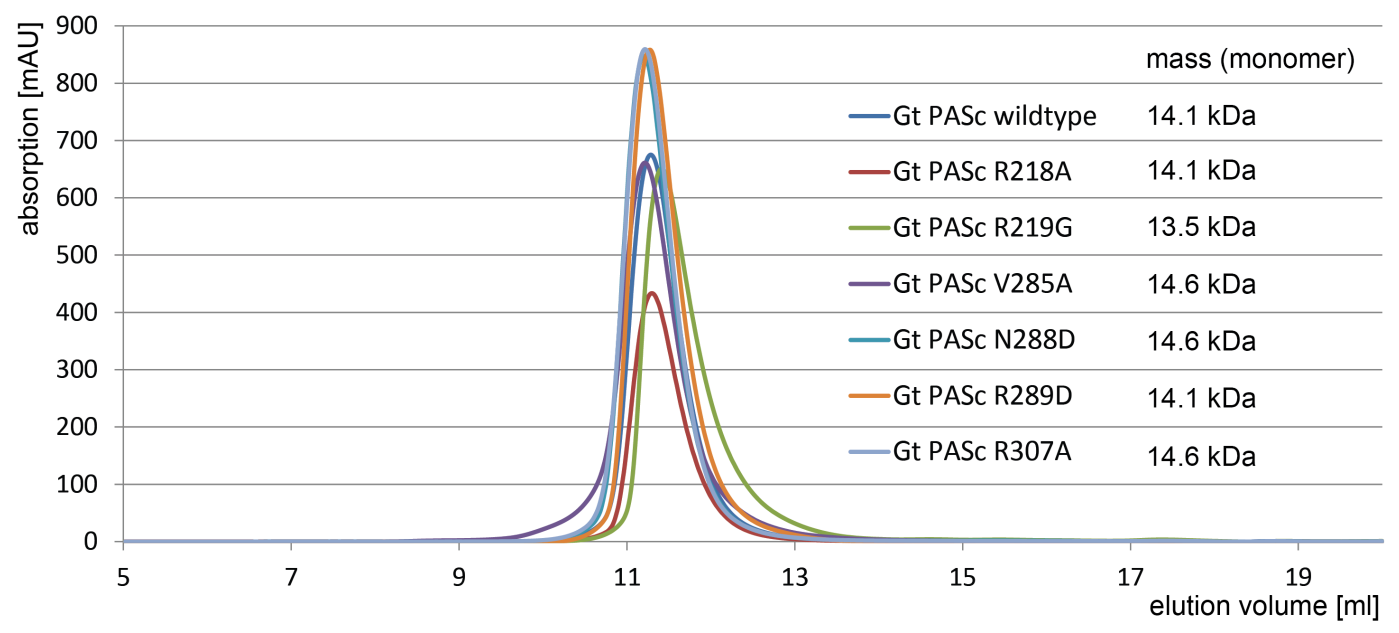

Figure 3.9: SEC profiles of CitA PASc mutants. Like for wild-type PASp and PASc, the molecular weight can be calculated from a calibration and is depicted for PASc mutant monomers, assuming dimers in solution. The SEC profile of wild-type PASc is shown as a reference.

and DctA interaction is intact in ON IIb-mutants, which therefore most likely correspond to the ligand induced wild-type conformation of DcuS.

In the case of N288 in G. thermodenitrificans CitA PASc the neighbouring R289, being a polar residue as well, was chosen as a second possible mutant to rule out errors in the sequence alignment. Like wild-type PASc, all selected point mutants are dimeric in solution based on SEC profiles (see figure 3.9p. The dimer is stable in solution; SEC was run at concentrations of $1.5 \mathrm{mM}, 150 \mu \mathrm{M}$ and $15 \mu \mathrm{M}$ for PASc N288D. In all cases, the elution profiles corresponded to dimeric protein. As SEC is limited by UV detection sensitivity, a concentration where monomeric protein could be observed was not reached. For all G. thermodenitrificans CitA point mutants, crystallisation trials were carried out (see table 3.1).

Table 3.1: Crystallisation of PASc mutants

\begin{tabular}{|l|l|}
\hline PASc mutant & Crystallisation condition \\
\hline R218A (SeMet) & $0.4 \mathrm{M} \mathrm{MgCl}_{2}, 23.5 \%$ PEG 3350, 0.1 M Tris pH 8.5 \\
E219G & no crystals \\
V285A (native) & $0.8 \mathrm{M} \mathrm{Na}_{2} \mathrm{HPO}_{4}, 0.8 \mathrm{M} \mathrm{KH} \mathrm{PO}_{4}, 0.1 \mathrm{M}$ HEPES pH 7.5 \\
N288D (SeMet) & $0.4 \mathrm{M} \mathrm{MCl}_{2}, 19 \% \mathrm{PEG} 8000,0.1 \mathrm{M}$ Tris pH 8.5 \\
R289D (SeMet) & $0.2 \mathrm{M} \mathrm{Li}_{2} \mathrm{SO}_{4}, 27 \%$ PEG $1000,0.1 \mathrm{M}$ phosphate-citrate pH 4.2 \\
R307A (native) & $2.2 \mathrm{M} \mathrm{NaCl}_{2} \% \mathrm{PEG} \mathrm{6000}$ \\
\hline
\end{tabular}



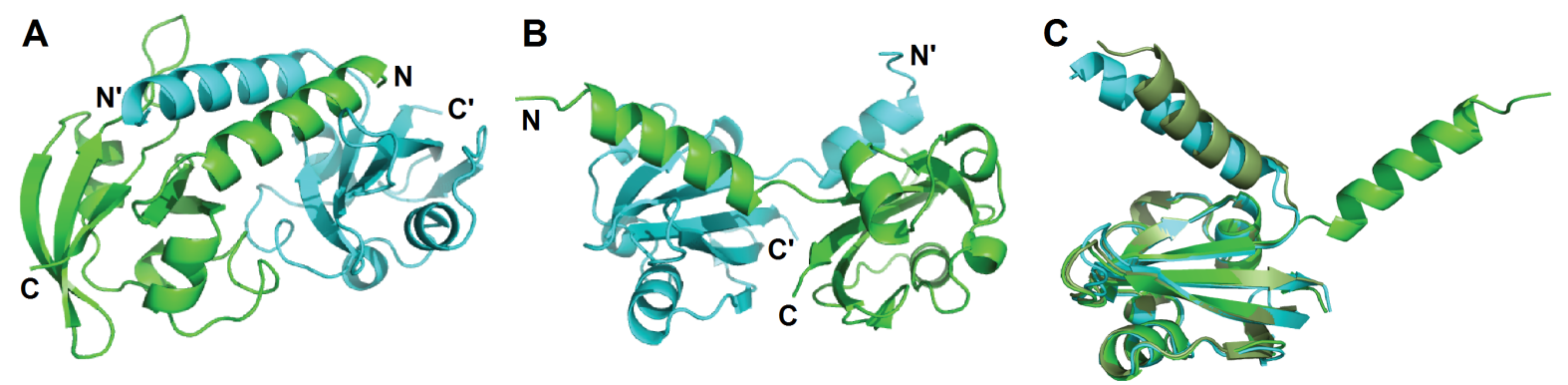

Figure 3.10: Crystal structures of proposed functional mutants of CitA PASc. A: The structure of PASc N288D reveals an anti-parallel dimer (monomers coloured green and cyan). PASc R218A yields an identical fold. B: PASc R289D crystallises as an open dimer in which the $N$-terminal helix interaction between the monomers is missing. $\mathrm{C}$ : Alignment of the PAS-core of one monomer for wild-type PASc (olive), PASc N288D (cyan) and PASc R289D (green). While the overall fold is retained, the position of the $N$-terminal helix varies significantly.

Crystal structures could be solved for the proposed OFF-mutants CitA PASc R218A and V285A as well as for the proposed ON-mutants N288D, R289D and R307A (for details on structural data contact Dr. Stefan Becker, Department of NMR-based Structural Biology, Max-Planck-Institute for Biophysical Chemistry, Göttingen, GER). The PAS-fold excluding the $N$-terminal helix was conserved in all mutants with a maximum backbone rmsd of $0.42 \AA$ compared to wild-type PASc, but the position of the $N$-terminal helix varied substantially in mutants R218A, N288D and R289D (see figure 3.10 C). PASc V285A and R307A crystal structures are identical to the wild-type structure. The reorientation of the $N$-terminal helix in PASc R218A, N288D and R289D is related to different orientations of PASc monomers with respect to each other. In PASc R218A and N288D, the $N$-terminal helices form an anti-parallel dimer not connected to the PAS core. In PASc R289D the helices of the two monomers do not interact with each other, but are contacting the central $\beta$-sheet scaffold in trans, thus creating an open dimer in which the central $\beta$-scaffolds of the two monomers are anti-parallel (see figure $3.10 \mathrm{~A}, \mathrm{~B}$ ). In contrast to DcuS, in vivo HK activity measurements on CitA PASc mutants carried out by the group of Prof. Unden did not show any effect over wild-type $G$. thermodenitrificans CitA for any of the PASc mutants. 


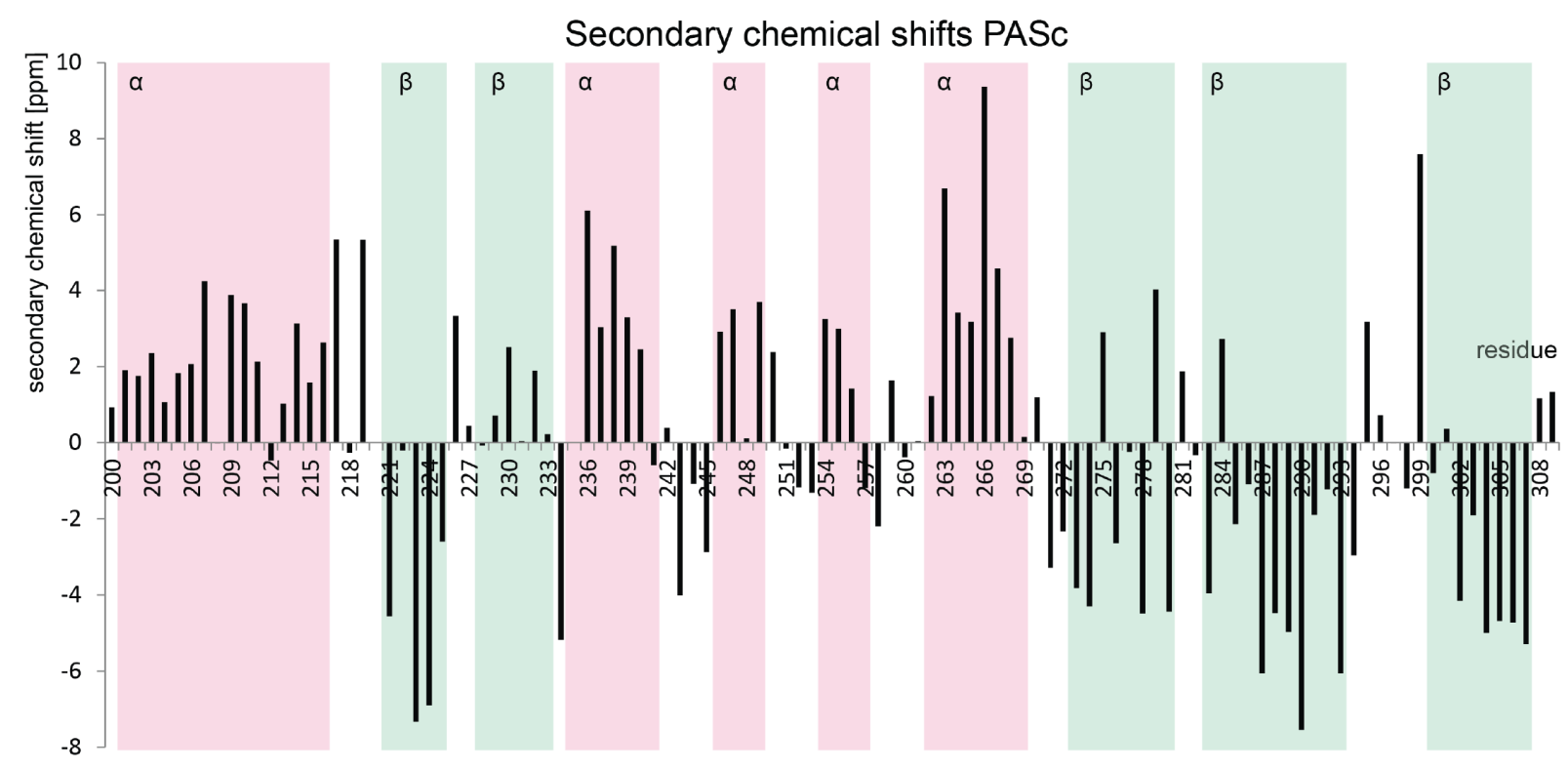

Figure 3.11: $\mathbf{C} \alpha-\mathbf{C} \beta$-secondary shift analysis of PASc in solution. The secondary chemical shifts reflect secondary structure propensity, with positive values indicating $\alpha$ helix, negative values corresponding to $\beta$-strands. The secondary structure elements of the PASc crystal structure are superimposed (red: $\alpha$-helix, green: $\beta$-strand).

Wild-type G. thermodenitrificans CitA PASc was assigned using liquid-state NMR experiments (see table 2.5). In total, $92 \%$ of proton, $85 \%$ of carbon and $69 \%$ of nitrogen resonances were assigned. The backbone assignment reached $86 \%$ completeness. The missing assignments are mainly clustered in the $N$-terminal helix due to very weak or non-existent peaks in ${ }^{15} \mathrm{~N}-\mathrm{HSQC}$-based experiments (see figure 3.12). Assignment of these residues was therefore mainly based on ${ }^{13} \mathrm{C}-\mathrm{HSQC}-\mathrm{NOESY}$ contacts and HCCH-TOCSY correlations. The $\mathrm{C} \alpha$-C $\beta$-secondary chemical shifts of assigned residues correspond well to secondary structure elements found in the crystal structure of PASc (see figure 3.11). Some residues in the second and third $\beta$-strand, expected to be negative, are found to display positive secondary shift values.

The PASc structure reveals twists in the two $\beta$-strands for which secondary shift values do not match secondary structure elements. Analysis of the backbone dihedral angles in the crystal structure demonstrates a deviation from ideal angles for anti-parallel $\beta$-strands $\left(\psi=-140^{\circ} ; \phi=135^{\circ}\right)$. The positive secondary chemical shift values therefore correspond with strained $\beta$-strands in the crystal structure. 


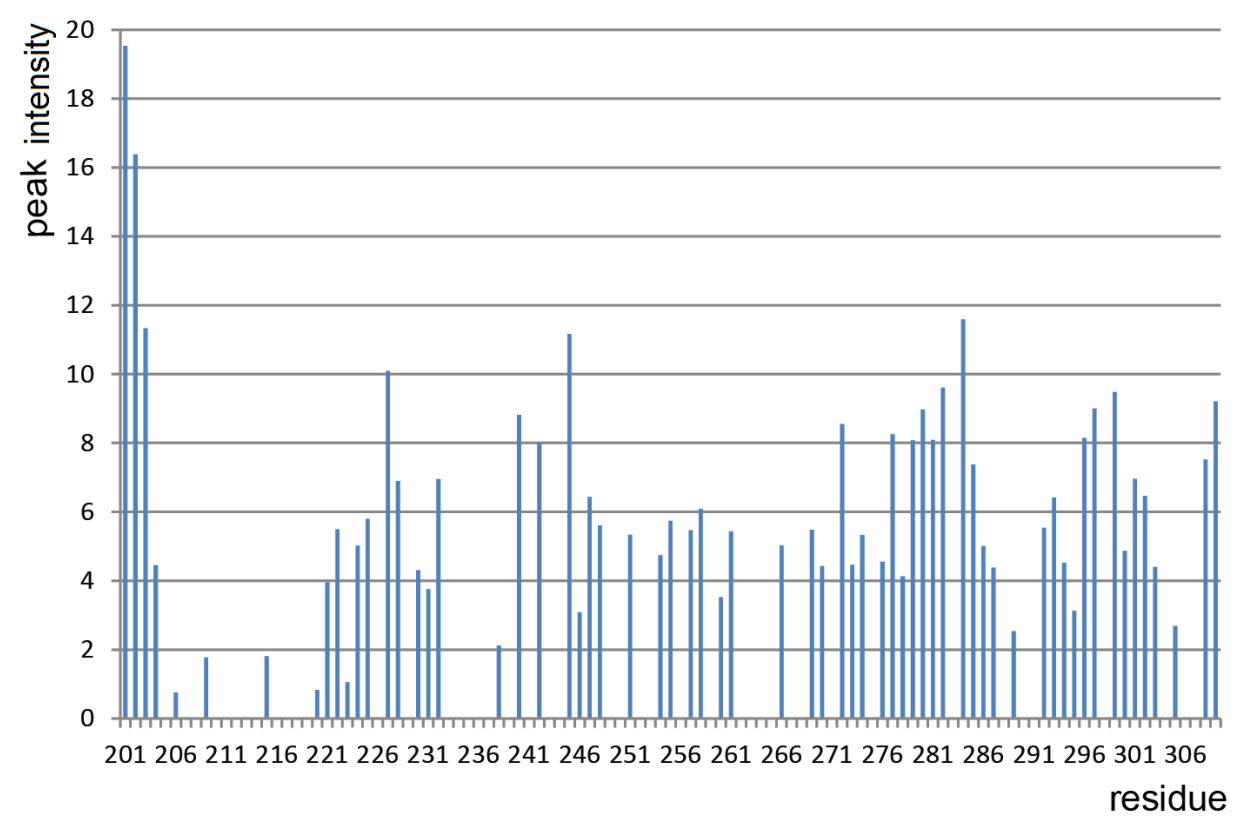

Figure 3.12: Peak intensity of PASc in a ${ }^{15} \mathrm{~N}-\mathrm{HSQC}$. Visualisation of the intensity of well separated peaks in a ${ }^{15} \mathrm{~N}-\mathrm{HSQC}$ experiment demonstrates the generally low intensity at the $N$-terminus of the domain. As assignment based on amide-correlation based spectra in this region was impossible, most resonances in the $N$-terminal helix were assigned based on ${ }^{13} \mathrm{C}-\mathrm{HSQC}-\mathrm{NOESY}$ and HCCH-TOCSY experiments.

To confirm that citrate is only binding to PASp and not to PASc, a control ${ }^{15} \mathrm{~N}-\mathrm{HSQC}$ of isolated PASc was set up with a twofold excess of citrate. As the spectrum is unchanged compared to citrate-free PASc (see figure 3.13) and no citrate was found in the crystal structure, effects on PASc in the citrate-bound form must be transmitted through binding of citrate to PASp alone. Additionally, the residues in the citrate-binding pocket of PASp are highly conserved (see figure 3.4 and not to be found in the sequence and structure of PASc (Gerharz et al. 2003). 


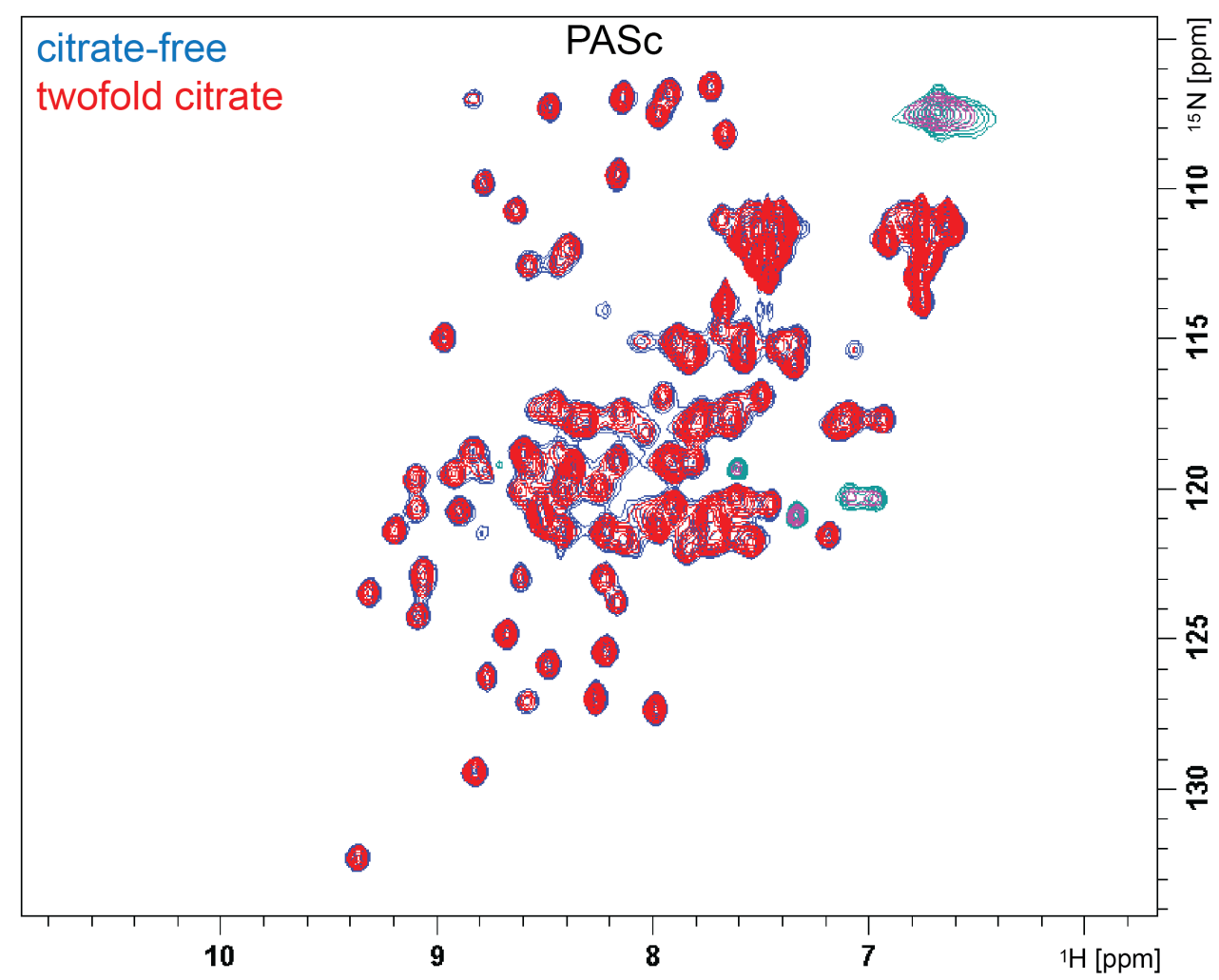

Figure 3.13: ${ }^{15} \mathrm{~N}-\mathrm{HSQC}$ of PASc with excess citrate. To exclude citrate binding capacities of CitA PASc, a spectrum of isolated PASc with twofold excess of citrate (red) was compared with the spectrum of a citrate-free sample (blue). Spectra are shown at slightly different contour levels for visibility. No citrate binding effect is observed.

\subsection{Liposome-embedded CitApc}

The liquid-state NMR characterisation of large membrane proteins is challenging due to the huge particle size and the corresponding anisotropy and low tumbling times (Cross and Opella, 1994). Additionally, membrane proteins have to be embedded in micelles, bicelles or lipid nanodiscs for liquid-state NMR studies. These membrane mimetic systems can influence protein structure and functionality in unexpected ways (Zhou and Cross, 2013). To overcome the liquid-state NMR limitations, G. thermodenitrificans CitApc was therefore studied by solid-state NMR spectroscopy of liposome-embedded protein. For forming the multi-lamellar liposomes, asolectin was chosen because of the low phase transition temperature which allowed recording of solid-state spectra at $\sim 10{ }^{\circ} \mathrm{C}$ in the liquid crystalline phase. At higher temperatures, heteronuclear magnetisation transfer is 
less efficient. By reducing the temperature from $25^{\circ} \mathrm{C}$ to $9{ }^{\circ} \mathrm{C}$, NCA signal intensity was increased by $70 \%$ (see figure 3.14 ).

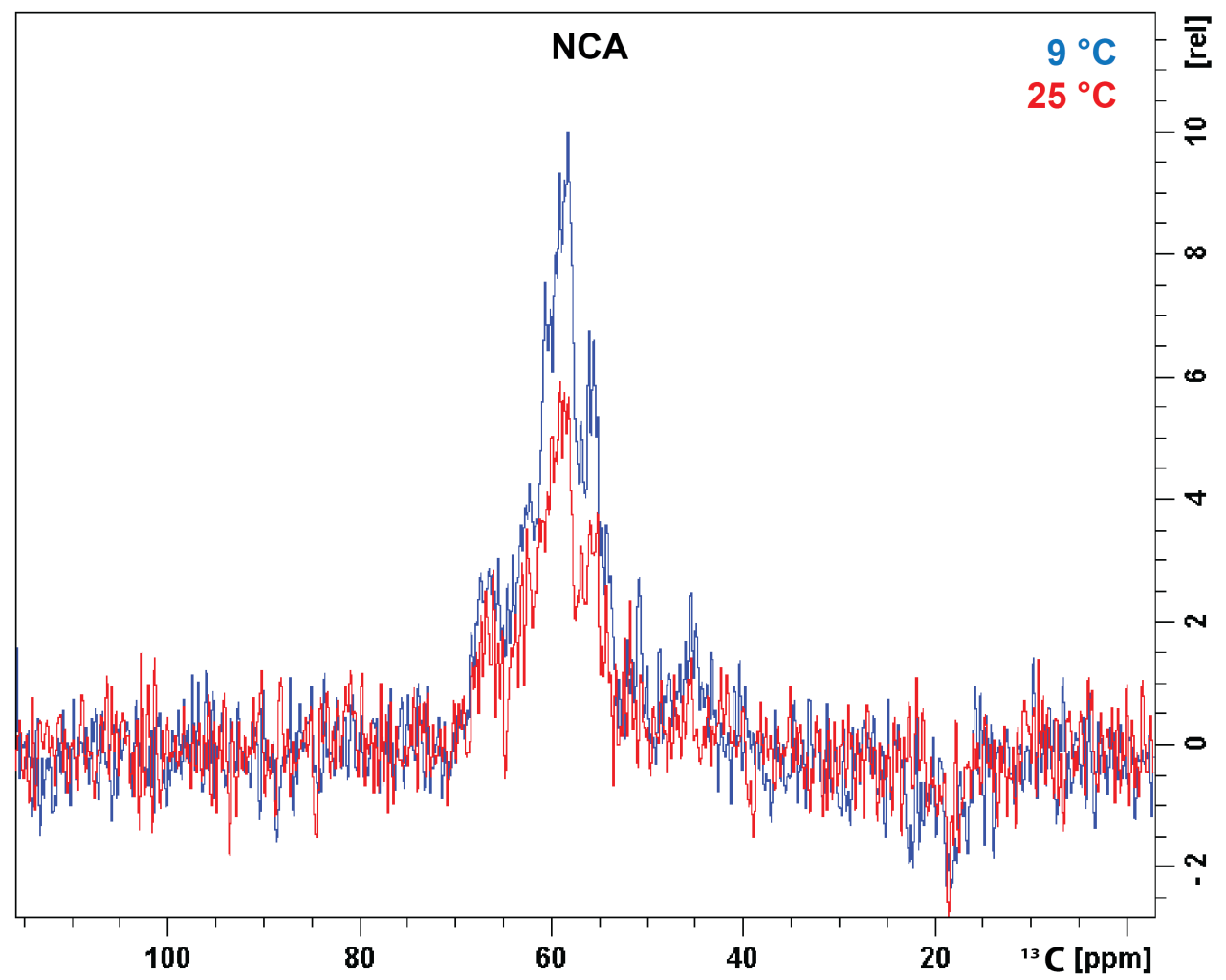

Figure 3.14: Heteronuclear cross-polarisation efficiency in CitApc at different temperatures. Upon reducing the temperature from $25{ }^{\circ} \mathrm{C}$ (red) to $9{ }^{\circ} \mathrm{C}$ (blue), peak intensity can be increased by $70 \%$ in an NCA-experiment.

Solid-state spectra were assigned using the liquid-state assignments and the approach outlined in chapter 1.7. For the globular domains, $94 \%$ of PASp and $40 \%$ of PASc residues could be assigned in $20 \mathrm{~ms}$ PDSD, NCACB, NCOCA, and NCOCACB spectra (see figure $3.15 \mathrm{~A}$ ). In most cases, the overlap between liquid-state resonance assignments and solid-state peak positions was better than $\pm 0.2 \mathrm{ppm}$ with the only major differences in the region of the PASp dimer interface (see figures 3.15 B and 3.16). Residues at the PASp dimer interface were assigned based on sequential assignment. As PASp is monomeric in solution, these differences can be expected for dimeric CitApc. 


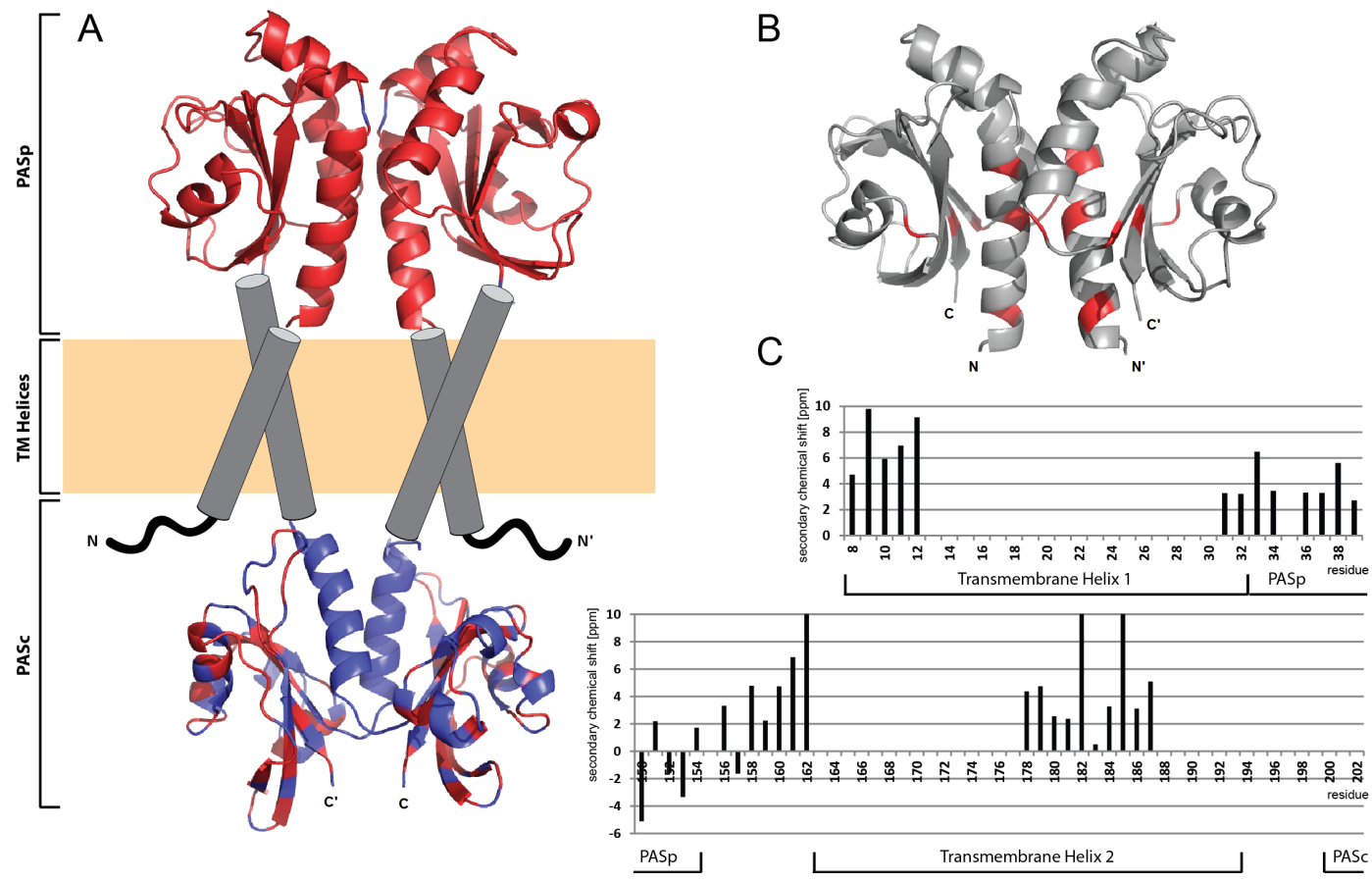

Figure 3.15: Solid-state assignments of wild-type CitApc. A: Assignments found for PASp and PASc using solid-state experiments. Assigned residues are highlighted in red, unassigned residues are shown in blue. Transmembrane helices are shown as grey cylinders due to the lack of structural information. B: Differences between liquid-state assignments of PASp and the solid-state assignments. $\mathrm{C} \alpha-\mathrm{C} \beta$-secondary chemical shift differences of more than $0.5 \mathrm{ppm}$ are highlighted red. $\mathrm{C}: \mathrm{C} \alpha$-C $\beta$-secondary chemical shift values of assigned residues in the transmembrane helices.

Based on the existing assignments of the globular domains and spectra for sequential assignment (3D NCACB, NCOCA, NCOCACB and 2D CA(NCO)CA), a partial de novoassignment of the transmembrane helices was possible. In total, 9 new residue assignments in the first and 17 assignments in the second transmembrane helix were obtained (see figure 3.15 C) and correspond to helical conformation based on secondary chemical shifts.

To access the citrate-free state, an R93A mutant was introduced in the periplasmic PAS domain. A 20 ms PDSD spectrum of citrate-free CitApc R93A in asolectin revealed peak doubling around the citrate binding pocket, with one set of peaks corresponding to the citrate-free and the other set corresponding to the citrate-bound state in solution (see figure $3.17 \mathrm{~A}$ ). In 3D spectra, only peaks matching the citrate-bound assignments were visible. Liquid-state spectra of asolectin solubilised in $10 \%$ sodium dodecyl sulfate revealed citrate impurities in the lipid mixture (see figure 3.17 B). CitApc R93A was 


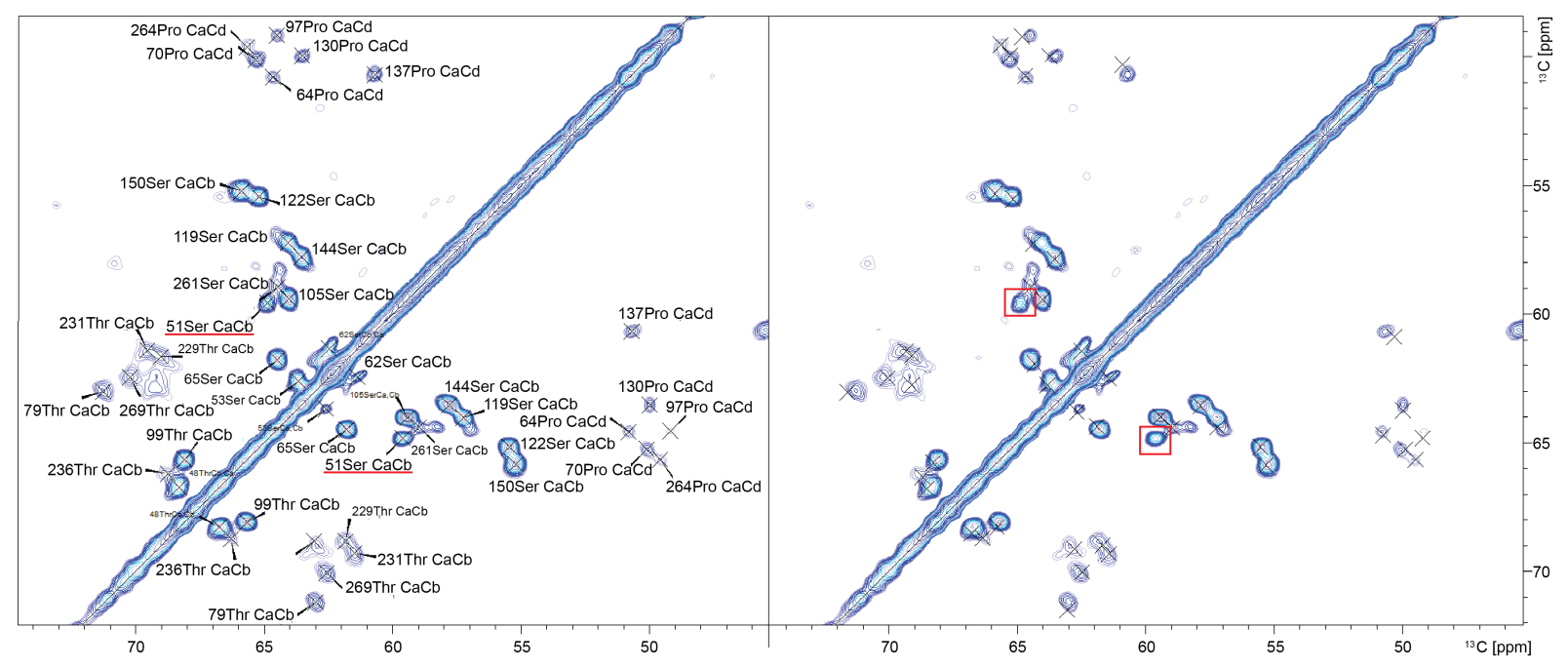

Figure 3.16: Assignment consistency between liquid- and solid-state NMR. Left: assigned peaks in the $\mathrm{Ser} / \mathrm{Thr} \mathrm{C} \alpha-\mathrm{C} \beta$ region of a PDSD spectrum. With exception of Ser51, all peaks presented here were assigned based on liquid-state data. Ser51, situated at the PASp dimer interface, was identified based on sequential assignment (red). Right: predicted peak positions for assigned peaks based solely on liquid-state NMR data. With few exceptions, the overlap between liquid- and solid-state peak positions is better than $0.2 \mathrm{ppm}$.

therefore not accessible in a pure citrate-free state in asolectin. The peak doubling detected in solid-state spectra suggests slow exchange between citrate and PASp on an NMR timescale, as opposed to the fast exchange observed in the isolated domain. The peak doubling was confirmed in a PDSD spectrum of CitApc R93A at $20^{\circ} \mathrm{C}$, the temperature of isolated PASp R93A titration.

To reach a citrate-free state of the receptor, new samples of

G. thermodenitrificans CitApc R93A in the pure phospholipid 1,2-dimyristoyl-sn-glycero-3-phosphocholine (DMPC) were produced. The assignment routine used for wild-type CitApc was repeated, yielding $81 \%$ of PASp and $59 \%$ of PASc residues that could directly be assigned based on liquid-state data. Additionally, a sample of CitApc R93A with excess citrate embedded in DMPC liposomes was produced to study the citrate-bound form of the R93A mutant receptor. Here, $86 \%$ of PASp and $45 \%$ of PASc could be assigned. The assignment of the PAS domains in the different CitApc constructs allows for a comparison between the different signalling states.

First, differences in secondary chemical shifts observed in liquid-state spectra of the 

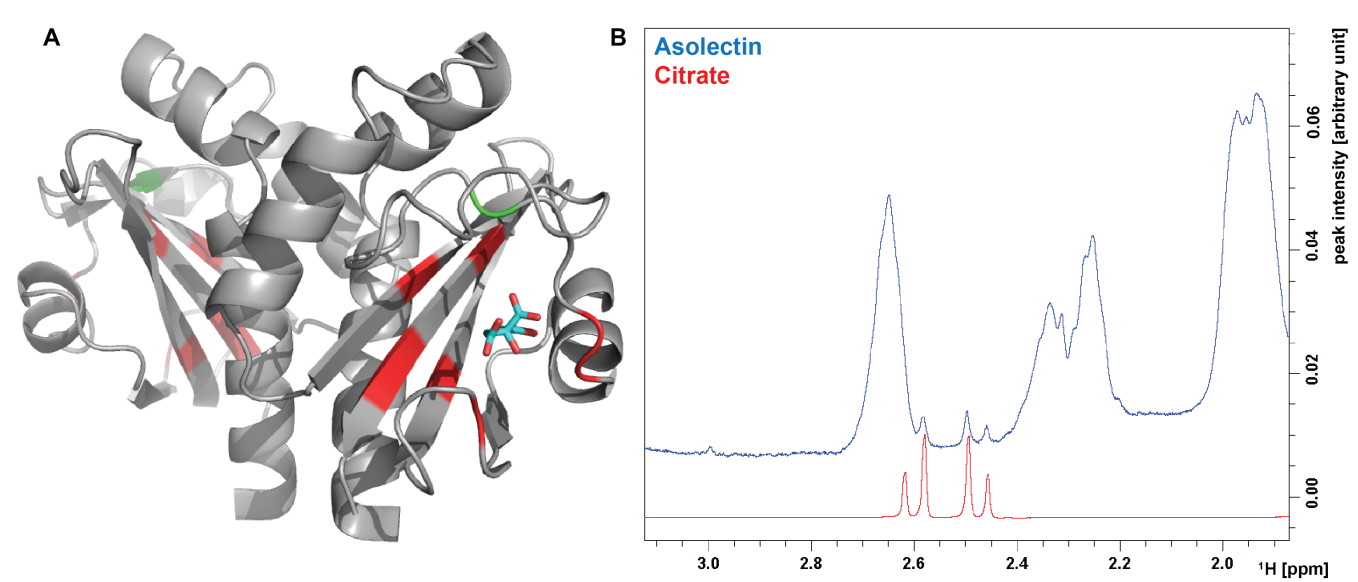

Figure 3.17: Effects of citrate impurities on PASp. A: Residues that can be assigned for both citrate-free and citrate-bound state in PDSD of CitApc R93A (citrate-free) are highlighted in red. The mutation site is shown in green. B: Citrate $\mathrm{CH}_{2}$-quartet visible in an asolectin proton spectrum (blue) solubilised in $10 \%$ sodium dodecyl sulfate (SDS). A spectrum of pure citrate in $10 \%$ SDS is shown in red.

isolated PASp between citrate-free and citrate-bound form can be confirmed for CitApc (see figure 3.19). Second, differences in the visibility of certain residues in PASc, mainly in the central $\beta$-scaffold, between citrate-free and citrate-bound CitApc R93A become apparent. In total, 62 residues of PASc in the citrate-free and 45 residues in the citratebound state could be assigned based on liquid-state chemical shifts; ambiguities in 2D PDSD spectra could be resolved in 3D NCACB and NCOCACB spectra for 2 residues in the citrate-free state and 5 residues in the citrate-bound state. As few PASc residues could be detected in 3D spectra due to low signal/noise (see figure 3.18), assignment of PASc relies predominantly on PDSD spectra.

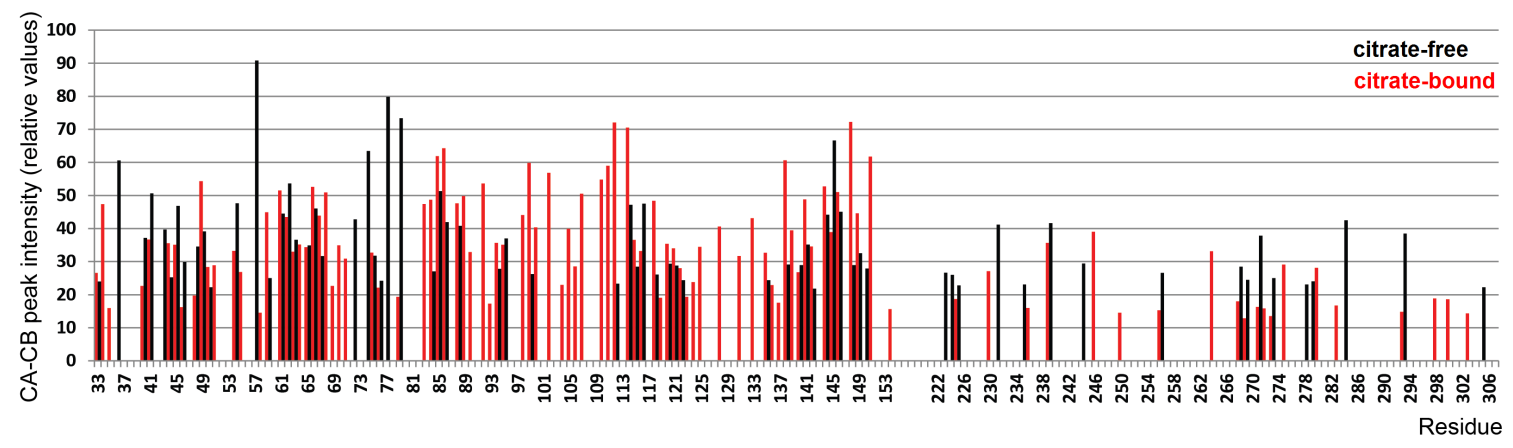

Figure 3.18: Peak intensity of PASp and PASc in solid-state spectra. The peak intensity of isolated $\mathrm{C} \alpha$-C $\beta$-peaks in 3D solid-state spectra reveals a generally reduced peak height in PASc for both citrate-free (black) and citrate-bound (red) CitApc. 


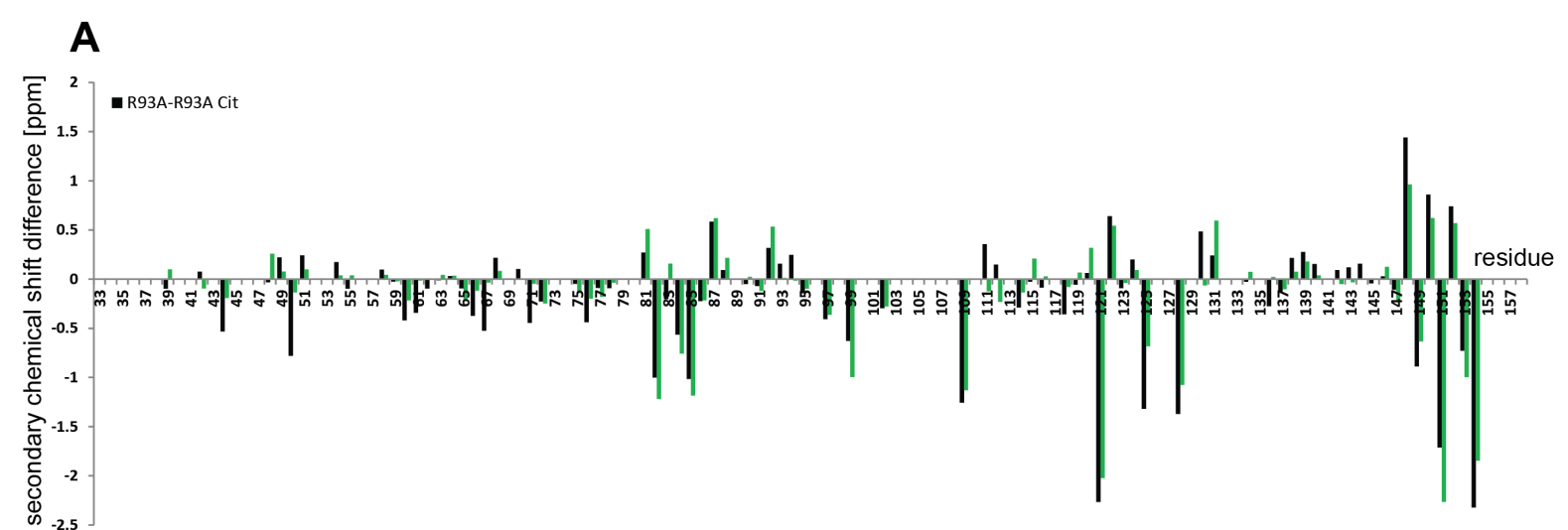

B
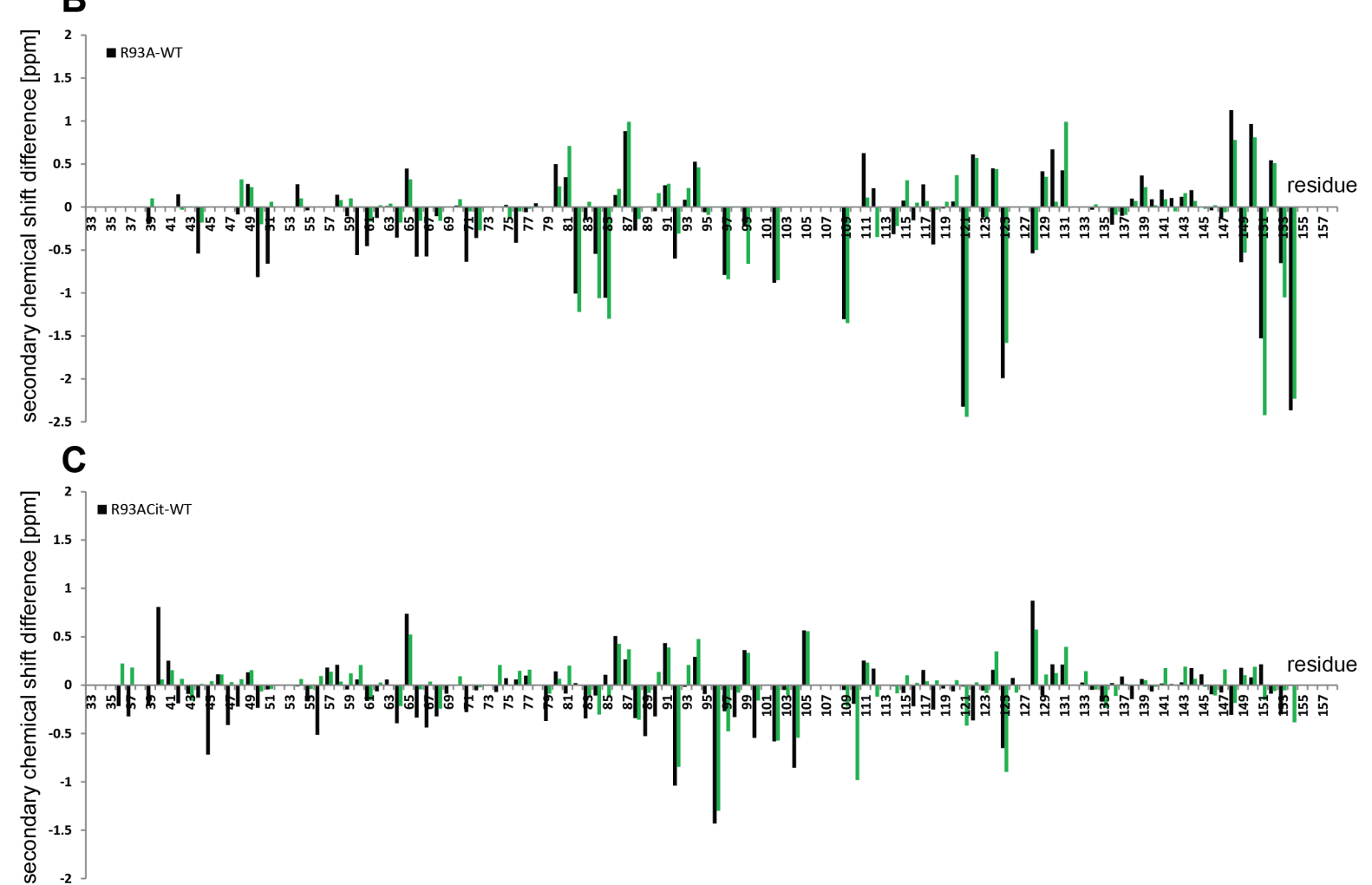

Figure 3.19: $\mathbf{C} \alpha-\mathrm{C} \beta$-secondary chemical shift differences in PASp of membraneembedded CitApc constructs. Secondary chemical shift differences of PASp in CitApc are shown in black; the secondary shift differences observed in isolated PASp (see figure 3.6) are shown again in green for comparison. Only secondary shift differences that are evaluated for both liquid- and solid-state spectra are shown for clarity. A: Secondary chemical shift changes between citrate-free and citrate-bound PASp R93A. B: Difference between PASp in citrate-free CitApc R93A and PASp in wild-type CitApc. C: Comparison of the citrate-bound PASp in CitApc R93A and PASp in wild-type CitApc. 


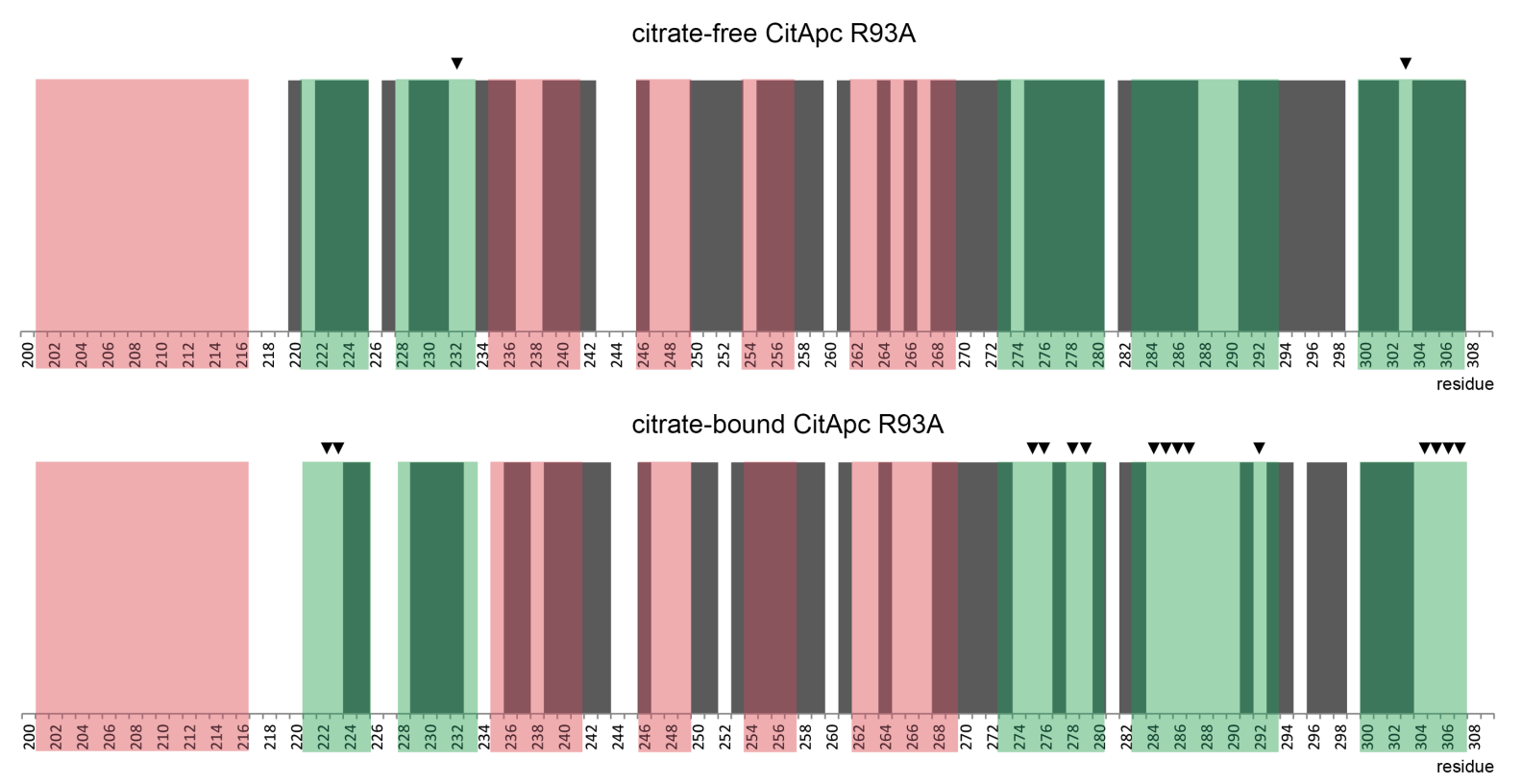

Figure 3.20: Assigned PASc residues in citrate-free and citrate-bound CitApc R93A. PASc residues assigned in citrate-free and citrate-bound CitApc R93A based on liquid-state chemical shifts are shown in grey. Secondary structure motifs of the PASc crystal structure are highlighted ( $\alpha$-helices red, $\beta$-strands green). Residues in $\beta$-strand conformation that are visible only in either citrate-free or citrate-bound state are marked with arrows.

Of the additional 16 residues of PASc that can be assigned in the citrate-free state, 15 are found in $\beta$-strands forming the PASc core (see figure 3.20). While the missing assignments in citrate-bound CitApc could be the result of a discrepancy of liquid-state shifts and solid-state peak positions, additional unassigned peaks would be expected in this scenario. For the case of residues in $\alpha$-helical conformation, these additional peaks could either correspond to PASc or the transmembrane helices, but additional peaks for residues in $\beta$-strand conformation could only be related to PASc if helical conformation is assumed for the transmembrane regions. In few cases where peak overlap is low, the existence of additional unassigned peaks in citrate-bound CitApc R93A, reflecting different conformations of $\beta$-strand residues that were assigned in citrate-free CitApc R93A, can be ruled out (see figure 3.21). Among the residues that are visible in the citrate-free state but cannot be assigned in the citrate-bound state is arginine 307 at the $C$-terminus of PASc, leading into the DHp domain and thus the kinase core. 

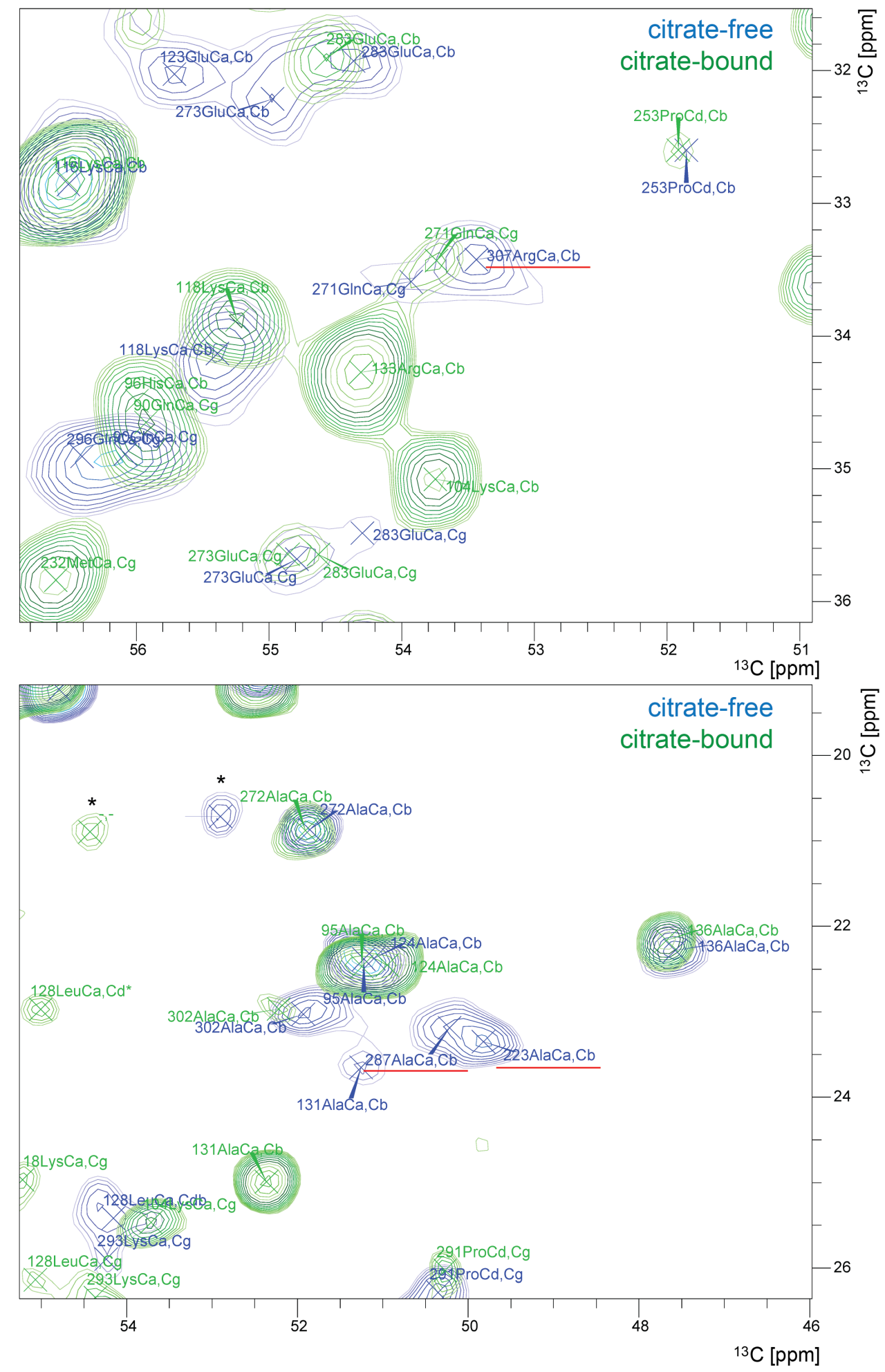

Figure 3.21: PASc visibility in PDSD spectra of citrate-free and citrate-bound CitApc R93A. For the highlighted residues (red) in $\beta$-strand conformation, liquid-state assignments could be confirmed in a PDSD spectrum of citrate-free CitApc R93A (blue), but not in the citrate-bound state (green). In citrate-bound CitApc R93A, no unassigned peaks in the vicinity of highlighted peak positions could be found. The peaks marked with asterisks are not assigned and correspond to an alanine in coil conformation. 


\section{Discussion}

\subsection{The periplasmic PAS domain (PASp)}

The first step towards proposing a signalling model for CitA is getting structural information on the signal receptor domain PASp in both signalling states. To this end, samples of Geobacillus thermodenitrificans CitA PASp were purified both for liquid-state NMR studies and crystallisation trials. Based on crystal structures available for the kinase core (Marina et al., 2005; Albanesi et al., 2009; Vu et al., 2011; Wang et al., 2013) and the homologous structure of citrate-bound CitA PASp from Klebsiella pneumoniae (Sevvana et al., 2008), a dimeric state of the kinase assembly can be assumed. Despite the proposed dimeric state in the full-length receptor, PASp of $G$. thermodenitrificans CitA appears to be a monomer in solution based on SEC profiles (see figure 3.1) and liquid-state NMR spectra. The apparent molecular weight of $17.8 \mathrm{kDa}$ is above the expected $14.9 \mathrm{kDa}$, but differences between observed and theoretical molecular weight are generally observed for proteins that are not spherical Andrews, 1964). The observed mass can thus not be attributed to PASp dimers. In addition, linewidth broadening for peaks around the dimerisation interface would be expected, but is not observed in a ${ }^{15} \mathrm{~N}-\mathrm{HSQC}$ spectrum (see figure 4.1). Interestingly, although the crystal structure of citrate-bound K. pneumoniae CitA PASp is dimeric, the crystal structure of citrate-free K. pneumoniae CitA PASp (Sevvana et al. 2008) and the NMR structure of Escherichia coli DcuS PASp (Pappalardo et al. 2003) show monomeric states of PASp domains. It therefore seems plausible that the dimerisation affinity of isolated PASp-domains is not necessarily high and that dimerisation of full-length histidine kinases is predominantly influenced by the transmembrane helix assembly and the DHp domains forming a helix bundle. 


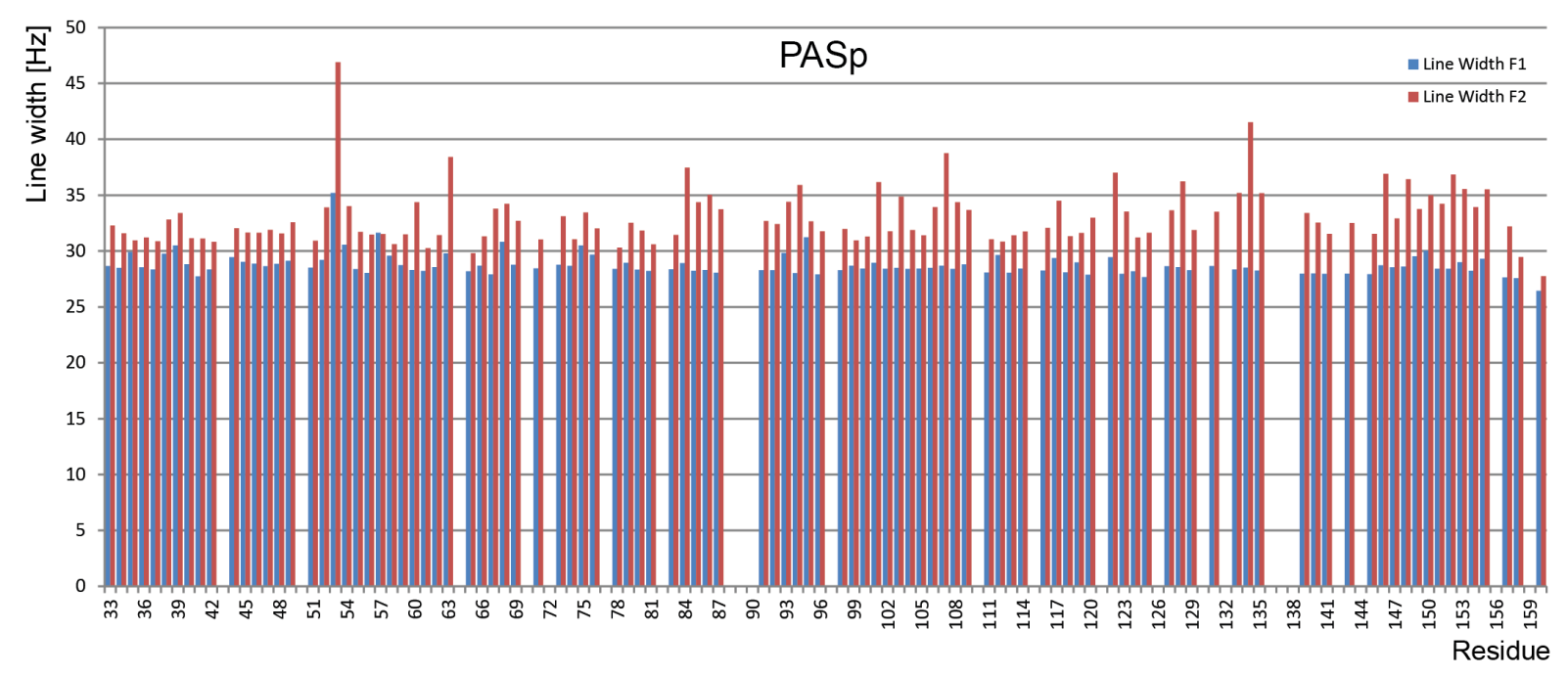

Figure 4.1: PASp linewidth in a ${ }^{15} \mathrm{~N}-$ HSQC. $A{ }^{15} \mathrm{~N}$ - and ${ }^{1} \mathrm{H}$-linewidth (F1 and F2, respectively) plot does not reveal regions with broadened lines indicative for a dimerisation propensity. Only isolated peaks in the ${ }^{15} \mathrm{~N}-\mathrm{HSQC}$ spectrum were analysed.

When G. thermodenitrificans CitA PASp was titrated with citrate, no binding was observed. While the lack of effect on chemical shifts during the titration might be related to a non-functional isolated receptor domain, full-length G. thermodenitrificans CitA clearly shows activity in vivo (see 3.1). Additionally, although no citrate was added during set-up, the crystal structure of E. coli CitA PASp contains citrate in the binding pocket. A similar behaviour was described for a ligand-binding PAS domain of HK DctB where succinate was found in the binding pocket of the crystal structure despite being absent in the purification and crystallisation protocol (Cheung and Hendrickson, 2008). It was

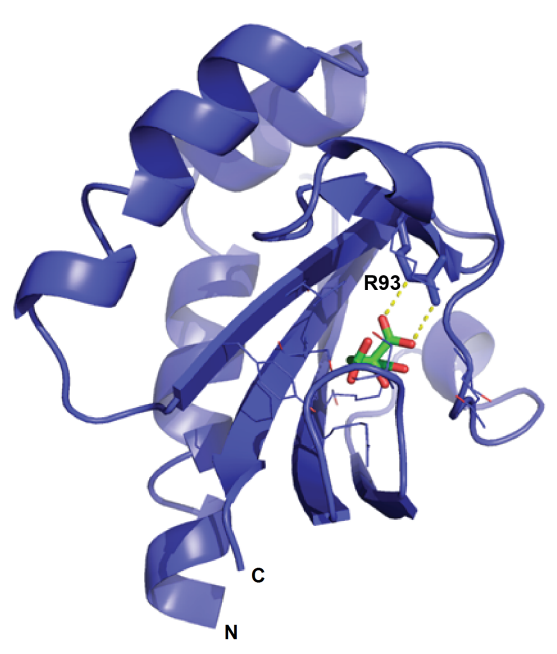

Figure 4.2: Mutation site in CitA PASp. Arginine 93 is shown as sticks, other residues in the citrate binding pocket as lines. The R93 side-chain forms two hydrogen bonds with a citrate carboxyl group. therefore reasonable to assume that the binding of citrate to PASp both for E. coli and $G$. thermodenitrificans CitA might be too strong to isolate a citrate-free state. Based on the crystal structures of citrate-bound K. pneumoniae CitA PASp and E. coli CitA PASp, a conserved arginine residue (Gerharz et al. 2003) contacting citrate 
in the binding pocket was identified (see figure 4.2). The corresponding arginine 93 in G. thermodenitrificans CitA PASp was mutated to alanine to reduce binding affinity. With the R93A mutant, chemical shift differences upon citrate addition to PASp could be observed, supporting the hypothesis that recombinant wild-type PASp is citrate-bound under experimental conditions. With G. thermodenitrificans CitA PASp R93A it is thus possible to study the receptor in both signalling states. The determined $\mathrm{K}_{\mathrm{D}}$ value of $624 \pm 21 \mu \mathrm{M}$ is two orders of magnitude weaker than the ligand binding affinity of wild-type K. pneumoniae CitA PASp (Kaspar et al., 1999), but in the same range or stronger than the affinity of E. coli DcuS towards its ligands (Kneuper et al., 2005). In vivo-studies on $G$. thermodenitrificans CitA R93A carried out by the group of Prof. Unden (Johannes Gutenberg-Univeristät Mainz, GER) demonstrated citrate specificity and receptor activity, indicating that the R93A mutant does not alter the signalling functionality of CitA, but only reduces citrate affinity (see figure 3.3).

\subsubsection{Citrate binding and activation of PASp}

Liquid-state NMR assignments of PASp R93A, both citrate-free and citrate-bound, allow for a detailed analysis of the effects of citrate binding. To visualise structural rearrangements caused by ligand binding, an I-TASSER model of $G$. thermodenitrificans CitA PASp based on K. pneumoniae CitA PASp was used. The changes to secondary structure can be correlated with differences in $\mathrm{C} \alpha$-C $\beta$-secondary chemical shifts. When $\mathrm{C} \alpha$ $\mathrm{C} \beta$-secondary shifts of citrate-free PASp R93A are compared with citrate-bound R93A, the whole central $\beta$-sheet scaffold including the $C$-terminal strand leading into the second transmembrane helix is affected (see figure $4.3 \mathrm{~A}$ ). This suggests that citrate is indeed binding to the pocket evident from crystal structures of homologous K. pneumoniae CitA PASp and E. coli CitA PASp. As a control of the physiological relevance of the citrate-bound state generated in PASp R93A, the $\mathrm{C} \alpha$-C $\beta$-secondary shifts of citratebound PASp R93A can be compared to wild-type PASp. The differences are all in close proximity to the mutation site, the remainder of the domain, including the central $\beta$ scaffold and the $C$-terminus, are conserved between the two constructs (see figure $4.3 \mathrm{~B}$ ). Not only does this confirm that wild-type PASp is in a citrate-bound state, but also that 


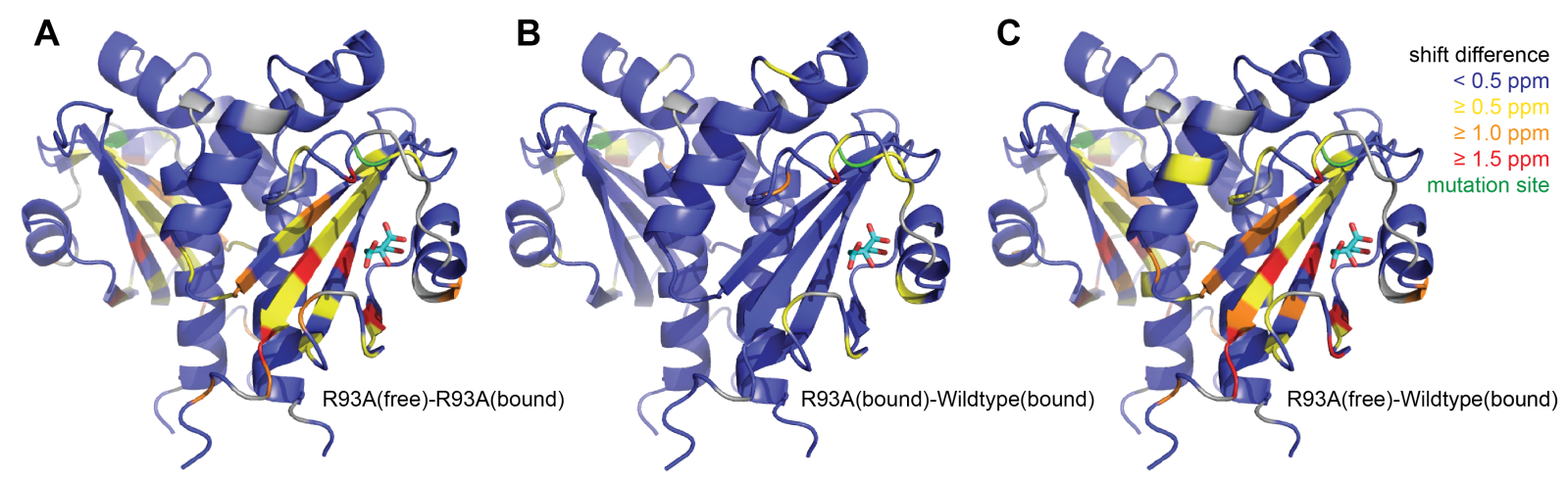

Figure 4.3: $\mathrm{C} \alpha-\mathrm{C} \beta$-secondary chemical shift changes upon PASp activation in solution. A: Differences between citrate-free and citrate-bound PASp R93A. The whole binding pocket undergoes structural reorganisation. Citrate is shown as cyan sticks for citrate-bound PASp. B: Comparison of citrate-bound PASp R93A and wild-type PASp. The citrate binding pocket is structurally unperturbed, indicating the same conformation of both proteins. Differences are seen around the mutation site R93A highlighted in green. C: Comparison of citrate-free PASp R93A and citrate-bound wild-type PASp reproduces differences observed between the two signalling states of PASp R93A.

citrate binding to PASp R93A restores a conformation very similar to that of wild-type protein. As a further control, shifts of citrate-free PASp R93A can be compared to the citrate-bound wild-type PASp; the shift differences observed match those for PASp R93A with and without citrate (see figure $4.3 \mathrm{C}$ ). The R93A mutant can therefore be used as a valid model for investigating citrate binding to CitA, circumventing the inaccessibility of inactivated PASp in wild-type G. thermodenitrificans CitA.

From crystal structures and NMR data on K. pneumoniae CitA PASp, a contraction of the $\beta$-scaffold upon citrate binding can be deduced (see figure 4.4). This contraction results in a shortening of the last $\beta$-strand in PASp by one amino acid (Sevvana et al. 2008). The same behaviour is apparent in PASp R93A of G. thermodenitrificans (see figure 4.5), where leucine 154 switches from negative to positive secondary chemical shift values upon citrate addition, corresponding to a transition from $\beta$-strand to $\alpha$-helical conformation. In a sequence alignment of $G$. thermodenitrificans CitA and K. pneumoniae CitA, the affected leucine 154 can be aligned with threonine 171 in K. pneumoniae CitA. Interestingly, threonine 171 is the residue which in the crystal structures of K. pneumoniae CitA is affected by the shortening of the $C$-terminal $\beta$-strand. The alignment of PASp domains can be visualised in an overlay of the crystal structure of citrate-free $K$. 


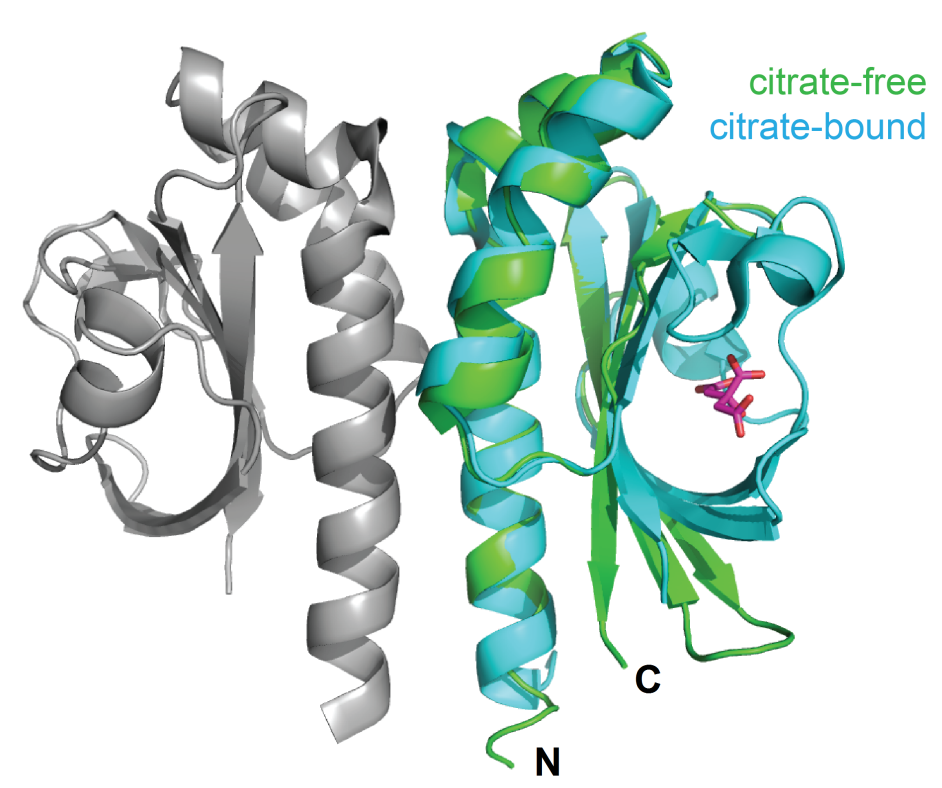

Figure 4.4: Structural reorganisation upon citrate binding in Klebsiella pneumoniae CitA PASp. An overlay of crystal structures of K. pneumoniae CitA PASp in citrate-free (green) and citrate-bound (cyan) states reveals a shortening of the $C$-terminal $\beta$-strand by one residue (Sevvana et al., 2008 ). Citrate found in the binding pocket of the citrate-bound form is shown in pink. PDB-accession codes for citrate-free and citratebound PASp: 2V9A and 2J8O.

pneumoniae CitA PASp with the I-TASSER structural model of G. thermodenitrificans CitA PASp (see figure 4.5 right). As K. pneumoniae CitA threonine 171 is structurally equivalent with $G$. thermodenitrificans CitA leucine 154, it is likely that the change in $\mathrm{C} \alpha-\mathrm{C} \beta$-secondary chemical shift observed for leucine 154 reflects a shortening of the $C$-terminal $\beta$-strand in $G$. thermodenitrificans CitA. While the secondary chemical shifts of glutamate 156 and succeeding residues also exhibit secondary shift changes upon citrate addition, they are not part of the isolated domain and changes are most likely unspecific. 

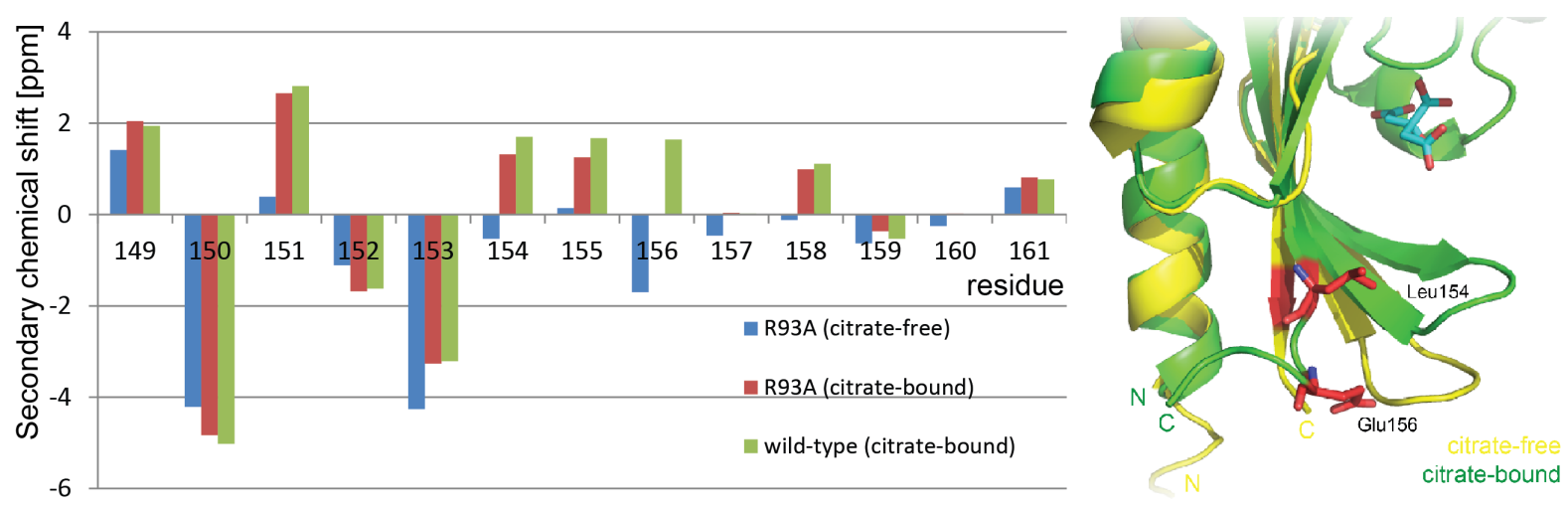

Figure 4.5: $\mathbf{C} \alpha-\mathbf{C} \beta$-secondary chemical shift differences between citrate-free and citrate-bound states. Left: Secondary chemical shifts indicate a secondary structure alteration at leucine 154, which switches from negative (indicative of $\beta$-strand conformation) in R93A to positive values (helical) in the citrate-bound states. Right: Comparison of the position of leucine 154 in a model of Geobacillus thermodenitrificans CitA PASp (green) based on citrate-bound Klebsiella pneumoniae CitA PASp and the corresponding residue in citrate-free $K$. pneumoniae CitA PASp (yellow). In the citrate-free state, the corresponding threonine 171 in $K$. pneumoniae CitA PASp is in $\beta$-strand conformation, while leucine 154 is at the $C$-terminus of the $\beta$-strand in the citrate-bound state. While the secondary chemical shift of glutamate 156 is also affected by citrate binding, it is not part of the domain and changes are most likely unspecific.

\subsection{The cytosolic PAS domain (PASc)}

Like PASp, samples of $G$. thermodenitrificans CitA PASc were produced both for crystallography and liquid-state NMR spectroscopy. As opposed to PASp, CitA PASc appears to be a dimer in solution based on the apparent molecular weight of $28.3 \mathrm{kDa}$ in SEC profiles, corresponding to a $14.1 \mathrm{kDa}$ monomer (see figure 3.1). As for PASp, the difference of $1.2 \mathrm{kDa}$ to the theoretical mass of PASc $(12.9 \mathrm{kDa})$ can be explained by taking into account deviations from ideal spheres in the overall PASc structure. In contrast to PASp, the $N$-terminal region of PASc appears to be affected by line broadening which likely reflects the dimerisation (see figure 4.6).

The dimeric state is retained in the crystal structure that could be solved for PASc (see figure 3.7 A). This structure corresponds well with the PAS domain (see figure 3.7 B) found in the cytoplasmic assembly of VicK (Wang et al., 2013), the first structure of a histidine kinase with adjacent PAS domain, with a backbone rmsd for one PAS-monomer of $1.63 \AA$. As the PASc structure is comparable to the VicK cytosolic PAS domain in 

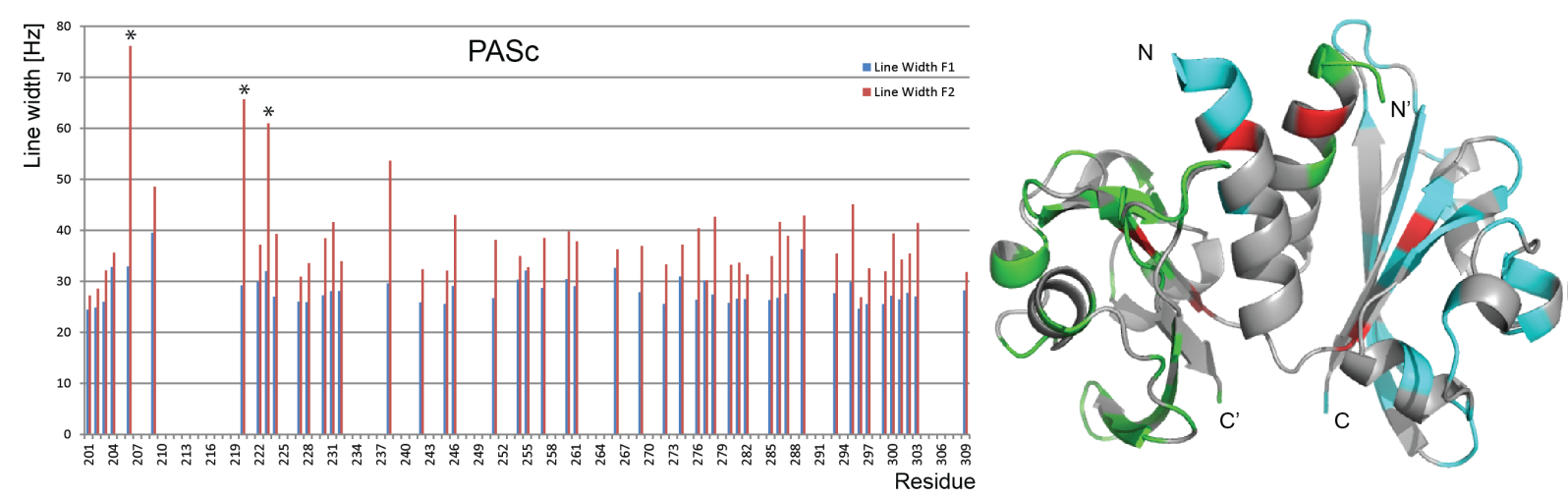

Figure 4.6: PASc linewidth in a ${ }^{15} \mathrm{~N}$-HSQC. Left: $\mathrm{A}{ }^{15} \mathrm{~N}$ - and ${ }^{1} \mathrm{H}$-linewidth (F1 and F2, respectively) plot demonstrates broadened lines at the $N$-terminus of PASc indicative for a dimerisation propensity. Only isolated peaks in the ${ }^{15} \mathrm{~N}-\mathrm{HSQC}$ spectrum were analysed. Right: Peaks with increased line widths (marked with asterisks) are plotted on the PASc crystal structure (red). The affected residues are close to the dimerisation interface. Overlapped or unassigned residues are greyed out.

context of the kinase core, the crystal structure of CitA PASc most likely represents a biologically relevant conformation. The liquid-state NMR assignments correspond well with structural features found in the crystal, the only major difference being residues in the second and third $\beta$-strand of the crystal structure which display positive secondary shifts in solution. However, these $\beta$-strands are twisted in the crystal structure and display unfavourable dihedral angles for extended conformations, thus reflecting unusual shifts for $\beta$-strands in solution. Chemical shift prediction based on the crystal structure (Han et al. 2011) did not yield satisfying results for comparison with liquid-state data as deviations of calculated chemical shifts from experimental values was in the range of 1-2 ppm.

As in VicK, the $N$-terminal helix bundle of $G$. thermodenitrificans CitA PASc is stabilised by a hydrophobic zipper motif (see figure 3.7). The hydrophobic interface between the helices covers $869 \AA^{2}$, the interface between one helix and the $\beta$-scaffold of the second monomer spans $1067 \AA^{2}$ (calculated using Pymol), suggesting a rigid binding of the PASc monomers. It is therefore quite surprising that crystal structures of PASc mutants based on functionally relevant mutants in DcuS (Monzel et al. 2013) yield very different structures (see figure 3.10). Of the proposed OFF-mutants, PASc V285A crystallised like wild-type, while PASc R218A, the second suggested OFF-mutant, forms an asymmetrical dimer like the proposed ON-mutant PASc N288D. On the other hand, the 
putative ON-mutant PASc R307A is structurally equivalent to wild-type PASc and the OFF-mutant V285A. In addition, in vivo activation studies on full-length G. thermodenitrificans CitA constructs with the mutations in PASc carried out by the group of Prof. Unden did not show any effect over wild-type CitA. All tested ON- and OFF-mutants were inactive without citrate and could be triggered by addition of $20 \mathrm{mM}$ citrate like wild-type protein. The expected effects on CitA functionality could not be confirmed for G. thermodenitrificans CitA PASc mutants. As there is structurally no consistent discrimination between $\mathrm{ON}$ - and OFF-mutants and no mutation effect on the full-length receptor, our results demonstrate that functional mutations in PASc cannot simply be transferred from homologous DcuS PASc.

Also, the biological relevance of mutant crystal structures (see figure 3.10 differing from wild-type PASc is questionable as the orientation of the $N$ - and $C$-termini is not compatible with a dimeric full-length receptor where the transmembrane helices should traverse the membrane in parallel orientation (see figure 4.7). The absence of any mutation effect in vivo also supports an identical PASc assembly between mutants and wild-type CitA. As a second state of PASc reflecting a second functional state most likely exists, the crystal structures obtained for PASc mutants might still contain information on functional roles. Although a complete reorganisation of the transmembrane helix bundle seems unlikely, helix tilts leading to an anti-parallel assembly of PASc monomers cannot be completely ruled out. Nonetheless, the vastly different orientations of the $N$-terminal helix in the PASc mutant crystal structures suggests that a high degree of structural flexibility around the $N$-terminal helix-pair might be possible. In such a scenario, the hydrophobic interfaces around the $N$-terminal helices could act as a lubricant to enable motions around the dimer core.

\subsection{Liposome-embedded CitApc}

\subsubsection{CitApc in Asolectin}

Mutation studies on PASc were inconclusive regarding differences between the ON- and OFF-state as shown in section 4.2. To analyse the role of PASc in CitA activity, solid- 

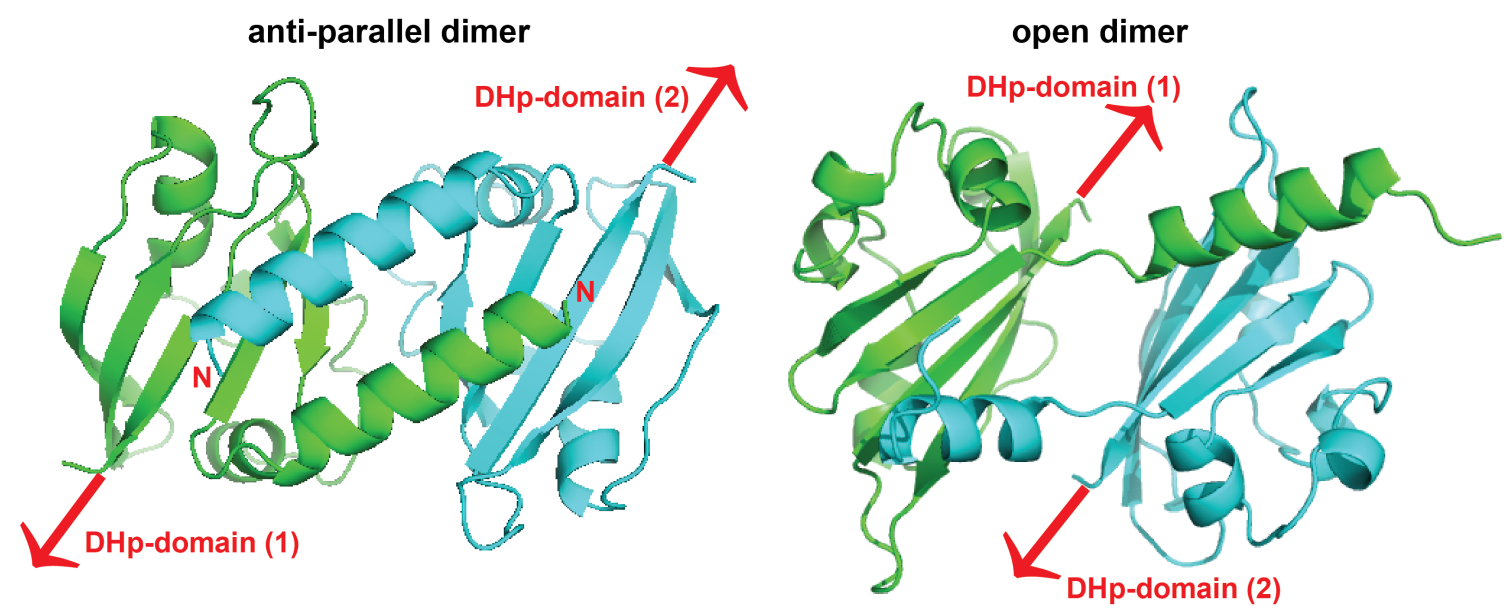

Figure 4.7: Orientation of monomers in PASc mutant crystal structures. For both crystal forms differing from wild-type found in PASc mutants, monomers are shown in green and cyan. The positions of the $C$-termini, which in full-length protein would be followed by the DHp domain, are highlighted in red. As DHp needs to be dimeric in functional receptors, physiological relevance of the crystal structures differing from wildtype is unlikely. In addition, the $N$-termini (N) in the anti-parallel crystal form are on opposite sides of the protein making attachment to the membrane impossible.

state NMR can be employed to characterise the different signalling states in context of the transmembrane helices. Citrate-bound wild-type CitApc reconstituted in asolectin was assigned based on liquid-state resonances for PASp and PASc. This left only a comparably small number of unassigned peaks which in part could be assigned to the two transmembrane helices (see figure 3.15). Since wild-type CitApc was purified in the citrate-bound state, the R93A mutant was introduced in the citrate binding pocket, allowing for study of both signalling states by reducing citrate affinity.

CitApc R93A samples were initially reconstituted in asolectin to compare with wildtype CitApc. In the citrate-free sample of $G$. thermodenitrificans CitApc R93A, peak doubling in PDSD spectra was observed for residues around the citrate binding pocket (see figure 3.17 A). The two resonance sets for affected residues corresponded to liquid-state assignments of the citrate-free and citrate-bound state, respectively. In the 3D spectra, only the citrate-bound state was visible. As peaks in 2D spectra are generally less intense for the citrate-free state (see figure 4.8), the signal/noise ratio is probably not sufficient for detection of the citrate-free state in 3D spectra. Subsequently, asolectin was identified 


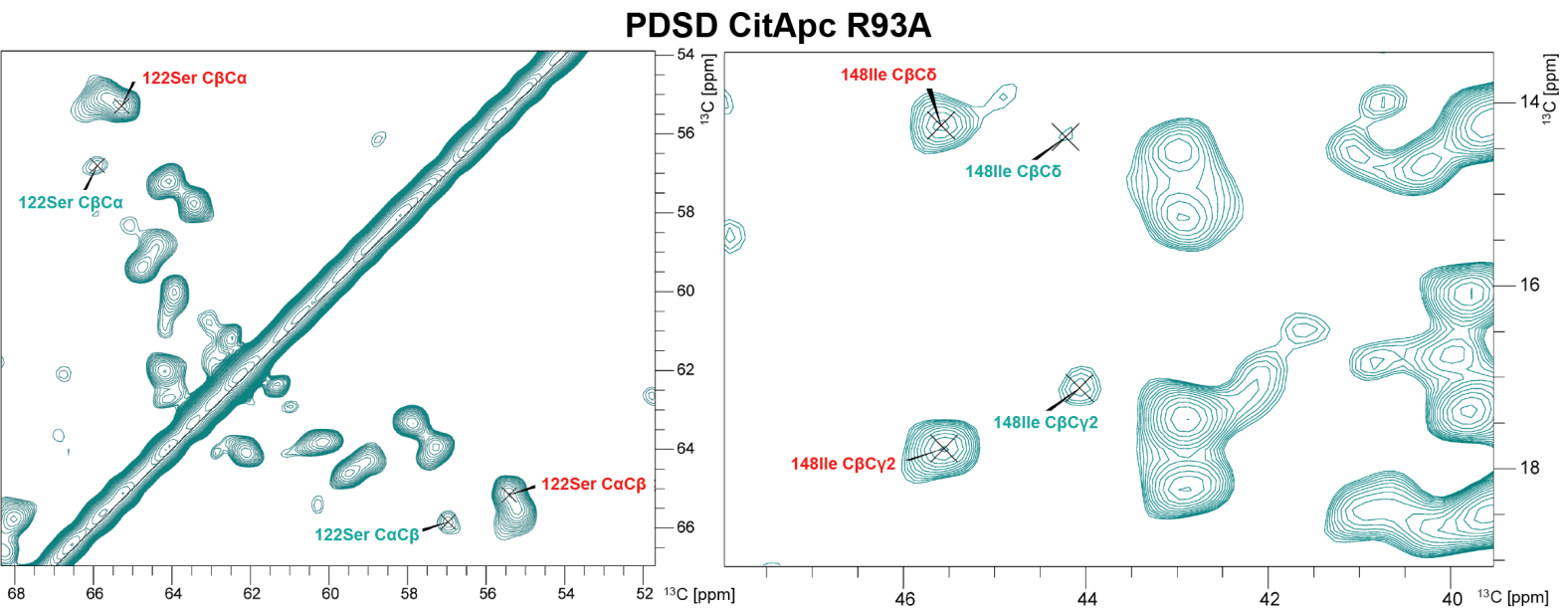

Figure 4.8: Peak doubling of PASp in a PDSD-spectrum of citrate-free CitApc R93A. For the citrate-free sample of CitApc R93A in asolectin, peak doubling for several residues around the citrate binding pocket was observed. One set of peaks corresponds to liquid-state assignments of citrate-free PASp R93A while the second signal set reflects citrate-bound PASp R93A. Examples for peak doublings are shown with serine 122 (left) and isoleucine 148 (right). In most cases, peaks corresponding to the citrate-free state (teal) are much weaker than peaks of citrate-bound PASp R93A (red).

as a possible source for citrate impurities in the sample. 1D proton spectra of asolectin in $10 \%$ SDS confirmed the presence of citrate in asolectin used for sample preparation (see figure $3.17 \mathrm{~B})$. To generate a citrate-free state of CitApc R93A, new samples were prepared in 1,2-dimyristoyl-sn-glycero-3-phosphocholine (DMPC) instead of asolectin. The peak doubling suggests slow exchange between CitApc R93A and citrate as opposed to the fast exchange observed for isolated PASp R93A. It can be concluded that citrate binding kinetics of PASp are dependent on structural context. Possibly, domain dynamics of PASp are reduced in context of the transmembrane helices, allowing for detection of both receptor states.

\subsubsection{CitApc R93A in DMPC}

As the phase transition point for DMPC is at $24{ }^{\circ} \mathrm{C}$ compared to the melting temperature of asolectin membranes below $0{ }^{\circ} \mathrm{C}$, initial experiments on DMPC-embedded CitApc R93A were carried out at $25^{\circ} \mathrm{C}$. At these high temperatures the $\mathrm{N}$-C-magnetisation transfer was very inefficient, thus later spectra were recorded at temperatures between $6{ }^{\circ} \mathrm{C}$ and $10{ }^{\circ} \mathrm{C}$, increasing the magnetisation transfer by $70 \%$ (see figure 3.14). Overall, spectra above 
and below the melting point of DMPC are comparable; the isolated domains are readily assignable based on liquid-state data in both cases (see figure 4.9).

As discussed in section 3.3 , the percentage of transferable assignments from liquid- to solid-state spectra is higher for PASp than for PASc in all cases. This is in part caused by a generally lower signal/noise ratio for PASc, as can be visualised for isolated $\mathrm{C} \alpha-\mathrm{C} \beta$ peaks in 3D-NCACB and NCOCACB spectra (see figure 3.18). In total, 25 PASc residues in citrate-free and 26 PASc residues in citrate-bound CitApc R93A could be assigned in $3 \mathrm{D}$ spectra. The number of unassigned peaks in $3 \mathrm{D}$ spectra does not account for the missing assignments based on liquid-state data (see table 4.1), especially if the missing assignments of transmembrane helices, which likely also contribute to unassigned peaks, are taken into account.

Table 4.1: Assignments of PAS domains in CitApc R93A.

\begin{tabular}{|c|c|c|c|c|}
\hline \multicolumn{5}{|c|}{ citrate-free CitApc R93A } \\
\hline \multirow[t]{4}{*}{ PASp } & spectrum & residues assigned & residues missing & unassigned peaks* \\
\hline & PDSD & 93 & 35 & - \\
\hline & NCACB & 70 & 58 & 14 \\
\hline & NCOCACB & 23 & 105 & 14 \\
\hline \multirow[t]{4}{*}{ PASc } & spectrum & residues assigned & residues missing & \\
\hline & PDSD & 59 & 50 & \\
\hline & NCACB & 24 & 85 & \\
\hline & NCOCACB & 2 & 108 & \\
\hline \multicolumn{5}{|c|}{ citrate-bound CitApc R93A } \\
\hline \multirow[t]{4}{*}{ PASp } & spectrum & residues assigned & residues missing & unassigned peaks \\
\hline & PDSD & 106 & 22 & - \\
\hline & NCACB & 101 & 27 & 26 \\
\hline & NCOCACB & 90 & 38 & 8 \\
\hline \multirow[t]{4}{*}{ PASc } & spectrum & residues assigned & residues missing & \\
\hline & PDSD & 40 & 69 & \\
\hline & NCACB & 21 & 88 & \\
\hline & NCOCACB & 5 & 104 & \\
\hline
\end{tabular}


PDSD CitApc R93A

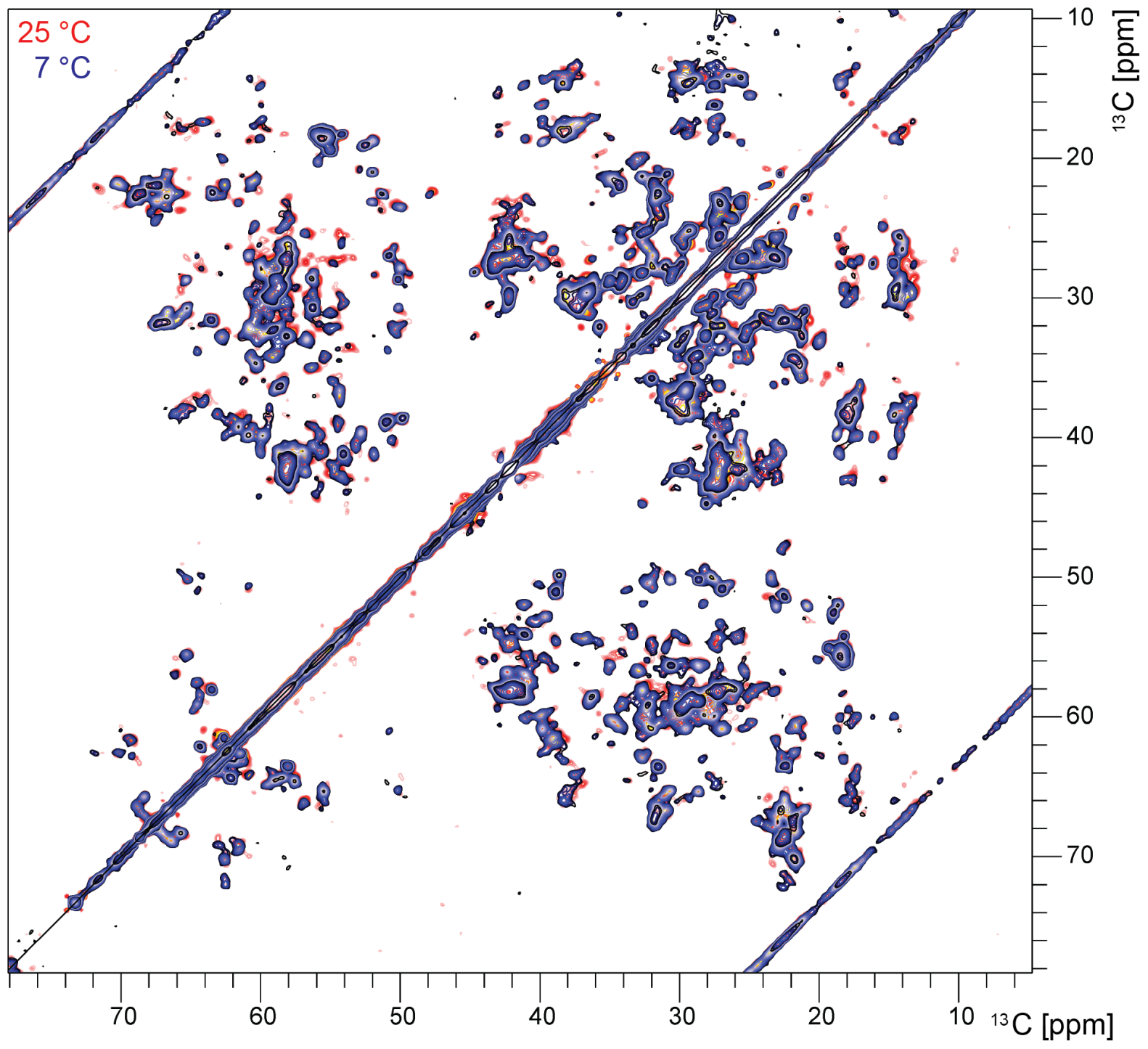

Figure 4.9: Spectra of CitApc R93A at different temperatures. PDSD-spectra of CitApc R93A were recorded above and below the phase transition temperature of DMPC. Proton 1D spectra were used for discrimination between the liquid crystalline and solid phases of DMPC. 
It is therefore likely that the discrepancy between liquid-state assignments and solidstate peak positions for certain parts of the PAS domains, most notably PASc $(59 \%$ and $45 \%$ assigned in citrate-free and citrate-bound state, respectively), is related to increased mobility of the invisible regions. INEPT spectra of CitApc R93A in both signalling states only contain peaks of lipid headgroups, so rapid exchange of unstructured protein regions can be ruled out. Also, no additional peaks appear in INEPT-spectra of the citratebound state. The non-assignable parts of PASp and PASc are therefore likely undergoing dynamic motions on a time scale that is not detectable with the acquired solid-state experiments.

The available assignments of PASp and PASc can be utilised to identify structural rearrangements in the two signalling states. Structural differences can be easily tracked in PASp by analysing $\mathrm{C} \alpha$-C $\beta$-secondary chemical shift changes upon citrate binding to CitApc R93A (see figure 4.10). The secondary structure reorganisation observed in liquid state (see section 4.1.1) can be reproduced in membrane-embedded solid state samples. It can thus be assumed that the changes observed for the individual PASp domain are comparable to the structural switching in context of the transmembrane helices. 


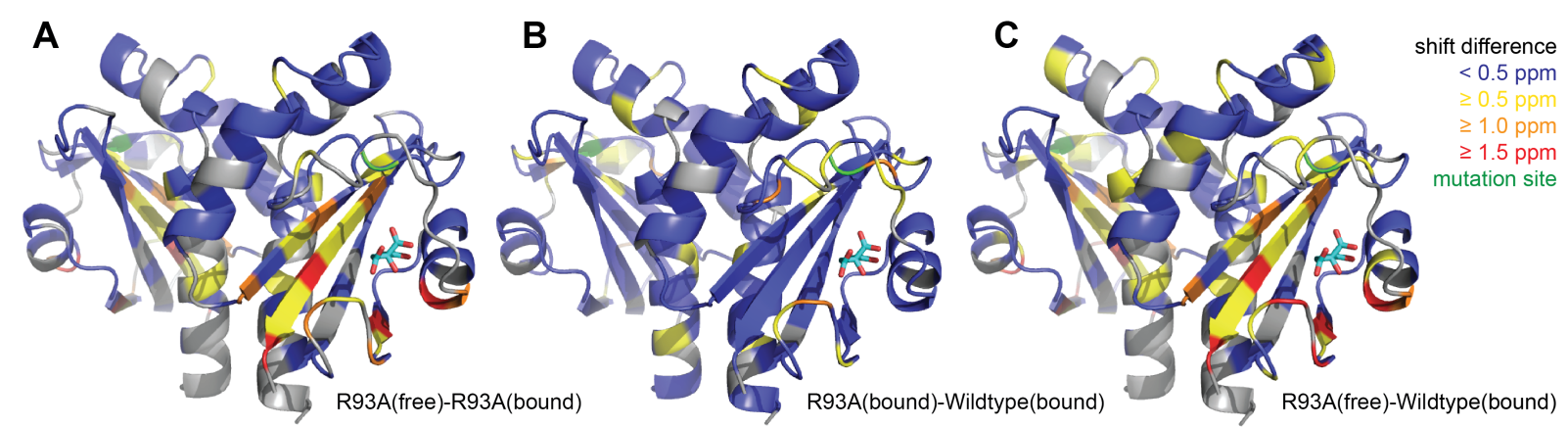

Figure 4.10: $\mathrm{C} \alpha-\mathrm{C} \beta$-secondary chemical shift differences of PASp in membraneembedded CitApc between the ON- and OFF-state. A: Differences between citrate-free and citrate-bound PASp R93A. Like in the isolated domains, the whole binding pocket undergoes structural reorganisation. Citrate is shown as cyan sticks for citratebound PASp. B: Comparison of citrate-bound PASp R93A and citrate-bound wild-type PASp. The citrate binding pocket is structurally conserved, indicating the same conformation of both citrate-bound states. Differences are seen around the mutation site R93A highlighted in green. C: Comparison of citrate-free PASp R93A and citrate-bound wildtype PASp reproduces differences observed between the ON- and OFF-states of PASp R93A.

Of note is the secondary chemical shift change of leucine 154 at the end of the $C$ terminal $\beta$-strand in PASp, which switches from extended conformation in citrate-free CitApc R93A to helical in citrate-bound samples of both CitApc wild-type and R93A (see figure 4.11). As solid-state assignments of residues succeeding leucine 154 are missing, other potential structural changes at the PASp - transmembrane helix interface remain to be elucidated. It can be concluded that the $C$-terminal $\beta$-strand is shortened by one amino acid upon citrate binding. This finding is in agreement with observations in crystal structures of citrate-free and citrate-bound CitA PASp in K. pneumoniae Sevvana et al. 2008). Just like in $G$. thermodenitrificans CitA PASp, the $C$-terminal $\beta$-strand is one amino acid shorter in the citrate-bound state due to the contraction of the domain upon citrate binding (Sevvana et al., 2008). 

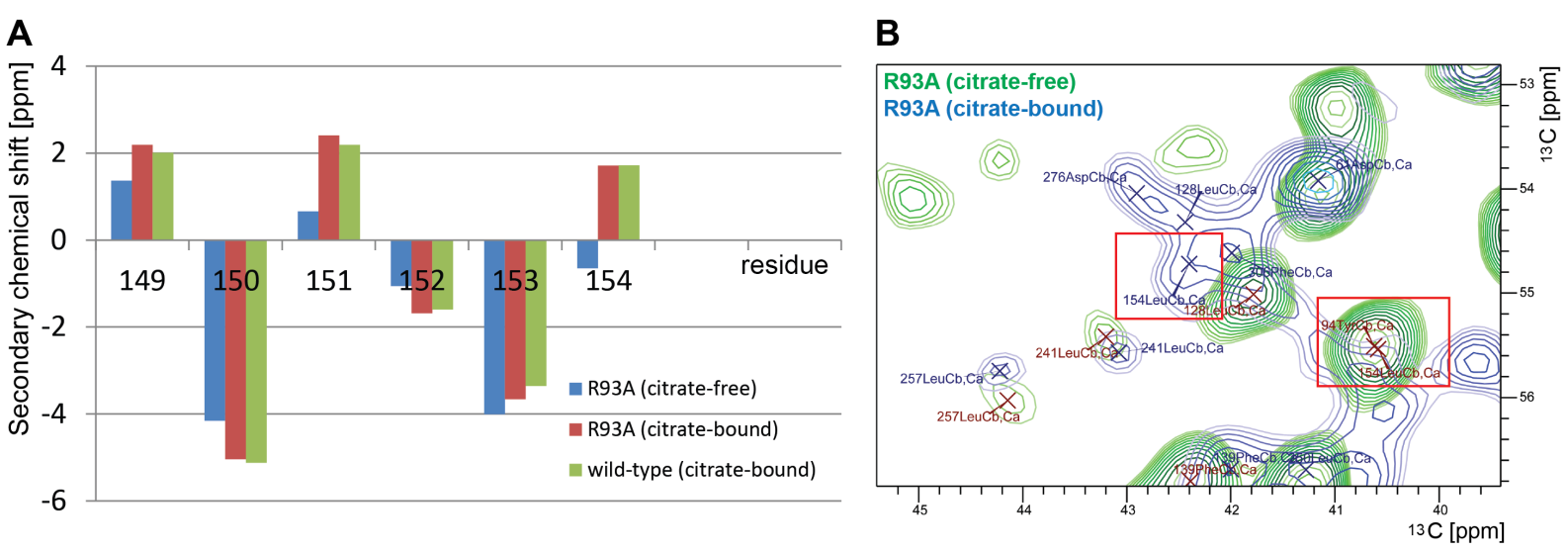

Figure 4.11: Spectral differences between the two signalling states at the PASpTM2-interface. A: $\mathrm{C} \alpha$ - $\mathrm{C} \beta$-secondary chemical shifts indicate a secondary structure alteration at leucine 154, which switches between extended conformation in citrate-free CitApc R93A and helical conformation in citrate-bound CitApc R93A. In citrate-bound wild-type CitApc, L154 is also found in helical conformation. Upon citrate binding, the $C$-terminal $\beta$-strand of PASp is thus shortened by one amino acid. B: Section of PDSD spectra of CitApc R93A in both citrate-free (blue) and citrate-bound (green) states. The $\mathrm{C} \alpha$-C $\beta$-crosspeak of leucine 154 is shifted upon citrate binding. Residues succeeding leucine 154 are not assigned in solid-state spectra.

Transmembrane signalling is conceivable with four principle mechanistic models: translation, piston-type displacement, pivot movement parallel to the membrane or rotation perpendicular to the membrane (Hulko et al., 2006; Matthews et al. 2006). Although other mechanisms cannot easily be excluded, the shortening of the $C$-terminal $\beta$-strand in CitA is consistent with a piston-model for transmembrane signalling (Ottemann et al. 1999). In this model, the second transmembrane helix is pulled out of the membrane upon signal recognition. This piston-like movement could be triggered by the contraction of PASp in CitA coupled with a shortening of the $C$-terminal $\beta$-strand (see figure 4.12) exerting a pull on the second transmembrane helix. In addition to the piston movement, a slight helix tilt or rotation could also contribute to net helix motion.

\subsubsection{Citrate affinity of PASp}

The tight binding of wild-type $G$. thermodenitrificans PASp to citrate is striking, as a sensor that cannot be switched off through releasing its ligand does not allow for regulation based on citrate availability. One reason for the tight ligand binding could be that both 


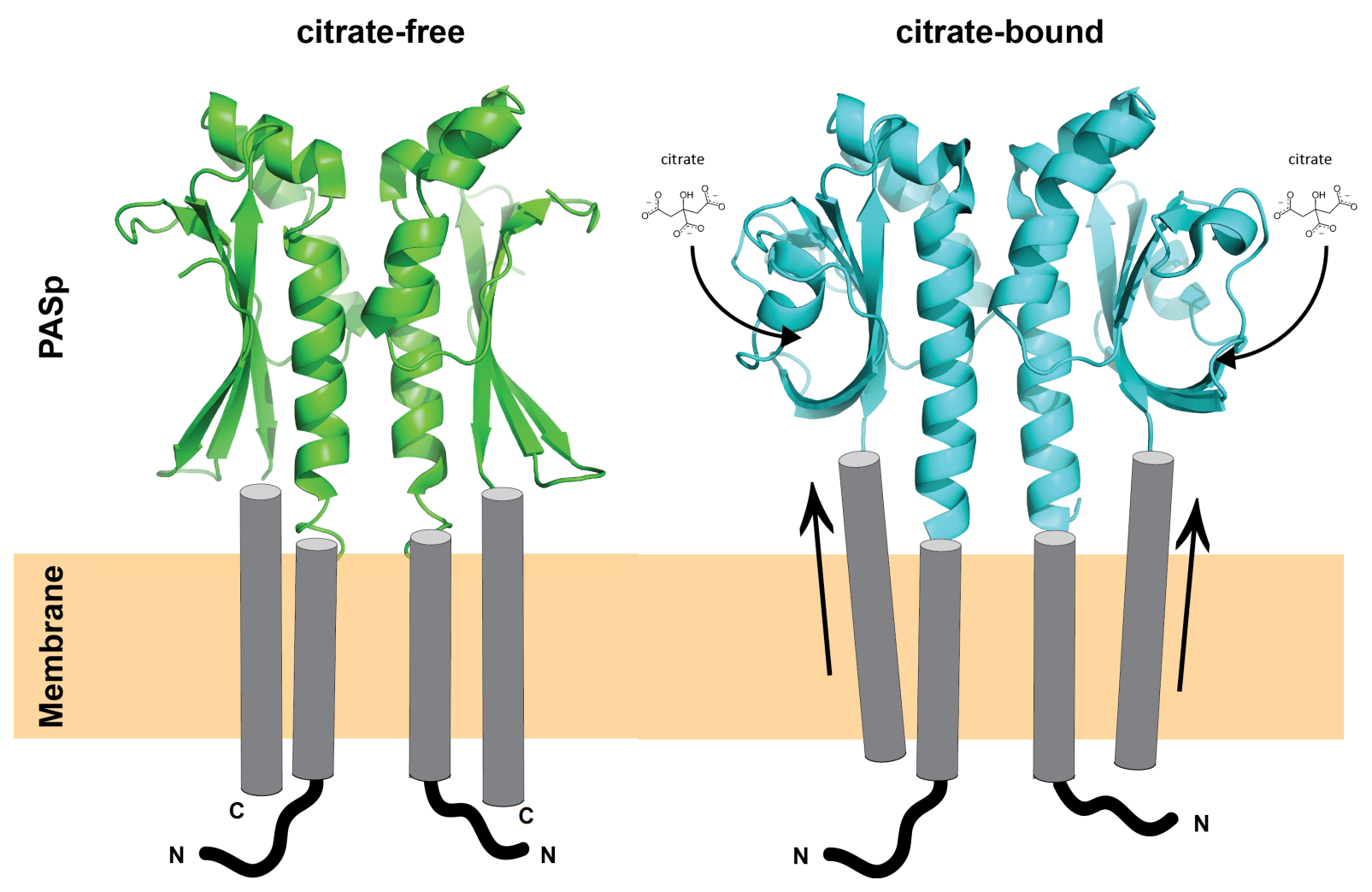

Figure 4.12: Piston-model for transmembrane signalling. Based on the crystal structures of Klebsiella pneumoniae CitA PASp, a signal transduction model has been proposed in which a citrate-binding induced pull on the terminal $\beta$-strand in PASp triggers a piston movement of the second transmembrane helix. PDB-accession codes for citratefree and citrate-bound PASp (Sevvana et al., 2008): 2V9A and 2J8O.

copies of PASp in the full-length receptor dimer need to bind citrate for signalling to occur, which would be facilitated by the low off-rate of binding. It has been suggested that a symmetry/asymmetry switch in the signal receiving domains could play a role in signal transduction (Neiditch et al., 2006; Moore and Hendrickson, 2012). However, this seems not to be the case in $G$. thermodenitrificans CitA as solid-state spectra reveal changes on the cytosolic part of CitApc R93A upon citrate addition and only one set of resonances for a CitA monomer is visible. It can therefore be assumed that citrate is bound to both PASp domains in the dimer. As no asymmetric species can be observed, activation of CitA through symmetric citrate binding seems plausible.

The release of citrate from PASp in vivo might be possible at the higher temperatures of G. thermodenitrificans habitats, reported at an optimum of $60-65{ }^{\circ} \mathrm{C}$ (Feng et al., 2007. Cihan et al., 2011). However, the tight ligand binding observed in G. thermodenitrificans 
CitA (see section 3.1) was observed for the mesophile E. coli CitA PASp as well. It is therefore likely that citrate is released from PASp by a mechanism yet to be understood. One potential mechanism of citrate release is by binding of a co-receptor of the TctCfamily. Tct is a tripartite tricarboxylate transporter, with TctC being a periplasmic tricarboxylate receptor (Ashton et al. 1980. Tct proteins are found in almost all bacteria, but the absence of TctA, TctB or TctC in several organisms led to the assumption that the individual components might have other roles than just tricarboxylate transport. In some instances, TctC is the only Tct component present in a genome. For Bacillus subtilis it has been postulated that this lone copy of TctC could interact with a HK with effects on switching of the sensor (Winnen et al., 2003) analogous to vir-operon activation in Agrobacterium tumefaciens (Cangelosi et al., 1990). As TctC homologues can be found in both G. thermodenitrificans and E. coli it is possible that it plays a role in signal recognition and deactivation of CitA PASp.

\subsubsection{Signalling effects in the cytosolic PAS domain}

For CitA PASp, analysing differences between the ON- and OFF-state of the receptor is straightforward due to the availability of both signalling states through addition of citrate to PASp R93A. For PASc however, it is impossible to predict which signalling state the crystal structure and the liquid-state NMR assignments correspond to. Therefore, tracking differences in the solid-state spectra for the first time opens up the possibility to study effects of citrate binding on the cytosolic PAS-domain. Parts of PASc are visible in all three samples, but sequential assignment is impossible due to the scarcity of PAScpeaks in 3D spectra. This lack of coverage could be caused by generally higher domain dynamics of PASc compared to PASp. While PASp is anchored to the transmembrane helix bundle both at the $N$ - and $C$-terminus, PASc is only linked to the central helical scaffold by the $N$-terminal helices, potentially allowing for increased mobility around the central coiled coil formed by the transmembrane helices. However, it is striking that large portions of PASc are not visible upon citrate binding in CitApc R93A while appearing in spectra of citrate-free CitApc R93A (see figure 4.13 and tables 4.1 and 8.9 . 

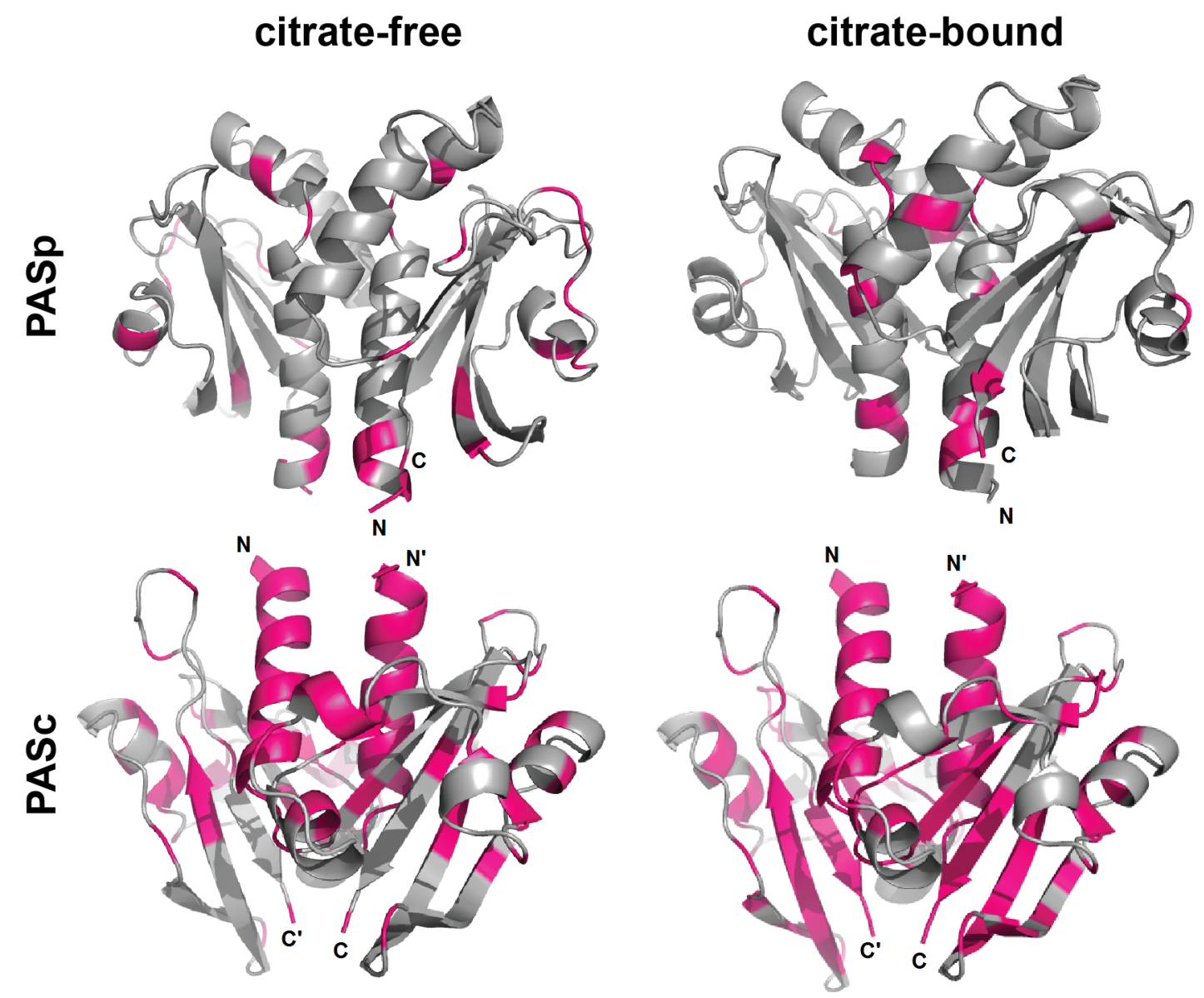

Figure 4.13: Visibility of PASp and PASc in solid-state spectra of CitApc R93A. In citrate-free PASp, almost the whole domain can be assigned in solid-state spectra. Unassigned residues are mostly found in a loop closing the citrate binding pocket and in one of the $\beta$-strands facing the $C$-terminus (unassigned residues highlighted in pink). In citrate-bound PASp, this loop and the whole $\beta$-scaffold can be assigned. While the $N$-terminal helix of PASc could not be assigned for both signalling states, large parts of the $\beta$-sheet core of PASc including the $C$-terminus are only visible in the citrate-free state and disappear in the citrate-bound state (unassigned residues highlighted in pink).

As additional peaks in 3D spectra that could be assigned to shifted PASc residues do not appear and INEPT spectra are also devoid of protein peaks, it is very likely that the decrease in PASc visibility upon citrate binding corresponds to increased flexibility in the citrate-bound state. The increased dynamics of the $C$-terminus in PASc could result in triggering the HK in full-length CitA. This assumption is backed by functional studies on the HK ArcB, where formation of disulfide bridges and therefore reduction of flexibility between two PAS-monomers preceding the DHp domain switches off the kinase 
activity (Malpica et al., 2004). In addition, increased PASc flexibility was proposed as the activity switch for E. coli DcuS (Etzkorn et al., 2008$)$. Functional mutants in DcuS PASc (Monzel et al., 2013) were employed to generate a constitutively active functional state of DcuSpc constructs (analogous to CitApc and consisting of both PAS domains and the transmembrane helices without the kinase core). Solid-state NMR spectra of precipitated DcuS PASc and kinase-competent DcuSpc in liposomes suggest disorder at the PASc dimer interface in the active receptor state. Based on dimeric crystal structures of homologous PAS domains, it was therefore postulated that PASc in inactive DcuS is more ordered and that the active state is characterised by increased flexibility. The similar effects observed for $G$. thermodenitrificans CitApc further support the role of PASc plasticity in signalling.

The proposition that changes in protein mobility at the interface of PASc and DHp could be the key for activating the kinase is in line with observations on crystal structures of the kinase core. In HK853, a HK of unknown function, the $N$-termini of the $\alpha 1$ helices in the DHp domains are unstructured in the active state of the kinase, while being in helical conformation in the inactive state (Marina et al. 2005, Casino et al. 2010). The same is true for the temperature sensor DesKC, where the crystal structure of the kinase-competent state $\operatorname{DesKC}_{\Delta 174}$ has a shortened $N$-terminal helix compared to $\operatorname{DesKC}_{\mathrm{H} 188 \mathrm{~V}}$, the phosphatase-competent state (Albanesi et al. 2009). This suggests that the $N$-terminal region of the helix bundle in DHp is intrinsically strained and activation of the kinase could either be triggered by the cogwheel rotation of a HAMP domain, a signal transducing domain found $C$-terminal of transmembrane helices in many HKs, as suggested by (Casino et al. 2010), or by reducing structural constraints like in PASc of CitA as shown here.

\subsubsection{PASc in context of full-length CitA}

The dimeric assembly of the $G$. thermodenitrificans CitA PASc crystal structure is easily superimposed with the structure solved for VicK, suggesting a similar mode of structural assembly for the two HKs (see figure 4.14 A and B). The backbone rmsd between individual PAS domains of $1.63 \AA$ can be reduced to $1.44 \AA$ by omitting the $N$ - 
terminal helix which is rotated by 14 degrees between the two crystal structures. The low coordinate deviation of the PAS core suggests that cytosolic PAS domains are structurally highly conserved between CitA and VicK. The sequence identity of $30 \%$ is comparable to the values found for periplasmic, citrate binding PAS domains.

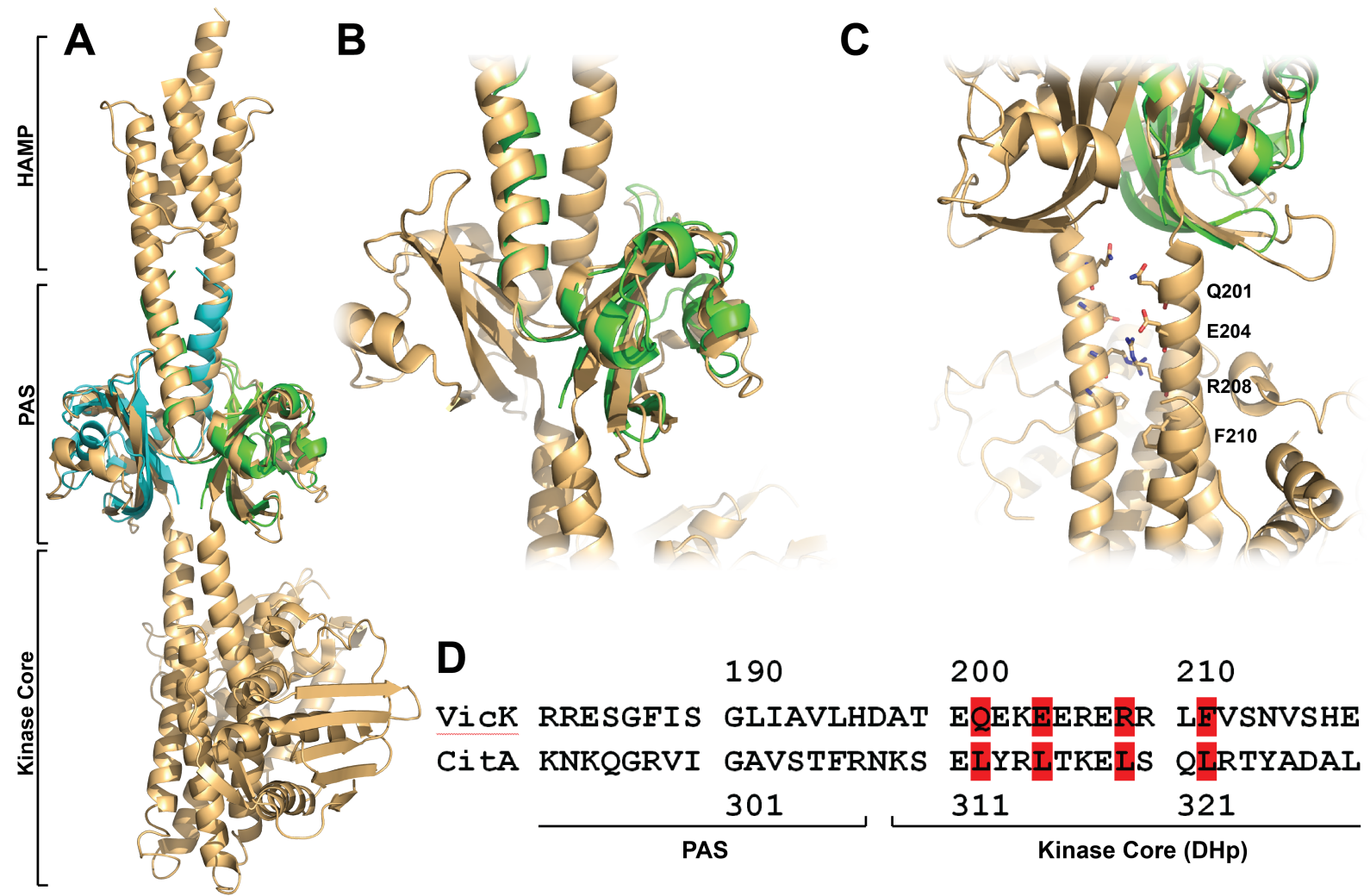

Figure 4.14: Comparison of VicK and CitA PASc crystal structures. A: The crystal structure of CitA PASc (green and cyan monomers) is easily superimposed with the structure of VicK (light orange, PDB accession code: 4I5S), a cytosolic HK containing HAMP and PAS domains preceding the kinase core. B: Close-up of one CitA PASc monomer aligned to VicK PAS with a backbone rmsd of $1.44 \AA$ for the PAS core. C: The $N$-terminal helix bundle interface of VicK DHp is characterised by a cluster of charged residues. D: a Dialign (Morgenstern, 2004) alignment of VicK and CitA reveals a leucine zipper at the CitA DHp interface in contrast to the charged interface in VicK DHp.

The different position of the $N$-terminal helix in CitA PASc is possibly caused by the lack of context. As $N$-terminal helices of the PAS-domain in VicK are extended to form a four-helix bundle, it can be assumed that a similar orientation is found in G. thermodenitrificans CitA PASc if the four-helix bundle of the transmembrane helices is taken into consideration. The predicted second transmembrane helix of G. thermodenitrificans 
CitA (residues 169-188) is followed by 26 residues in helical conformation, including the $N$-terminal helix of the PASc crystal structure. In VicK, 22 residues are needed to bridge the gap between the HAMP four-helix bundle and the PAS core. Therefore, a similar protein architecture in CitA is conceivable.

Differences between VicK and CitA can be found at the $C$-terminus of the PAS-domain leading into the DHp-domain. In VicK, the $N$-terminus of DHp is highly charged, leading to stabilising salt bridges between E205 and R208 of different monomers (see figure $4.14 \mathrm{C}$ ), whereas the CitA sequence reveals a leucine zipper motif at the $N$-terminus of DHp (see figure $4.14 \mathrm{D}$ ). Consequently, the rigidity of the two different DHp domains might be fine-tuned to the different functional roles. In VicK, the PAS domain is believed to receive stimuli, whereas in CitA, the stimulus is received in the periplasm and transferred to the kinase via PASc.

\subsubsection{Signal transduction model}

One major question that still remains unanswered is concerning the role of the transmembrane helices during signalling. The combined data collected on K. pneumoniae CitA and G. thermodenitrificans CitA suggest a piston model, in which the contraction of the $\beta$-scaffold of PASp upon citrate binding leads to a shortening of the $C$-terminal $\beta$-strand and as a consequence a pull on the second transmembrane helix. For a piston movement to occur, different residues around the second transmembrane helix will come in contact with the membrane. Therefore, two different positions of the second transmembrane helix have to be accessible: in the citrate-bound state, residues inside the membrane would have to be displaced towards the $C$-terminus when compared with the citrate-free state due to the pull on the $N$-terminus of the helix (see figure 4.15).

Transmembrane helix prediction software (Hofmann and Stoffel, 1993; Cserzo et al. 1997: Sonnhammer et al., 1998: Tusnády and Simon, 2001) gives accurate positions for helix one (residues 7-26) and helix two (residues 169-188). Interestingly, six residues before the predicted $N$-terminus of the second transmembrane helix a tryptophane residue (W163) is situated. A similar arrangement is found in E. coli CitA, where a tryptophane is positioned four residues $N$-terminal of the second transmembrane helix and a second 


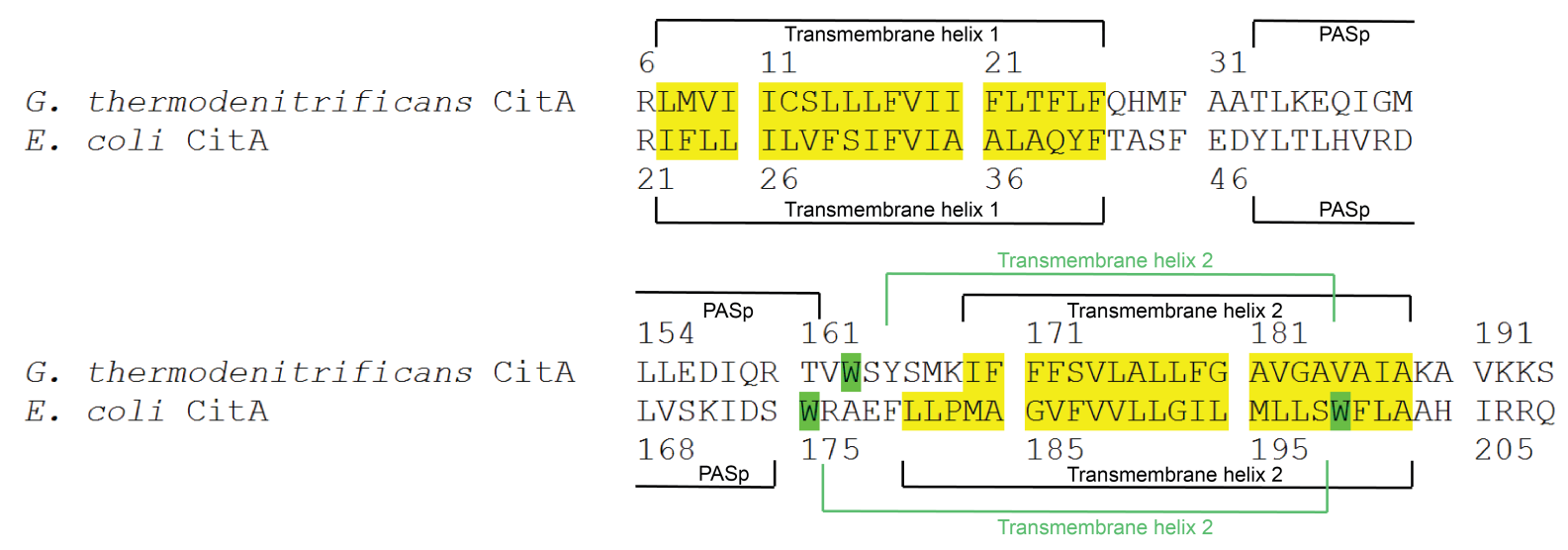

Figure 4.15: Transmembrane helices in CitA. In an alignment of Geobacillus thermodenitrificans CitA with Escherichia coli CitA, the position of transmembrane segments can be predicted (yellow). Both in G. thermodenitrificans CitA and E. coli CitA, tryptophane residues (green) are positioned in proximity of transmembrane regions. If the predicted position of the second transmembrane helix is assumed to correspond to the citrate-bound state, a second position of the helix closer to the $N$-terminus (green brackets) would bring the tryptophane residues close to the membrane interfaces and could reflect the citrate-free state.

tryptophane four residues before the predicted $C$-terminus of the transmembrane helix (see figure 4.15). As tryptophane residues are often found at transmembrane helix surfaces and the databases for transmembrane helix prediction are based on static helices, one could speculate that the predicted position of the second transmembrane helix corresponds to the citrate-bound state and a second position of the helix with the tryptophane closer to the lipid interface reflects the citrate-free state (see figure 4.16). According to the piston model, the position of the $N$-terminus of the second transmembrane helix would be closer to the membrane surface in the citrate-free state. The position of tryptophane 163 in CitA suggests that a second orientation of the $C$-terminal transmembrane helix and thus a piston movement pulling the $N$-terminal residues out of the membrane is possible. In addition to a piston movement, helix rotation is conceivable and cannot be excluded. 


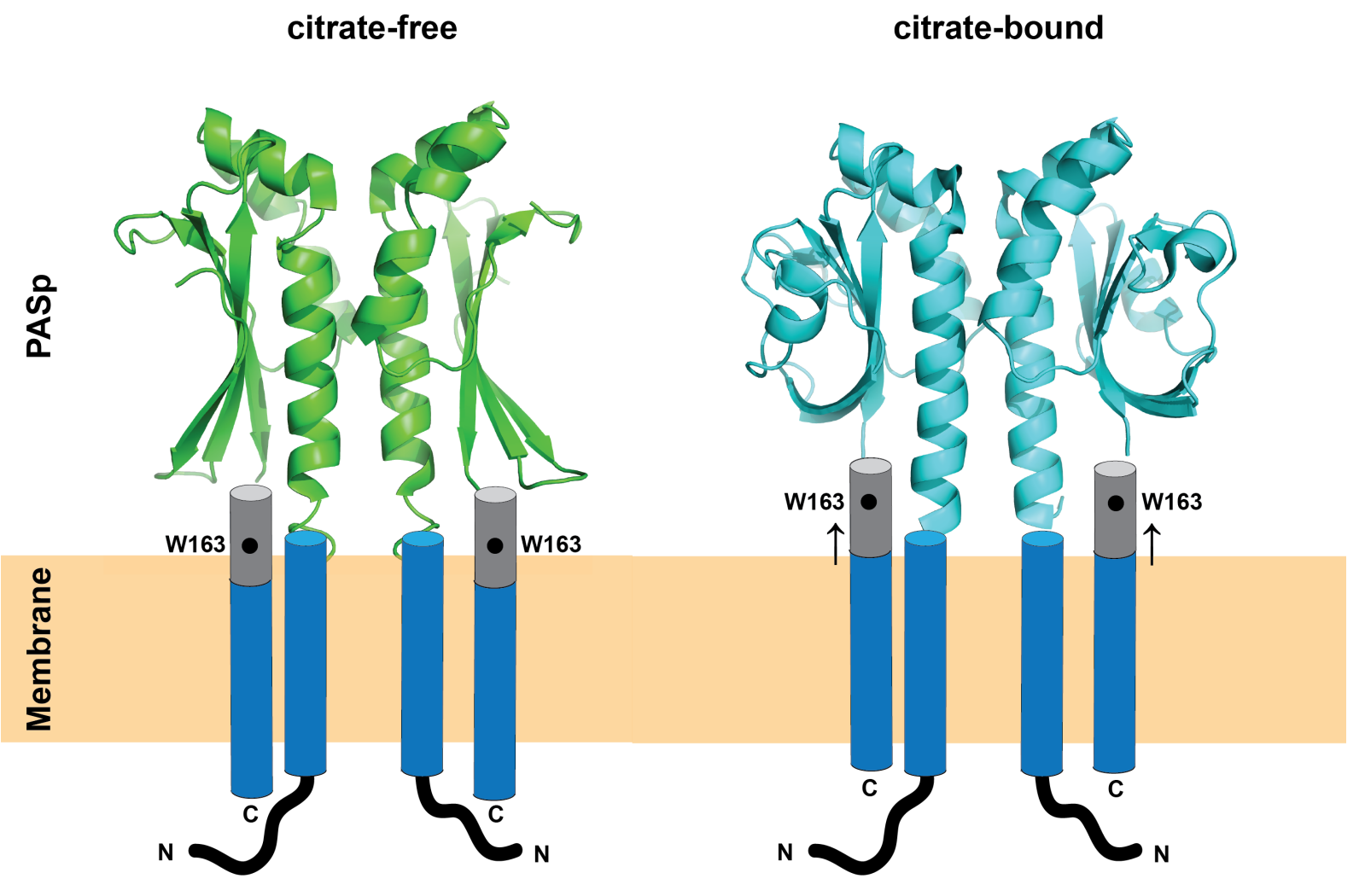

Figure 4.16: Transmembrane helix piston model. Transmembrane section predictions yield well defined regions for both the first and the second transmembrane helix (blue). A hypothetical helix displacement according to the piston model would bring tryptophane 163, predicted to be six residues away from the second transmembrane helix, closer to the membrane interface and could represent a citrate-free state. The citratebound state would in this case be reflected by the predicted position for the second transmembrane helix, with the pull originating in citrate-bound PASp dragging tryptophane 163 towards the periplasm. Klebsiella pneumoniae CitA PASp structures were utilised to display both signalling sates.

\subsection{Outlook}

In this work, the shortening of the $C$-terminal $\beta$-strand found in $K$. pneumoniae CitA PASp could be confirmed in context of the transmembrane helices. Unfortunately, the scarcity of NMR data on the transmembrane regions does not allow for a detailed analysis of helix reorientations during the signalling process. To overcome this blind spot, a variety of approaches could be used. First, the solid-state assignment is at the moment limited by signal/noise ratio for the transmembrane sections. The most complete assignment was obtained for wild-type CitApc in asolectin; CitApc R93A constructs in DMPC yielded 
less peaks that could be related to the transmembrane helices. Therefore, the membrane environment could be a limiting factor to spectral quality. Since it is not guaranteed that a lipid composition resembling native $G$. thermodenitrificans membranes will produce optimal spectra at the low temperatures needed for solid-state NMR experiments, a variety of different lipid environments for CitApc could be tested and optimised.

Second, assignment of the transmembrane helices could be facilitated by using selective labelling approaches to simplify spectra so that distance information could be obtained from 2D experiments. For example, alanine forward labelling (LeMaster and Cronan, 1982; LeMaster and Richards, 1982) could be used to obtain distance information based on known alanine residues in the transmembrane helices. Furthermore, leucine forward labelling could reveal and identify leucine pairs and triplets found in the transmembrane helices. Leucine labelling could also be utilised to obtain information on the leucine 154 - leucine 155 residue pair at the second transmembrane helix interface.

Third, the use of proton-detected solid-state NMR experiments might result in new assignment possibilities for the transmembrane helices. Finally, solid-state assignments of transmembrane helix residues could be employed to obtain distance restraints to correlate helix contacts with potential signalling models.

With scanning cysteine accessibility mutagenesis (SCAM) (Zhu and Casey, 2007), an alternative strategy could be employed to test the piston-movement hypothesis of transmembrane signalling. With SCAM, the solvent accessibility of residues around the membrane interfaces can be determined. Assuming a piston model, different residues of the second transmembrane helix would be expected to be buried in the membrane and could be identified.

Another point that needs to be clarified is the fate of PASc in the citrate-bound state. As the liquid-state NMR data on wild-type PASc best match the citrate-free CitApc R93A, it likely represents the OFF-state. To achieve a more favourable state of PASc for NMR studies, low-temperature experiments could be carried out to reduce domain dynamics. Alternatively, electron paramagnetic resonance (EPR) spectroscopy (Perozo et al. 1999) could be employed to determine distances between selected residues of PASc from different monomers in the citrate-free and citrate-bound state. If residues at the 
$C$-terminus of PASc are selected, the inter-domain distance could be probed for increased flexibility in the citrate-bound state. These experiments could also be carried out in fulllength CitA and thus in context of the DHp domain. The dimer assembly of PASc mutants differing from the wild-type crystal structure should be further investigated. Although in vivo data suggest wild-type like assemblies of PASc for all point mutants, the dimerisation propensity of isolated PASc mutants suggests that the anti-parallel orientation of monomers might also exist in solution. This could be tested with liquid-state NMR spectroscopy by identifying inter-monomer NOE contacts. Anti-parallel orientations would also easily be identifiable with EPR-spectroscopy.

In addition to optimising solid-state NMR sample conditions, the structure of CitA PASp R93A still needs to be solved. Although the model based on homologous domains is close to experimental structures for the citrate-bound state, the model of the citrate-free state does not represent the experimental results demonstrating an extended last $\beta$-strand in comparison with citrate-bound PASp. As NMR assignments are available, it should be possible to obtain structures based on NOEs and RDCs. These structures will very likely reproduce previous findings on $K$. pneumoniae CitA PASp and might even deepen the understanding on transitions in the PASp-transmembrane helix 2-interface. As citrate binding kinetics seem to be affected by structural context, a ligand titration of CitApc R93A might be employed to determine the dissociation constant for PASp R93A in its native state for comparison with the results obtained on the isolated domain.

Ideally, structural information should be gathered on full-length CitA reconstituted in liposomes, as the lack of context at the $C$-terminus of PASc might still affect functional states in CitApc studied so far. Solid-state NMR of full-length CitA will most likely be challenging because of the increased protein size leading to crowded spectra. However, due to the flexibility observed in crystal structures of the kinase core, CA-domains will likely not be observable, thus adding only the DHp domain to be assigned in addition to the PAS domains and transmembrane helices. To facilitate assignment, further liquidstate constructs of DHp or the kinase core could be produced for transfer of liquid-state assignments to solid-state spectra. In addition to the R93A mutant in PASp, different PASc mutants yielding anti-parallel crystal structures could also be studied in context 
of full-length CitA to identify potential different orientations. By characterising fulllength CitA R93A in both signalling states, it might be possible to formulate a final, consistent model for the function of each individual domain and their interactions in CitA transmembrane signalling. 


\section{Abstract}

Bacteria utilise two component systems (TCS) consisting of a homodimeric receptor histidine kinase $(\mathrm{HK})$ and a response regulator $(\mathrm{RR})$ as a prevalent mechanism of stimulus perception and signal transduction. TCSs are key players in the regulation of metabolism, motility and development, and in addition are crucial for virulence in a number of pathogenic species. The study of TCSs is therefore motivated by their importance as a fundamental and widely used signalling system.

In this study, the Geobacillus thermodenitrificans Citrate receptor A (CitA) is used as a model system for HKs. Free citrate is recognised by a periplasmic PAS (Per-ArntSim) domain (PASp) and the input signal is then relayed to a second, cytosolic PAS domain (PASc) before leading to auto-phosphorylation in the conserved kinase core. Even though the phosphate transfer mechanism of the kinase has been described in depth, signal transduction across the membrane remains poorly understood. The aim of this $\mathrm{PhD}$ project therefore is to elucidate the signalling mechanism of CitA by means of combining liquid- and solid-state-NMR spectroscopy with X-ray crystallography.

Our results show a shortening of the $C$-terminal $\beta$-strand of CitA PASp by one residue upon citrate binding, potentially exerting a pull on the second transmembrane helix. The restructuring of the $C$-terminus of PASp is in agreement with previously published results on an isolated citrate-binding PAS domain and a piston model for transmembrane helix motion. Additionally, liposome-embedded CitA constructs for the first time allow monitoring changes in the cytosol upon periplasmic citrate binding. In the citrate-bound state, PASc mobility increases, suggesting a constraining role of PASc keeping the kinase domain in an inactive conformation until CitA is triggered. 



\section{Bibliography}

C. Aaij and P. Borst. The gel electrophoresis of DNA. Biochim. Biophys. Acta, 1972. $10(269(2)) ; 192-200$.

A. E. Abo-Amer, J. Munn, K. Jackson, M. Aktas, P. Golby, D. J. Kelly and S. C. Andrews. DNA interaction and phosphotransfer of the C4-dicarboxylate-responsive DcuSDcuR two-component regulatory system from Escherichia coli. J. Bacteriol., 2003. 186(6); $1879-1889$

A. Adiguzel, H. Ozkan, O. Baris, K. Inan, M. Gulluce and F. Sahin. Identification and characterization of thermophilic bacteria isolated from hot springs in Turkey. J. Microbiol. Methods, 2009. 79; 321-328.

D. Albanesi, M. Martín, F. Trajtenberg, M. C. Mansilla, A. Haouz, P. M. Alzari, D. de Mendoza and A. Buschiazzo. Structural plasticity and catalysis regulation of a thermosensor histidine kinase. Proc. Natl. Acad. Sci. U. S. A., 2009. 106(38); 1618516190.

S. F. Altschul, W. Gish, W. Miller, E. W. Myers and D. J. Lipman. Basic local alignment search tool. J. Mol. Biol., 1990. 215; 403-410.

A. Ambroz. Denitrobacterium thermophilus spec. nov. Ein Beitrag zur Biologie der thermophilen Bakterien. Zbl. Bakt. Parasit., 1913. 2; 3-16.

P. Andrews. Estimation of the molecular weights of proteins by Sephadex gel-filtration. Biochem. J., 1964. 91; 222-233. 
O. Ashenberg, A. E. Keating and M. T. Laub. Helix bundle loops determine whether histidine kinases autophosphorylate in cis or in trans. J. Mol. Biol., 2013. 425; 11981209.

D. M. Ashton, G. D. Sweet, J. M. Somers and W. W. Kay. Citrate transport in salmonella typhimurium: Studies with 2-fluoro-L-erythrocitrate as a substrate. Can. J. Biochem., 1980. 58; 797-803.

D. Auguin, P. Barthe, C. Royer, M.-H. Stern, M. Noguchi, S. T. Arold and C. Roumestand. Structural basis for the co-activation of protein kinase B by T-cell Leukemia-1 (TCL1) family proto-oncoproteins. J. Biol. Chem., 2004. 279(34); 35890-35902.

A. Bax, M. Clore and A. M. Gronenborn. 1H-1H correlation via isotropic mixing of 13C magnetization, a new three-dimensional approach for assigning $1 \mathrm{H}$ and $13 \mathrm{C}$ spectra of 13C-enriched proteins. J. Magn. Reson., 1990. 88(2); 425-431.

K. A. Borkovich and M. I. Simon. Coupling of receptor function to phosphate-transfer reactions in bacterial chemotaxis. Methods Enzymol., 1991. 200; 205-214.

M. Bott, M. Meyer and P. Dimroth. Regulation of anaerobic citrate metabolism in Klebsiella pneumoniae. Mol. Microbiol., 1995. 18(3); 533-546.

P. D. Boyer, M. DeLuca, K. E. Ebner, D. E. Hultquist and J. B. Peter. Identification of phosphohistidine in digests from a probable intermediate of oxidative phosphorylation. $J$. Biol. Chem., 1962. 237; 3306.

D. Bray. Protein molecules as computational elements in living cells. Nature, 1995. $376(6538) ; 307-312$.

A. T. Brünger. Free R value: a novel statistical quantity for assessing the accuracy of crystal structures. Nature, 1992. 355; 472-475.

G. A. Cangelosi, R. G. Ankenbauer and E. W. Nester. Sugars induce the Agrobacterium virulence genes through a periplasmic binding protein and a transmembrane signal protein. Proc. Natl. Acad. Sci. U. S. A., 1990. 87; 6708-6712. 
P. Casino, L. Miguel-Romero and A. Marina. Visualizing autophosphorylation in histidine kinases. Nature Communications, 2014. 5; 1-12.

P. Casino, V. Rubio and A. Marina. Structural insight into partner specificity and phosphoryl transfer in two-component signal transduction. Cell, 2009. 139; 325-336.

P. Casino, V. Rubio and A. Marina. The mechanism of signal transduction by twocomponent systems. Curr. Opin. Struct. Biol., 2010. 20; 763-771.

M. Chamkha, S. Mnif and S. Sayadi. Isolation of a thermophilic and halophilic tyrosoldegrading Geobacillus from aTunisian high-temperature oilfield. FEMS Microbiol. Lett., 2008. 283; 23-29.

J. Cheung, C. A. Bingman, M. Reyngold, W. A. Hendrickson and C. D. Waldburger. Crystal structure of a functional dimer of the PhoQ sensor domain. J. Biol. Chem., 2008. 283(20); 13762-13770.

J. Cheung and W. A. Hendrickson. Crystal structures of C4-dicarboxylate ligand complexes with sensor domains of histidine kinases DcuS and DctB. J. Biol. Chem., 2008. $283(44) ; 30256-30265$.

V. Chevelkov, K. Giller, S. Becker and A. Lange. Efficient CO-CA transfer in highly deuterated proteins by band-selective homonuclear cross-polarization. J. Magn. Reson., 2013a. 230; 205-211.

V. Chevelkov, C. Shi, H. K. Fasshuber, S. Becker and A. Lange. Efficient band-selective homonuclear CO-CA cross-polarization in protonated proteins. J. Biomol. NMR, 2013b. $56 ; 303-311$.

U. S. Cho, M. W. Bader, M. F. Amaya, M. E. Daley, R. E. Klevit, S. I. Miller and W. Xu. Metal bridges between the PhoQ sensor domain and the membrane regulate transmembrane signaling. J. Mol. Biol., 2006. 356(5); 1193-1206.

A. C. Cihan, B. Ozcan, N. tekin and C. Cokmus. Geobacillus thermodenitrificans subsp. calidus, subsp. nov., a thermophilic and a-glucosidase producing bacterium isolated from Kizilcahamam, Turkey. J. Gen. Appl. Microbiol., 2011. 57; 83-92. 
P. J. Cock and D. E. Whitworth. Evolution of prokaryotic two-component system signaling pathways: gene fusions and fissions. Mol Biol. Evol., 2007. 24; 2355-2357.

N. Coudevylle, P. Montaville, A. Leonov, M. Zweckstetter and S. Becker. Structural determinants for $\mathrm{Ca} 2+$ and phosphatidylinositol 4,5-bisphosphate binding by the $\mathrm{C} 2 \mathrm{~A}$ domain of Rabphilin-3A. J. Biol. Chem., 2008. 283(51); 35918-35928.

T. A. Cross and S. J. Opella. Solid-state NMR structural studies of peptides and proteins in membranes. Curr. Opin. Struct. Biol., 1994. 4; 574-581.

M. Cserzo, E. Wallin, I. Simon, G. von Heijne and A. Elofsson. Prediction of transmembrane alpha-helices in procariotic membrane proteins: the Dense Alignment Surface method. Protein Eng., 1997. 10(6); 673-676.

F. Delaglio, S. Grzesiek, G. W. Vuister, G. Zhu, J. Pfeifer and A. Bax. NMRPipe: a multidimensional spectral processing system based on UNIX pipes. J. Biomol. NMR, 1995. 6; 277-293.

J.-N. Dumez, M. E. Halse, M. C. Butler and L. Emsley. A first-principles description of proton-driven spin diffusion. Phys. Chem. Chem. Phys., 2011. 14; 86-89.

R. Dutta and M. Inouye. GHKL, an emergent ATPase/kinase superfamily. Trends Biochem. Sci., 2001. 25; 24-29.

M. Etzkorn, H. Kneuper, P. Dünnwald, V. Vijayan, J. Krämer, C. Griesinger, S. Becker, G. Unden and M. Baldus. Plasticity of the PAS domain and a potential role for signal transduction in the histidine kinase DcuS. Nat. Struct. Mol. Biol., 2008. 15(10); 10311039.

L. Feng, W. Wang, J. Cheng, Y. Ren, G. Zhao, C. Gao, Y. Tang, X. Liu, W. Han, X. Peng, R. Liu and L. Wang. Genome and proteome of long-chain alkane degrading Geobacillus thermodenitrificans NG80-2 isolated from a deep-surface oil reservoir. Proc. Natl. Acad. Sci. U. S. A., 2007. 104(13); 5602-5607. 
H. U. Ferris, S. Dunin-Horkawicz, N. Hornig, M. Hulko, J. Martin, J. E. Schultz, K. Zeth, A. N. Lupas and M. Coles. Mechanism of regulation of receptor histidine kinases. Structure, 2012. 20; 56-66.

D. P. Frueh. Practical aspects of NMR signal assignment in larger and challenging proteins. Proc. Nucl. Magn. Reson. Spectrosc., 2014. 78; 47-75.

C. A. Fyfe, K. C. Wong-Moon, Y. Huang and H. Grondey. INEPT experiments in solidstate NMR. J. Am. Chem. Soc., 1995. 117(41); 10397-10398.

R. Gao and A. M. Stock. Biological insights from structures of two-component proteins. Annu. Rev. Microbiol., 2009. 63; 133-154.

T. Gerharz, S. Reinelt, S. Kaspar, L. Scapozza and M. Bott. Identification of basic amino acid residues important for citrate binding by the periplasmic receptor domain of the sensor kinase CitA. Biochemistry, 2003. 42; 5917-5924.

P. Golby, S. Davies, D. J. Kelly, J. R. Guest and S. C. Andrews. Identification and characterization of a two-component sensor-kinase and response-regulator system (DcuSDcuR) controlling gene expression in response to C4-dicarboxylates in Escherichia coli. J. Bacteriol., 1999. 181(4); 1238-1248.

W. Gong, B. Hao and M. K. Chan. New mechanistic insights from structural studies of the oxygen-sensing domain of Bradyrhizobium japonicum FixL. Biochemistry, 2000. 39(14); 3955-3962.

M. Goujon, H. McWilliam, W. Li, F. Valentin, S. Squizzato, J. Paern and R. Lopez. A new informatics analysis tools framework at EMBL-EBI (2010). Nucleic Acids Res., 2010. 38(2); 695-699.

T. W. Grebe and J. B. Stock. The histidine protein kinase superfamily. Adv. Microb. Physiol., 1999. 41; 139-227.

B. Han, Y. Liu, S. Ginzinger and D. Wishart. SHIFTX2: significantly improved protein chemical shift prediction. J. Biomol. NMR, 2011. 50(1); 43-57. 
P. I. Hanson and H. Schulman. Neuronal Ca2+/ Calmodulin-dependent protein kinases. Annu. Rev. Biochem., 1992. 61; 559-601.

W. A. Hendrickson, J. R. Horton and D. M. LeMaster. Selenomethionyl proteins produced for analysis by multiwavelength anomalous diffraction (MAD): a vehicle for direct determination of three-dimensional structure. EMBO J., 1990. 9(5); 1665-1672.

J. F. Hess, R. B. Bourret and M. I. Simon. Histidine phosphorylation and phosphoryl group transfer in bacterial chemotaxis. Nature, 1988. 336; 139-143.

K. Hofmann and W. Stoffel. TMbase - a database of membrane spanning proteins segments. Biol. Chem., 1993. 374; 166.

W. Hsing, F. D. Russo, K. K. Bernd and T. J. Silhavy. Mutations that alter the kinase and phosphatase activities of the two-component sensor EnvZ. J. Bacteriol., 1998. 180(17); $4538-4546$.

M. Hulko, F. Berndt, M. Gruber, J. U. Linder, V. Truffault, A. Schultz, J. Martin, J. E. Schultz, A. N. Lupas and M. Coles. The HAMP domain structure implies helix rotation in transmembrane signaling. Cell, 2006. 126; 929-940.

M. Ikura, L. E. Kay and A. Bax. A novel approach for sequential assignment of $1 \mathrm{H}$, $13 \mathrm{C}$ and $15 \mathrm{~N}$ spectra of larger proteins: Heteronuclear triple-resonance three-dimensional NMR spectroscopy. Biochemistry, 1990. 29; 4659-4667.

I. G. Janausch, I. Garcia-Moreno and G. Unden. Function of DcuS from Escherichia coli as a fumarate-stimulated histidine protein kinase in vitro. J. Biol. Chem., 2002. 277(42); 39809-39814.

S. Kaspar and M. Bott. The sensor kinase CitA (DpiB) of Escherichia coli functions as a high-affinity citrate receptor. Arch. Microbiol., 2002. 177; 313-321.

S. Kaspar, R. Perozzo, S. Reinelt, M. Meyer, K. Pfister, L. Scapozza and M. Bott. The periplasmic domain of the histidine autokinase CitA functions as a highly specifc citrate receptor. Mol. Microbiol., 1999. 33(4); 858-872. 
L. A. Kelley and M. J. E. Sternberg. Protein structure prediction on the web: A case study using the Phyre server. Nat. Methods, 2009. 4; 363-371.

J. Key, M. Hefti, E. B. Purcell and K. Moffat. Structure of the redox sensor domain of Azotobacter vinelandii NifL at atomic resolution: signaling, dimerization, and mechanism. Biochemistry, 2007. 46(12); 3614-3623.

H. Kneuper, I. G. Janausch, V. Vijayan, M. Zweckstetter, V. Bock, C. Griesinger and G. Unden. The nature of the stimulus and of the fumarate binding site of the fumarate sensor DcuS of Escherichia coli. J. Biol. Chem., 2005. 280(21); 20596-20603.

K. K. Koretke, A. N. Lupas, P. V. Warren, M. Rosenberg and J. R. Brown. Evolution of two-component signal transduction. Mol. Biol. Evol., 2000. 17; 1956-1970.

T. Krell, J. Lacal, A. Busch, H. Silva-Jiménez, M.-E. Guazzaroni and J. L. Ramos. Bacterial sensor kinases: diversity in the recognition of environmental signals. Annu. Rev. Microbiol., 2010. 64; 539-559.

J. Lacal, A. Busch, M. E. Guazzaroni, T. Krell and J. L. Ramos. The TodS-TodT two-component regulatory system recognizes a wide range of effectors and works with DNA-bending proteins. Proc. Natl. Acad. Sci. U. S. A., 2006. 103(21); 8191-8196.

D. M. LeMaster and J. E. Cronan. Biosynthetic production of 13C-labeled amino acids with site-specific enrichment. J. Biol. Chem., 1982. 257(3); 1224-1230.

D. M. LeMaster and F. M. Richards. Preparative-scale isolation of isotopically labeled amino acids. Anal. Biochem., 1982. 122(2); 238-247.

R. Malpica, B. Franco, C. Rodriguez, O. Kwon and D. Georgellis. Identification of a quinone-sensitive redox switch in the ArcB sensor kinase. Proc. Natl. Acad. Sci. U. S. A., 2004. 101(36); 13318-13323.

A. Marina, C. D. Waldburger and W. A. Hendrickson. Structure of the entire cytoplasmic portion of a sensor histidine-kinase protein. EMBO J., 2005. 24; 4247-4259. 
E. E. Matthews, M. Zoonens and D. M. Engelman. Dynamic helix interactions in transmembrane signaling. Cell, 2006. 127; 447-450.

T. L. Maugeri, C. Gugliandolo, D. Caccamo and E. Stackebrandt. Three novel halotolerant and thermophilic Geobacillus strains from shallow marine vents. System. Appl. Microbiol., 2002. 25; 450-455.

L. P. McIntosh and F. W. Dahlquist. Biosynthetic incorporation of $15 \mathrm{~N}$ and $13 \mathrm{C}$ for assignment and interpretation of nuclear magnetic resonance spectra of proteins. Q. Rev. Biophys., 1990. 23(1); 1-38.

W. J. Metzler, K. L. Constantine, M. S. Friedrichs, A. J. Bell, E. G. Ernst, T. B. Lavoie and L. Mueller. Characterization of the three-dimensional solution structure of human profilin: $1 \mathrm{H}, 13 \mathrm{C}$, and 15N NMR assignments and global folding pattern. Biochemistry, 1993. 32(50); 13818-13829.

C. Monzel, P. Degreif-Dünnwald, C. Gröpper, C. Griesinger and G. Unden. The cytoplasmic PASc domain of the sensor kinase DcuS of Escherichia coli: role in signal transduction, dimer formation, and DctA interaction. Microbiology, 2013. 2(6); 912-927.

J. O. Moore and W. A. Hendrickson. An asymmetry-to-symmetry switch in signal transmission by the histidine kinase receptor for TMAO. Structure, 2012. 20; 729-741.

B. Morgenstern. DIALIGN: Multiple DNA and protein sequence alignment at BiBiServ. Nucleic Acids Res., 2004. 32(2); 33-36.

G. Mosqueda, M. I. Ramos-González and J. L. Ramos. Toluene metabolism by the solventtolerant Pseudomonas putida DOT-T1 strain, and its role in solvent impermeabilization. Gene, 1999. 232(1); 69-76.

K. Nath and B. A. Azzolina. Cleavage properties of site-specific restriction endonucleases. Gene Amplif. Anal., 1981. 1; 113-130.

M. B. Neiditch, M. J. Federle, A. J. Pompeani, R. C. Kelly, D. L. Swem, P. D. Jeffrey, B. L. Bassler and F. M. Hughson. Ligand-induced asymmetry in histidine sensor kinase complex regulates quorum sensing. Cell, 2006. 126(6); 1095-1108. 
A. J. Ninfa, E. G. Ninfa, A. N. Lupas, A. Stock, B. Magasanik and J. Stock. Crosstalk between bacterial chemotaxis signal transduction proteins and regulators of transcription of the Ntr regulon: evidence that nitrogen assimilation and chemotaxis are controlled by a common phosphotransfer mechanism. Proc. Natl. Acad. Sci. U. S. A., 1988. 85; 5492-5496.

T. Ogino, M. Matsubara, N. Kato, Y. Nakamura and T. Mizuno. An Escherichia coli protein that exhibits phosphohistidine phosphatase activity towards the HPt domain of the ArcB sensor involved in the multistep His-Asp phosphorelay. Mol. Microbiol., 1998. $27 ; 573-585$.

K. M. Ottemann, W. Xiao, Y. K. Shin and D. E. Koshland. A piston model for transmembrane signaling of the Aspartate Receptor. Science, 1999. 285; 1751-1754.

L. Pappalardo, I. G. Janausch, V. Vijayan, E. Zientz, J. Junker, W. Peti, M. Zweckstetter, G. Unden and C. Griesinger. The NMR structure of the sensory domain of the membranous two-component fumarate sensor (histidine protein kinase) DcuS of Escherichia coli. J. Biol. Chem., 2003. 278(40); 39185-39188.

M. Perego. Kinase-phosphatase competition regulates Bacillus subtilis development. Trends Microbiol., 1998. 6; 366-370.

M. Perego and J. A. Hoch. Protein aspartate phosphatases control the output of twocomponent signal transduction systems. Trends Genet., 1996. 12(3); 97-101.

E. Perozo, D. M. Cortez and L. G. Cuello. Structural rearrangements underlying K+channel activation gating. Science, 1999. 285(5424); 73-78.

M. M. Pierce, C. S. Raman and B. T. Nall. Isothermal titration calorimetry of proteinprotein interactions. Methods, 1999. 19(2); 213-221.

A. I. Podgornaia, P. Casino, A. Marina and M. T. Laub. Structural basis of a rationally rewired protein-protein interface critical to bacterial signaling. Structure, 2013. 21; 16361647. 
A. Razvi and M. J. Scholtz. Lessons in stability from thermophilic proteins. Protein Sci, 2006. 15(7); 1569-1587.

S. Reinelt, E. Hofmann, T. Gerharz, M. Bott and D. R. Madden. The structure of the periplasmic ligand-binding domain of the sensor kinase CitA reveals the first extracellular PAS domain. J. Biol. Chem., 2003. 278(40); 39189-39196.

M. Ryan T, B. P. Tripet, J. R. Pearlstone, L. B. Smillie and B. D. Sykes. Defining the region of Troponin-I that binds to Troponin-C. Biochemistry, 1999. 38; 5478-5489.

R. K. Saiki, D. H. Gelfand, S. Stoffel, S. J. Scharf, R. Higuchi, G. T. Horn, K. B. Mullis and H. A. Erlich. Primer-directed enzymatic amplification of DNA with a thermostable DNA polymerase. Science, 1988. 239(4839); 487-491.

F. Sanger and A. R. Coulson. A rapid method for determining sequences in DNA by primed synthesis with DNA polymerase. J. Mol. Biol., 1975. 94; 441-448.

M. Sevvana, V. Vijayan, M. Zweckstetter, S. Reinelt, D. R. Madden, R. Herbst-Irmer, G. M. Sheldrick, M. Bott, C. Griesinger and S. Becker. A ligand-induced switch in the periplasmic domain of sensor histidine kinase CitA. J. Mol. Biol., 2008. 377; 512-523.

C. Shi, H. K. Fasshuber, V. Chevelkov, S. K. Vasa, S. Becker and A. Lange. BSH-CP based 3D solid-state NMR experiments for protein resonance assignment. J. Biomol. NMR, 2014. 59(1); 15-22.

E. L. L. Sonnhammer, G. von Heijne and A. Krogh. A hidden Markov model for predicting transmembrane helices in protein sequences. Proc. of Sixth Int. Conf. on Intelligent Systems for Molecular Biology, 1998. pp. 175-182.

O. Soubias, V. Réat, O. Saurel and A. Milon. High resolution 2D 1H-13C correlation of cholesterol in model membrane. J. Magn. Reson., 2002. 158(1); 143-148.

P. A. Steinmetz, S. Wörner and G. Unden. Differentiation of DctA and DcuS function in the DctA/DcuS sensor complex of Escherichia coli: function of DctA as an activity switch and of DcuS as the C4-dicarboxylate sensor. Mol. Microbiol., 2014. 94(1); 218-229. 
T. J. Stevens, R. H. Fogh, W. Boucher, V. A. Higman, F. Eisenmenger, B. Bardiaux, B. J. van Rossum, H. Oschkinat and E. D. Laue. A software framework for analysing solid-state MAS NMR data. J. Biomol. NMR, 2011. 51(4); 437-447.

A. Sugino, H. M. Goodman, H. L. Heyneker, J. Shine, H. W. Boyer and N. R. Cozzarelli. Interaction of bacteriophage T4 RNA and DNA ligases in joining of duplex DNA at base-paired ends. J. Biol. Chem., 1977. 252; 3987-3994.

D. Suter and R. R. Ernst. Spin diffusion in resolved solid-state NMR spectra. Phys. Rev. $B$, 1985. 32(9); 5608-5627.

H. Szurmant, R. A. White and J. A. Hoch. Sensor complexes regulating two-component signal transduction. Curr. Opin. Microbiol., 2007. 17; 706-715.

B. L. Taylor and I. B. Zhulin. PAS domains: Internal sensors of oxygen, redox potential and light. Microbiol. Mol. Biol. Rev., 1999. 63(2); 479-506.

P. Thomason and R. Kay. Eukaryotic signal transduction via histidine-aspartate phosphorelay. J. Cell Sci., 2000. 113(3); 3141-3150.

G. E. Tusnády and I. Simon. The HMMTOP transmembrane topology prediction server. Bioinformatics, 2001. 17; 849-850.

W. F. Vranken, W. Boucher, T. J. Stevens, R. H. Fogh, A. Pajon, M. Llinas, E. L. Ulrich, J. L. Markley, J. Ionides and E. D. Laue. The CCPN data model for NMR spectroscopy: development of a software pipeline. Proteins, 2005. 59(4); 687-696.

J. Vreede, M. A. van der Horst, K. J. Hellingwerf, W. Crielaard and D. M. van Aalten. PAS domains. Common structure and common flexibility. J. Biol. Chem., 2003. 278(20); 18434-18439.

A. Vu, D. J. Hamel, H. Zhou and F. W. Dahlquist. The structure and dynamic properties of the complete histidine phosphotransfer domain of the chemotaxis specific histidine autokinase CheA from Thermotoga maritima. J. Biomol. NMR, 2011. 51; 49-55. 
C. Wang, J. Sang, J. Wang, M. Su, J. S. Downey, Q. Wu, S. Wang, Y. Cai, X. Xu, J. Wu, D. B. Senadheera, D. G. Cvitkovitch, L. Chen, S. D. Goodman and A. Han. Mechanistic insights revealed by the crystal structure of a histidine kinase with signal transducer and sensor domains. PLoS Biol., 2013. 11(2); 1-14.

Y. Wang and O. Jardetzky. Probability-based protein secondary structure identification using combined NMR chemical-shift data. Protein Sci., 2002. 11(4); 852-861.

F. H. Westheimer. Why nature chose phosphates. Science, 1987. 235(4793); 1173-1178.

D. White, R. J. Sharp and F. G. Priest. A polyphasic taxonomic study of thermophilic bacilli from a wide geographical area. Antonie van Leeuwenhoek, 1993. 64; 357-386.

B. Winnen, R. N. Hvorup and M. H. S. Jr. The Tripartite Tricarboxylate Transporter (TTT) family. Res. Microbiol., 2003. 154; 457-465.

P. M. Wolanin, P. a. Thomason and J. B. Stock. Histidine protein kinases: key signal transducers outside the animal kingdom. Genome Biol., 2002. 3(10); 3013.1-3013.8.

S. Yamada, H. Sugimoto, M. Kobayashi, A. Ohno, H. Nakamura and Y. Shiro. Structure of PAS-linked histidine kinase and the response regulator complex. Structure, 2009. 17(10); $1333-1344$.

N. Yao, Y. Ren and W. Wang. Genome Sequence of a Thermophilic Bacillus, Geobacillus thermodenitrificans DSM465. Genome Announc., 2013. 1(6); 1-2.

J. Zapf, U. Sen, Madhusudan, J. A. Hoch and K. I. Varughese. A transient interaction between two phosphorelay proteins trapped in a crystal lattice reveals the mechanism of molecular recognition and phosphotransfer in signal transduction. Structure, 2000. 8; $851-862$.

E. M. Zdobnov and R. Apweiler. InterProScan - an Integration Platform for the SignatureRecognition Methods in InterPro. Bioinformatics, 2001. 17(9); 847-848.

Y. Zhang. I-TASSER Server for Protein 3D Structure Prediction. Bioinformatics, 2008. $9(40) ; 1-8$. 
H.-X. Zhou and T. A. Cross. Modeling the membrane environment has implications for membrane protein structure and function: Influenza A M2 protein. Protein Sci., 2013. 22; 381-394.

Q. Zhu and J. R. Casey. Topology of transmembrane proteins by scanning cysteine accessibility mutagenesis methodology. Methods, 2007. 41(4); 439-450.

E. Zientz, J. Bongaerts and G. Unden. Fumarate Regulation of Gene Expression in Escherichia coli by the DcuSR (dcuSR Genes) Two-Component Regulatory System. J. Bacteriol., 1998. 180(20); 5421-5425. 



\section{Acknowledgements}

First, I would like to thank Prof. Christian Griesinger for giving me the opportunity to conduct my doctoral thesis in his department. I am very grateful for the excellent supervision from Prof. Griesinger, Prof. Adam Lange and Dr. Stefan Becker over the course of my thesis project. I would also like to thank Prof. Gottfried Unden from the University of Mainz and his co-workers for the fruitful collaboration and helpful discussions. I am indebted to all people involved in the project for guidance, constructive criticism, support and advice throughout the last four years.

I would like to express my gratitude to the members of my thesis committee, Prof. Claudia Steinem and Prof. Blanche Schwappach for the productive meetings and invaluable input regarding difficulties faced during experiments. I thank Prof. Patrick Cramer, Prof. Michael Meinecke and Dr. Martin Kollmar for their participation in my oral examination.

Furthermore, I would like to express my appreciation to Karin Giller for providing excellent protein samples for solid-state NMR spectroscopy. I also thank Kerstin Overkamp and Gerhard Wolf for mass spectrometry of protein samples. A special thanks to the current and previous members of the biochemistry lab staff for the superb working atmosphere and fun times in and around the lab.

I would like to acknowledge Dr. Luigi Russo, Dr. Venita Daebel and Dr. Chaowei Shi for sharing their knowledge on various aspects of NMR spectroscopy with me. I am also indebted to Dr. Dirk Bockelmann for support with the computers and software. I thank the whole NMR II staff for the outstanding atmosphere and would especially like to thank Sebastian Täubert, Dr. Florian Siepel, Dr. Manuel Schmidt, Christian Schmidt, Dr. Ann-Christin Pöppler, Eibe Dücker, Dr. Philip Lottmann and Dr. Saskia Villinger for their help and insightful discussions. 
I am very grateful for the huge amounts of measurement time taken from Dr. Rasmus Linser and for sharing his ideas for further solid-state NMR experiments with me. I appreciate the proof-reading of Dr. Peggy Findeisen and Christian Schmidt, who impressed me with the most thorough proof-reading possible.

Thanks for being the greatest bands in the world to Selling Illusions, Solid Salad and Castle Green T, hope you will all continue to play one way or another. I would also like to thank all my friends for all the great times we had over the years, whether in Göttingen, Bielefeld, Löhne or St. Andrews.

I express my deepest thanks to my family and most of all my parents for being there for me all my life and their ceaseless trust and support, without which I would never have come so far. Finally, I thank Tina Huskobla with all my heart for her love, for finding me and being the one for me. 


\section{List of abbreviations}

APS

ArcB

Arnt

Asp

ATP

BSH-CP

$\mathrm{CA}$

CheA

CitA/CitB

CitApc

DctA

DcuB/DcuR/DcuS

DesK

DHp

DMPC

DNA

dNTP

DTT

EDTA

EnvZ

EPR

GHL ATPase

GyrB
Ammonium persulfate

Anoxic redox control protein B

Aryl hydrocarbon receptor nuclear translocator

Aspartate

Adenosine triphosphate

Band-selective homonuclear cross-polarisation

Catalytic and ATP-binding domain

Chemotaxis kinase $\mathrm{A}$

Citrate receptor protein $\mathrm{A} / \mathrm{B}$

CitA construct containing PASp and PASc

Dicarboxylate transporter protein A

Dicarboxylate uptake protein $\mathrm{B} / \mathrm{R} / \mathrm{S}$

Desaturase regulating kinase

Dimerisation and histidine phosphorylation domain

1,2-Dimyristoyl-sn-glycero-3-phosphocholine

Desoxyribonucleic acid

Desoxyribonucleotide triphosphate

Dithiothreitol

Ethylenediaminetetraacetate

Envelope stress response protein Z

Electron paramagnetic resonance

GyrB, Hsp90, MutL ATPase

Gyrase B 
H-box

HAMP

His

HK

$\mathrm{HPt}$

Hsp90

HSQC

INEPT

IPTG

LB

LDAO

LuxQ

MAS

MutL

NMR

NOE

NOESY

NTA

NtrB

OD

PAGE

PAS

PASc

PASp

PCR

PDSD

PER

PhoQ

PMSF
Homology box containing phosphorylated His

Histidine kinase, adenylate cyclase, methyl accepting protein and phosphatase domain

Histidine

Histidine kinase

Histidine phosphotransfer domain

Heat shock protein 90

Heteronuclear single-quantum coherence

Insensitive nuclei enhanced by polarisation transfer isopropyl $\beta$-D-1-thiogalactopyranoside

Luria-Bertani broth

Lauryldimethylamine N-oxide

Bioluminescence protein Q

Magic-angle spinning

Mutationally inactivated protein L

Nuclear magnetic resonance

Nuclear overhauser effect

NOE-spectroscopy

Nitrilotriacetic acid

Nitrogen regulatory protein B

Optical density

polyacrylamide gel electrophoresis

Per-Arnt-Sim domain

cytosolic PAS domain

periplasmic PAS domain

Polymerase chain reaction

Proton driven spin diffusion

Period clock protein

Nonspecific acid phosphatase protein Q

Phenylmethanesulfonylfluoride 
RDC Residual dipolar couplings

REC Receiver domain

RNA Ribonucleic acid

RR Response regulator

SCAM Scanning cysteine accessibility mutagenesis

SEC Size exclusion chromatography

SeMet Selenomethionine

Ser Serine

SIM Single-minded protein

SDS Sodium dodecylsulfate

TAE Tris-Acetic acid-EDTA buffer

TCS Two-component system

TctA/TctB/TctC Tricarboxylate transporter A/B/C

TEMED Tetramethylethylenediamine

TEV Tobacco etch virus

Thr Threonine

TOCSY Total correlation spectroscopy

TodS Toluene dioxygenase pathway protein $\mathrm{S}$

Tyr Tyrosine

UV ultraviolet

VicK Virulence competence Kinase

YT Yeast tryptone medium 



\section{Appendix}

\subsection{Expression vectors}

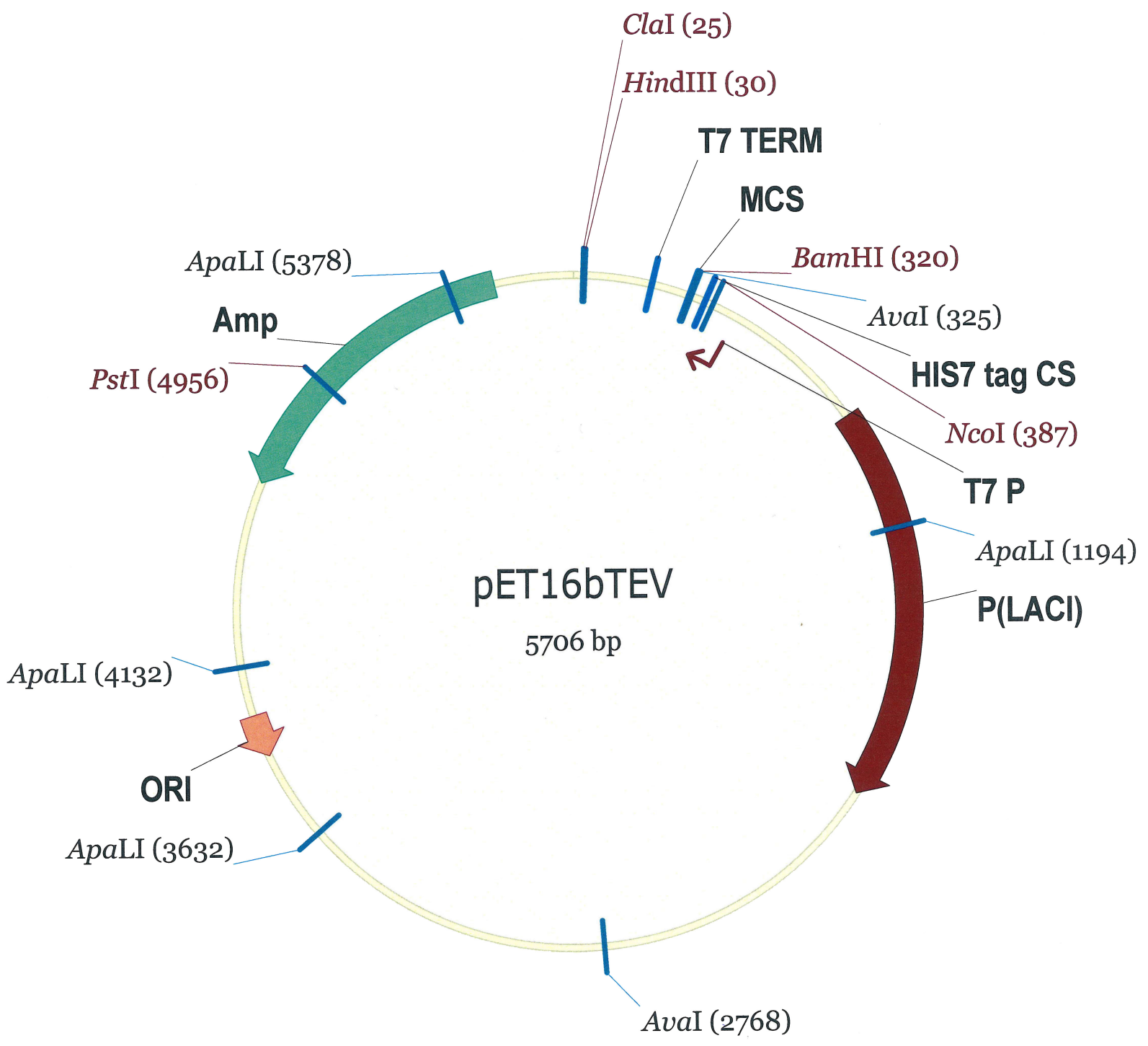

Figure 8.1: Plasmid map of pET16bTEV. 


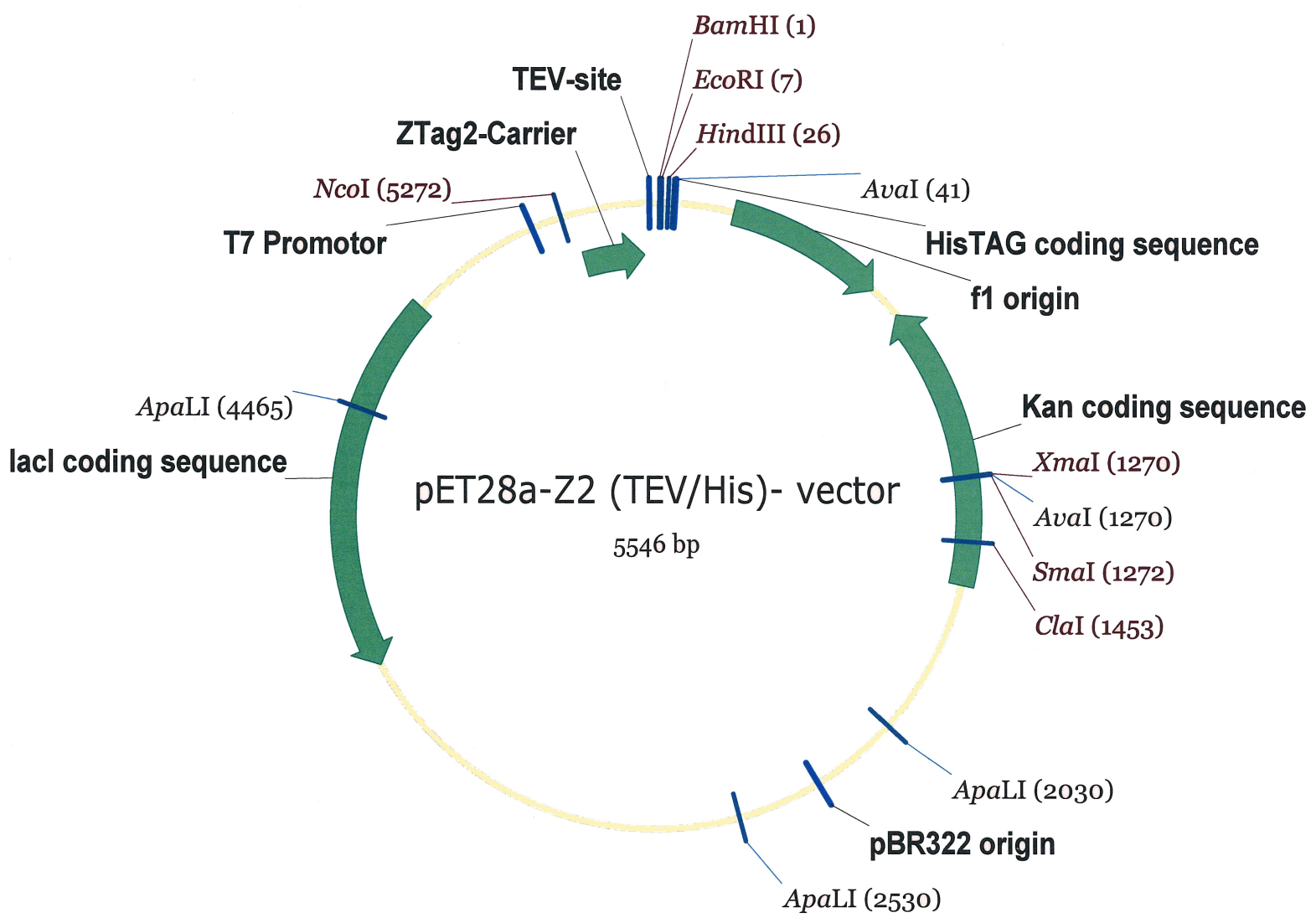

Figure 8.2: Plasmid map of pET28a-Z2. 


\subsection{PASc crystal data collection, phasing and refinement statistics}

Table 8.1: Data collection and phasing for CitA PASc

\begin{tabular}{|c|c|c|c|}
\hline & Peak & Inflection & $\begin{array}{l}\text { High-energy re- } \\
\text { mote }\end{array}$ \\
\hline & \multicolumn{3}{|c|}{ Data collection statistics } \\
\hline Wavelength $[\AA]$ & 0.97929 & 0.97976 & 0.97163 \\
\hline X-ray source & \multirow{3}{*}{\multicolumn{3}{|c|}{$\begin{array}{c}\text { X10SA, Swiss light source } \\
\text { Pilatus } 6 \mathrm{M} \\
\mathrm{P} 2_{1} 2_{1} 2_{1}\end{array}$}} \\
\hline Detector & & & \\
\hline Space group & & & \\
\hline \multirow[t]{4}{*}{ Unit cell parameters ${ }^{\mathrm{a}}$} & $\mathrm{a}=34.45 \AA$ & $\mathrm{a}=34.52 \AA$ & $\mathrm{a}=34.51 \AA$ \\
\hline & $\mathrm{b}=74.03 \AA$ & $\mathrm{b}=74.28 \AA$ & $\mathrm{b}=74.20$ \\
\hline & $c=75.08 \AA$ & $c=75.35 \AA$ & $c=75.26 \AA$ \\
\hline & $\alpha=\beta=\gamma=90^{\circ}$ & $\alpha=\beta=\gamma=90^{\circ}$ & $\alpha=\beta=\gamma=90^{\circ}$ \\
\hline Resolution $[\AA]$ & $1.78(1.88-1.78)$ & $1.99(2.09-1.99)$ & $1.97(2.07-1.97)$ \\
\hline $\begin{array}{l}\text { No. of reflections } \\
\text { (unique) }\end{array}$ & 18,999 & 26,252 & 14,181 \\
\hline Completeness [\%] & $99.3(96.5)$ & $99.5(96.7)$ & $99.6(97.6)$ \\
\hline Mean $\mathrm{I} /[\sigma \mathrm{I}]$ & $10.78(2.4)$ & $12.97(2.65)$ & $13.18(3.82)$ \\
\hline \multirow[t]{2}{*}{$\mathrm{R}_{\text {Int }}[\%]^{\mathrm{b}}$} & $8.97(50.64)$ & $11.0(51.46)$ & $7.86(38.04)$ \\
\hline & \multicolumn{3}{|c|}{ Substructure solution (SHELX) } \\
\hline $\mathrm{CC}_{\text {HREM/PEAK }}$ & \multirow{5}{*}{\multicolumn{3}{|c|}{$\begin{array}{c}31.8 \% \text { at } 2.4-2.2 \AA \\
32.3 \% \text { at } 3.0-2.6 \AA \\
35.9 \% \text { at } 3.5-3.0 \AA \\
4 \\
42.2 / 37.6\end{array}$}} \\
\hline $\mathrm{CC}_{\text {HREM/INFL }}$ & & & \\
\hline $\mathrm{CC}_{\mathrm{PEAK} / \mathrm{INFL}}$ & & & \\
\hline No. of sites & & & \\
\hline $\mathrm{CC}_{\mathrm{ALL} / \mathrm{WEAK}}$ & & & \\
\hline
\end{tabular}

${ }^{\text {a }}$ Values in parentheses are outer-resolution shells

${ }^{\mathrm{b}} R_{\text {int }}=\mid F_{0}^{2}-F_{0}^{2}($ mean $) \mid / \Sigma\left[F_{0}^{2}\right]$ 
Table 8.2: Refinement statistics for CitA PASc

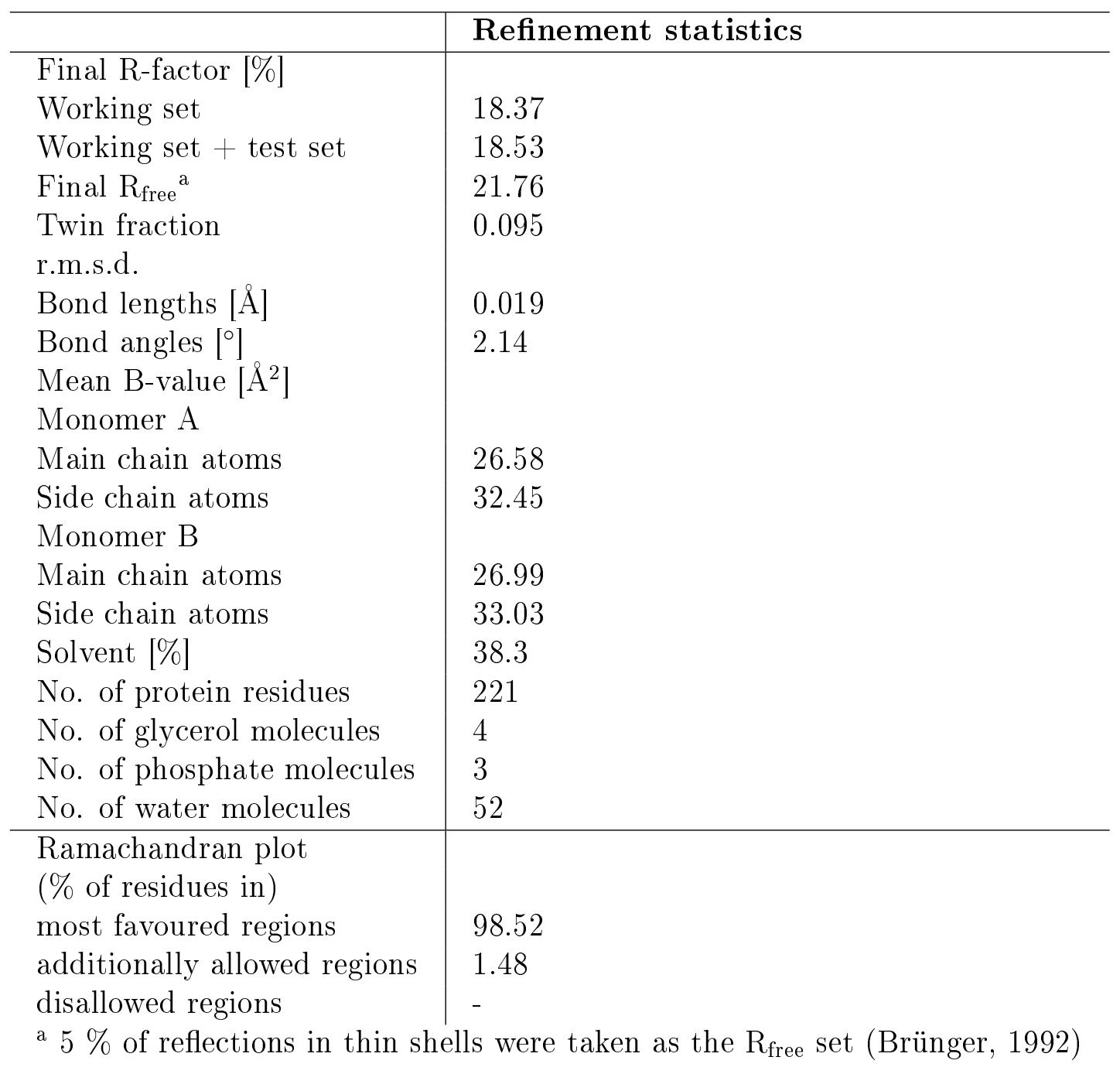

\subsection{NMR assignments}




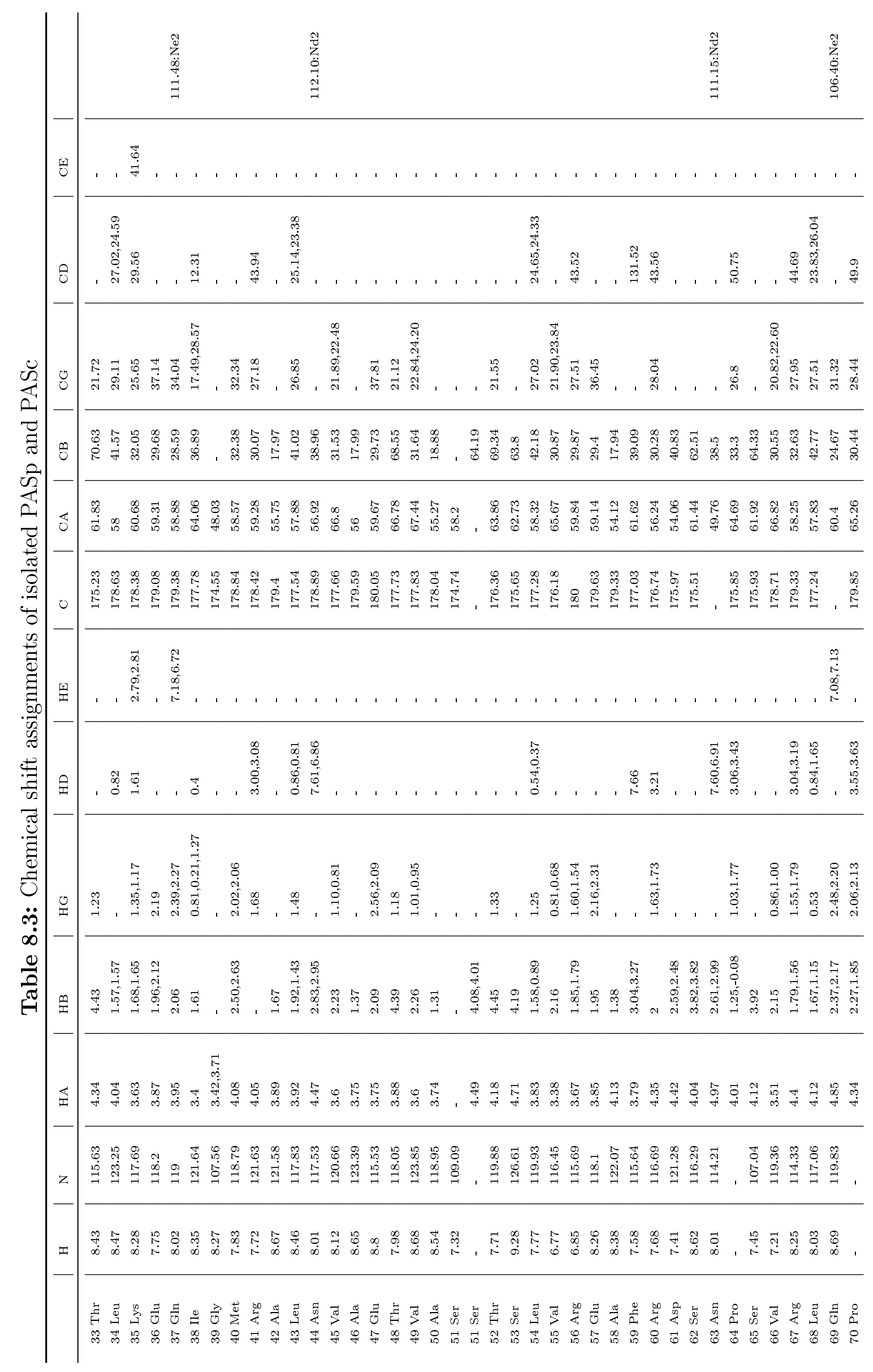




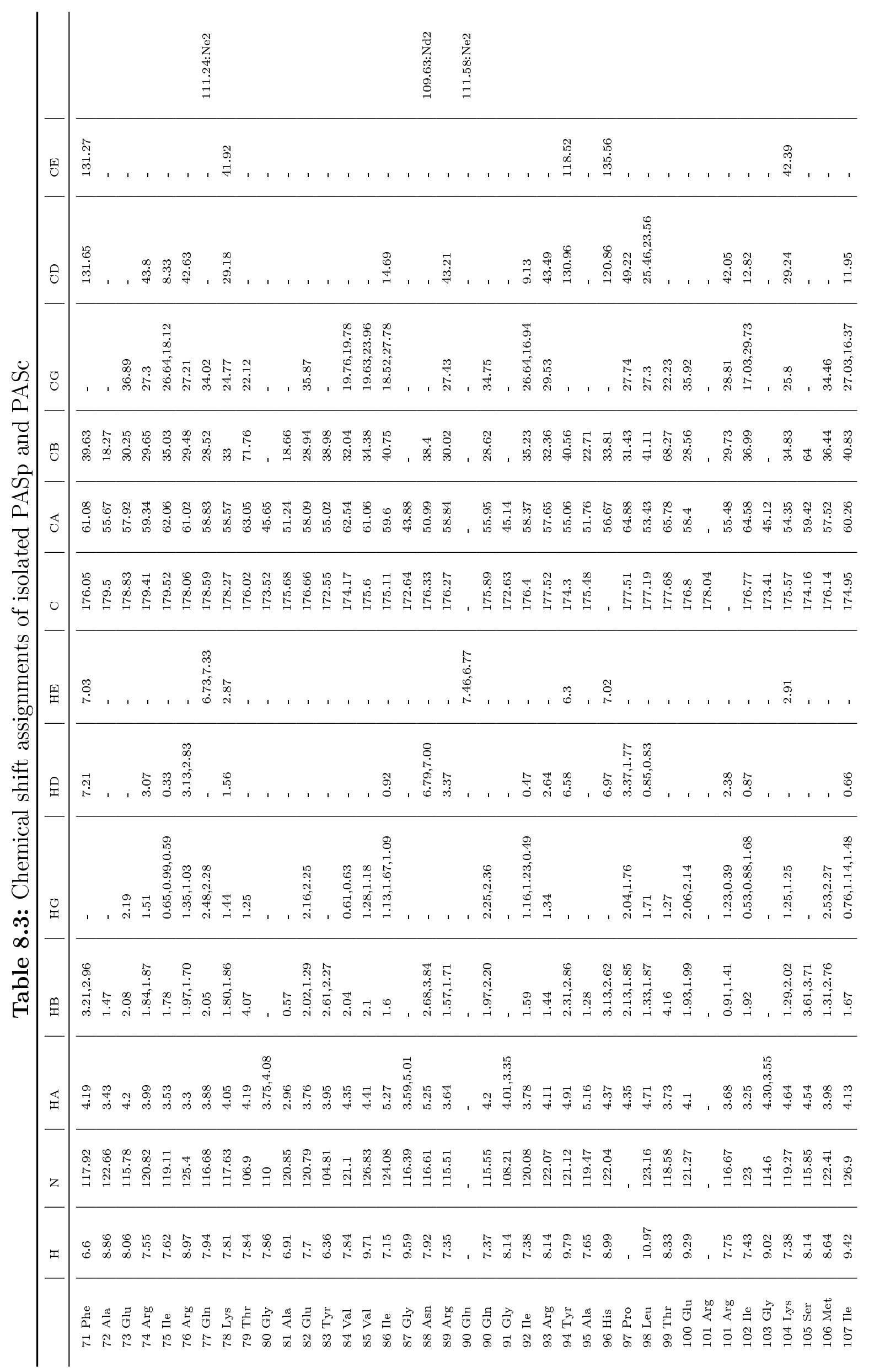




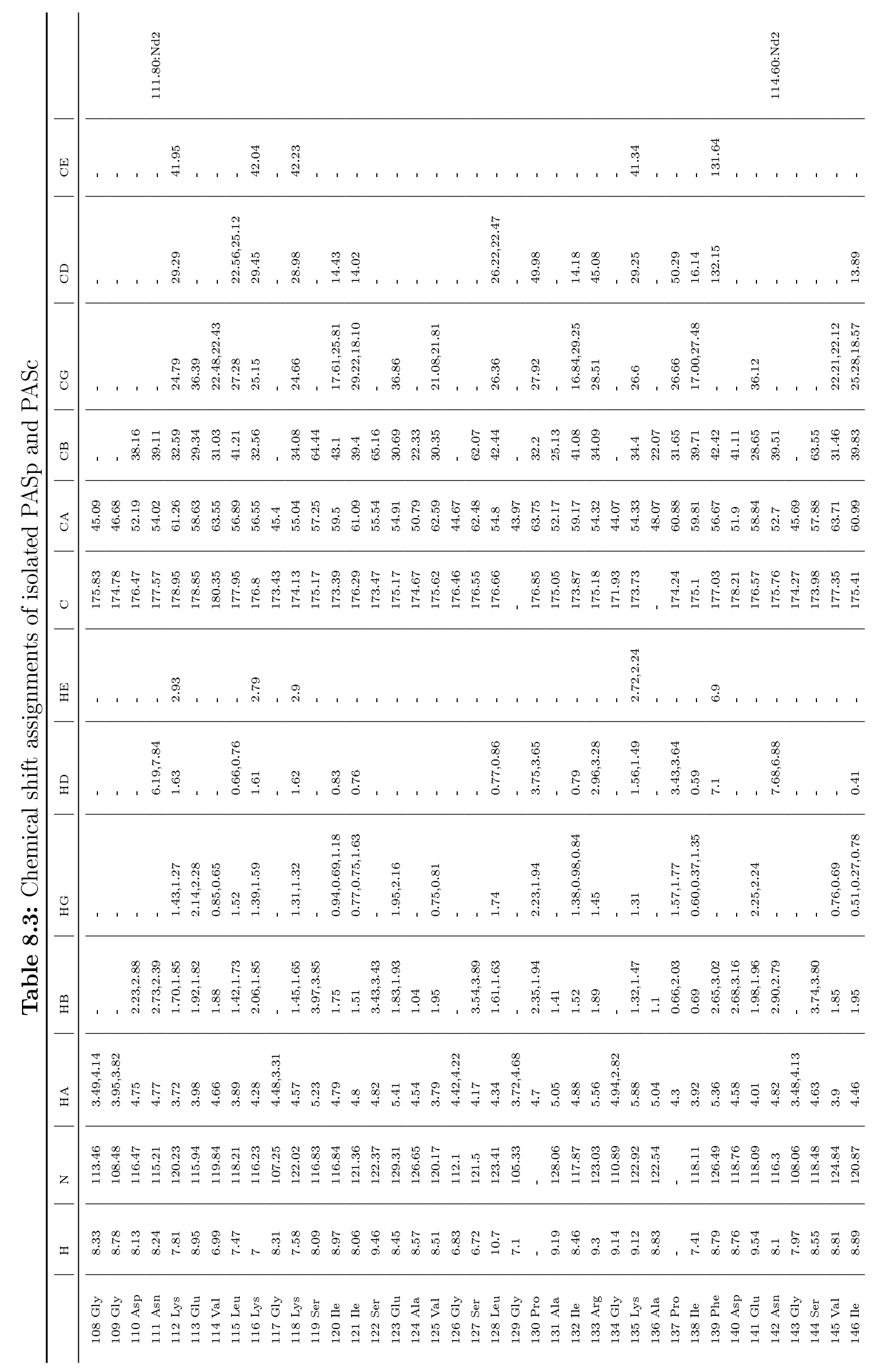




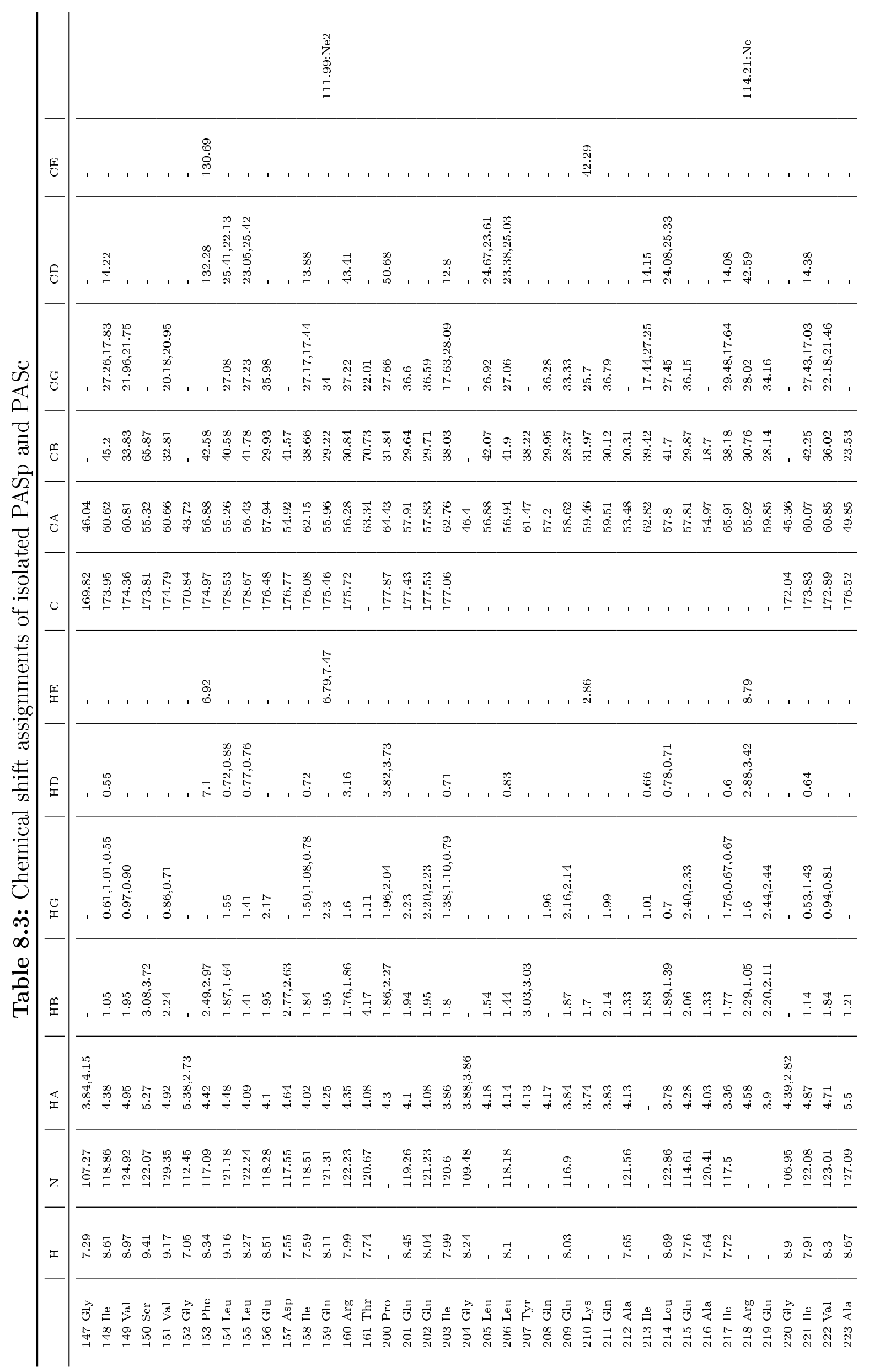




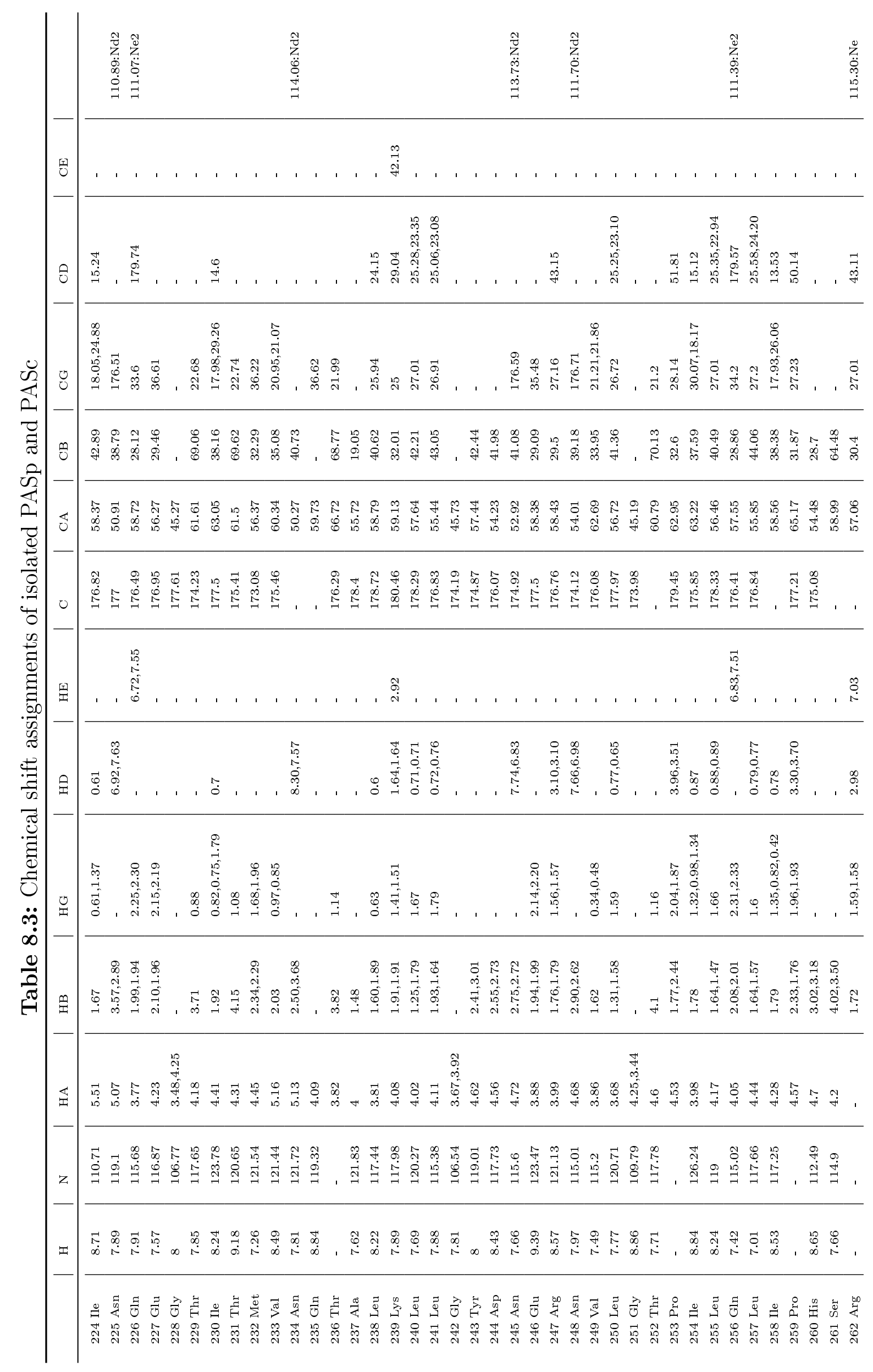



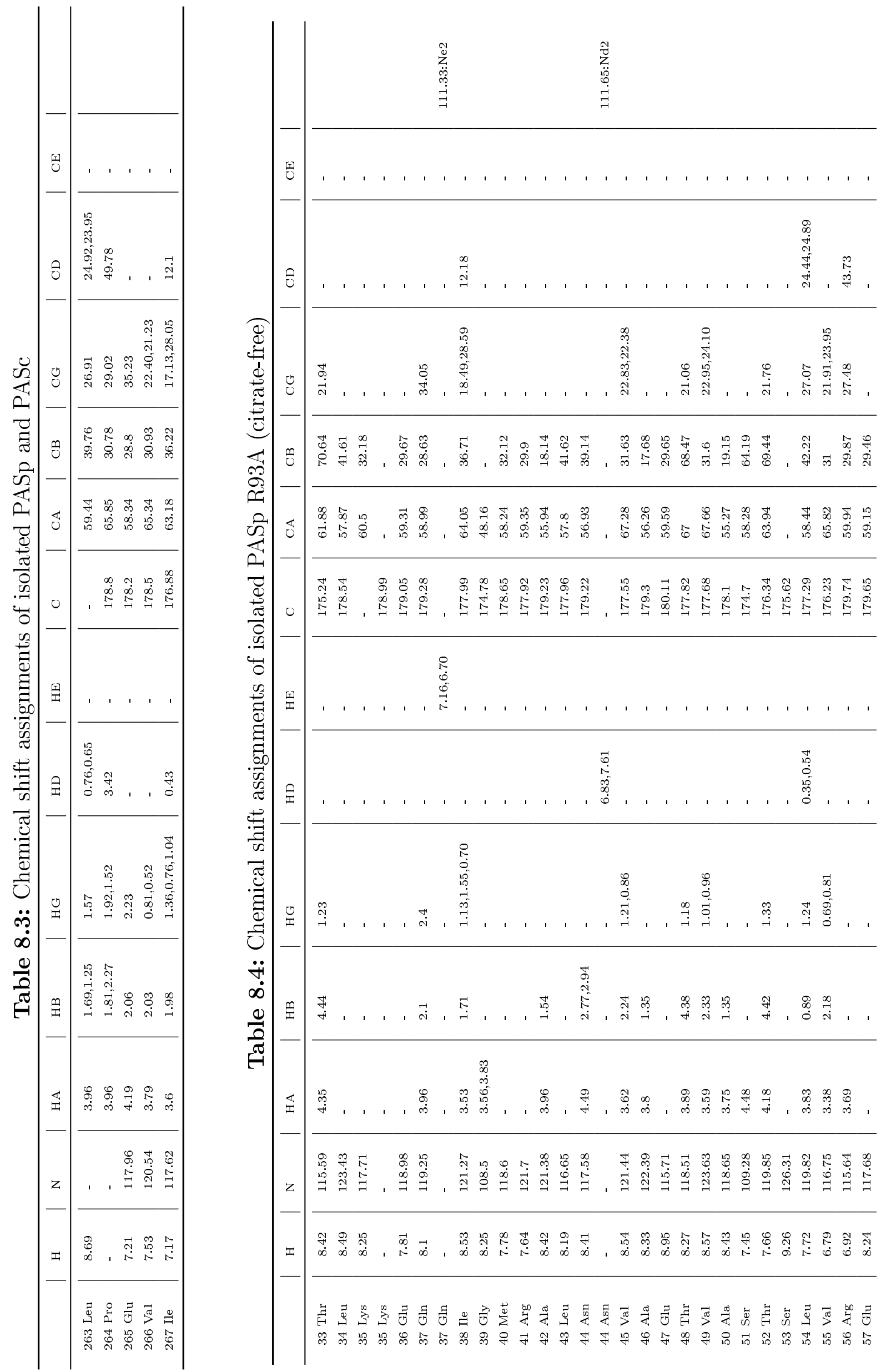


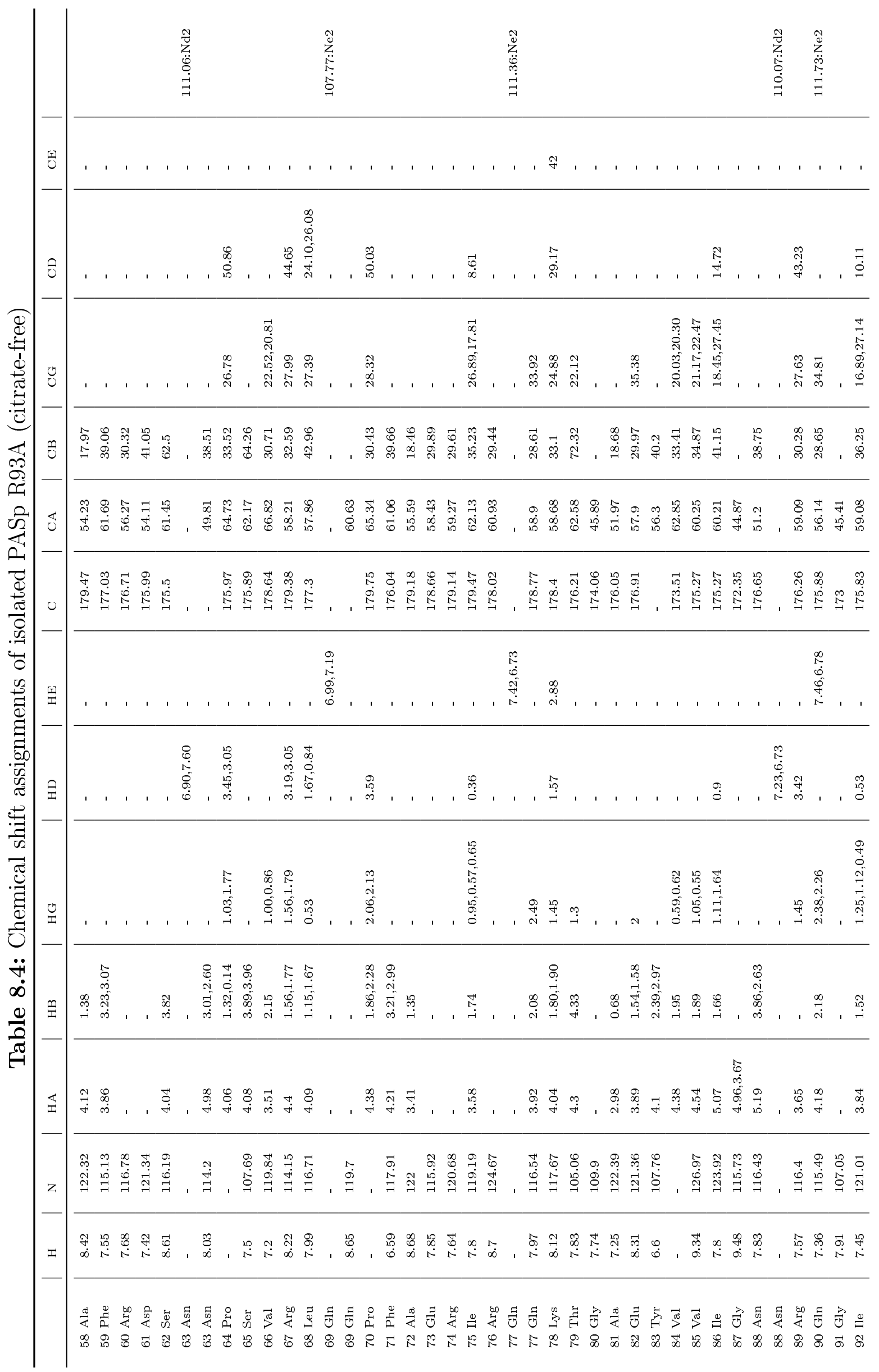




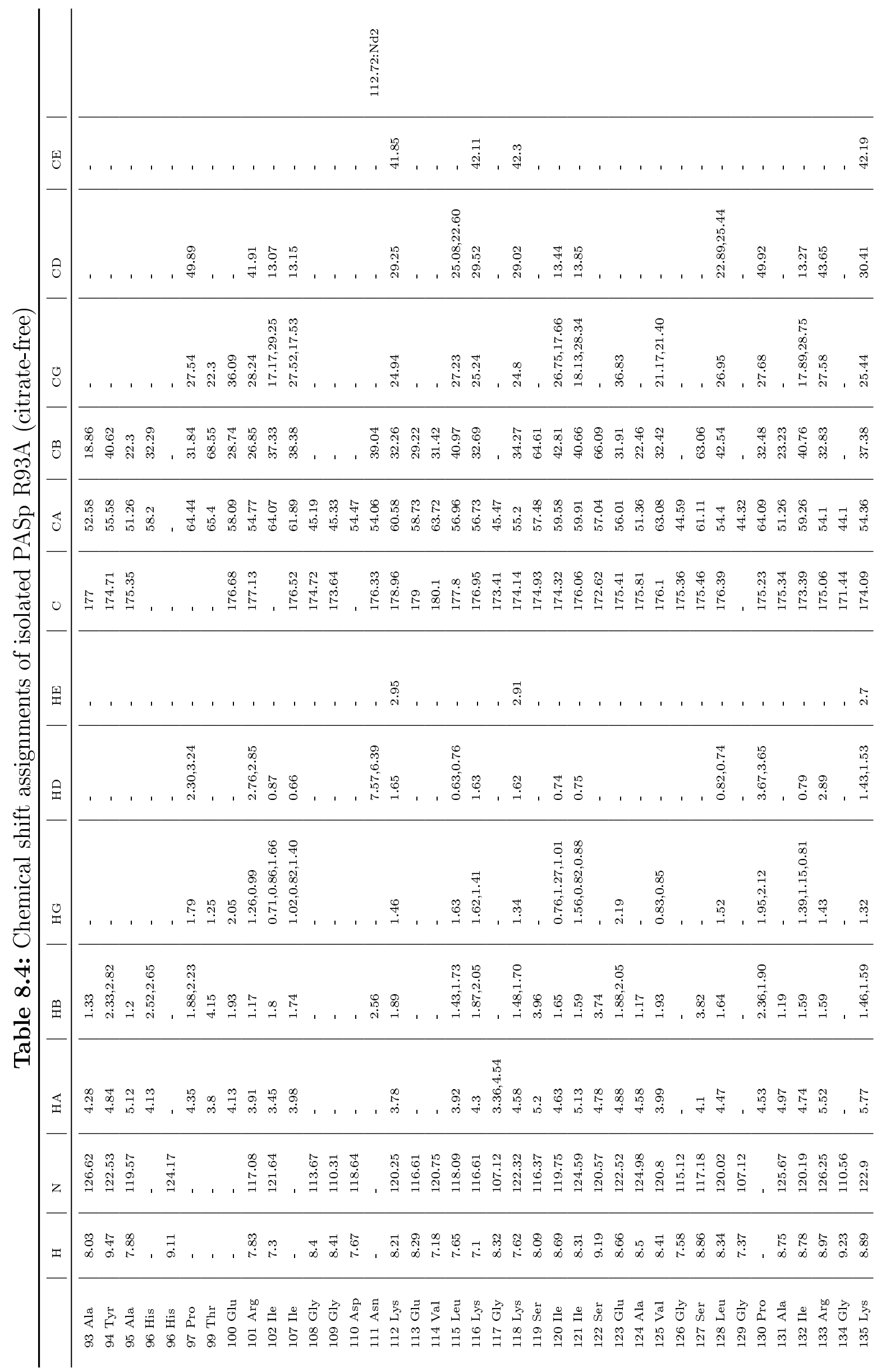




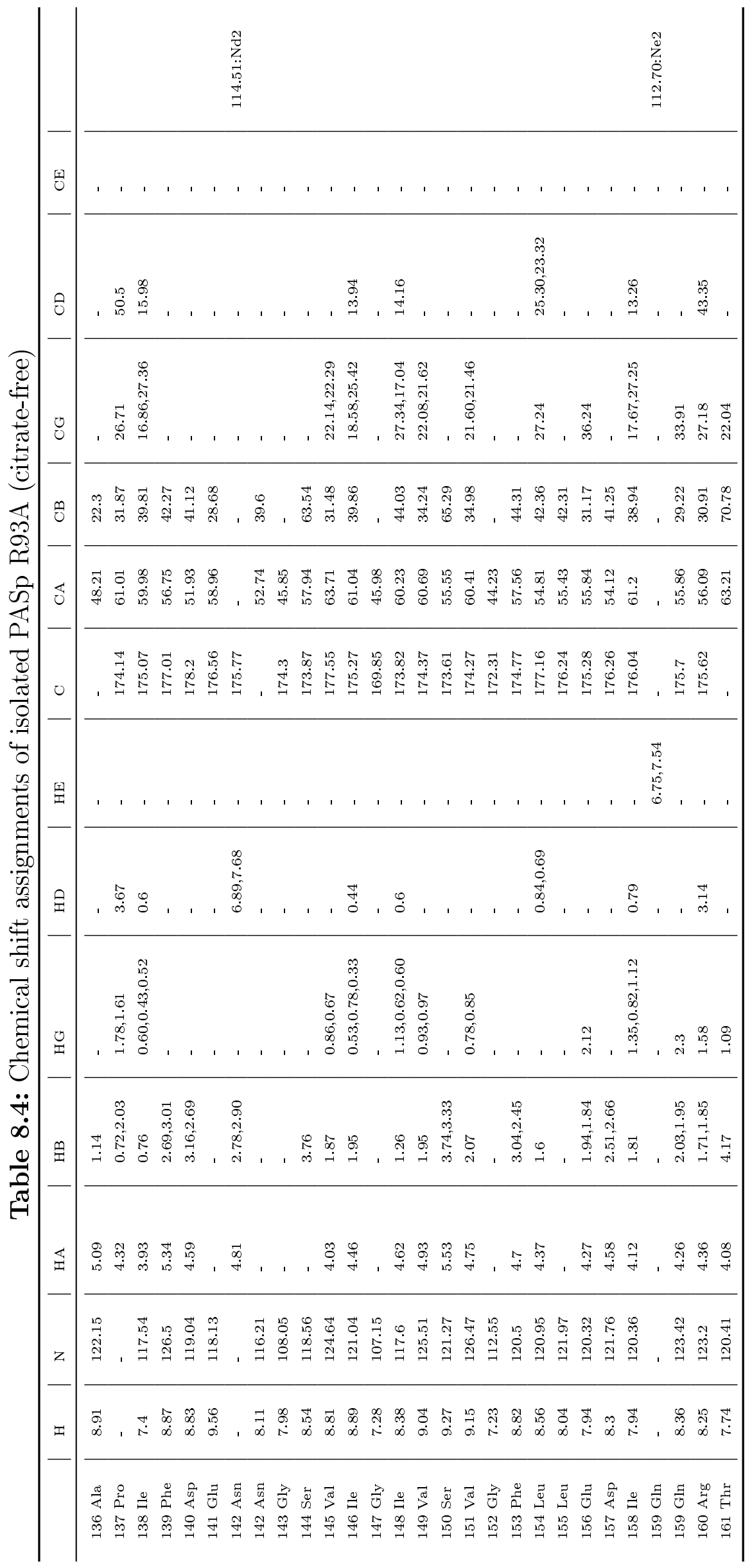

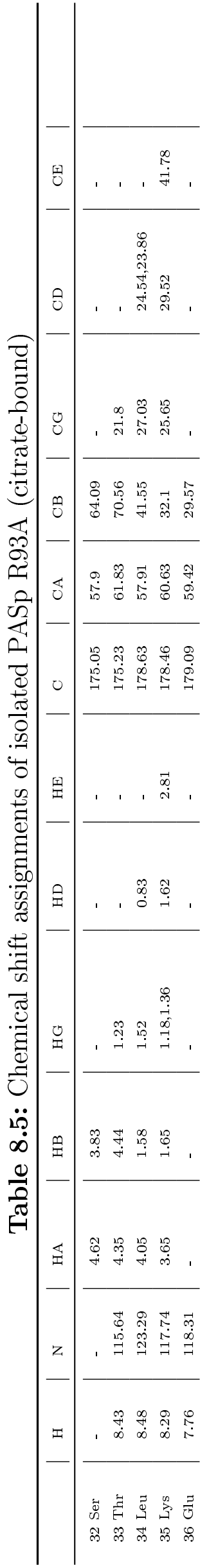




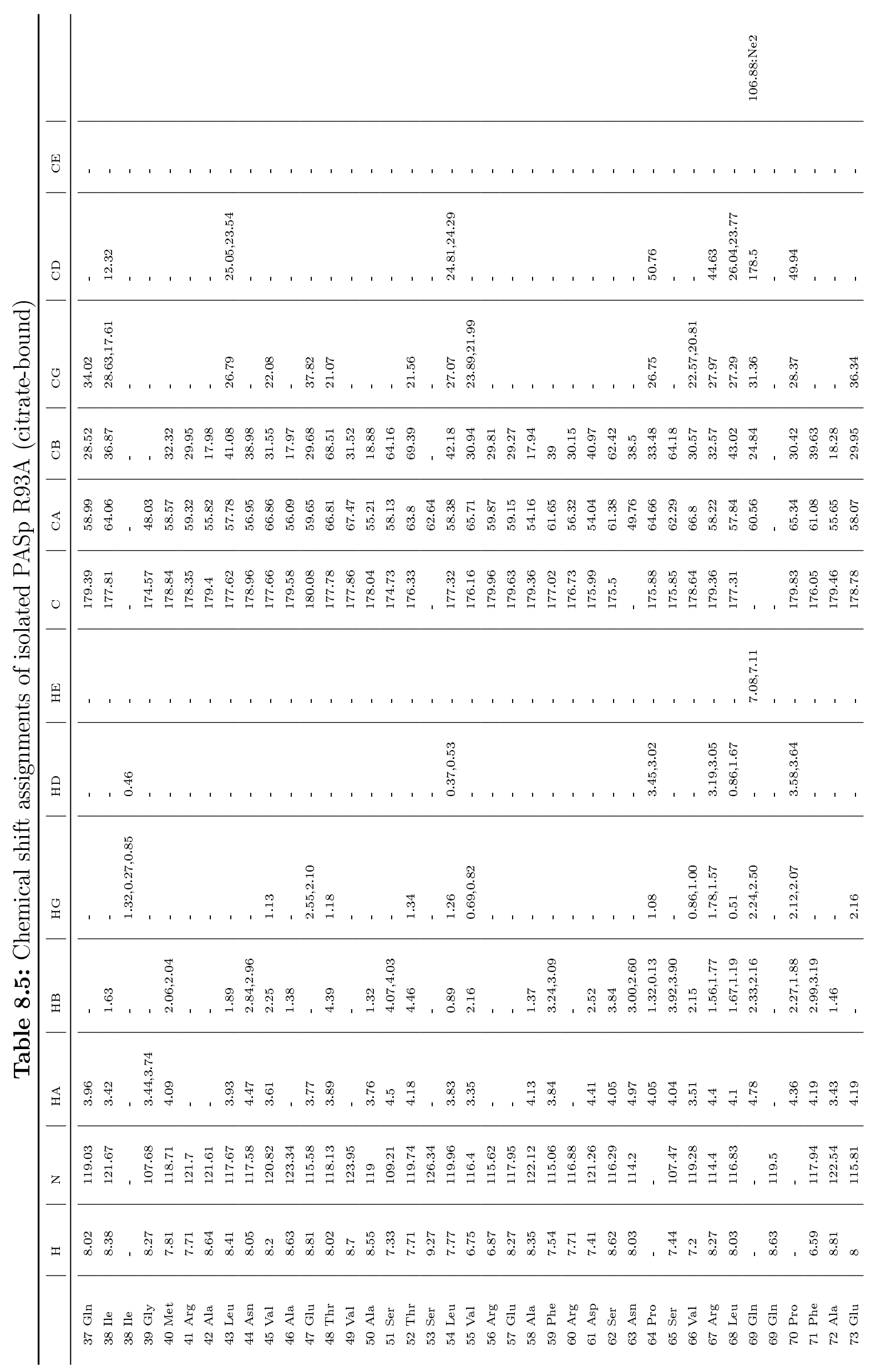




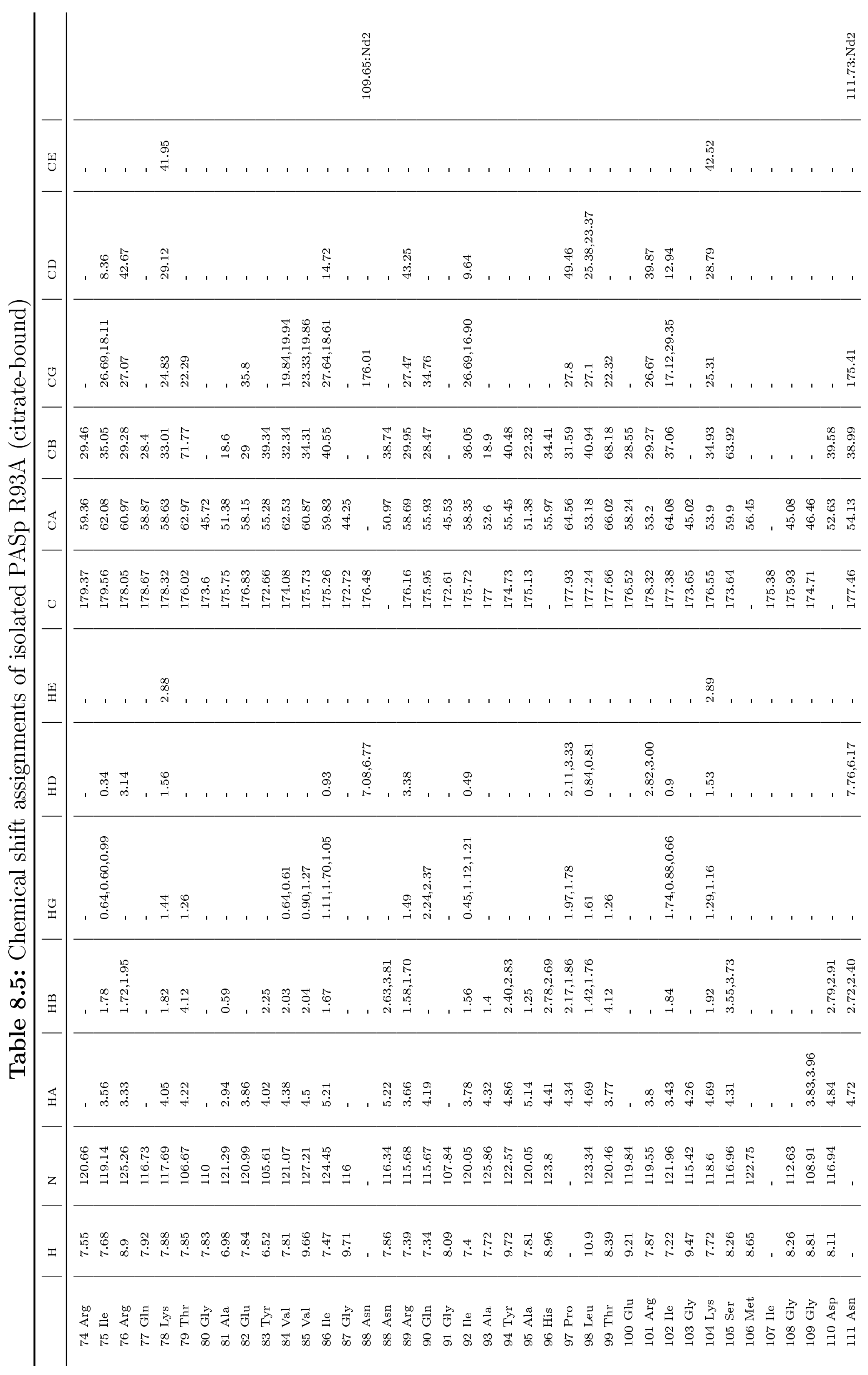




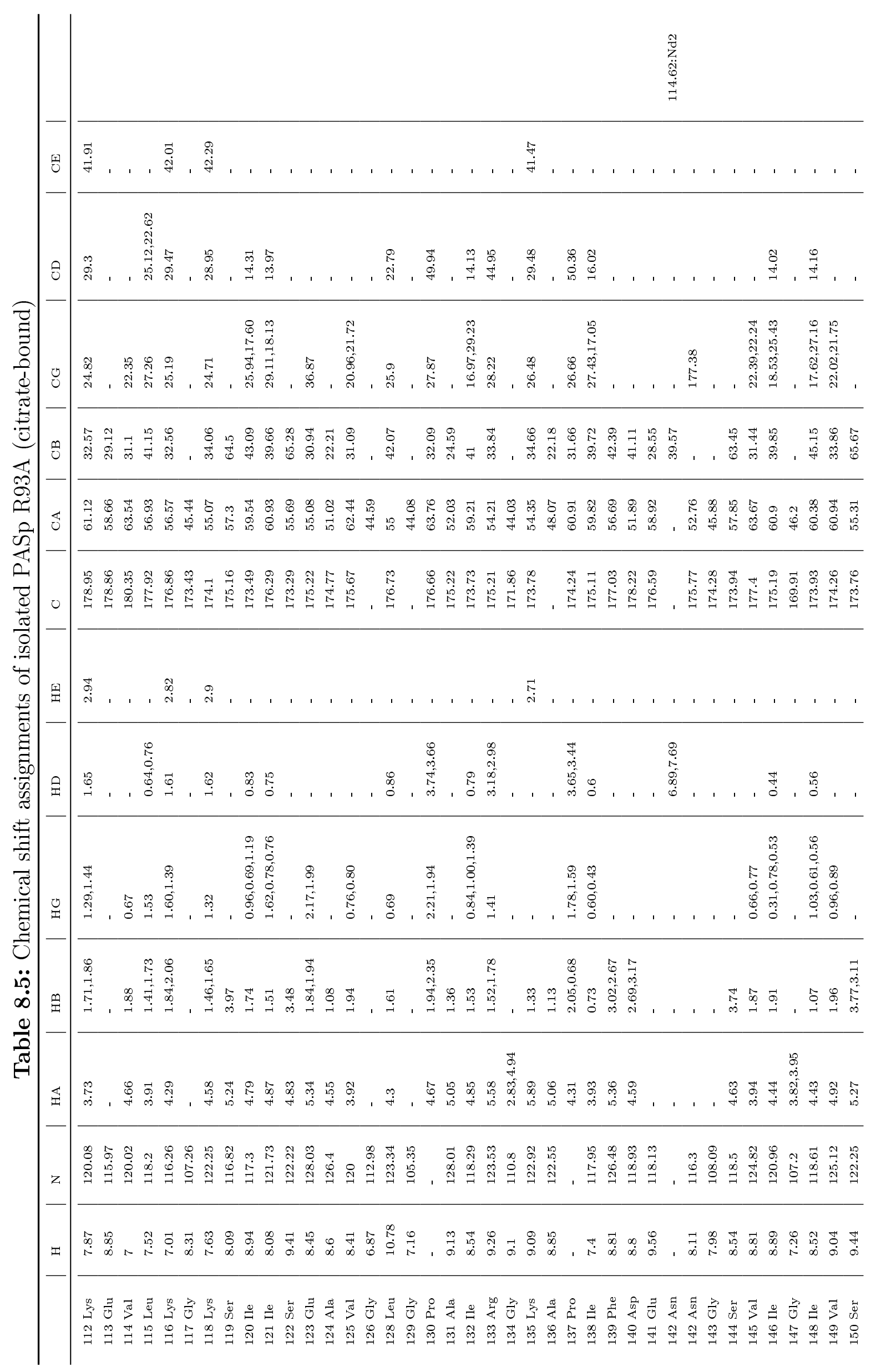




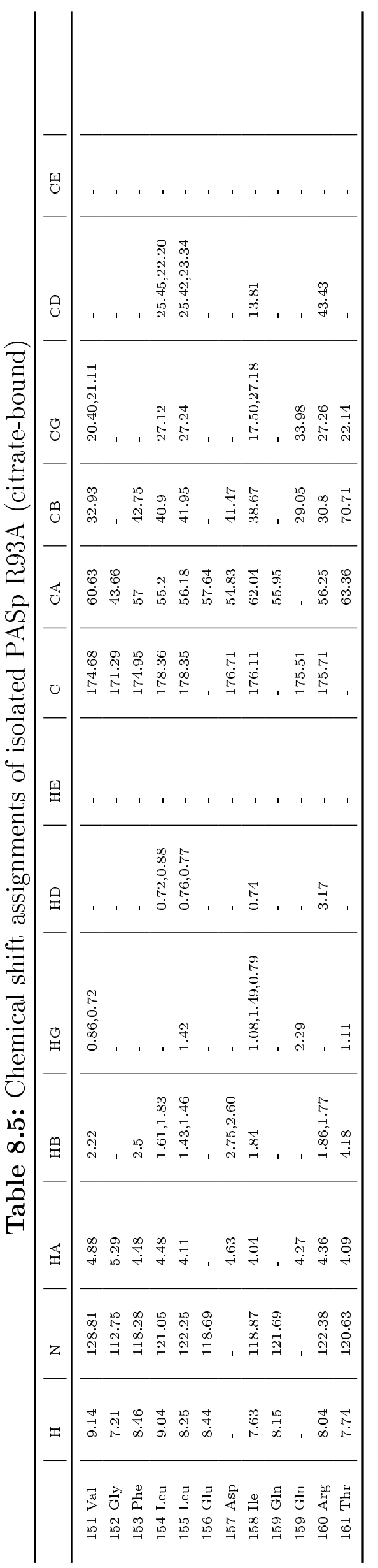


Table 8.6: Chemical shift assignments of wild-type CitApc

\begin{tabular}{|c|c|c|c|c|c|c|c|c|}
\hline & $\mathrm{N}$ & $\mathrm{C}$ & $\mathrm{CA}$ & $\mathrm{CB}$ & $\mathrm{CG}$ & $\mathrm{CD}$ & $\mathrm{CE}$ & \\
\hline $8 \mathrm{Met}$ & - & - & 58.97 & 32.08 & - & - & - & \\
\hline 9 Val & 120.9 & 176.94 & 65.67 & 30.88 & - & - & - & \\
\hline $10 \mathrm{Ile}$ & 116.87 & 177.76 & 66.24 & 37.97 & - & - & - & \\
\hline $11 \mathrm{Ile}$ & 121.45 & 177.85 & 66.62 & 37.91 & 17.88 & - & - & \\
\hline 12 Cys & 116.47 & 180.1 & 65.54 & 27.1 & - & - & - & \\
\hline 31 Ala & 121.44 & 179.52 & 55.53 & 18.64 & - & - & - & \\
\hline 32 Ala & 119.14 & 180.96 & 55.09 & 18.25 & - & - & - & \\
\hline $33 \mathrm{Thr}$ & 116.01 & 176.07 & 66.72 & 68.43 & - & - & - & \\
\hline 34 Leu & 123.37 & 178.61 & 58.09 & 41.72 & 29.14 & $24.33,27.14$ & - & \\
\hline 35 Lys & - & 178.31 & 60.72 & - & - & - & - & \\
\hline 36 Glu & 118.17 & 179.02 & 59.32 & 29.54 & 36.9 & - & - & \\
\hline $37 \mathrm{Gln}$ & 118.49 & 178.91 & 58.74 & 28.4 & - & - & - & \\
\hline 38 Ile & 123.13 & 177.86 & 65.26 & 37.28 & - & - & - & \\
\hline 39 Gly & 107.67 & 174.61 & 47.96 & - & - & - & - & \\
\hline $40 \mathrm{Met}$ & 119.69 & 179.07 & 58.86 & 32.85 & 32.84 & - & - & \\
\hline $41 \mathrm{Arg}$ & - & - & 59.26 & 30.09 & - & - & - & \\
\hline 42 Ala & 121.55 & 179.49 & 55.62 & 17.86 & - & - & - & \\
\hline 43 Leu & 117.82 & 177.81 & 57.77 & 40.95 & 26.84 & $25.36,23.25$ & - & \\
\hline $44 \mathrm{Asn}$ & 117.27 & 178.86 & 56.61 & 38.78 & 175.42 & - & - & 112.07: Nd2 \\
\hline $45 \mathrm{Val}$ & 121.45 & 177.25 & 67.86 & 31.74 & - & - & - & \\
\hline 46 Ala & 124.12 & 179.74 & 56.06 & 18.2 & - & - & - & \\
\hline $47 \mathrm{Glu}$ & 114.84 & 180.12 & 58.9 & 30.13 & 37.8 & - & - & \\
\hline $48 \mathrm{Thr}$ & 118.97 & 176.05 & 66.67 & 68.23 & 20.88 & - & - & \\
\hline $49 \mathrm{Val}$ & - & 178.1 & 67.39 & 31.98 & $22.80,24.54$ & - & - & \\
\hline $50 \mathrm{Ala}$ & 118.94 & 178.13 & 55.17 & 18.75 & - & - & - & \\
\hline 51 Ser & 111.87 & - & 59.53 & 64.83 & - & - & - & \\
\hline 53 Ser & - & - & 62.68 & 63.67 & - & - & - & \\
\hline 54 Leu & 120.17 & 177.09 & 58.24 & 42.19 & 27.18 & 24.63 & - & \\
\hline $55 \mathrm{Val}$ & 114.83 & 175.83 & 65.52 & 30.97 & $23.74,21.88$ & - & - & \\
\hline $56 \mathrm{Arg}$ & 114.87 & 180.42 & 59.85 & 29.88 & - & 43.5 & - & \\
\hline $57 \mathrm{Glu}$ & 117.09 & 179.19 & 59.17 & 29.41 & 36.49 & 182.83 & - & \\
\hline 58 Ala & 120.55 & 179.26 & 53.89 & 18.11 & - & - & - & \\
\hline 59 Phe & 115.98 & 177.05 & 61.63 & 38.84 & - & - & - & \\
\hline $60 \mathrm{Arg}$ & 116.77 & 176.72 & 56.13 & 29.84 & 28.56 & 43.39 & - & \\
\hline $61 \mathrm{Asp}$ & 121.26 & 175.92 & 53.88 & 40.8 & - & - & - & \\
\hline 62 Ser & 116.44 & 175.68 & 61.35 & 62.4 & - & - & - & \\
\hline $63 \mathrm{Asn}$ & 114.15 & 174.07 & 49.63 & 38.4 & 177.73 & - & - & 111.39: Nd2 \\
\hline 64 Pro & - & 175.83 & 64.69 & 33.39 & 26.86 & 50.78 & - & \\
\hline 65 Ser & 106.93 & 176.17 & 61.81 & 64.47 & - & - & - & \\
\hline $66 \mathrm{Val}$ & 119.46 & 178.99 & 66.8 & 30.58 & $22.77,20.99$ & - & - & \\
\hline $67 \mathrm{Arg}$ & 114.5 & 179.24 & 58.74 & 32.73 & 28.13 & 45.06 & - & \\
\hline 68 Leu & 117.18 & 177.49 & 57.83 & 42.98 & 27.42 & $24.18,26.13$ & - & \\
\hline 69 Gln & 120.09 & 174.87 & 60.29 & 24.61 & 30.91 & - & - & \\
\hline 70 Pro & - & $178.08,180.17$ & 65.35 & 30.7 & 28.78 & 50.09 & - & \\
\hline 71 Phe & 117.99 & 176.13 & 61.08 & 39.5 & - & - & - & \\
\hline $72 \mathrm{Ala}$ & 122.24 & 179.68 & 55.81 & 18.3 & - & - & - & \\
\hline $73 \mathrm{Glu}$ & 117.05 & 178.82 & 57.83 & - & - & - & - & \\
\hline $74 \mathrm{Arg}$ & 121.5 & 178.78 & 59.14 & 29.54 & 27.34 & 43.69 & - & \\
\hline 75 Ile & 117.48 & 179.62 & 62.03 & 34.66 & $19.08,26.03$ & 10.52 & - & \\
\hline $76 \mathrm{Arg}$ & 125.62 & 178.14 & 61.06 & 29.41 & 26.51 & 42.45 & - & \\
\hline $77 \mathrm{Gln}$ & 116.5 & 178.69 & 58.71 & 28.38 & 34.1 & - & - & \\
\hline 78 Lys & - & 178.52 & 58.58 & 32.94 & 24.52 & 29.12 & 42.12 & \\
\hline $79 \mathrm{Thr}$ & 106.03 & 175.85 & 63.01 & 71.29 & 22.58 & - & - & \\
\hline 80 Gly & 108.79 & 173.73 & 45.36 & - & - & - & - & \\
\hline 81 Ala & 121.8 & 175.6 & 51.53 & 18.37 & - & - & - & \\
\hline $82 \mathrm{Glu}$ & 120.97 & 176.46 & 57.63 & 28.97 & 35.27 & 181.77 & - & \\
\hline 83 Tyr & 104.31 & 172.61 & 54.59 & 38.94 & - & - & - & \\
\hline $84 \mathrm{Val}$ & 121.07 & 174.18 & 62.47 & 31.9 & $19.65,19.65$ & - & - & \\
\hline $85 \mathrm{Val}$ & 126.53 & 175.78 & 60.93 & 34.43 & $24.16,19.72$ & - & - & \\
\hline 86 Ile & 124.01 & 175.17 & 59.51 & 40.73 & $27.82,18.54$ & 14.78 & - & \\
\hline 87 Gly & 116.39 & 172.61 & 43.72 & - & - & - & - & \\
\hline $88 \mathrm{Asn}$ & 116.67 & 176.53 & 50.92 & 38.41 & 175.89 & - & - & 109.87: Nd2 \\
\hline 89 Arg & 115.69 & 176.38 & 58.78 & 29.93 & 27.36 & 43.17 & - & \\
\hline
\end{tabular}


Table 8.6: Chemical shift assignments of wild-type CitApc

\begin{tabular}{|c|c|c|c|c|c|c|c|c|}
\hline & $\mathrm{N}$ & $\mathrm{C}$ & $\mathrm{CA}$ & $\mathrm{CB}$ & $\mathrm{CG}$ & $\mathrm{CD}$ & $\mathrm{CE}$ & \\
\hline $90 \mathrm{Gln}$ & 115.74 & 175.92 & 56.04 & 28.57 & 34.91 & - & - & \\
\hline 91 Gly & 108.36 & 172.67 & 45.09 & - & - & - & - & \\
\hline $92 \mathrm{Ile}$ & 120.16 & 176.46 & 58.27 & 35.18 & $26.67,17.09$ & 9.25 & - & \\
\hline $93 \mathrm{Arg}$ & 122.06 & 177.53 & 57.58 & 32.41 & 29.59 & 43.51 & - & \\
\hline 94 Tyr & 121.05 & 174.1 & 55.1 & 40.67 & - & - & - & \\
\hline $95 \mathrm{Ala}$ & 119.5 & 175.7 & 51.74 & 22.69 & - & - & - & \\
\hline $96 \mathrm{His}$ & 122.15 & 172.01 & 56.65 & 33.65 & - & - & - & \\
\hline 97 Pro & - & 177.79 & 64.56 & 31.43 & 27.84 & 49.17 & - & \\
\hline 98 Leu & 124.09 & 177.31 & 53.47 & 41.01 & 27.57 & $23.74,25.70$ & - & \\
\hline $99 \mathrm{Thr}$ & 118.46 & 177.89 & 65.68 & 68.14 & 22.52 & - & - & \\
\hline $100 \mathrm{Glu}$ & 121.58 & 177.01 & 58.39 & 28.32 & 35.98 & - & - & \\
\hline $101 \mathrm{Arg}$ & 116.67 & 178.12 & 55.58 & 29.81 & 28.96 & 42.08 & - & \\
\hline 102 Ile & 123.39 & 176.88 & 64.74 & 37.19 & $17.26,29.96$ & 13.17 & - & \\
\hline 103 Gly & 114.83 & 173.4 & 45.12 & - & - & - & - & \\
\hline 104 Lys & 119.31 & 175.65 & 54.21 & 34.63 & 25.9 & 29.23 & 42.31 & \\
\hline 105 Ser & 116.03 & 174.23 & 59.42 & 64.02 & - & - & - & \\
\hline $106 \mathrm{Met}$ & 122.55 & 176.28 & 57.46 & 36.45 & 34.57 & - & - & \\
\hline 107 Ile & 127.18 & 175.01 & 60.11 & 40.9 & $16.48,27.23$ & 12.17 & - & \\
\hline 108 Gly & 113.68 & 175.94 & 44.99 & - & - & - & - & \\
\hline 109 Gly & 108.63 & 174.8 & 46.57 & - & - & - & - & \\
\hline 110 Asp & 116.48 & 176.62 & 52.09 & 38.14 & 182.12 & - & - & \\
\hline 111 Asn & 115.42 & 177.62 & 53.94 & 38.97 & - & - & - & 111.94: $\mathrm{Nd} 2$ \\
\hline 112 Lys & 120.63 & 179.09 & 61.2 & 32.7 & 25.03 & - & - & \\
\hline 113 Glu & 115.82 & 178.96 & 58.63 & 29.27 & 36.4 & - & - & \\
\hline $114 \mathrm{Val}$ & 120.02 & 180.65 & 63.38 & 31.08 & $22.48,22.48$ & - & - & \\
\hline 115 Leu & 118.63 & 178.33 & 56.99 & 41.24 & 27.39 & $22.73,25.27$ & - & \\
\hline 116 Lys & 116.34 & 176.87 & 56.5 & 32.69 & 25.23 & 29.46 & 42.13 & \\
\hline 117 Gly & 107.54 & 173.48 & 45.14 & - & - & - & - & \\
\hline 118 Lys & 122.14 & 173.91 & 55.45 & 33.75 & 25.31 & - & - & \\
\hline 119 Ser & 116.82 & 175.3 & 57.29 & 64.08 & - & - & - & \\
\hline 120 Ile & 117.48 & 173.62 & 59.31 & 43 & $17.69,25.71$ & 14.56 & - & \\
\hline 121 Ile & 121.57 & 176.47 & 60.95 & 39.36 & $29.38,18.39$ & 14.17 & - & \\
\hline 122 Ser & 122.45 & 173.58 & 55.39 & 65.22 & - & - & - & \\
\hline $123 \mathrm{Glu}$ & 129.5 & 175.25 & 54.81 & 30.81 & 37.09 & 183.08 & - & \\
\hline 124 Ala & 126.99 & 174.75 & 50.7 & 22.36 & - & - & - & \\
\hline $125 \mathrm{Val}$ & 120.32 & 175.76 & 62.5 & 30.29 & $21.06,21.91$ & - & - & \\
\hline 126 Gly & 111.96 & 176.61 & 44.66 & - & - & - & - & \\
\hline 127 Ser & 121.42 & 176.55 & 62.43 & 62.04 & - & - & - & \\
\hline 128 Leu & 123.49 & 176.66 & 54.66 & 42.25 & 26.54 & $22.53,25.97$ & - & \\
\hline 129 Gly & 105.54 & - & 43.88 & - & - & - & - & \\
\hline 130 Pro & - & 177.31 & 63.55 & 32.31 & 28.2 & 50 & - & \\
\hline $131 \mathrm{Ala}$ & - & 174.99 & 52.26 & 25.07 & - & - & - & \\
\hline 132 Ile & 118.02 & 174 & 59.94 & 40.7 & 28.78 & - & - & \\
\hline 133 Arg & 123.06 & 175.2 & 54.31 & 34.17 & 28.98 & 44.86 & - & \\
\hline 134 Gly & 110.98 & 171.74 & 44.09 & - & - & - & - & \\
\hline 135 Lys & 123.08 & 173.54 & 54.34 & 34.15 & 26.65 & 29.33 & 41.42 & \\
\hline $136 \mathrm{Ala}$ & 123.1 & 173.77 & 47.59 & 22.02 & - & - & - & \\
\hline 137 Pro & - & 174.53 & 60.76 & 31.77 & 26.77 & 50.69 & - & \\
\hline $138 \mathrm{Ile}$ & 118.24 & 175.24 & 59.79 & 39.75 & $27.60,17.32$ & 16.31 & - & \\
\hline 139 Phe & 126.31 & 177.18 & 56.65 & 42.53 & - & - & - & \\
\hline 140 Asp & 119.04 & 178.34 & 51.83 & 41.11 & 179.22 & - & - & \\
\hline 141 Glu & 118.25 & 176.8 & 58.84 & 28.62 & 36.06 & - & - & \\
\hline 142 Asn & 116.33 & 175.89 & 52.65 & 39.65 & - & - & - & \\
\hline 143 Gly & 108.53 & 173.99 & 45.75 & - & - & - & - & \\
\hline 144 Ser & 117.82 & 174.17 & 57.72 & 63.55 & - & - & - & \\
\hline $145 \mathrm{Val}$ & 125.06 & 177.51 & 63.56 & 31.53 & $22.06,22.06$ & - & - & \\
\hline 146 Ile & 120.86 & 175.45 & 60.88 & 39.71 & $18.66,25.36$ & 14.16 & - & \\
\hline 147 Gly & 107.25 & 169.95 & 45.9 & - & - & - & - & \\
\hline $148 \mathrm{Ile}$ & 119.14 & 174.12 & 60.65 & 45.45 & $27.34,18.12$ & 14.39 & - & \\
\hline $149 \mathrm{Val}$ & 124.95 & 174.34 & 60.88 & 33.72 & $21.91,21.91$ & - & - & \\
\hline $150 \mathrm{Ser}$ & 122.07 & 173.84 & 55.25 & 65.86 & - & - & - & \\
\hline $151 \mathrm{Val}$ & 129.4 & 174.93 & 60.31 & 33.03 & $20.28,21.25$ & - & - & \\
\hline $152 \mathrm{Gly}$ & 112.15 & 170.8 & 43.72 & - & - & - & - & \\
\hline
\end{tabular}


Table 8.6: Chemical shift assignments of wild-type CitApc

\begin{tabular}{|c|c|c|c|c|c|c|c|}
\hline & $\mathrm{N}$ & $\mathrm{C}$ & $\mathrm{CA}$ & $\mathrm{CB}$ & $\mathrm{CG}$ & $\mathrm{CD}$ & $\mathrm{CE}$ \\
\hline 153 Phe & 116.38 & 175.08 & 57.15 & 43.24 & - & - & - \\
\hline 154 Leu & 120.66 & - & 55.32 & 40.57 & 27.19 & $25.54,21.92$ & - \\
\hline $156 \mathrm{Glu}$ & 119.05 & 178.07 & 59.25 & 29.63 & - & - & - \\
\hline $157 \mathrm{Asp}$ & 118.88 & 178.58 & 57.28 & 41.39 & - & - & - \\
\hline $158 \mathrm{Ile}$ & 122.44 & $178.11,178.08$ & 65.23 & 38.09 & $16.60,28.36$ & 14.47 & - \\
\hline $159 \mathrm{Gln}$ & 117.8 & 178.91 & 58.64 & 29.19 & - & - & - \\
\hline $160 \mathrm{Arg}$ & 120.29 & 179.47 & 60.18 & 30.01 & - & - & - \\
\hline $161 \mathrm{Thr}$ & 119.33 & 176.93 & 67.04 & 68.34 & - & - & - \\
\hline $162 \mathrm{Val}$ & 122.29 & 179.8 & 67.76 & 31.62 & - & - & - \\
\hline 178 Leu & 123.31 & 178.37 & 58.38 & 41.08 & - & - & - \\
\hline 179 Phe & 116.53 & 178.39 & 60.65 & 38.31 & - & - & - \\
\hline 180 Gly & 105.74 & 174.57 & 47.85 & - & - & - & - \\
\hline 181 Ala & 124.62 & 179.37 & 55.81 & 19.83 & - & - & - \\
\hline $182 \mathrm{Val}$ & 117.18 & 178.72 & 67.03 & 31.22 & - & - & - \\
\hline 183 Gly & 105.12 & - & 45.79 & - & - & - & - \\
\hline 184 Ala & 122.85 & 181.15 & 55.03 & 18.28 & - & - & - \\
\hline $185 \mathrm{Val}$ & 117.34 & 177.68 & 66.7 & 31.62 & - & - & - \\
\hline 186 Ala & 121.12 & 180.56 & 55.47 & 18.73 & - & - & - \\
\hline $187 \mathrm{Ile}$ & 118.62 & 180.09 & 65.85 & 38.43 & $15.89,29.61$ & 13.73 & - \\
\hline $222 \mathrm{Val}$ & - & 173.55 & 60.75 & 35.93 & $22.36,21.12$ & - & - \\
\hline 223 Ala & - & 176.62 & 50 & 23.35 & - & - & - \\
\hline 224 Ile & - & - & 58.27 & 42.93 & $18.24,24.89$ & 15.26 & - \\
\hline 227 Glu & - & - & 56.16 & 29.61 & 36.64 & - & - \\
\hline $229 \mathrm{Thr}$ & - & 174.32 & 61.69 & 68.91 & 22.95 & - & - \\
\hline 230 Ile & - & - & 62.99 & 38.03 & $17.96,29.36$ & 14.51 & - \\
\hline $231 \mathrm{Thr}$ & - & - & 61.44 & 69.44 & 23.03 & - & - \\
\hline 234 Asn & - & - & 50.09 & 41.03 & - & - & - \\
\hline $236 \mathrm{Thr}$ & - & - & 66.24 & 68.74 & - & - & - \\
\hline 237 Ala & - & - & 55.64 & 19.12 & - & - & - \\
\hline 241 Leu & - & - & 55.71 & 43.38 & 26.92 & $23.31,25.17$ & - \\
\hline $244 \mathrm{Asp}$ & - & - & 53.73 & 41.81 & - & - & - \\
\hline $252 \mathrm{Thr}$ & - & - & 60.64 & 70.15 & 21.51 & - & - \\
\hline 253 Pro & - & 178.96 & 62.88 & 32.65 & 28.28 & 51.92 & - \\
\hline 255 Leu & - & - & 56.27 & 40.61 & 27.01 & $23.06,25.50$ & - \\
\hline $258 \mathrm{Ile}$ & - & - & 57.75 & 38.55 & 25.97 & - & - \\
\hline 259 Pro & - & - & 65.02 & 32 & 27.29 & 50.04 & - \\
\hline 261 Ser & - & - & 58.96 & 64.44 & - & - & - \\
\hline 264 Pro & - & - & 65.68 & 30.84 & 29.15 & 49.58 & - \\
\hline $266 \mathrm{Val}$ & - & - & 65.09 & 30.88 & $22.69,21.26$ & - & - \\
\hline $268 \mathrm{Arg}$ & - & - & 59.15 & 31.02 & 27.57 & 43.08 & - \\
\hline $269 \mathrm{Thr}$ & - & 177.72 & 62.54 & 70.11 & 21.83 & - & - \\
\hline 270 Gly & - & 172.98 & 46.63 & - & - & - & - \\
\hline $271 \mathrm{Gln}$ & - & 174.31 & 53.88 & 30.28 & 33.38 & - & - \\
\hline 272 Ala & 125.79 & 176.29 & 51.85 & 20.88 & - & - & - \\
\hline 273 Glu & - & - & 54.81 & 32.49 & 35.55 & - & - \\
\hline 275 Asp & - & - & 55.61 & 39.54 & - & - & - \\
\hline $276 \mathrm{Asp}$ & - & - & 53.86 & 42.81 & - & - & - \\
\hline 277 Glu & - & - & 56.41 & 30.56 & 37.3 & - & - \\
\hline $279 \mathrm{Val}$ & - & - & 61.46 & 32.63 & $21.10,21.10$ & - & - \\
\hline 281 Gly & - & 175.4 & 47.14 & - & - & - & - \\
\hline $283 \mathrm{Glu}$ & - & - & 54.57 & 31.99 & 35.63 & - & - \\
\hline $284 \mathrm{Thr}$ & - & - & 63.13 & 68.73 & 22.21 & - & - \\
\hline $286 \mathrm{Ile}$ & - & - & 59.19 & 38.24 & - & - & - \\
\hline 287 Ala & - & - & 50.36 & 23.11 & - & - & - \\
\hline 291 Pro & - & - & 61.75 & 31.89 & 26.28 & 50.23 & - \\
\hline 293 Lys & - & - & 54.29 & 36.45 & 26.37 & 29.48 & 42.19 \\
\hline $294 \mathrm{Asn}$ & - & - & 50.61 & 38.86 & - & - & - \\
\hline $296 \mathrm{G} \ln$ & - & - & 56.38 & 28.42 & 34.92 & - & - \\
\hline $300 \mathrm{Ile}$ & - & - & 60.55 & 38.96 & $26.42,18.18$ & 14 & - \\
\hline 301 Gly & - & 170.82 & 45.68 & - & - & - & - \\
\hline 302 Ala & - & - & 52.32 & 22.48 & - & - & - \\
\hline $305 \mathrm{Thr}$ & - & - & 57.97 & 70.77 & 22.73 & - & - \\
\hline 307 Arg & - & - & 53.49 & 33.53 & 27.59 & 43.72 & - \\
\hline
\end{tabular}


Table 8.6: Chemical shift assignments of wild-type CitApc

Table 8.7: Chemical shift assignments of CitApc R93A (citrate-free)

\begin{tabular}{|c|c|c|c|c|c|c|c|c|}
\hline & $\mathrm{N}$ & $\mathrm{C}$ & $\mathrm{CA}$ & $\mathrm{CB}$ & $\mathrm{CG}$ & $\mathrm{CD}$ & $\mathrm{CE}$ & \\
\hline 35 Lys & - & 178.98 & 60.31 & - & - & - & - & \\
\hline 36 Glu & 118.94 & - & 59.42 & 29.78 & - & - & - & \\
\hline 38 Ile & - & - & - & - & - & - & - & \\
\hline 39 Gly & 108.52 & 174.61 & 47.97 & - & - & - & - & \\
\hline $40 \mathrm{Met}$ & 118.83 & - & 58.6 & 31.88 & - & - & - & \\
\hline 41 Arg & 121.5 & - & 59.06 & 29.67 & - & - & - & \\
\hline $42 \mathrm{Ala}$ & - & 179.24 & 55.96 & 18.23 & - & - & - & \\
\hline 43 Leu & 116.65 & - & 57.77 & 41.79 & - & - & - & \\
\hline 44 Asn & 117.64 & - & 56.45 & 39.05 & 176.19 & - & - & \\
\hline $45 \mathrm{Val}$ & 121.38 & 177.21 & 67.57 & 31.62 & - & - & - & \\
\hline $46 \mathrm{Ala}$ & 122.28 & 179.28 & 55.92 & 18.17 & - & - & - & \\
\hline $47 \mathrm{Glu}$ & 115.92 & 180.11 & 59.48 & 29.84 & - & - & - & \\
\hline $48 \mathrm{Thr}$ & 118.79 & - & 66.68 & 68.31 & 20.91 & - & - & \\
\hline $49 \mathrm{Val}$ & 123.62 & 177.72 & 67.38 & 31.74 & $22.78,24.44$ & - & - & \\
\hline $50 \mathrm{Ala}$ & 119.04 & 178 & 55.02 & 19.22 & - & - & - & \\
\hline 51 Ser & 109.72 & 174.97 & 58.3 & 64.23 & - & - & - & \\
\hline $52 \mathrm{Thr}$ & 119.87 & - & 64.18 & - & - & - & - & \\
\hline 53 Ser & - & - & 62.94 & 63.98 & - & - & - & \\
\hline 54 Leu & 119.85 & - & 58.22 & 42.02 & - & - & - & \\
\hline $55 \mathrm{Val}$ & 116.59 & - & 65.57 & 31.1 & $21.75,23.53$ & - & - & \\
\hline 56 Arg & - & - & - & - & - & - & - & \\
\hline 57 Glu & 117.8 & 179.83 & 58.98 & 29.34 & - & - & - & \\
\hline $58 \mathrm{Ala}$ & 122.15 & 179.45 & 54.17 & 18.3 & - & - & - & \\
\hline 59 Phe & 115.19 & 177.03 & 61.57 & 38.87 & - & - & - & \\
\hline $60 \mathrm{Arg}$ & 117.03 & 176.58 & 56.17 & 30.4 & 28.08 & 43.57 & - & \\
\hline 61 Asp & 121.38 & 175.86 & 54.01 & 41.14 & - & - & - & \\
\hline 62 Ser & 116.61 & 175.49 & 61.38 & 62.53 & - & - & - & \\
\hline 63 Asn & 114.41 & - & 49.74 & 38.57 & 177.7 & - & - & 111.38: Nd2 \\
\hline 64 Pro & - & 176.02 & 64.48 & 33.54 & 26.77 & 50.79 & - & \\
\hline 65 Ser & 107.84 & 175.74 & 62.12 & 64.25 & - & - & - & \\
\hline $66 \mathrm{Val}$ & 120.01 & 178.59 & 66.56 & 30.89 & $22.64,20.94$ & - & - & \\
\hline 67 Arg & 114.27 & 179.26 & 57.92 & 32.49 & 27.95 & 44.47 & - & \\
\hline 68 Leu & 117.02 & 177.36 & 57.85 & 43.06 & 27.24 & $25.96,24.14$ & - & \\
\hline $69 \mathrm{Gln}$ & 119.64 & - & 60.37 & - & 32.19 & - & - & \\
\hline $69 \mathrm{Gln}$ & - & - & - & 24.9 & - & - & - & \\
\hline 70 Pro & - & 179.87 & 65.28 & 30.63 & 28.56 & 50.06 & - & \\
\hline 71 Phe & 117.9 & 175.94 & 60.67 & 39.73 & - & - & - & \\
\hline $72 \mathrm{Ala}$ & 121.88 & 179.17 & 55.56 & 18.44 & - & - & - & \\
\hline $73 \mathrm{Glu}$ & 115.99 & - & 58.28 & 29.91 & - & - & - & \\
\hline $74 \mathrm{Arg}$ & 120.72 & 178.97 & 59.06 & 29.45 & 27.34 & 43.56 & - & \\
\hline 75 Ile & 118.38 & - & 62.14 & 34.82 & $26.28,18.37$ & 10.12 & - & \\
\hline 76 Arg & 124.72 & 178.05 & 60.85 & 29.56 & - & - & - & \\
\hline $77 \mathrm{Gln}$ & 116.61 & 178.79 & 58.82 & 28.69 & 34.01 & 179.86 & - & \\
\hline 78 Lys & 117.49 & 178.44 & 58.62 & 32.95 & 24.86 & 29.15 & 42.24 & \\
\hline $79 \mathrm{Thr}$ & 104.6 & - & 62.46 & 72.13 & - & - & - & \\
\hline 80 Gly & 109.45 & 174.01 & 45.81 & - & - & - & - & \\
\hline $81 \mathrm{Ala}$ & 122.9 & 176.24 & 52.02 & 18.63 & - & - & - & \\
\hline $82 \mathrm{Glu}$ & 121.48 & - & 57.38 & 29.77 & - & - & - & \\
\hline 83 Tyr & - & - & 56.09 & 40.55 & - & - & - & \\
\hline $84 \mathrm{Val}$ & - & 173.77 & 62.72 & 32.82 & $19.76,20.18$ & - & - & \\
\hline $84 \mathrm{Val}$ & 119.77 & - & - & - & - & - & - & \\
\hline $85 \mathrm{Val}$ & 127.27 & 175.25 & 60.23 & 34.84 & $21.24,22.37$ & - & - & \\
\hline 86 Ile & 124.21 & 175.15 & 59.94 & 40.98 & $18.52,27.42$ & 14.52 & - & \\
\hline 87 Gly & 116.1 & 172.35 & 44.87 & - & - & - & - & \\
\hline 88 Asn & 116.74 & - & 50.93 & 38.84 & - & - & - & \\
\hline 89 Arg & 115.88 & - & 59.24 & 30.28 & - & - & - & \\
\hline $90 \mathrm{Gln}$ & 115.87 & 175.97 & 56.12 & 28.67 & 34.87 & - & - & \\
\hline
\end{tabular}


Table 8.7: Chemical shift assignments of CitApc R93A (citrate-free)

\begin{tabular}{|c|c|c|c|c|c|c|c|}
\hline & $\mathrm{N}$ & C & $\mathrm{CA}$ & $\mathrm{CB}$ & $\mathrm{CG}$ & $\mathrm{CD}$ & $\mathrm{CE}$ \\
\hline 91 Gly & 107.05 & 173.14 & 45.33 & - & - & - & - \\
\hline 92 Ile & 121.01 & 176.05 & 58.83 & 36.38 & $17.01,27.17$ & 10.3 & - \\
\hline $93 \mathrm{Ala}$ & 126.66 & 176.95 & 52.46 & 18.9 & - & - & - \\
\hline 94 Tyr & 122.71 & - & 55.59 & 40.68 & - & - & - \\
\hline 95 Ala & 120.01 & 175.44 & 51.34 & 22.38 & - & - & - \\
\hline $96 \mathrm{His}$ & 124.15 & - & 58.12 & - & - & - & - \\
\hline 97 Pro & - & - & 64.15 & 31.84 & 27.45 & 49.97 & - \\
\hline 98 Leu & - & - & - & - & - & - & - \\
\hline $99 \mathrm{Thr}$ & 118.53 & - & - & - & - & - & - \\
\hline $99 \mathrm{Thr}$ & - & - & 65.57 & 68.26 & 22.42 & - & - \\
\hline $100 \mathrm{Glu}$ & - & - & - & 28.84 & 36.17 & - & - \\
\hline $101 \mathrm{Arg}$ & - & - & - & 26.46 & 28.28 & - & - \\
\hline 102 Ile & - & - & 63.85 & 37.29 & $29.32,17.35$ & 13.18 & - \\
\hline 103 Gly & - & - & - & - & - & - & - \\
\hline 104 Lys & - & - & - & - & - & - & - \\
\hline $105 \mathrm{Ser}$ & - & - & - & - & - & - & - \\
\hline 106 Met & - & - & - & - & - & - & - \\
\hline $107 \mathrm{Ile}$ & - & - & - & 38.64 & $17.69,27.34$ & 13.04 & - \\
\hline 109 Gly & 110.35 & 173.7 & 45.09 & - & - & - & - \\
\hline 111 Asn & - & - & 54.4 & 38.86 & - & - & - \\
\hline 111 Asn & - & - & - & - & - & - & - \\
\hline 112 Lys & 120.61 & - & 60.82 & 32.27 & - & 29.35 & - \\
\hline 113 Glu & 116.66 & 178.91 & 58.66 & 29.34 & - & - & - \\
\hline $114 \mathrm{Val}$ & 120.99 & 180.37 & 63.45 & 31.46 & 22.31 & - & - \\
\hline 115 Leu & 118.35 & 177.85 & 56.77 & 40.99 & 27.25 & $25.25,22.66$ & - \\
\hline 116 Lys & 116.66 & 176.91 & 56.49 & 32.72 & 25.28 & 29.59 & 42.12 \\
\hline 117 Gly & 107.46 & 173.38 & 45.35 & - & - & - & - \\
\hline 118 Lys & 122.26 & 174.13 & 55.38 & 34.15 & 24.97 & - & 42.31 \\
\hline 119 Ser & 116.47 & 174.99 & 57.45 & 64.31 & - & - & - \\
\hline $120 \mathrm{Ile}$ & 120.5 & - & 59.25 & 42.9 & 17.88 & - & - \\
\hline $121 \mathrm{Ile}$ & 124.52 & 175.71 & 59.82 & 40.65 & $18.47,28.36$ & - & - \\
\hline $122 \mathrm{Ser}$ & 120.32 & 172.65 & 56.78 & 65.99 & - & - & - \\
\hline $123 \mathrm{Glu}$ & 122.63 & - & 55.91 & 32 & 36.92 & - & - \\
\hline 124 Ala & 124.93 & - & 51.11 & 22.39 & - & - & - \\
\hline $125 \mathrm{Val}$ & 120.71 & - & 62.58 & 32.44 & $21.18,21.18$ & - & - \\
\hline 126 Gly & 115.36 & - & 44.81 & - & - & - & - \\
\hline $127 \mathrm{Ser}$ & - & - & 61.15 & 63.03 & - & - & - \\
\hline 128 Leu & - & 176.26 & 54.19 & 42.34 & 27.05 & $23.01,25.40$ & - \\
\hline 129 Gly & 107.14 & - & 44.35 & - & - & - & - \\
\hline 130 Pro & - & - & 64.16 & 32.36 & 27.77 & 49.88 & - \\
\hline 131 Ala & - & 175.58 & 51.31 & 23.54 & - & - & - \\
\hline $133 \mathrm{Arg}$ & 125.96 & - & 54.2 & - & - & - & - \\
\hline 134 Gly & 110.3 & 171.34 & 44.05 & - & - & - & - \\
\hline 135 Lys & 122.67 & 173.79 & 54.18 & 37.18 & - & - & - \\
\hline 136 Ala & 122.87 & - & 47.65 & 22.27 & - & - & - \\
\hline 137 Pro & - & 174.38 & 60.78 & 31.92 & 26.74 & 50.59 & - \\
\hline $138 \mathrm{Ile}$ & 117.89 & 174.92 & 59.88 & 39.76 & $17.50,27.36$ & 15.92 & - \\
\hline 139 Phe & 126.59 & 176.93 & 56.68 & 42.1 & - & - & - \\
\hline $140 \mathrm{Asp}$ & 119.51 & 178.34 & 51.96 & 41.12 & - & - & - \\
\hline 141 Glu & 118.26 & - & 58.94 & 28.69 & - & - & - \\
\hline $142 \mathrm{Asn}$ & 116.39 & 175.71 & 52.7 & 39.58 & 177.21 & - & - \\
\hline 143 Gly & 108.16 & 174.3 & 45.8 & - & - & - & - \\
\hline 144 Ser & 118.76 & 173.9 & 57.93 & 63.5 & - & - & - \\
\hline $145 \mathrm{Val}$ & 124.83 & 177.52 & 63.44 & 31.54 & $22.32,22.32$ & - & - \\
\hline 146 Ile & 121.23 & 175.12 & 60.79 & 39.69 & $18.57,25.56$ & 14.22 & - \\
\hline 147 Gly & 107.03 & 169.99 & 45.92 & - & - & - & - \\
\hline $148 \mathrm{Ile}$ & 118.17 & 173.92 & 60.25 & 44.34 & - & - & - \\
\hline $149 \mathrm{Val}$ & 125.61 & 174.44 & 60.71 & 34.26 & $21.96,21.47$ & - & - \\
\hline 150 Ser & 121.49 & 173.8 & 55.38 & 65.15 & - & - & - \\
\hline $151 \mathrm{Val}$ & - & 174.25 & 60.49 & 34.72 & $21.43,21.43$ & - & - \\
\hline 152 Gly & 112.34 & 172.37 & 44.28 & - & - & - & - \\
\hline 153 Phe & - & - & 57.7 & 44.2 & - & - & - \\
\hline 154 Leu & - & - & 54.69 & 42.35 & 27.24 & $25.34,23.23$ & - \\
\hline
\end{tabular}


Table 8.7: Chemical shift assignments of CitApc R93A (citrate-free)

\begin{tabular}{|c|c|c|c|c|c|c|c|}
\hline & $\mathrm{N}$ & $\mathrm{C}$ & $\mathrm{CA}$ & $\mathrm{CB}$ & $\mathrm{CG}$ & $\mathrm{CD}$ & $\mathrm{CE}$ \\
\hline 155 Leu & - & - & - & - & - & - & - \\
\hline 157 Asp & - & - & - & - & - & - & - \\
\hline 179 Phe & - & - & - & - & - & - & - \\
\hline $180 \mathrm{Gly}$ & - & - & - & - & - & - & - \\
\hline 210 Lys & - & - & - & - & - & - & - \\
\hline 216 Ala & - & - & - & - & - & - & - \\
\hline 220 Gly & - & 172.44 & 45.07 & - & - & - & - \\
\hline $222 \mathrm{Val}$ & - & 173.21 & 61.03 & 35.77 & $20.56,22.16$ & - & - \\
\hline $223 \mathrm{Ala}$ & 128.11 & 176.39 & 49.85 & 23.26 & - & - & - \\
\hline 224 Ile & 110.98 & - & 58.23 & 42.82 & $24.86,18.13$ & 15.28 & - \\
\hline 225 Asn & 119.34 & - & 50.85 & 38.8 & - & - & - \\
\hline $226 \mathrm{Gln}$ & - & 176.59 & 59 & - & - & - & - \\
\hline 227 Glu & 116.77 & - & 56.33 & 29.73 & - & - & - \\
\hline $229 \mathrm{Thr}$ & - & 174.26 & 61.52 & 69.07 & 22.96 & - & - \\
\hline $230 \mathrm{Ile}$ & - & 177.36 & 63.03 & 38.16 & $29.28,18.09$ & 14.51 & - \\
\hline $231 \mathrm{Thr}$ & 121.08 & - & 61.43 & 69.4 & - & - & - \\
\hline 234 Asn & - & - & 50.25 & 40.26 & - & - & - \\
\hline $235 \mathrm{Gln}$ & 119.64 & - & 59.75 & 28.04 & - & - & - \\
\hline $236 \mathrm{Thr}$ & - & - & 66.31 & 68.62 & 22.35 & - & - \\
\hline 239 Lys & 117.68 & - & 58.91 & 32.14 & 25.05 & - & - \\
\hline 240 Leu & 120.69 & - & 57.69 & 42.16 & 27 & $25.01,23.78$ & - \\
\hline 241 Leu & - & - & 55.59 & 43.03 & 27.12 & $25.30,22.97$ & - \\
\hline 242 Gly & 106.48 & 174.06 & 45.69 & - & - & - & - \\
\hline 243 Tyr & 119.02 & - & - & 42.15 & - & - & - \\
\hline 244 Asp & - & - & 54.02 & 42.02 & - & - & - \\
\hline $245 \mathrm{Asn}$ & 115.27 & - & - & - & - & - & - \\
\hline $246 \mathrm{Glu}$ & - & - & 58.3 & 29.06 & 35.56 & - & - \\
\hline $247 \mathrm{Arg}$ & 121.01 & - & 58.3 & - & - & - & - \\
\hline 250 Leu & - & 177.9 & 56.52 & 41.43 & 26.78 & $25.23,23.10$ & - \\
\hline 251 Gly & 109.65 & 173.94 & 45.33 & - & - & - & - \\
\hline $252 \mathrm{Thr}$ & - & - & 60.68 & 69.96 & 21.44 & - & - \\
\hline 253 Pro & - & - & 62.76 & 32.55 & 28.17 & 51.73 & - \\
\hline 255 Leu & - & - & 56.31 & 40.62 & 27 & $25.34,22.88$ & - \\
\hline $256 \mathrm{Gln}$ & 114.77 & - & 57.38 & 29.07 & 34.2 & - & - \\
\hline 257 Leu & - & - & 55.81 & 44.2 & 27.13 & - & - \\
\hline $258 \mathrm{Ile}$ & - & - & 58.32 & 38.16 & 25.92 & 13.67 & - \\
\hline 259 Pro & - & - & 65.06 & 31.93 & 27.24 & 50.12 & - \\
\hline 261 Ser & 115.02 & - & 58.57 & 64.28 & - & - & - \\
\hline 263 Leu & 122.85 & - & - & 39.57 & - & - & - \\
\hline 264 Pro & - & - & 65.68 & 30.82 & 29.3 & 49.82 & - \\
\hline 265 Glu & - & 178.08 & 58.5 & - & - & - & - \\
\hline $266 \mathrm{Val}$ & 120.68 & - & 65.25 & 30.91 & $22.38,21.26$ & - & - \\
\hline $268 \mathrm{Arg}$ & 118.31 & 178.9 & 59.34 & 30.97 & 27.46 & 43.16 & - \\
\hline $269 \mathrm{Thr}$ & 106.65 & 177.36 & 62.51 & 70.31 & 21.82 & - & - \\
\hline 270 Gly & 112.2 & 173.2 & 46.52 & - & - & - & - \\
\hline $271 \mathrm{Gln}$ & 119.7 & 174.01 & 53.92 & 30.23 & 33.4 & - & - \\
\hline 272 Ala & 125.59 & 176.5 & 51.89 & 20.88 & - & - & - \\
\hline 273 Glu & 119.44 & - & 54.84 & 32.04 & 35.62 & - & - \\
\hline 275 Asp & - & 174.49 & 55.73 & 39.62 & - & - & - \\
\hline 276 Asp & 120.77 & - & 53.94 & 42.88 & - & - & - \\
\hline 277 Glu & 126.42 & - & 56.56 & 30.49 & 37.19 & - & - \\
\hline 278 Met & 124.31 & - & 54.6 & 37.01 & 30.89 & - & - \\
\hline $279 \mathrm{Val}$ & 121.78 & - & 61.27 & 32.37 & $21.07,21.07$ & - & - \\
\hline 280 Leu & - & - & 53.8 & 45.08 & 27.03 & - & - \\
\hline 282 Gly & - & 173.52 & 45.03 & - & - & - & - \\
\hline $283 \mathrm{Glu}$ & - & - & 54.35 & 31.94 & 35.53 & - & - \\
\hline $284 \mathrm{Thr}$ & 118.75 & - & 62.86 & 68.94 & 22.36 & - & - \\
\hline $285 \mathrm{Val}$ & - & - & - & 35.39 & $21.19,19.40$ & - & - \\
\hline 286 Ile & - & - & 59.33 & 38.42 & 27.27 & - & - \\
\hline 287 Ala & - & - & 50.19 & 23.15 & - & - & - \\
\hline 291 Pro & - & - & 62.32 & 32.21 & 26.25 & 50.33 & - \\
\hline 292 Ile & - & - & 60.48 & 39.13 & 27.3 & - & - \\
\hline 293 Lys & 125.95 & - & 54.22 & 36.61 & 25.97 & 29.54 & 42.18 \\
\hline
\end{tabular}


Table 8.7: Chemical shift assignments of CitApc R93A (citrate-free)

\begin{tabular}{l|l|l|l|l|l|l|l|l|l}
\hline & $\mathrm{N}$ & $\mathrm{C}$ & $\mathrm{CA}$ & $\mathrm{CB}$ & $\mathrm{CG}$ & $\mathrm{CD}$ & $\mathrm{CE}$ & \\
\hline 294 Asn & - & - & 50.25 & 38.42 & 176.29 & - & - & \\
295 Lys & 118.67 & - & 59.01 & 31.97 & - & 28.97 & - & \\
296 Gln & 116.08 & 175.96 & 56.38 & 28.49 & 34.88 & - & - & \\
297 Gly & 107.46 & 173.55 & 45.3 & - & - & - & - & \\
$298 \mathrm{Arg}$ & - & - & 54.78 & 30.84 & 27.27 & - & - & \\
300 Ile & 119.86 & 175.43 & 60.55 & 39.06 & $18.16,26.48$ & 13.93 & - & \\
301 Gly & 108.42 & 170.74 & 45.51 & - & - & - & - & \\
302 Ala & 120.04 & 173.43 & 51.99 & 22.98 & - & - & - & \\
303 Val & 118.29 & - & - & - & - & - & - & \\
304 Ser & - & 174.36 & 55.58 & 66.06 & - & - & - & \\
305 Thr & - & - & 57.94 & 70.95 & 22.84 & - & - & \\
306 Phe & - & - & 54.71 & 41.94 & - & - & - & \\
307 Arg & - & 174.96 & 53.49 & 33.4 & 26.98 & - & 29.94 & - & \\
309 Lys & - & - & - & 33.98 & 25.6 & &
\end{tabular}

Table 8.8: Chemical shift assignments of CitApc R93A (citrate-bound)

\begin{tabular}{|c|c|c|c|c|c|c|c|}
\hline & $\mathrm{N}$ & C & $\mathrm{CA}$ & $\mathrm{CB}$ & $\mathrm{CG}$ & $\mathrm{CD}$ & $\mathrm{CE}$ \\
\hline 34 Leu & 123.37 & - & - & - & - & - & - \\
\hline 35 Lys & 117.21 & - & 60.88 & 31.85 & - & & \\
\hline $36 \mathrm{Glu}$ & 118.38 & - & 59.08 & 29.62 & - & - & - \\
\hline $37 \mathrm{Gln}$ & 118.61 & 179.38 & 58.85 & 28.62 & 34.04 & - & - \\
\hline 39 Gly & 107.64 & 174.79 & 47.84 & - & - & - & - \\
\hline $40 \mathrm{Met}$ & 119.1 & 178.84 & 58.88 & 32.1 & - & - & - \\
\hline $41 \mathrm{Arg}$ & 121.4 & - & 58.95 & 29.52 & - & - & - \\
\hline 42 Ala & 121.77 & 179.1 & 55.49 & 18.09 & - & - & - \\
\hline 43 Leu & 117.74 & 177.63 & 57.78 & 41.14 & 26.93 & $23.19,25.46$ & \\
\hline $44 \mathrm{Asn}$ & 117.72 & - & 56.57 & 38.85 & - & - & - \\
\hline $45 \mathrm{Val}$ & 120.94 & - & 67.08 & 31.64 & $22.02,22.02$ & - & - \\
\hline 46 Ala & 123.89 & 179.76 & 56.23 & 18.24 & - & - & - \\
\hline $47 \mathrm{Glu}$ & - & - & 59.41 & 29.75 & - & - & - \\
\hline $48 \mathrm{Thr}$ & 118.62 & 177.63 & 66.66 & 68.46 & 20.95 & - & - \\
\hline $49 \mathrm{Val}$ & 123.92 & - & 67.34 & 31.91 & $22.97,24.60$ & - & - \\
\hline 50 Ala & 118.98 & 178.35 & 55.03 & 18.74 & - & - & - \\
\hline 51 Ser & 112.03 & - & 59.56 & 64.87 & - & - & - \\
\hline $52 \mathrm{Thr}$ & - & 176.04 & - & - & - & - & - \\
\hline 53 Ser & - & - & 62.22 & - & - & - & - \\
\hline 54 Leu & 119.64 & 177.6 & 58.33 & 42.29 & 27.11 & 24.78 & - \\
\hline $55 \mathrm{Val}$ & - & 175.95 & 65.4 & 31.06 & $23.61,21.78$ & - & - \\
\hline $56 \mathrm{Arg}$ & 115.59 & - & 59.73 & 30.1 & - & - & - \\
\hline $57 \mathrm{Glu}$ & - & - & - & - & - & 182.8 & - \\
\hline $57 \mathrm{Glu}$ & 118.4 & - & 59.1 & 29.29 & 36.39 & - & - \\
\hline $58 \mathrm{Ala}$ & 122.29 & 179.41 & 54.11 & 18.2 & - & - & - \\
\hline 59 Phe & 114.98 & 177.17 & 61.58 & 38.86 & - & - & - \\
\hline $60 \mathrm{Arg}$ & 117.06 & - & 56.15 & 29.79 & - & - & - \\
\hline $61 \mathrm{Asp}$ & 121.24 & 176.03 & 54 & 40.98 & - & - & - \\
\hline 62 Ser & 116.54 & 175.68 & 61.36 & 62.54 & - & - & - \\
\hline $63 \mathrm{Asn}$ & 114.22 & - & 49.71 & 38.46 & - & - & - \\
\hline 64 Pro & - & 175.85 & 64.45 & 33.61 & 26.85 & 50.84 & - \\
\hline 65 Ser & 107.29 & 175.84 & 62.3 & 64.24 & - & - & - \\
\hline $66 \mathrm{Val}$ & 119.08 & 178.88 & 66.66 & 30.85 & $22.76,20.99$ & - & - \\
\hline $67 \mathrm{Arg}$ & 114.54 & 179.43 & 58.14 & 32.6 & 28.11 & 44.66 & - \\
\hline 68 Leu & 116.87 & 177.15 & 57.87 & 43.36 & 27.39 & $24.03,25.93$ & - \\
\hline $69 \mathrm{Gln}$ & 119.72 & - & 60.36 & 24.76 & 31.06 & 178.43 & - \\
\hline 70 Pro & - & 180.1 & 65.33 & 30.71 & 28.65 & 50.1 & - \\
\hline 71 Phe & 117.2 & 176.06 & 60.92 & 39.63 & - & - & - \\
\hline 72 Ala & 122.26 & 179.65 & 55.84 & 18.42 & - & - & - \\
\hline $73 \mathrm{Glu}$ & 115.81 & - & 57.84 & - & - & - & - \\
\hline $74 \mathrm{Arg}$ & - & - & 59.12 & 29.81 & 27.43 & - & - \\
\hline 75 Ile & - & 179.87 & 62.03 & 34.69 & $26.10,19.06$ & 10.05 & - \\
\hline $76 \mathrm{Arg}$ & 125.4 & 177.97 & 60.98 & 29.36 & 26.21 & 42.71 & - \\
\hline
\end{tabular}


Table 8.8: Chemical shift assignments of CitApc R93A (citrate-bound)

\begin{tabular}{|c|c|c|c|c|c|c|c|c|}
\hline & $\mathrm{N}$ & $\mathrm{C}$ & $\mathrm{CA}$ & $\mathrm{CB}$ & $\mathrm{CG}$ & $\mathrm{CD}$ & $\mathrm{CE}$ & \\
\hline 77 Gln & 116.9 & 178.74 & 58.7 & 28.42 & 34.05 & - & - & \\
\hline 79 Thr & 106.13 & 176.05 & 62.93 & 71.46 & 22.44 & - & - & \\
\hline 80 Gly & 110.08 & 173.74 & 45.32 & - & - & - & - & \\
\hline $81 \mathrm{Ala}$ & 121.29 & 175.56 & 51.42 & 18.43 & - & - & - & \\
\hline $82 \mathrm{Glu}$ & 121.13 & 176.72 & 57.65 & 29.01 & 35.28 & 181.66 & - & \\
\hline 83 Tyr & 104.43 & - & - & - & - & - & - & \\
\hline 83 Tyr & - & 172.86 & 54.57 & 39.22 & - & - & - & \\
\hline $84 \mathrm{Val}$ & 121.17 & 174.24 & 62.37 & 32.02 & $19.74,19.74$ & - & - & \\
\hline $85 \mathrm{Val}$ & 127.22 & - & 60.91 & 34.38 & $19.82,23.59$ & - & - & \\
\hline 86 Ile & 124.63 & 175.34 & 59.65 & 40.33 & $27.70,18.78$ & 14.77 & - & \\
\hline 87 Gly & 116.16 & 172.89 & 44.06 & - & - & - & - & \\
\hline 88 Asn & 116.58 & 176.63 & 50.83 & 38.78 & 176.08 & - & - & 110.06: Nd2 \\
\hline $89 \mathrm{Arg}$ & 115.7 & 176.25 & 58.5 & 30.24 & 28.04 & 43.61 & - & \\
\hline $90 \mathrm{Gln}$ & 115.83 & 176.06 & 55.85 & 28.68 & 34.78 & - & - & \\
\hline 91 Gly & 108.02 & 172.66 & 45.5 & - & - & - & - & \\
\hline 92 Ile & 120.1 & 175.82 & 58.12 & 36.11 & $17.01,26.73$ & 9.81 & - & \\
\hline 93 Ala & 125.62 & 177.09 & 52.5 & 19.14 & - & - & - & \\
\hline $94 \mathrm{Tyr}$ & 122.68 & 174.85 & 55.47 & 40.7 & - & - & - & \\
\hline $95 \mathrm{Ala}$ & 120.1 & 175.38 & 51.31 & 22.45 & - & - & - & \\
\hline 96 His & - & 172.65 & - & - & - & - & - & \\
\hline 96 His & 124.09 & - & 55.98 & 34.44 & - & - & - & \\
\hline 97 Pro & - & 178.18 & 64.51 & 31.68 & 27.99 & 49.45 & - & \\
\hline 98 Leu & 123.76 & 177.21 & 53.17 & 41.04 & 27.25 & 25.48 & - & \\
\hline $99 \mathrm{Thr}$ & 120.93 & 177.62 & 66.06 & 68.2 & 22.45 & - & - & \\
\hline $100 \mathrm{Glu}$ & 120.07 & 176.53 & 58.23 & 28.7 & 36.16 & - & - & \\
\hline 102 Ile & 122.3 & 177.45 & 64.06 & 37.2 & $29.58,17.33$ & 13.15 & - & \\
\hline 103 Gly & 115.65 & 173.66 & 45.03 & - & - & - & - & \\
\hline 104 Lys & 118.81 & - & 53.81 & 35.08 & 25.43 & 28.83 & 42.42 & \\
\hline 105 Ser & 117.41 & 173.38 & 60.05 & 64.01 & - & - & - & \\
\hline 106 Met & 122.69 & - & 56.66 & - & - & - & - & \\
\hline 107 Ile & 130.42 & 175.59 & 59.71 & 40.09 & $16.87,26.96$ & 11.2 & - & \\
\hline 108 Gly & 112.74 & 176.47 & 45.07 & - & - & - & - & \\
\hline 109 Gly & 108.77 & 175.03 & 46.59 & - & - & - & - & \\
\hline 110 Asp & 116.5 & - & 52.16 & 38.44 & 181.88 & - & - & \\
\hline 110 Asp & - & 176.82 & - & - & - & - & - & \\
\hline 111 Asn & 115.48 & - & - & - & - & - & - & \\
\hline 111 Asn & - & - & 54.17 & 39 & 175.52 & - & - & 111.91: Nd2 \\
\hline 112 Lys & 120.25 & 178.89 & 61.23 & 32.73 & 25.13 & 29.55 & 42.01 & \\
\hline 113 Glu & 115.86 & 178.97 & 58.72 & 29.28 & 36.54 & - & - & \\
\hline $114 \mathrm{Val}$ & 120.27 & 180.63 & 63.36 & 31.17 & $22.48,22.48$ & - & - & \\
\hline 115 Leu & 118.49 & 178.04 & 56.84 & 41.22 & 27.29 & $25.33,22.73$ & - & \\
\hline 116 Lys & 116.31 & 176.94 & 56.5 & 32.8 & 25.26 & 29.65 & 42.14 & \\
\hline 117 Gly & 107.4 & 173.62 & 45.33 & - & - & - & - & \\
\hline 118 Lys & 122.91 & 174.11 & 55.24 & 33.82 & 24.99 & 29.22 & - & \\
\hline 119 Ser & 116.83 & 175.2 & 57.29 & 64.16 & - & - & - & \\
\hline 120 Ile & 117.15 & - & 59.33 & 43.11 & $25.68,17.64$ & 14.5 & - & \\
\hline 121 Ile & 121.55 & - & 60.96 & 39.47 & $18.40,29.31$ & 14.2 & - & \\
\hline 122 Ser & 122.63 & 173.53 & 55.38 & 65.48 & - & - & - & \\
\hline $123 \mathrm{Glu}$ & 129.29 & 175.3 & 54.84 & 30.96 & 37.07 & - & - & \\
\hline 124 Ala & 126.7 & 174.77 & 50.87 & 22.45 & - & - & - & \\
\hline $125 \mathrm{Val}$ & 120.15 & 175.73 & 62.32 & 30.84 & $21.02,21.78$ & - & - & \\
\hline 126 Gly & 112.61 & 176.79 & 44.75 & - & - & - & - & \\
\hline 127 Ser & - & - & 62.12 & 63.14 & - & - & - & \\
\hline 128 Leu & 123.51 & 176.87 & 55.07 & 41.81 & 26.15 & $22.95,22.95$ & - & \\
\hline $129 \mathrm{Gly}$ & 105.34 & - & 43.84 & - & - & - & - & \\
\hline 130 Pro & - & - & 63.61 & 32.27 & 28.13 & 49.91 & - & \\
\hline 131 Ala & 130.19 & 175.18 & 52.35 & 24.96 & - & - & - & \\
\hline 132 Ile & 117.96 & 173.8 & 59.58 & 40.74 & - & - & - & \\
\hline $133 \mathrm{Arg}$ & 123.21 & 175.03 & 54.36 & 34.17 & 28.9 & 45.07 & - & \\
\hline 134 Gly & 110.77 & 172.01 & 43.94 & - & - & - & - & \\
\hline 135 Lys & 122.98 & 173.6 & 54.28 & 34.26 & 26.63 & 29.37 & 41.42 & \\
\hline 136 Ala & 123.04 & 174.46 & 47.67 & 22.14 & - & - & - & \\
\hline 137 Pro & - & 174.59 & 60.75 & 31.74 & 26.82 & 50.71 & - & \\
\hline
\end{tabular}


Table 8.8: Chemical shift assignments of CitApc R93A (citrate-bound)

\begin{tabular}{|c|c|c|c|c|c|c|c|}
\hline & $\mathrm{N}$ & $\mathrm{C}$ & $\mathrm{CA}$ & $\mathrm{CB}$ & $\mathrm{CG}$ & $\mathrm{CD}$ & $\mathrm{CE}$ \\
\hline $138 \mathrm{Ile}$ & 118.2 & 175.25 & 59.77 & 39.88 & $27.54,17.50$ & 16.05 & - \\
\hline 139 Phe & 126.44 & 177.29 & 56.73 & 42.46 & - & - & - \\
\hline 140 Asp & 119.3 & 178.24 & 51.88 & 41.17 & - & - & - \\
\hline 140 Asp & - & - & - & - & 179.22 & - & - \\
\hline $141 \mathrm{Glu}$ & 118.06 & 176.85 & 58.84 & 28.62 & 35.89 & - & - \\
\hline $142 \mathrm{Asn}$ & 116.43 & 175.82 & 52.71 & 39.65 & 177.26 & - & - \\
\hline $143 \mathrm{Gly}$ & 108.03 & 174.27 & 45.71 & - & - & - & - \\
\hline 144 Ser & 118.91 & 174.2 & 57.91 & 63.51 & - & - & - \\
\hline $145 \mathrm{Val}$ & 125.07 & 177.46 & 63.52 & 31.47 & $22.34,22.34$ & - & - \\
\hline 146 Ile & 120.97 & 175.19 & 60.78 & 39.77 & $25.58,18.65$ & 14.33 & - \\
\hline 147 Gly & 107.12 & 170.08 & 46 & - & - & - & - \\
\hline $148 \mathrm{Ile}$ & 119.05 & 173.93 & 60.46 & 45.61 & $17.93,27.27$ & 14.39 & - \\
\hline $149 \mathrm{Val}$ & 125.1 & 173.7 & 61 & 33.77 & $22.00,22.00$ & - & - \\
\hline 150 Ser & 122.7 & 173.82 & 55.25 & 65.81 & - & - & - \\
\hline $151 \mathrm{Val}$ & 129.13 & 175.03 & 60.32 & 32.87 & $21.33,20.32$ & - & - \\
\hline 152 Gly & 112.4 & 171.15 & 43.66 & - & - & - & - \\
\hline 153 Phe & - & 174.91 & 57.07 & - & - & - & - \\
\hline 154 Leu & 120.47 & - & 55.34 & 40.65 & 27.13 & $25.68,21.79$ & - \\
\hline $222 \mathrm{Val}$ & - & - & 60.47 & - & - & - & - \\
\hline $223 \mathrm{Ala}$ & - & - & 50.04 & - & - & - & - \\
\hline 224 Ile & - & 176.85 & 58.35 & 42.75 & $18.29,24.90$ & 15.19 & - \\
\hline $225 \mathrm{Asn}$ & 119.06 & - & 50.6 & 38.83 & - & - & - \\
\hline $229 \mathrm{Thr}$ & - & - & 61.69 & 68.99 & 22.94 & - & - \\
\hline $230 \mathrm{Ile}$ & 124.37 & 177.55 & 62.9 & 38.16 & $18.02,29.35$ & 14.45 & - \\
\hline $231 \mathrm{Thr}$ & 121.05 & - & 61.51 & 69.45 & 23.12 & - & - \\
\hline 232 Met & - & - & 56.6 & 32.9 & 35.83 & - & - \\
\hline $233 \mathrm{Val}$ & - & - & 60.3 & - & - & - & - \\
\hline 234 Asn & - & - & 50.04 & - & - & - & - \\
\hline $236 \mathrm{Thr}$ & - & - & 66.44 & 68.65 & 22.16 & - & - \\
\hline $236 \mathrm{Thr}$ & 115.41 & - & - & - & - & - & - \\
\hline 237 Ala & 121.59 & 178.76 & 55.54 & 19.05 & - & - & - \\
\hline 239 Lys & 117.86 & - & 59.08 & 32.23 & 25.18 & 29.31 & 41.96 \\
\hline 240 Leu & 120.52 & - & 57.62 & 42.09 & 27.01 & $23.76,24.92$ & - \\
\hline 241 Leu & - & - & 55.51 & 43.33 & 27.17 & 23.19 & - \\
\hline 242 Gly & - & 174.16 & 45.71 & - & - & - & - \\
\hline 243 Tyr & - & 175.05 & 57.31 & 42.6 & - & - & - \\
\hline 246 Glu & - & - & 58.4 & 28.95 & - & - & - \\
\hline $247 \mathrm{Arg}$ & 120.49 & - & 58.43 & 29.19 & - & - & - \\
\hline 248 Asn & 115.01 & - & 54.14 & 39.16 & - & - & - \\
\hline $249 \mathrm{Val}$ & - & - & 62.69 & - & - & - & - \\
\hline 250 Leu & 120.8 & - & 56.69 & 41.51 & - & - & - \\
\hline 251 Gly & - & 173.95 & 45.32 & - & - & - & - \\
\hline 253 Pro & - & - & 62.91 & 32.56 & 28.19 & 51.84 & - \\
\hline 254 Ile & - & - & - & 37.91 & $30.19,17.99$ & 15.3 & - \\
\hline 255 Leu & 118.95 & - & 56.29 & 40.88 & - & - & - \\
\hline $256 \mathrm{Gln}$ & 115.42 & - & 57.53 & 29.11 & 34.23 & - & - \\
\hline 257 Leu & - & - & 55.98 & 44.09 & 27.09 & - & - \\
\hline $258 \mathrm{Ile}$ & - & - & - & 38.46 & 26.04 & 13.8 & - \\
\hline 259 Pro & - & - & 65.23 & 31.95 & 27.3 & 50.29 & - \\
\hline 261 Ser & - & - & 58.88 & 64.43 & - & - & - \\
\hline 264 Pro & - & - & 65.76 & 30.38 & 29.04 & - & - \\
\hline 265 Glu & 117.57 & - & - & - & - & - & - \\
\hline $268 \mathrm{Arg}$ & 117.38 & - & 59.11 & 31.04 & 27.53 & 43.14 & - \\
\hline $269 \mathrm{Thr}$ & 107.41 & - & 62.58 & 70.33 & 21.64 & - & - \\
\hline 270 Gly & 111.94 & 173.12 & 46.62 & - & - & - & - \\
\hline $271 \mathrm{Gln}$ & 119.23 & - & 53.87 & 30.31 & 33.5 & - & - \\
\hline 272 Ala & 125.37 & - & 51.94 & 20.95 & - & - & - \\
\hline $273 \mathrm{Glu}$ & 119.83 & 173.77 & 54.76 & 32.05 & 35.69 & - & - \\
\hline $274 \mathrm{Tyr}$ & - & - & 56.53 & - & - & - & - \\
\hline 275 Asp & - & 174.45 & 55.45 & 39.48 & - & - & - \\
\hline 276 Asp & 120.77 & - & 53.85 & - & - & - & - \\
\hline 277 Glu & - & - & 56.28 & 30.62 & 37.54 & - & - \\
\hline 278 Met & 124.47 & - & - & - & - & - & - \\
\hline
\end{tabular}


Table 8.8: Chemical shift assignments of CitApc R93A (citrate-bound)

\begin{tabular}{l|l|l|l|l|l|l|l|l|l}
\hline & $\mathrm{N}$ & $\mathrm{C}$ & $\mathrm{CA}$ & $\mathrm{CB}$ & $\mathrm{CG}$ & $\mathrm{CD}$ & $\mathrm{CE}$ & \\
\hline $280 \mathrm{Leu}$ & - & 176.07 & 54.02 & 44.92 & 26.85 & - & - & \\
$281 \mathrm{Gly}$ & 116.65 & - & - & - & - & - & - \\
$282 \mathrm{Gly}$ & - & 173.5 & 45.02 & - & - & - & - \\
$283 \mathrm{Glu}$ & 120.67 & - & 54.59 & 31.91 & 35.6 & - & - \\
$288 \mathrm{Asn}$ & - & - & 52.07 & - & - & - & - \\
$289 \mathrm{Arg}$ & 119.17 & - & - & - & - & - & - \\
$291 \mathrm{Pro}$ & - & - & 61.97 & 32.63 & 26.05 & 50.23 & - \\
$293 \mathrm{Lys}$ & 126.06 & 176.62 & 54.25 & 36.48 & 26.29 & 29.57 & 42.25 & \\
$294 \mathrm{Asn}$ & - & 177.93 & 50.65 & 38.81 & - & - & - \\
$296 \mathrm{Gln}$ & - & - & 56.25 & 28.22 & - & - & - \\
$297 \mathrm{Gly}$ & - & 173.55 & 45.18 & - & - & - & - \\
$298 \mathrm{Arg}$ & 121.88 & - & 54.93 & 31.01 & - & - & - \\
$300 \mathrm{Ile}$ & 120.14 & - & 60.73 & 39.02 & $18.20,26.33$ & 13.9 & - & \\
$301 \mathrm{Gly}$ & - & 170.7 & 45.69 & - & - & - & - \\
$302 \mathrm{Ala}$ & - & 173.79 & 52.23 & 22.96 & - & - & - \\
303 Val & 118.85 & - & 59.25 & 35.81 & - & - & \\
\hline
\end{tabular}

Table 8.9: Residues of PASc visible in spectra of CitApc R93A.

\begin{tabular}{|c|c|c|c|c|c|}
\hline \multirow[b]{2}{*}{ residue } & citrate-free & citrate-bound & \multirow[b]{2}{*}{ residue } & citrate-free & citrate-bound \\
\hline & \multicolumn{2}{|c|}{ visible residues } & & \multicolumn{2}{|c|}{ visible residues } \\
\hline 200 & - & - & 255 & $\mathrm{x}$ & $\mathrm{x}$ \\
\hline 201 & - & - & 256 & $\mathrm{x}$ & $\mathrm{x}$ \\
\hline 202 & - & - & 257 & $\mathrm{x}$ & $\mathrm{x}$ \\
\hline 203 & - & - & 258 & $\mathrm{x}$ & $\mathrm{x}$ \\
\hline 204 & & & 259 & $\mathrm{x}$ & $\mathrm{x}$ \\
\hline 205 & - & - & 260 & - & - \\
\hline 206 & - & - & 261 & $\mathrm{x}$ & $\mathrm{x}$ \\
\hline 207 & - & - & 262 & - & - \\
\hline 208 & - & - & 263 & - & - \\
\hline 209 & - & - & 264 & $\mathrm{x}$ & $\mathrm{x}$ \\
\hline 210 & - & - & 265 & - & - \\
\hline 211 & - & - & 266 & $\mathrm{x}$ & - \\
\hline 212 & - & - & 267 & - & - \\
\hline 213 & - & - & 268 & $\mathrm{x}$ & $\mathrm{x}$ \\
\hline 214 & - & - & 269 & $\mathrm{x}$ & $\mathrm{x}$ \\
\hline 215 & - & - & 270 & $\mathrm{x}$ & $\mathrm{x}$ \\
\hline 216 & - & - & 271 & $\mathrm{x}$ & $\mathrm{x}$ \\
\hline 217 & - & - & 272 & $\mathrm{x}$ & $\mathrm{x}$ \\
\hline 218 & - & - & 273 & $\mathrm{x}$ & $\mathrm{x}$ \\
\hline 219 & - & - & 274 & - & - \\
\hline 220 & $\mathrm{x}$ & & 275 & $\mathrm{x}$ & \\
\hline 221 & - & - & 276 & $\mathrm{x}$ & - \\
\hline 222 & $\mathrm{x}$ & - & 277 & $\mathrm{x}$ & $\mathrm{x}$ \\
\hline 223 & $\mathrm{x}$ & - & 278 & $\mathrm{x}$ & - \\
\hline 224 & $\mathrm{x}$ & $\mathrm{x}$ & 279 & $\mathrm{x}$ & - \\
\hline 225 & $\mathrm{x}$ & $\mathrm{x}$ & 280 & $\mathrm{x}$ & $\mathrm{x}$ \\
\hline 226 & - & - & 281 & - & - \\
\hline 227 & $\mathrm{x}$ & - & 282 & $\mathrm{x}$ & $\mathrm{x}$ \\
\hline 228 & - & - & 283 & $\mathrm{x}$ & $\mathrm{x}$ \\
\hline 229 & $\mathrm{x}$ & $\mathrm{x}$ & 284 & $\mathrm{x}$ & - \\
\hline 230 & $\mathrm{x}$ & $\mathrm{x}$ & 285 & $\mathrm{x}$ & - \\
\hline 231 & $\mathrm{x}$ & $\mathrm{x}$ & 286 & $\mathrm{x}$ & - \\
\hline 232 & - & $\mathrm{x}$ & 287 & $\mathrm{x}$ & - \\
\hline 233 & - & - & 288 & - & - \\
\hline 234 & $\mathrm{x}$ & - & 289 & - & - \\
\hline 235 & $\mathrm{x}$ & - & 290 & - & - \\
\hline 236 & $\mathrm{x}$ & $\mathrm{x}$ & 291 & $\mathrm{x}$ & $\mathrm{x}$ \\
\hline 237 & & $\mathrm{x}$ & 292 & $\mathrm{x}$ & - \\
\hline 238 & - & - & 293 & $\mathrm{x}$ & $\mathrm{x}$ \\
\hline 239 & $\mathrm{x}$ & $\mathrm{x}$ & 294 & $\mathrm{x}$ & $\mathrm{x}$ \\
\hline 240 & $\mathrm{x}$ & $\mathrm{x}$ & 295 & $\mathrm{x}$ & - \\
\hline
\end{tabular}




\begin{tabular}{l|l|l|l|l|l}
241 & $\mathrm{x}$ & $\mathrm{x}$ & 296 & $\mathrm{x}$ & $\mathrm{x}$ \\
242 & $\mathrm{x}$ & $\mathrm{x}$ & 297 & $\mathrm{x}$ & $\mathrm{x}$ \\
243 & - & $\mathrm{x}$ & 298 & $\mathrm{x}$ & - \\
244 & - & - & - & $\mathrm{x}$ \\
245 & - & $\mathrm{x}$ & 300 & $\mathrm{x}$ & $\mathrm{x}$ \\
246 & $\mathrm{x}$ & - & $\mathrm{x}$ & $\mathrm{x}$ \\
247 & - & - & 302 & $\mathrm{x}$ & $\mathrm{x}$ \\
248 & - & - & 304 & $\mathrm{x}$ & - \\
249 & - & 305 & $\mathrm{x}$ & - \\
250 & $\mathrm{x}$ & $\mathrm{x}$ & 306 & $\mathrm{x}$ & - \\
251 & $\mathrm{x}$ & $\mathrm{x}$ & 307 & $\mathrm{x}$ & - \\
252 & $\mathrm{x}$ & - & 308 & - &
\end{tabular}

\subsection{Pulse programs}

\subsubsection{Liquid-state NMR}

${ }^{15} \mathrm{~N}-\mathrm{HSQC}$

;hsqc15N.new

;D. Lee, Nov. 2002

;15N-1H HSQC correlations without water saturation

; The delay for 3-9-19 watergate (d5) should be matched

; with $1 / \mathrm{d} ; \mathrm{d}=$ distance of next null point (in $\mathrm{Hz}$ ).

;S. Mori et al, JMR B108, 94-98 (1995)

;pl1 : power for $1 \mathrm{H}$

;pl2 : power for $13 \mathrm{C}$

;pl3 : power for $15 \mathrm{~N}$

;pl13 : power for $15 \mathrm{~N}$ waltz16 decoupling

;p1 : 90 degree hard pulse $1 \mathrm{H}$

;p3 : 90 degree hard pulse 13C

;p4 : 180 degree hard $13 \mathrm{C}$ pulse (225d for $5 / 600$ )

;p5 : 90 degree hard pulse $15 \mathrm{~N}$

;pcpd3 : 90 deg cpd-pulse15N(waltz16,160u)

;d1 : relaxation delay

;d2 : INEPT delay $(2.7 \mathrm{~m})$

;d5 : delay for $3-9-19=1 /(\mathrm{Hz}$ between nulls $)$

;in0 : 1/(2 SW) $(\mathrm{Hz})$ 
;p21 : 500u (Gradient in
;p22 : 500u (Gradient for
;p23 : $1 \mathrm{~m}$ (Gradient for s
;gpz1 : $19 \%$
;gpz2 : $30 \%$
;gpz3 : $65 \%$
\# include < Avance.incl>
define delay INEPT_W
define delay INEPT_D

define GRADIENT1 10u p21:gp1 200u

define GRADIENT2 10u p22:gp2 200u

define GRADIENT3 10u p23:gp3 200u

"p2 $=2 * \mathrm{p} 1 "$

"p $6=2 * \mathrm{p} 5 "$

"in0 $=$ inf $1 / 2 "$

"d0=in0/2-p5*2/3.14159-p1"

"d $3=\mathrm{d} 5 / 2-\mathrm{p} 5$ "

"INEPT_D $=\mathrm{d} 2-\mathrm{p} 21-210 \mathrm{u} "$

"INEPT_W $=\mathrm{d} 2-\left(\mathrm{p} 23+210 \mathrm{u}+\mathrm{p} 1{ }^{*} 2.3846+\mathrm{d} 5 * 2.5\right) "$

$110 \mathrm{u} \mathrm{ze}$

$21 \mathrm{~m}$ do:f3

d1 pl1:f1

20u pl3:f3

20u LOCKH_ON

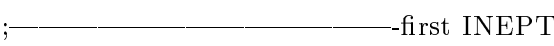

(p1 ph20):f1

GRADIENT1

INEPT_D

(center(p2 ph21):f1 (p6 ph1):f3)

GRADIENT1

INEPT_D

(p1 ph21):f1

GRADIENT2

; - $-15 \mathrm{~N}$ evolution

(p5 ph1):f3

(refalign (d0 p2 ph23 d0):f1 center (p3 ph23 1.5u p4 ph20 1.5u p3 ph23):f2)

(p5 ph20):f3

GRADIENT2 


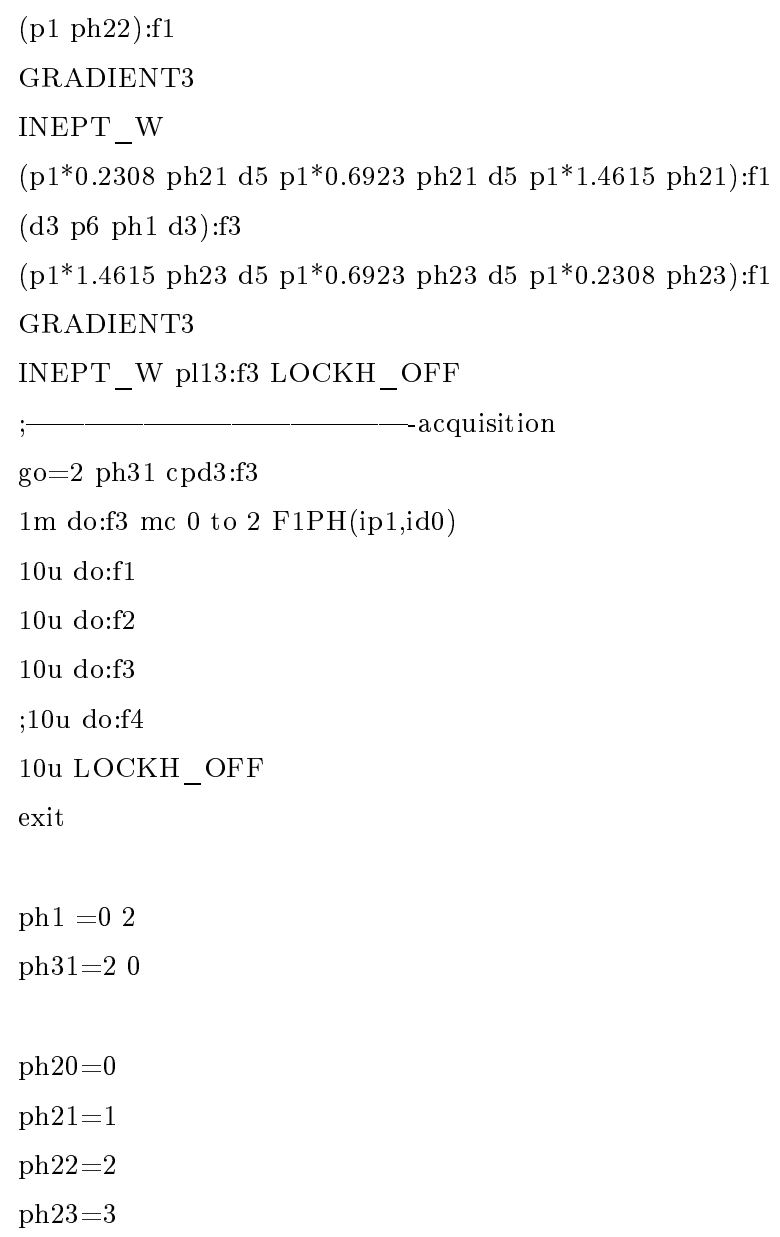

\section{${ }^{15} \mathrm{~N}-\mathrm{NOESY}-\mathrm{HSQC}$}

;hsqc15N.new

;D. Lee, Nov. 2002

;15N-1H HSQC correlations without water saturation ;The delay for 3-9-19 watergate (d5) should be matched ; with $1 / \mathrm{d} ; \mathrm{d}=$ distance of next null point (in $\mathrm{Hz}$ ).

;S. Mori et al, JMR B108, 94-98 (1995)

;pl1 : power for $1 \mathrm{H}$

;pl2 : power for $13 \mathrm{C}$

;pl3 : power for $15 \mathrm{~N}$

;pl13 : power for $15 \mathrm{~N}$ waltz16 decoupling

;p1 : 90 degree hard pulse $1 \mathrm{H}$

;p3 : 90 degree hard pulse 13C

;p4 : 180 degree hard 13C pulse (225d for $5 / 600)$ 
;p5 : 90 degree hard pulse $15 \mathrm{~N}$

;pcpd3 : 90 deg cpd-pulse15N(waltz16,160u)

;d1 : relaxation delay

;d2 : INEPT delay $(2.7 \mathrm{~m})$

;d5 : delay for $3-9-19=1 /(\mathrm{Hz}$ between nulls $)$

;d8 : NOESY mixing

;in0 : 1/(2 SW) $(\mathrm{Hz})$

;p20 : 1m (Gradient in cleaning)

;p21 : 500u (Gradient in first INEPT)

;p22 : 500u (Gradient for z-filter)

;p23 : 1m (Gradient for second INEPT)

;p24 : 500u (Gradient for z-filter)

;p25 : 1m (Gradient for mixing)

;gpz0 : $80 \%$

:gpz1 : $19 \%$

;gpz2 : $30 \%$

;gpz3 : $65 \%$

;gpz4 : $37 \%$

;gpz5 : $60 \%$

;cnst22: 13C betw. CO and C(ali) [100ppm]

;cnst23: 13C betw. C(ali) and C(aro) [70ppm]

include $<$ Avance_dl.incl $>$

define delay INEPT_W

define delay INEPT D

define GRADIENT0 10u p20:gp0 200u

define GRADIENT1 10u p21:gp1 200u

define GRADIENT2 10u p22:gp2 200u

define GRADIENT3 10u p23:gp3 200u

define GRADIENT4 10u p24:gp4 200u

define GRADIENT5 10u p25:gp5 200u

"p2 $=2 * \mathrm{p} 1 "$

"p6 $=2 * \mathrm{p} 5$ "

"in0 $=$ inf $1 / 2$ "

"in $10=$ inf $2 / 2$ "

"d0=in0/2-p1 ${ }^{*} 2 / 3.14159 "$

"d10=in 10/2-p5*2/3.14159"

"d $7=\mathrm{d} 8-(\mathrm{p} 25+210 \mathrm{u}) "$ 
"d3=d5/2-p5"

"INEPT_D=d2-p21-210u"

"INEPT_W=d2-(p23+210u+p $\left.1 *_{2} 2.3846+\mathrm{d} 5 * 2.5\right)$ "

aqseq 312

$110 u$ ze

$21 \mathrm{~m}$

10u do:f3

d1

10u pl1:f1

10u pl2:f2

20u pl3:f3

20u LOCKH_ON

$10 \mathrm{u}$

GRADIENT0

$4 \mathrm{~m}$

$10 \mathrm{u} \mathrm{fq}=\mathrm{cnst} 23(\mathrm{bf} \mathrm{ppm}): \mathrm{f} 2$

$20 \mathrm{u}$

(refalign (p1 ph1 d0 d0 p1 ph2):f1 center (p6 ph20):f3 center(p3 ph21 1.5u p4 ph20 1.5u p3 ph21):f2) GRADIENT5

$\mathrm{d} 7 \mathrm{fq}=\mathrm{cnst} 22(\mathrm{bf} \mathrm{ppm}): \mathrm{f} 2$

;- - - first INEPT

$(\mathrm{p} 1 \mathrm{ph} 20): \mathrm{f} 1$

GRADIENT1

INEPT_D

(center(p2 ph21):f1 (p6 ph20):f3)

GRADIENT1

INEPT_D

(p1 ph21):f1

GRADIENT2

$;-15 \mathrm{~N}$ evolution

; (p5 ph3):f3

(refalign (p5 ph3 d10 d10 p5 ph20):f3 center (p2 ph23):f1 center (p3 ph23 1.5u p4 ph20 1.5u p3 ph23):f2)

; (p5 ph20):f3

GRADIENT4

; - - - - _ _ INECond INEPT

(p1 ph22):f1

GRADIENT3

INEPT_W

(p1*0.2308 ph21 d5 p1*0.6923 ph21 d5 p1*1.4615 ph21):f1

(d3 p6 ph20 d3):f3

(p1*1.4615 ph23 d5 p1*0.6923 ph23 d5 p1*0.2308 ph23):f1

GRADIENT3

INEPT_W pl13:f3 LOCKH_OFF 


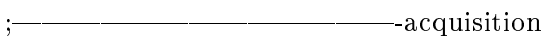

go $=2$ ph31 $\operatorname{cpd} 3: \mathrm{f} 3$

$1 \mathrm{~m}$ do:f3 mc $\# 0$ to 2

F1PH(ip1,id0)

F2PH(rp1 \& rd0 \& ip3,id10)

10u do:f1

10u do:f2

$10 \mathrm{u}$ do:f3

10u LOCKH_OFF

exit

ph1 =00 022

ph2 $=000022222$

ph3 $=02$

ph31=20020220

ph20 $=0$

ph21 $=1$

ph $22=2$

ph $23=3$

\section{HCCH-TOCSY}

Bruker standard pulse program: hcchdigp3d2

\section{HNCO}

Bruker standard pulse program: hncogp3d

\section{${ }^{13}$ C-NOESY-HSQC}

Bruker standard pulse program: noesyhsqcetgp3d

\section{HNCA}

Bruker standard pulse program: hncagpwg3d

\section{CBCACONH}

Bruker standard pulse program: cbcaconhgpwg3d 


\subsubsection{Solid-state NMR}

\section{PDSD}

;sd.ksei

; Pulse program

$;===========$

$1 \mathrm{ze}$

2 d1 do:f2

$1 \mathrm{u} f \mathrm{q}=0: \mathrm{f} 2$

; set initial power levels

$2 \mathrm{u} \mathrm{pl2:f2}$

;90 f2

p2:f2 ph1

;CP f2-f1, uses sp0 power level

(p15 pl5 ph2):f1 (p15:sp0 ph0):f2

;t1 evolution

$1 \mathrm{u} \mathrm{pl12:f2}$

$1 \mathrm{u}$ cpds $2: f 2$

d0

;SD

(p1 pl1 ph3):f1

d11 do:f2

(p1 pl1 ph4):f1

;decoupling

$1 \mathrm{u}$ pl12:f2

$1 \mathrm{u}$ cpds $2: f 2$

;acquisition

go $=2$ ph31

$1 \mathrm{~m}$ do:f2

$100 \mathrm{~m}$ wr $\# 0$ if $\# 0 \mathrm{zd}$

$1 \mathrm{~m}$ ido

$1 \mathrm{~m}$ ip2

lo to 2 times td 1

Halt Acqu, 1m 
exit

ph0 $=0$

ph1 = 11111111

33333333

ph2 $=0$

ph3 = 11113333

ph4 = 0123

ph31=0 01232301

23010123

\section{CANCO}

; CXNCY_3D.suva

;3D version of CXNCY (N-CY) correlation experiment (TPPI in both indirect dimensions)

$; \mathrm{H}$ to $\mathrm{CX} \mathrm{CP}===>\mathrm{CX}$ evoltion $===>\mathrm{CX}$ to $\mathrm{N} \mathrm{CP}===>\mathrm{N}$ evolution $===>\mathrm{N}$ to $\mathrm{CY} \mathrm{CP}===>\mathrm{C}$ evolution ;CW decoupling on protons during $\mathrm{N}$ from/to $\mathrm{C}$ transfer

;Similar Proton decoupling during both acquisition dimensions

; N (J) decoupling using 180 pulse in the indirect F1 dimension

; C (J) decoupling using 180 pulse in the indirect F2 dimension

; Variables introduction

; $==============$

;pl2 H 90 pulse power

;p2 H 90 pulse length

;131 (=2) HCX CP ramp on H, (=3) HCX CP ramp on C

;P15 HCX CP build up time

;pl5 (=sp1) HCX CP power on CX

;pl6 (=sp0) HCX CP power on $\mathrm{H}$

;cnst10 HCX CP offset on $\mathrm{C}$

; cnst20 HN CP offset on $\mathrm{H}$

;pl1 C 90 pulse power

;p1 C 90 pulse length

;p4 $\left(=2^{*} \mathrm{p} 1\right) \times 180$ pulse length

;29 (=1) CXN CP ramp on CX, (=3) CXN CP ramp on N, (=13) CXN CP ramp on both NC

;p35 CXN CP build up time

;p19 (=sp5) CXN CP power on $\mathrm{N}$

;pl10 (=sp6) CXN CP power on $\mathrm{C}$

;130 (=1) NCY CP ramp on CY, (=3) NCY CP ramp on N, (=13) NCY CP ramp on both NC

;cnst11 NCY CP offset on $\mathrm{C}$

;cnst12 C offset for $\mathrm{C}$ j decoupling during $\mathrm{N}$ evolution

;P25 NCY CP build up time 
;pl7 (=sp2) NCY CP power on C

;pl8 (=sp3) NCY CP power on $\mathrm{N}$

;pl3 N 90 pulse power

;p3 N 90 pulse length

;p5 (= 2*p3) N 180 pulse length

;pl11 H CW decoupling during NC CP

;pl12 H decoupling during both acquisitions

;cpds2 H decoupling program

;p31 H decoupling pulse length

;cnst21 H decoupling offset

\section{; Set variables}

$:======-=-$

;"131 = 2"

;"sp0 = pl6"

;"sp1 = pl5"

;"130 = 1"

;"sp2 = p17"

;"sp3 = pl8"

;"sp4 = pl10"

;"sp5 = p19"

;"p4 $=2^{*} \mathrm{p} 1 "$

;"p5 = 2*p3"

;"cnst63 = pl12"

;"cnst62 = pl11"

"d0=1u"

"in $0=\inf 1 / 2$ "

"d10= $1 \mathrm{u} "$

"in $10=\inf 2 / 2 "$

\section{; Begin Pulse program}

$1 \mathrm{ze}$

; _ Relaxation \& reset parameters

2 d1 do:f2

$2 \mathrm{u} \mathrm{pl1:f1} \mathrm{pl2:f2} \mathrm{pl5:f3}$ 


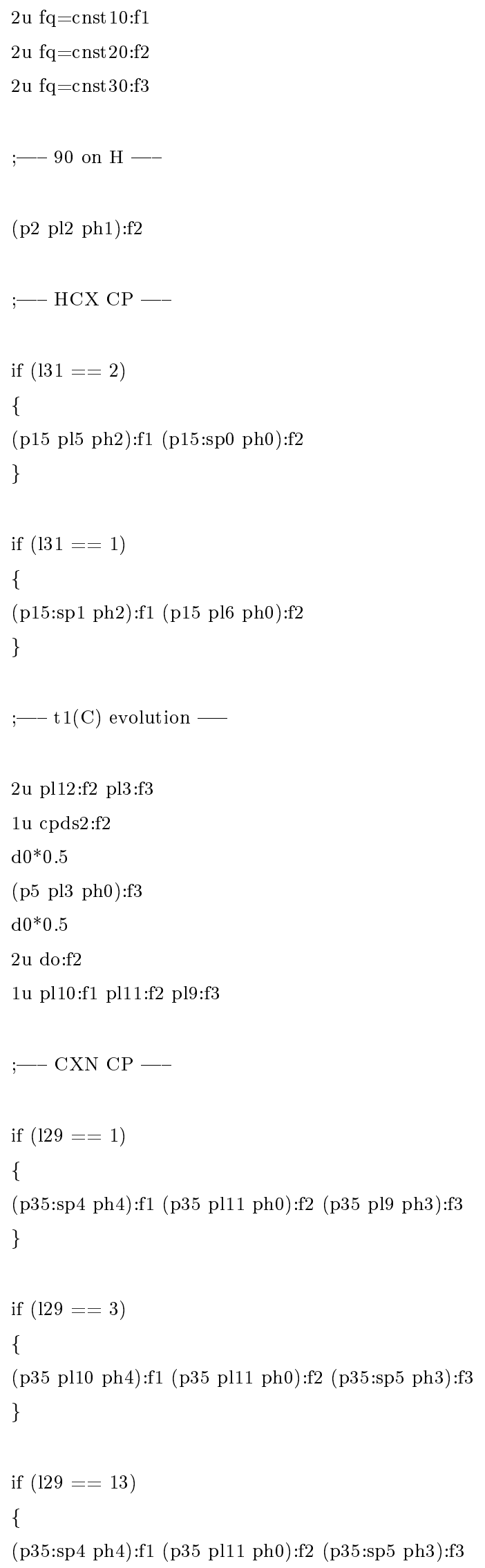


\}

;- $-\mathrm{t} 2(\mathrm{~N})$ evolution -

$1 \mathrm{u} \mathrm{pl1:f1} \mathrm{pl12:f2}$

$1 \mathrm{u}$ cpds2:f2

$2 \mathrm{u} \mathrm{fq}=\mathrm{cnst} 12: \mathrm{f} 1$

$\mathrm{d} 10 * 0.5$

(p4 pl1 ph0):f1

$\mathrm{d} 10^{*} 0.5$

$2 \mathrm{u}$ do:f2

2u pl7:f1 pl11:f2 pl8:f3

$;-\mathrm{NCY} \mathrm{CP}-$

$2 \mathrm{u} \mathrm{fq}=$ cnst $11: \mathrm{f} 1$

if $(130==1)$

\{

(p25:sp2 ph5):f1 (p25 pl11 ph0):f2 (p25 pl8 ph6):f3

\}

if $(130==3)$

\{

(p25 pl7 ph5):f1 (p25 pl11 ph0):f2 (p25:sp3 ph6):f3

\}

if $(130==13)$

\{

(p25:sp2 ph5):f1 (p25 pl11 ph0):f2 (p25:sp3 ph6):f3

\}

;- acquisition with $\mathrm{H}$ decoupling -

$2 \mathrm{u} \mathrm{fq}=0: \mathrm{f} 1$

$1 \mathrm{u} \mathrm{pl12:f2}$

1u cpds2:f2

go $=2$ ph 31

$1 \mathrm{~m}$ do:f2

;- write data -

$10 \mathrm{~m}$ wr $\# 0$ if $\# 0 \mathrm{zd}$

$1 \mathrm{~m} \operatorname{id} 10$ 
$1 \mathrm{~m}$ ip3

lo to 2 times td2

$1 \mathrm{~m} \operatorname{rd} 10$

$1 \mathrm{~m}$ rp3

$1 \mathrm{~m}$ ido

$1 \mathrm{~m}$ ip2

lo to 2 times $\operatorname{td} 1$

Halt Acqu, $1 \mathrm{~m}$

exit

;_ Phase cycling _-

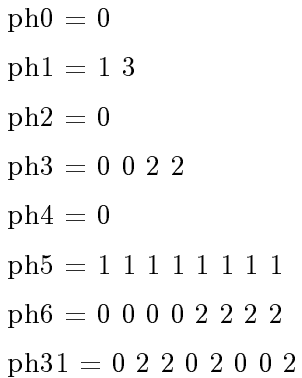

; END Pulse program

$;===============$

\section{CA(NCO)CA}

; CXNCYCZ_BSHCP_CC_2D.suva

;2D (CC) version of CXNCYCZ correlation experiment (TPPI in both indirect dimensions)

$; \mathrm{H}$ to $\mathrm{CX} \mathrm{CP}===>\mathrm{CX}$ evolution $===>\mathrm{CX}$ to $\mathrm{N} \mathrm{CP}===>\mathrm{N}$ to $\mathrm{CY} \mathrm{CP}===>\mathrm{CYCZ} \mathrm{BSHCP}===>\mathrm{C}$ evolution ;CW decoupling on protons during $\mathrm{N}$ from/to $\mathrm{C}$ transfer

;Similar Proton decoupling during both acquisition dimensions

; $\mathrm{N}(\mathrm{J})$ decoupling using 180 pulse in the indirect $\mathrm{F} 1$ dimension

; C (J) decoupling using 180 pulse in the indirect F2 dimension

; Variables introduction

$================$

;pl2 H 90 pulse power

;p2 H 90 pulse length

;131 (=2) HCX CP ramp on H, (=3) HCX CP ramp on C 
;P15 HCX CP build up time

;pl5 (=sp1) HCX CP power on CX

;pl6 (=sp0) HCX CP power on $\mathrm{H}$

;cnst10 HCX CP offset on $\mathrm{C}$

;cnst20 HN CP offset on $\mathrm{H}$

;pl1 C 90 pulse power

;p1 C 90 pulse length

;p4 (=2*p1) X 180 pulse length

;129 (=1) CXN CP ramp on CX, (=3) CXN CP ramp on N, (=13) CXN CP ramp on both NC

;p35 CXN CP build up time

;pl9 (=sp5) CXN CP power on $\mathrm{N}$

;pl10 (=sp4) CXN CP power on $\mathrm{C}$

;130 (=1) NCY CP ramp on CY, (=3) NCY CP ramp on N, (=13) NCY CP ramp on both NC

;cnst11 NCY CP offset on C

;P25 NCY CP build up time

;pl7 (=sp2) NCY CP power on $\mathrm{C}$

;pl8 (=sp3) NCY CP power on N

;pl3 N 90 pulse power

;p3 N 90 pulse length

;p5 (=2*p3) N 180 pulse length

;pl11 H CW decoupling during NC CP

;pl13 H CW decoupling during COCA BSHCP

;cpd1 $\mathrm{H}$ decoupling during COCA BSHCP

;pl17 COCA BSH CP power on $\mathrm{C}$

;p17 13C COCA CP contact time

;p18 CO flip pulse ca. 60 grad

; cnst13 COCA BSHCP offset on CA

;p19 CO flip to Y, ca. $4.5 \mathrm{u}$

;pl12 H decoupling during both acquisitions

;cpds2 $\mathrm{H}$ decoupling program

;p31 H decoupling pulse length

;cnst21 H decoupling offset

; Set variables

$$
\begin{aligned}
; " 131 & =2 " \\
; " s p 0 & =\text { pl6" } \\
; " s p 1 & =\text { p15" } \\
; " 130 & =1 " \\
; " s p 2 & =\text { p17" } \\
; " s p 3 & =\text { pl8" } \\
; " s p 4 & =\text { pl10" } \\
; " s p 5 & =\text { p19" }
\end{aligned}
$$


;"p4 = 2*p1"

;"p5 $=2^{*} \mathrm{p} 3 "$

;"cnst63 = pl12"

;"cnst62 = pl11"

;"sp17 = pl17"

;"cnst61 = pl13"

"d0 $=0.4 \mathrm{u} "$

"in0 $=\inf 1 / 2 "$

; Begin Pulse program

$;===============$

1 ze

;- Relaxation \& reset parameters -

$2 \mathrm{~d} 1 \mathrm{do}: \mathrm{f} 2$

2u pl1:f1 pl2:f2 pl5:f3

$2 \mathrm{u} \mathrm{fq}=\mathrm{cnst} 10: \mathrm{f} 1$

$2 \mathrm{ufq}=\mathrm{cnst} 20: \mathrm{f} 2$

$2 \mathrm{u} \mathrm{fq}=\mathrm{cnst} 30: \mathrm{f} 3$

; 90 on $\mathrm{H}-$

(p2 pl2 ph1):f2

;- HCX CP -

if $(131==2)$

\{

(p15 pl5 ph2):f1 (p15:sp0 ph0):f2

\}

if $(131==1)$

\{

(p15:sp1 ph2):f1 (p15 pl6 ph0):f2

\}

;- - t1(C) evolution -

2u pl12:f2 pl3:f3

1u cpds $2: f 2$ 
$\mathrm{d} 0 * 0.5$

(p5 pl3 ph0):f3

$\mathrm{d} 0 * 0.5$

$2 \mathrm{u}$ do:f2

1u pl10:f1 pl11:f2 pl9:f3

$;-\mathrm{CXN} \mathrm{CP}-$

if $(129==1)$

\{

(p35:sp4 ph4):f1 (p35 pl11 ph0):f2 (p35 pl9 ph3):f3

\}

if $(129==3)$

\{

(p35 pl10 ph4):f1 (p35 pl11 ph0):f2 (p35:sp5 ph3):f3 \}

if $(129==13)$

\{

(p35:sp4 ph4):f1 (p35 pl11 ph0):f2 (p35:sp5 ph3):f3 \}

$;-\mathrm{NCY} \mathrm{CP}-$

$1 \mathrm{u} \mathrm{fq}=\mathrm{cnst} 11: \mathrm{f} 1$

1u pl7:f1 pl11:f2 pl8:f3

if $(130==1)$

\{

(p25:sp2 ph5):f1 (p25 pl11 ph0):f2 (p25 pl8 ph6):f3

\}

if $(130==3)$

\{

(p25 pl7 ph5):f1 (p25 pl11 ph0):f2 (p25:sp3 ph6):f3

\}

if $(130==13)$

\{

(p25:sp2 ph5):f1 (p25 pl11 ph0):f2 (p25:sp3 ph6):f3

\}

;- COCA BSH CP \& CW during $\mathrm{CP}$ 
0.8u pl1:f1 pl13:f2

$0.8 \mathrm{u}$ cpds1:f2

(p18 pl1 ph18):f1

$1 \mathrm{u} \mathrm{fq}=\mathrm{cnst} 13: \mathrm{f} 1$

(p17:sp17 ph17):f1

(p19 pl1 ph19):f1

$1 \mathrm{u}$ do:f2

;_ acquisition with $\mathrm{H}$ decoupling

$2 \mathrm{u} f \mathrm{q}=0: \mathrm{f} 1$

$1 \mathrm{u}$ pl12:f2

1u cpds2:f2

go $=2 \mathrm{ph} 31$

10u do:f2

;- write data \& 2D increments -

$10 \mathrm{~m} w \mathrm{r} \# 0$ if $\# 0 \mathrm{zd}$

$1 \mathrm{~m}$ ido

1m ip2

lo to 2 times td 1

Halt Acqu, $1 \mathrm{~m}$

exit

;- Phase cycling -

ph0 $=0$

ph1 $=13$

ph2 $=0$

$\mathrm{ph} 3=0$

ph4 $=0022$

ph5 $=1111111133333333$

ph $6=\begin{array}{lllllll}0 & 0 & 0 & 0 & 2 & 2 & 2\end{array} 2$

ph17=1111111133333333

ph18 = 22222222200000000

ph19= 3333333311111111

ph31 $=0220200220020220$

; END Pulse program 


\section{NCACB}

;NCACB_3D.cshi

;DREAM for N-CA-CB, protonated sample

"p $4=2 * \mathrm{p} 1 "$

"p $6=2 * \mathrm{p} 3 "$

"d $0=0.2 \mathrm{u} "$

"d $10=0.2 \mathrm{u}$ "

"in $0=\inf 1 / 2 "$

"in $10=$ inf $2 / 2 "$

1 ze

2 d1 do:f2

$1 \mathrm{u}$ do:f3

$1 \mathrm{u} f \mathrm{q}=0: \mathrm{f} 2$

; $1 \mathrm{u} \mathrm{fq}=\mathrm{cnst} 13: \mathrm{f3} ; 15 \mathrm{~N}$ freq

; 1u pl13:f3 ; 15N/13C GARP/W16

$2 \mathrm{u} \mathrm{fq}=$ cnst10:f1; C0 freq.

$1 \mathrm{u} \mathrm{pl2:f2} \mathrm{pl5:f3}$

; H 90

p2:f2 ph1

; $\mathrm{HN} \mathrm{CP}$

(p15:sp1 ph0):f2 (p15 pl5 ph2):f3

; t1 $(\mathrm{N})$ evolution

$1 \mathrm{u} \mathrm{pl12:f2}$

$1 \mathrm{u}$ cpds2:f2

$\mathrm{d} 0 * 0.5$

(p4 pl1 ph0):f1

$\mathrm{d} 0 * 0.5$

$1 \mathrm{u}$ do:f2

; $\mathrm{NC} \mathrm{CP}$

if $(130==1)$

$\{(\mathrm{p} 25: \mathrm{sp} 2 \mathrm{ph} 4): \mathrm{f} 1$ (p25 pl11 ph0):f2 (p25 pl8 ph3):f3

\}

if $(130==2)$

$\{(\mathrm{p} 25$ pl7 ph4):f1 (p25 pl11 ph0):f2 (p25:sp3 ph3):f3 
; - Second $\mathrm{t} 2(\mathrm{CO})$ evolution -

1u pl12:f2 pl3:f3

1u cpds2:f2

$\mathrm{d} 10 * 0.5$

(p6 pl3 ph0):f3

$\mathrm{d} 10 * 0.5$

$1 \mathrm{u}$ do:f2

; DREAM for CACB transfer

$1 \mathrm{u} \mathrm{fq}=$ cnst $25: \mathrm{f} 1$

(p17:sp17 ph17):f1 (p17 pl14 ph0):f2

;- acquisition with $\mathrm{H}$ decoupling -

$1 \mathrm{u}$ pl12:f2

1u cpds2:f2

; 1u cpds3:f3 ;

go $=2 \mathrm{ph} 31$

10u do:f2

; 10u do:f3

- write data \& 3D increments -

$10 \mathrm{~m}$ wr $\# 0$ if $\# 0 \mathrm{zd}$

$1 \mathrm{~m}$ id 10

$1 \mathrm{~m}$ ip4

lo to 2 times $\operatorname{td} 2$

$1 \mathrm{~m} \operatorname{rd} 10$

$1 \mathrm{~m}$ rp4

$1 \mathrm{~m}$ id0

1m ip2

lo to 2 times td 1

HaltAcqu, $1 \mathrm{~m}$

exit

$\mathrm{ph} 0=02 ; 1 \mathrm{H} \mathrm{cp}$

ph1=11113333;1H p90 excite

ph2 $=0022 ; 15 \mathrm{~N}$ in 1 Hto $15 \mathrm{~N} \mathrm{cp}$

$\mathrm{ph} 3=0 ; 15 \mathrm{~N}$ in $\mathrm{NCA} \mathrm{dcp}$

$\mathrm{ph} 4=0$

ph17=0 00000000222222222 


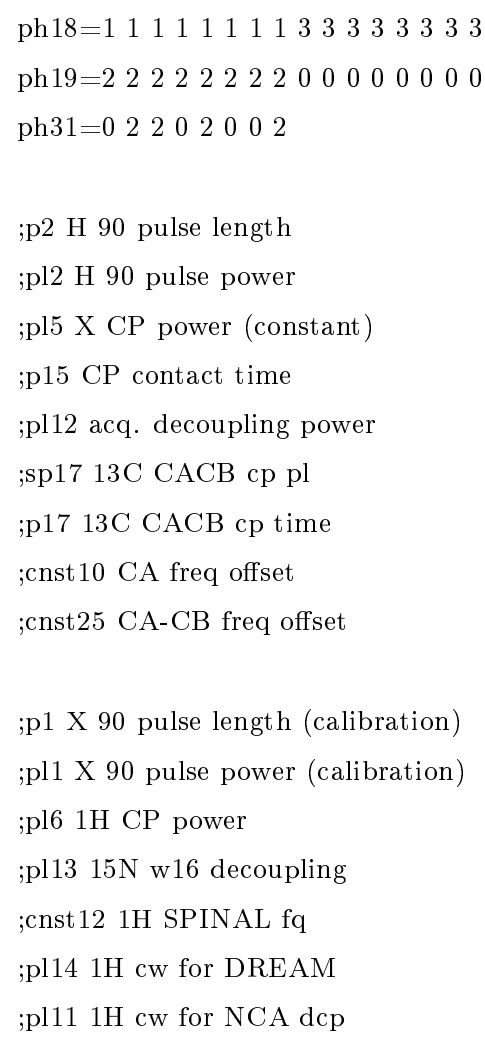

\section{NCACO}

; $\mathrm{NCACO}_{-} \mathrm{BSHCP}_{-} 3 \mathrm{D} . \mathrm{suva}$

;3D version of NCACO correlation experiment (TPPI in both indirect dimensions)

$; \mathrm{H}$ to $\mathrm{N} \mathrm{CP}===>\mathrm{N}$ evolution $===>\mathrm{N}$ to $\mathrm{CA} \mathrm{CP}==>\mathrm{CO}$ evolution $==>\mathrm{CACO} \mathrm{BSHCP}==>\mathrm{C}$ evolution ;CW decoupling on protons during $\mathrm{N}$ to $\mathrm{C}$ transfer and CACO BSH CP

;Similar Proton decoupling during both acquisition dimensions

; C (J) decoupling using 180 pulse in the indirect F1 dimension

; N (J) decoupling using 180 pulse in the indirect F2 dimension

; Variables introduction

;pl2 H 90 pulse power ;p2 H 90 pulse length ;131 (=2) HN CP ramp on $\mathrm{H},(=3) \mathrm{HN}$ CP $\operatorname{ramp}$ on $\mathrm{N}$ ;P15 HN CP build up time ;pl5 (=sp1) HN CP power on $\mathrm{N}$ ;pl6 (=sp0) HN CP power on $\mathrm{H}$ ; cnst30 HN CP offset on $\mathrm{N}$ ; cnst20 HN CP offset on $\mathrm{H}$ 
;pl1 X 90 pulse power

;p1 X 90 pulse length

;p4 (=2*p1) X 180 pulse length

;cnst10 NCO CP offset on CO

;130 (=1) NC CP ramp on C, (=3) NC CP ramp on N, (=13) NC CP ramp on both NC

;P25 NC CP build up time

;pl7 (=sp2) NC CP power on C

;pl8 (=sp3) NC CP power on $\mathrm{N}$

;pl11 H CW decoupling during NC CP

;pl13 H CW decoupling during CACO BSHCP

;cpd1 $\mathrm{H}$ decoupling during CACO BSHCP

;pl17 CACO BSH CP power on C

;p17 13C CACO CP contact time

;cnst11 CACO BSHCP offset on CA

;p19 CO flip to Y, ca. 4.5u

;pl12 $\mathrm{H}$ decoupling during both acquisitions

;cpd2 $\mathrm{H}$ decoupling program

;p31 H decoupling pulse length

;cnst21 H decoupling offset

\section{; - - - - - - - - - - -}

; Set variables

$;==========$

;"131 = 2"

;"sp0 = pl6"

;"sp $1=\mathrm{pl} 15^{\prime \prime}$

;"sp2 = pl7"

;"sp3 = pl8"

$; " \mathrm{p} 4=2^{*} \mathrm{p} 1 "$

;"p6 $=2 * \mathrm{p} 3 "$

;"cnst63 = pl12"

;"cnst62 = pl11"

;"sp17 = pl17"

;"cnst61 = pl13"

"d0 $=0.2 \mathrm{u} "$

"in0 $=$ inf $1 / 2 "$

$" \mathrm{~d} 10=0.2 \mathrm{u} "$

"in10 = inf2/2"

; Begin Pulse program 
$1 \mathrm{ze}$

;- Relaxation \& reset parameters

2 d1 do:f2

2u pl1:f1 pl2:f2 pl5:f3

$2 \mathrm{ufq}=0: \mathrm{f} 1$

$2 \mathrm{ufq}=\mathrm{cnst} 20: \mathrm{f} 2$

$2 \mathrm{u} \mathrm{fq}=\mathrm{cnst} 30: \mathrm{f3}$

;- 90 on $\mathrm{H}$

(p2 pl2 ph1):f2

;- HN CP -

if $(131==2)$

\{

(p15:sp0 ph0):f2 (p15 pl5 ph2):f3

\}

if $(131==3)$

\{

(p15 pl6 ph0):f2 (p15:sp1 ph2):f3

\}

;- First t1 (N) evolution -

2u pl1:f1 pl12:f2

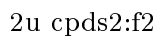

$\mathrm{d} 0 * 0.5$

(p4 pl1 ph5):f1

$\mathrm{d} 0 * 0.5$

$2 \mathrm{u}$ do:f2

$2 \mathrm{ufq}=\mathrm{cnst} 10: \mathrm{f} 1$

;- $\mathrm{NC} \mathrm{CP}-$

if $(130==1)$

\{

(p25:sp2 ph4):f1 (p25 pl11 ph5):f2 (p25 pl8 ph3):f3

\} 


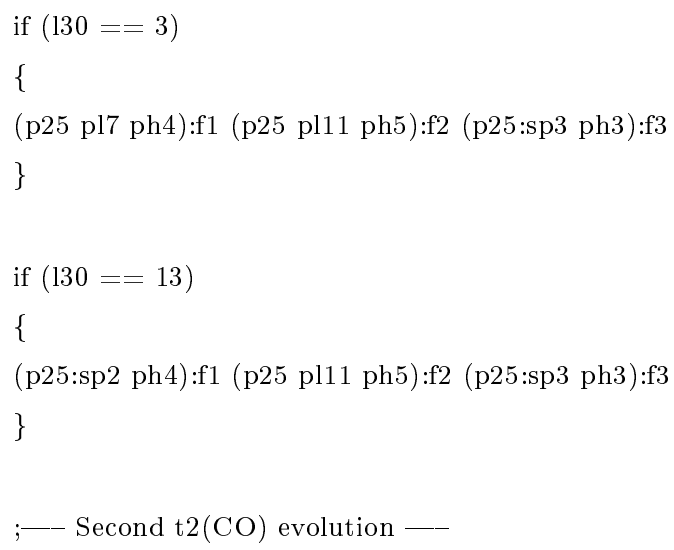

$1 \mathrm{u}$ do:f2

;- acquisition with $\mathrm{H}$ decoupling

1u pl12:f2

1u cpds2:f2

go $=2 \mathrm{ph} 31$

10u do:f2

;- write data \& 3D increments -

$10 \mathrm{~m} w \mathrm{r} \# 0$ if $\# 0 \mathrm{zd}$

$1 \mathrm{~m}$ id 10

$1 \mathrm{~m}$ ip4

lo to 2 times td2 
$1 \mathrm{~m} \operatorname{rd} 10$

$1 \mathrm{~m} \mathrm{rp} 4$

$1 \mathrm{~m}$ id0

$1 \mathrm{~m}$ ip2

lo to 2 times $\operatorname{td} 1$

Halt Acqu, $1 \mathrm{~m}$

exit

;-_ Phase cycling _

ph0 $=02$

ph1 = 11113333

ph2 $=0022$

$\operatorname{ph} 3=0$

$\mathrm{ph} 4=0$

ph $5=0$

ph17 = 00000000022222222

$\mathrm{ph} 19=1111111133333333$

$\mathrm{ph} 31=02202002$

\section{; END Pulse program}

\section{NCOCA}

\section{;NCOCA_BSH_3d.cshi}

; $\mathrm{BSH}$ for $\mathrm{N}-\mathrm{CO}-\mathrm{CA}$, protonated sample ; v2 for CO flip along Y axis

$$
\begin{aligned}
& \text { "p } 4=2^{*} \mathrm{p} 1 " \\
& \text { "p6=2*p3" } \\
& \text { "in } 0=\mathrm{inf} 1 / 2 " \\
& \text { "in } 10=\mathrm{inf} 2 / 2^{\prime} \\
& \text { "d0=1u" } \\
& \text { "d } 10=1 \mathrm{u}^{\prime}
\end{aligned}
$$

; Pulse program

$1 \mathrm{ze}$

2 d1 do:f2

; $1 \mathrm{u}$ do:f3 
$1 \mathrm{u} \mathrm{fq}=0: \mathrm{f} 2$

; $1 \mathrm{u} \mathrm{fq}=$ cnst $13: \mathrm{f} 3 ; 15 \mathrm{~N}$ freq

; 1u pl13:f3 ; 15N/13C GARP/W16

$1 \mathrm{u} \mathrm{fq}=$ cnst $10: \mathrm{f} 1$; C0 freq.

10u pl2:f2 pl5:f3

; H 90

p2:f2 ph1

; $\mathrm{HN} \mathrm{CP}$

(p15:sp1 ph0):f2 (p15 pl5 ph2):f3

; t1 (N) evolution

$1 \mathrm{u} \mathrm{pl12:f2}$

1u cpds2:f2

d $0 * 0.5$

(p4 pl1 ph0):f1

d $0 * 0.5$

$1 \mathrm{u}$ do:f2

; $\mathrm{NC} \mathrm{CP}$

$1 \mathrm{u} \mathrm{fq}=\mathrm{cnst} 11: \mathrm{f} 1$

if $(130==1)$

$\{(\mathrm{p} 25: \mathrm{sp} 2 \mathrm{ph} 4): \mathrm{f} 1$ (p25 pl11 ph0):f2 (p25 pl8 ph3):f3

\}

if $(130==2)$

$\{(\mathrm{p} 25 \mathrm{pl}$ ph4):f1 (p25 pl11 ph0):f2 (p25:sp3 ph3):f3

\}

; t2(CX) evolution

1u pl12:f2 pl3:f3

1u cpds2:f2

$\mathrm{d} 10 * 0.5$

(p6 pl3 ph0):f3

$\mathrm{d} 10 * 0.5$

$1 \mathrm{u} \mathrm{do:f2}$

; flip CO for COCA cp

$1 \mathrm{u}$ pl1:f1

(p18 ph18):f1

; COCA cp

$1 \mathrm{u} \mathrm{fq}=\mathrm{cnst} 25: \mathrm{f} 1$

(p17:sp17 ph17):f1 (p17 pl14 ph3):f2

; (p19 ph19):f1 ; CA lock on X, CO flip to Y 


\author{
; Acquisition with $\mathrm{H}$ decoupling \\ 1u pl12:f2 \\ 1u cpds2:f2 \\ go $=2$ ph 31 \\ 10u do:f2 \\ ; Write data \& 3D increments \\ $10 \mathrm{~m}$ wr $\# 0$ if $\# 0 \mathrm{zd}$ \\ $1 \mathrm{~m}$ id 10 \\ $1 \mathrm{~m}$ ip4 \\ lo to 2 times $\operatorname{td} 2$ \\ $1 \mathrm{~m}$ rd10 \\ $1 \mathrm{~m}$ rp4 \\ $1 \mathrm{~m}$ id0 \\ $1 \mathrm{~m}$ ip2 \\ lo to 2 times $\operatorname{td} 1$
}

Halt Acqu, $1 \mathrm{~m}$

exit

$\mathrm{ph} 0=02 ; 1 \mathrm{H} \mathrm{cp}$

ph1= $11113333 ; 1 \mathrm{H}$ p90 excite

$\mathrm{ph} 2=0022 ; 15 \mathrm{~N}$ in $1 \mathrm{Hto} 15 \mathrm{~N} \mathrm{cp}$

$\mathrm{ph} 3=0 ; 15 \mathrm{~N}$ in NCA dcp

$\operatorname{ph} 4=0$

ph17=0 00000000022222222

ph18=1111111133333333

ph19=2 222222200000000

ph31=0 222020002

;p2 H 90 pulse length

;pl2 H 90 pulse power

;pl5 X CP power (constant)

;p15 CP contact time

;pl12 acq. decoupling power

;pl17 13C COCA cp pl

;p17 13C COCA cp time

;pl18 = pl1, CO flip pulse

;p18 CO flip pulse ca. 60 grad

;cnst10 CO freq offset

;cnst25 CA freq offset

;p1 X 90 pulse length (calibration)

;p4 X 180 pulse length (calibration) 
;pl1 X 90 pulse power (calibration) ;p3 N 90 pulse length (calibration) ;p6 N 180 pulse length (calibration) ;pl3 N 90 pulse power (calibration) ;pl6 1H CP power ;pl13 15N w16 decoupling ;cnst12 1H SPINAL fa ;pl14 1H cw for BSH ;pl11 1H cw for NCA dcp ;pl8 $15 \mathrm{~N}$ in NCO dcp ;p19 CO flip to Y, ca. 4.5u

\section{NCOCACB}

;NCOCACB_3D.cshi

; BSH for N-CO-CACB

"p $4=2^{*} \mathrm{p} 1 "$

"in0 $=$ inf $1 / 2 "$

"in $10=$ inf2 $/ 2$ "

$1 \mathrm{ze}$

2 d 1 do:f2

$1 \mathrm{u}$ do:f3

$2 \mathrm{u}$ fq $=0: \mathrm{f} 2$

$2 \mathrm{u} \mathrm{fq}=$ cnst $10: \mathrm{f} 1$; C0 freq.

2u pl2:f2 pl5:f3

; H 90

p2:f2 ph1

; HN CP

(p15:sp1 ph0):f2 (p15 pl5 ph2):f3

; t1(N) evolution

1u pl12:f2

1u cpds2:f2

d $0 * 0.5$

(p4 pl1 ph0):f1

$\mathrm{d} 0 * 0.5$

$1 \mathrm{u}$ do:f2

; $\mathrm{NC} \mathrm{CP}$

if $(130==1)$

$\{(\mathrm{p} 25: \mathrm{sp} 2 \mathrm{ph} 4): \mathrm{f} 1$ (p25 pl11 ph0):f2 (p25 pl8 ph3):f3 
\}

if $(130==2)$

$\{(\mathrm{p} 25 \mathrm{pl}$ ph4):f1 (p25 pl11 ph0):f2 (p25:sp3 ph3):f3

\}

; t2(CO) evolution

1u pl12:f2 pl3:f3

$1 \mathrm{u} \operatorname{cpds} 2: \mathrm{f} 2$

$\mathrm{d} 0 * 0.5$

(p6 pl3 ph0):f3

$\mathrm{d} 0 * 0.5$

$1 \mathrm{u}$ do:f2

; BSH for COCA transfer

(p18 pl1 ph18):f1 ; flip CO

$1 \mathrm{u} \mathrm{fq}=$ cnst25:f1 ; CA freq.

(p17:sp17 ph17):f1 (p17 pl14 ph0):f2 ; BSH CP with cw proton dec.

; (p19 ph19):f1 ; CA lock on X, CO flip to Y

; DREAM for CACB transfer

;; $1 \mathrm{u} \mathrm{fq}=\mathrm{cnst} 26: \mathrm{f} 1$

(p21:sp21 ph21):f1 (p21 pl21 ph0):f2

\section{; Acqusition}

$1 \mathrm{u}$ pl12:f2 pl13:f3

$1 \mathrm{u} \operatorname{cpds} 2: \mathrm{f} 2$

; 1u cpds3:f3 ;

go $=2 \mathrm{ph} 31$

$10 \mathrm{u}$ do:f2

; 10u do:f3

; Write data \& 3D increments

$10 \mathrm{~m}$ wr $\# 0$ if $\# 0 \mathrm{zd}$

$1 \mathrm{~m} \operatorname{id} 10$

$1 \mathrm{~m}$ ip4

lo to 2 times td2

$1 \mathrm{~m}$ rd10

$1 \mathrm{~m} \mathrm{rp} 4$

$1 \mathrm{~m}$ ido

$1 \mathrm{~m}$ ip4

lo to 2 times td 1 
Halt Acqu, $1 \mathrm{~m}$

exit

$\mathrm{ph} 0=02 ; 1 \mathrm{H} \mathrm{cp}$

ph1= $11113333 ;$ 1H p90 excite

$\mathrm{ph} 2=0022 ; 15 \mathrm{~N}$ in $1 \mathrm{Hto} 15 \mathrm{~N} \mathrm{cp}$

$\mathrm{ph} 3=0 ; 15 \mathrm{~N}$ in $\mathrm{NCA} \mathrm{dcp}$

$\mathrm{ph} 4=0 ; 13 \mathrm{C}$ in $\mathrm{NCO}$

ph17=0 000000022222222 ;BSH-CP

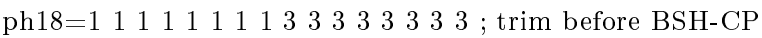

ph19=2 222222200000000 ; CO along Y

ph21=0 00000000222222222

ph31=0 222020002

;p2 H 90 pulse length

;pl2 H 90 pulse power

;pl5 X CP power (constant)

;p15 CP contact time

;pl12 acq. decoupling power

;pl17 13C COCA cp pl

;p17 13C COCA cp time

$;$ pl18 = pl1, CO flip pulse

;p18 CO flip pulse ca. $60 \mathrm{grad}$

;cnst10 CO freq offset

;cnst25 CA freq offset

;cnst26 CA freq offset

;p1 X 90 pulse length (calibration)

;pl1 X 90 pulse power (calibration)

;pl6 1H CP power

;pl13 15N w16 decoupling

;cnst12 1H SPINAL fq

;pl14 1H cw for BSH

;pl11 1H cw for NCA dcp

;pl8 $15 \mathrm{~N}$ in NCO dcp

;p19 CO flip to Y, ca. 4.5u

\section{HC-INEPT}

; inept1D.hh

; based on cp.ksei

; last change: 30-Oct-2006, 31.Oktober: with 13c-decoupling

; cnst2 $=145$

; cnst $3=6$ 
;echo delays

;OWNER $=$ nmrsu

"d $4=1 /\left(4^{*}\right.$ cnst 2$) "$

"d $3=1 /($ cnst $3 *$ cnst 2$) "$

"in $0=\inf 1 / 4$ "

;compensation delays

; $1>$ p2

;"d5=p1-p2"

;"d $6=\mathrm{d} 5 / 2 "$

; Pulse program

$;=====-+----$

1 ze ;accumulate into an empty memory

2 d1 do:f2

$1 \mathrm{u} f \mathrm{q}=0: \mathrm{f} 2$

;90 1H

2u pl2:f2 pl1:f1

p2:f2 ph1

d0

p1*2:f1 ph0

do

;spinecho

d4

$\left(\mathrm{p} 2 *_{2} \mathrm{ph} 2\right): \mathrm{f} 2\left(\mathrm{p} 1 *^{*} \mathrm{ph} 4\right): \mathrm{f} 1$

; (d5 p2*2 ph2):f2 (p1*2 ph4):f1

d4

;PT

(p2 ph3):f2 (p1 ph5):f1

; (d6 p2 ph3):f2 (p1 ph5):f1

;spinecho

d3

$\left(\mathrm{p} 2{ }^{*} 2 \mathrm{ph} 2\right): \mathrm{f} 2\left(\mathrm{p} 1 *^{*} \mathrm{ph} 6\right): \mathrm{f} 1$

; (d5 p2 $*_{2}$ ph2):f2 (p1 $*_{2}$ ph6):f1

d3

;acquisition with decoupling (choose GARP)

$1 \mathrm{u} \mathrm{pl12:f2}$

$1 \mathrm{u}$ cpds $2: f 2$ 
;1u pl12:f2

go $=2 \mathrm{ph} 31$

$1 \mathrm{~m}$ do:f2 ; decoupler off

$100 \mathrm{~m}$ wr $\# 0$ if $\# 0 \mathrm{zd}$

$1 \mathrm{~m}$ ido

$1 \mathrm{~m}$ ip1

lo to 1 times td 1

Halt Acqu, $1 \mathrm{~m}$;jump address for protection files exit ;quit

$\mathrm{ph} 0=02$

;ph1 = 00000000022222222

ph1 $=02$

ph2 $=02$

;ph3 = 1133

ph3 $=1$

ph4 $=02$

;ph5 = 0000111122223333

ph5 = 0022

;ph6 = 02021313

ph $6=13$

;ph31=0 0221133

ph31= 1331 



\section{Curriculum Vitae}

\section{Personal data}

$\begin{array}{ll}\text { Name } & \text { Benjamin Schomburg } \\ \text { Date of Birth } & 11.06 .1985 \\ \text { Place of Birth } & \text { Löhne } \\ \text { Nationality } & \text { German }\end{array}$

\section{Education}

1991-1995 Primary school Grundschule Gohfeld

1995-2004 Secondary school Städtisches Gymnasium Löhne

2004-2005 Community Service at the City Environmental Office Löhne

2005-2010 Biochemistry Studies at the University of Bielefeld

2010 Master thesis at the University of St. Andrews, United Kingdom. Subject: Monitoring structural changes in an FbaB-CnaB2 mutant by NMR spectroscopy, supervisor: Dr. Uli Schwarz-Linek.

2010-2014 Ph.D. student at the Max Planck Insitute for Biophysical Chemistry in Göttingen, Germany. Subject: Transmembrane Signalling: Structural and functional Studies on Histidine Kinase CitA, supervisor: Prof. Dr. Christian Griesinger.

Göttingen, December 2014 